\title{
Development of a powertrain control algorithm for a compound- split diesel hybrid-electric vehicle
}

\author{
Douglas Alan Ward \\ West Virginia University
}

Follow this and additional works at: https://researchrepository.wvu.edu/etd

\section{Recommended Citation}

Ward, Douglas Alan, "Development of a powertrain control algorithm for a compound-split diesel hybridelectric vehicle" (2012). Graduate Theses, Dissertations, and Problem Reports. 334.

https://researchrepository.wvu.edu/etd/334

This Thesis is protected by copyright and/or related rights. It has been brought to you by the The Research Repository @ WVU with permission from the rights-holder(s). You are free to use this Thesis in any way that is permitted by the copyright and related rights legislation that applies to your use. For other uses you must obtain permission from the rights-holder(s) directly, unless additional rights are indicated by a Creative Commons license in the record and/ or on the work itself. This Thesis has been accepted for inclusion in WVU Graduate Theses, Dissertations, and Problem Reports collection by an authorized administrator of The Research Repository @ WVU. For more information, please contact researchrepository@mail.wvu.edu. 


\title{
DEVELOPMENT OF A POWERTRAIN CONTROL ALGORITHM FOR A COMPOUND-SPLIT DIESEL HYBRID-ELECTRIC VEHICLE
}

\author{
by \\ Douglas Alan Ward \\ Thesis submitted to the \\ Benjamin M. Statler College of Engineering and Mineral Resources \\ at West Virginia University \\ in partial fulfillment of the requirements \\ for the degree of \\ Master of Science \\ in \\ Mechanical Engineering \\ W. Scott Wayne, Ph.D., Chair \\ Christopher M. Atkinson, Sc.D. \\ James E. Smith, Ph.D.
}

Department of Mechanical and Aerospace Engineering

Morgantown, West Virginia

2012

Keywords: Controls; Hybrid Vehicles; Electric Vehicles; Emissions; Fuel Efficiency; EcoCAR 


\title{
DEVELOPMENT OF A POWERTRAIN CONTROL ALGORITHM FOR A COMPOUND-SPLIT DIESEL HYBRID-ELECTRIC VEHICLE
}

\author{
Douglas Alan Ward
}

\begin{abstract}
The goal of this research was to develop a unique powertrain control algorithm for a dieselpowered compound-split hybrid crossover utility vehicle (CUV) and evaluate the fuel consumption and greenhouse gas emissions benefits that can be realized compared to existing non-hybrid, gasolinepowered CUVs. This was achieved through the implementation of engine on/off functionality, regenerative braking, and electric-only drive. The research was conducted in conjunction with the university's participation in EcoCAR: The NeXt Challenge, an inter-collegiate advanced vehicle engineering competition focused on developing alternatively powered vehicles in the interest of providing improved fuel efficiency and reduced tailpipe emissions while maintaining useful vehicle functionality. Prior to construction, the proposed vehicle was simulated for fuel efficiency and carbon dioxide emissions using the Powertrain System Analysis Toolkit. Initial simulation results indicated that the proposed compound-split hybrid vehicle would achieve 35 mpgge combined fuel economy and produce carbon dioxide at a rate of $242 \mathrm{~g} / \mathrm{mi}$. A 2009 Saturn Vue was modified to accept the proposed hybrid powertrain consisting of a 1.3 liter diesel engine, 2-mode compound-split transaxle, and lithium-ion high-voltage battery system. This vehicle served as the platform for the development and validation of the powertrain control algorithm. Using the vehicle's CAN communication capabilities, auxiliary control units were integrated to manage the new powertrain components and implement the control strategy. The project vehicle and control algorithm were validated and tested on-road for fuel efficiency and performance. The final powertrain control algorithm developed through this research included automatic engine start/stop, regenerative braking, and full-electric driving capability at speeds up to $25 \mathrm{mph}$. In its final configuration, the WVU 2-mode hybrid-electric vehicle achieved city/highway fuel economy of 24.5/31.5 mpgge. Compared to the base vehicle, the project vehicle achieved a $28.9 \%$ improvement in city fuel economy, a $21.2 \%$ improvement in highway fuel economy, and a $20 \%$ reduction of in-use $\mathrm{CO}_{2}$ emissions.
\end{abstract}




\section{Acknowledgements}

The work discussed in these pages has been everything but a solo effort; I'm just the guy who got to write about it. The success of this project relied on a total team effort and I was lucky enough to work with some of the hardest-working, brightest people l've ever met. l'd like to take a page or so here to recognize a few of them.

I would first like to thank Dr. Scott Wayne for letting me hang around for an extra two years, getting paid to do what I do for fun in my free time. I've heard horror stories about research advisors abusing their assistants and setting unreasonable deadlines and I can safely state that Dr. Wayne has to be the best advisor in the college. He was always available to answer any questions I had, he was actively involved in the project, and he was just a genuinely good guy, even if he is of the "Blue Oval" persuasion. I can only hope that my future bosses are the same way... minus the Ford thing.

Next I would like to thank my partner in crime, Mr. Zhenhua Zhu. Zhen taught me everything I know about programming and it was a joy going to the shop every day and getting to hang out (and occasionally work) with him. He gave me an appreciation for all types of foreign food and taught me that there is always a better deal out there somewhere. I'll miss the days we spent testing and tweaking the

Vue, cruising around Morgantown, getting stranded, and then pushing the car back to the shop off the front bumper of my truck.

I would also like to thank my committee, Dr. Chris Atkinson and Dr. Jim Smith, for their willingness to be involved and associated with this thesis. I strongly believe that advanced vehicle projects must continue to be offered by the university, regardless of involvement in an external competition, and it's comforting to know that there is still interest in advanced vehicle technology among the WVU engineering community.

Now I would like to recognize some of the outstanding team members with whom I had the privilege of working. Alan Kuskil and Tyler DiMartino were two great workers from Year 2. Tyler wasn't afraid to work late into the night when we installed the high-voltage battery for the first time and Alan was the most organized member of the team. If it weren't for Alan's hard work with the reports, we probably would've been kicked out of the competition. Tony McCann was an electrical circuit genius. He created devices and built the high-voltage battery system, all of which worked flawlessly once installed in the vehicle.

Seth Hipkins, Mike Houle, and Zach Kamen were the backbone of the Year 3 team. We had so much work to do in Year 3 and the team was at its smallest at that time, only 13 or so. Mike spent an entire day getting the exhaust system designed and installed, Zach was willing to do any job, whatever needed done, and Seth was probably the hardest-working member of any EcoCAR team. He designed and installed the fuel tank and winch system, he got the car painted, and he was always in the shop. He also nearly ruptured my eardrum. And have you seen his acting in that commercial?! 
I would also like to thank Cesar "Sal" Sandoval-Leon. Although he joined the team late in Year 3, he travelled with us to the final competition and was very helpful in getting all of our reports and presentations prepared. He showed himself to be a very aggressive driver which I appreciated. He was removed from a Chevrolet Volt after speeding and killing a few cones at a driving event held during the final competition which made us all laugh. After the competition was over, Sal joined Zhen and me in testing the project vehicle. He is a Ph.D. student also working with Dr. Wayne.

I need to also thank Chris Trush, our GM mentor throughout the EcoCAR competition. While most of our issues regarding the diesel engine had no answer, Chris did his best to help us out however he could. I really thank Chris for pushing me to interview with GM during the EcoCAR final competition. If it weren't for his recommendation, I wouldn't have been offered the job I've dreamt about all of my life.

Last but not least I would like to thank Megan. My decision to enter graduate school had absolutely nothing to do with a desire to further my education. In fact, I've never really enjoyed school. Who likes homework? I applied for graduate school at the last minute to stay close to her and the rest is, as they say, history.

I am honored to have been given the opportunity to commit to record the work performed over this three year period. This paper has taken well over a year to write (closer to two now) thanks to the obligations of the project as well as last year's TA activity with Dr. Smith's EcoCAR replacement course which was truly a joyful distraction. I look at this thesis as two unique documents. It is both a technical discussion of the vehicle design process and a chronicle of the most enjoyable and rewarding period of my life.

Designing and building a vehicle in conjunction with EcoCAR: The NeXt Challenge was an in-depth and challenging project requiring the cooperation of multiple engineering disciplines utilizing many different engineering techniques. For the students involved, it was an invaluable learning experience having access to a real vehicle and state-of-the-art hardware in an attempt to solve a real problem that will confound this new generation of engineers for the foreseeable future. Although the university was not selected to compete in EcoCAR 2, all of the necessary steps should be taken so that WVU can enter the next advanced vehicle technology competition and once again showcase the abilities of its engineering students against other top engineering schools around the world. Let's Go... Mountaineers. 


\section{Table of Contents}

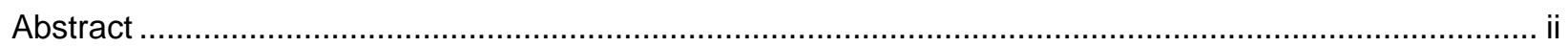

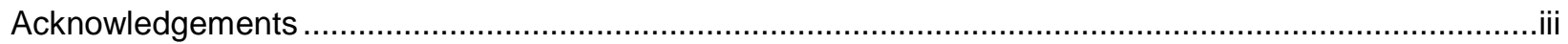

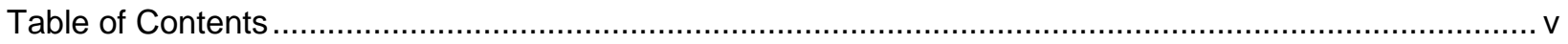

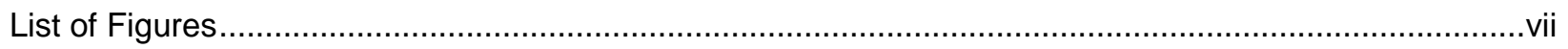

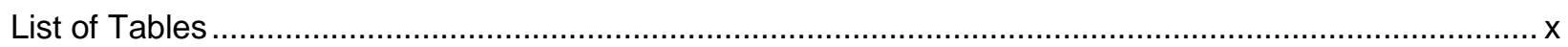

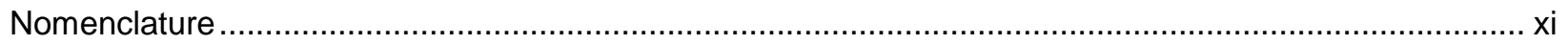

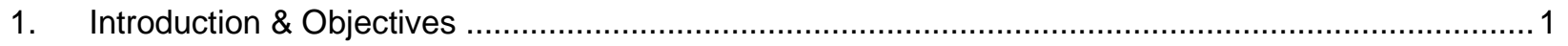

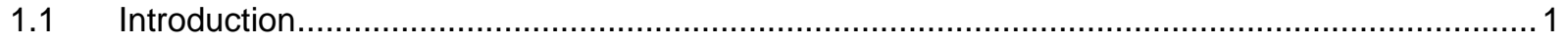

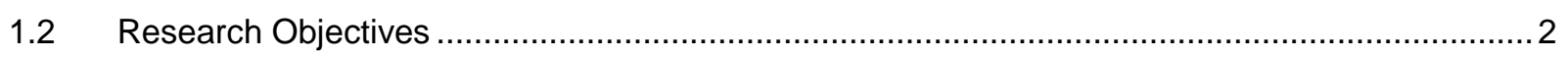

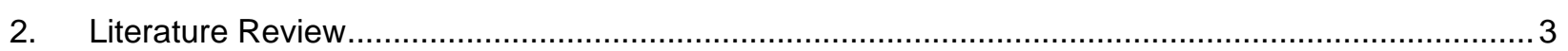

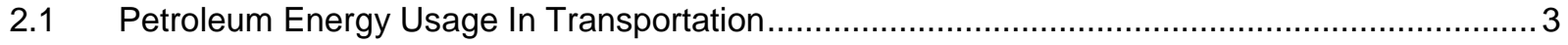

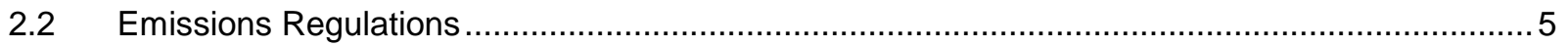

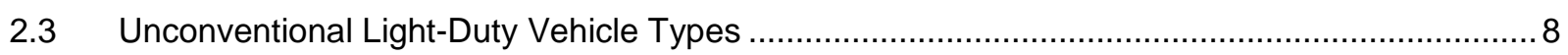

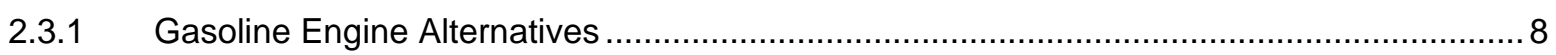

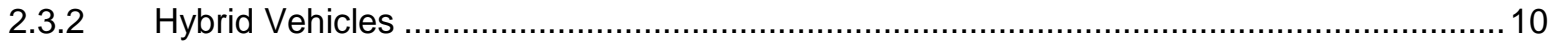

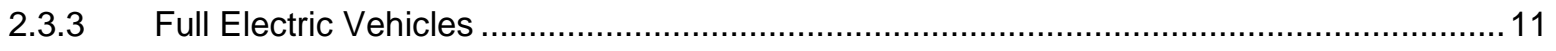

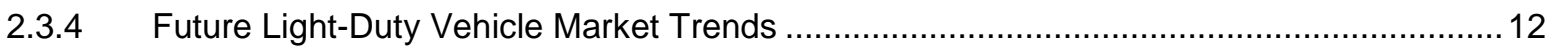

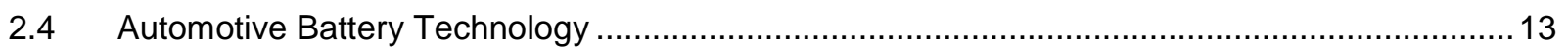

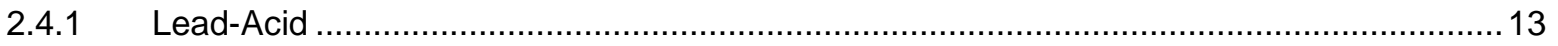

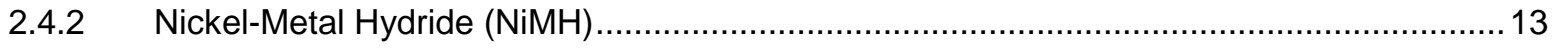

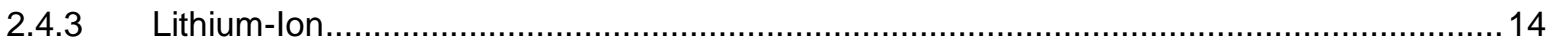

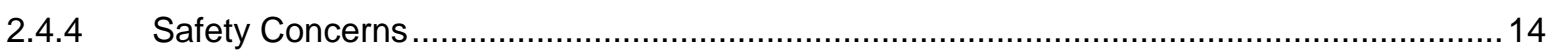

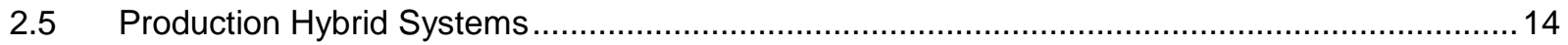

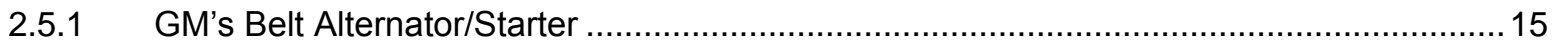

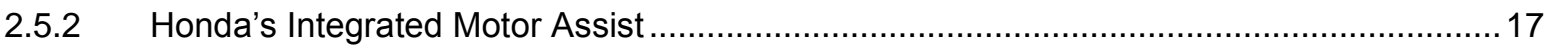

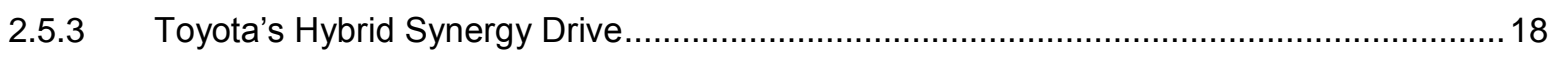

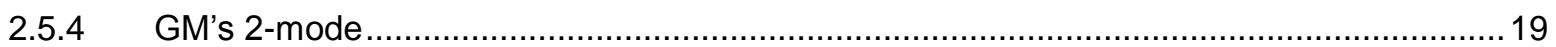

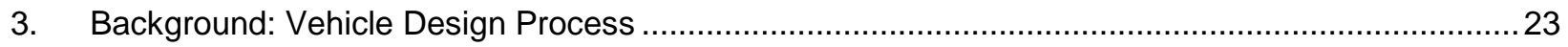

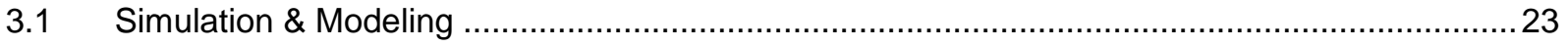

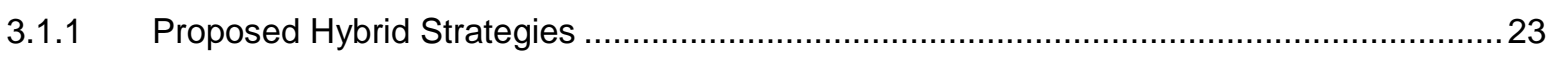

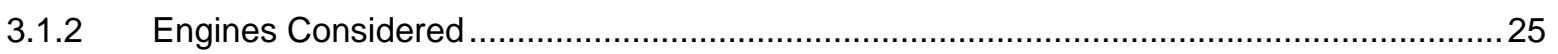

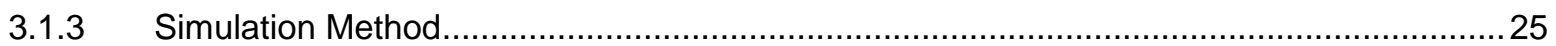

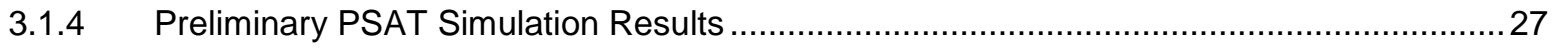

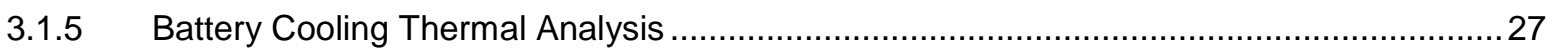

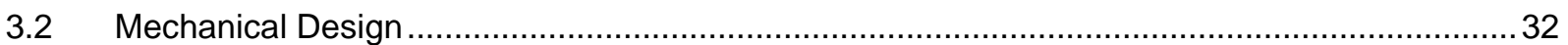




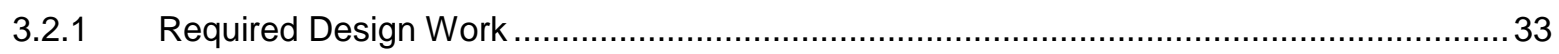

3.2.2 Transmission Adapter Strength Analysis ................................................................ 51

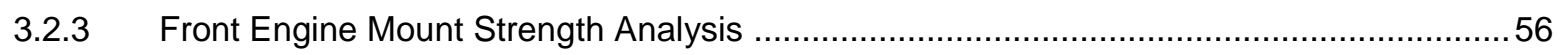

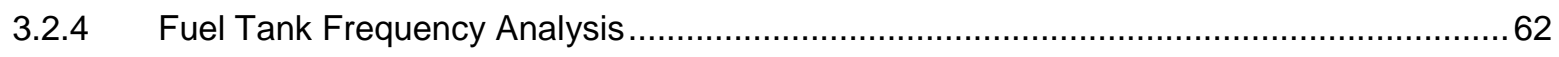

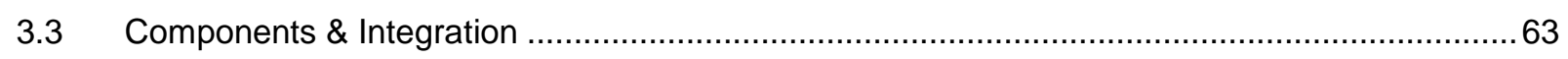

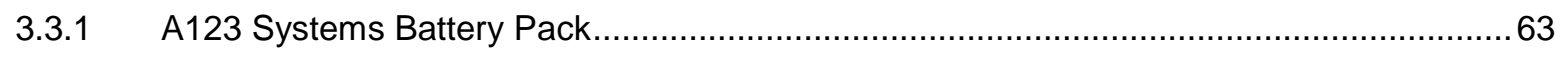

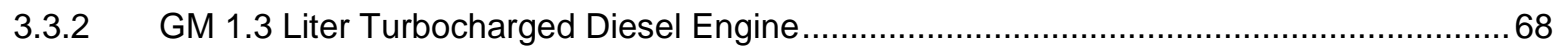

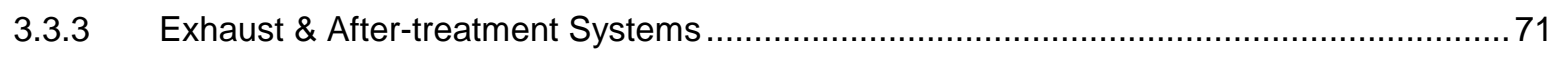

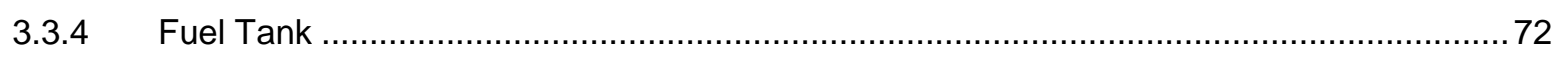

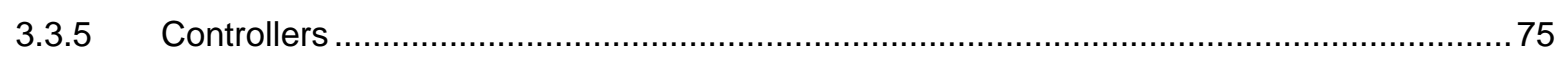

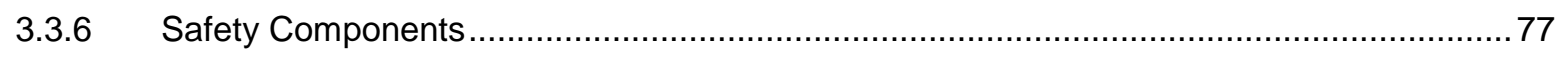

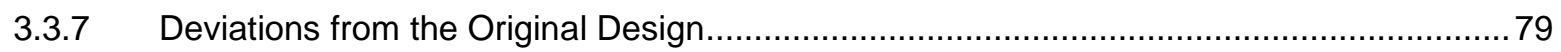

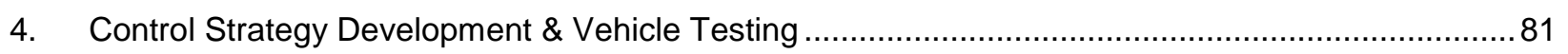

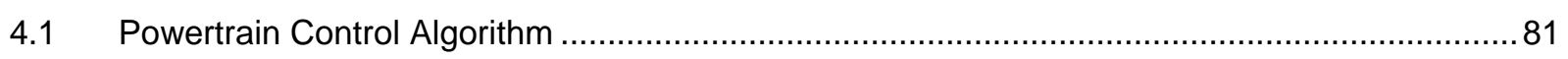

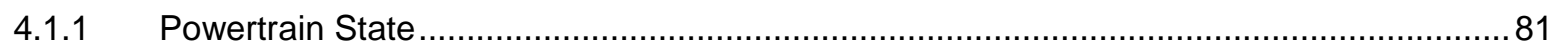

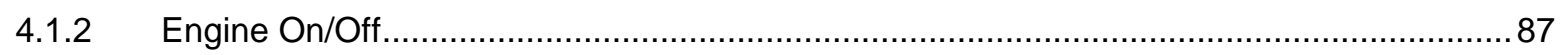

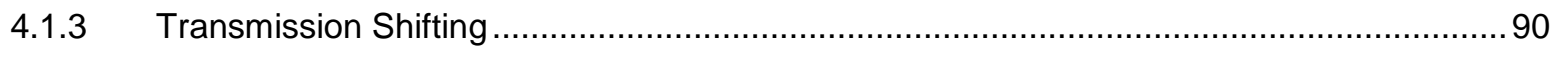

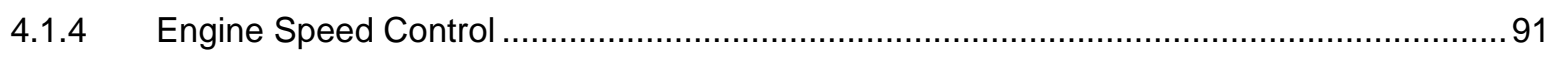

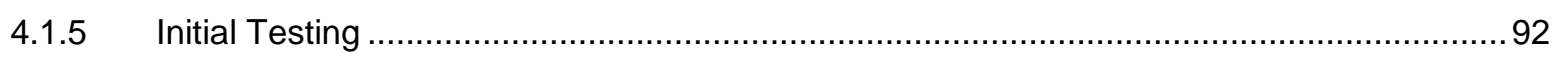

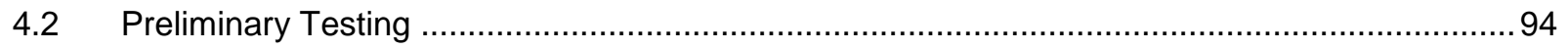

4.2.1 Preliminary Testing and Optimization ................................................................... 94

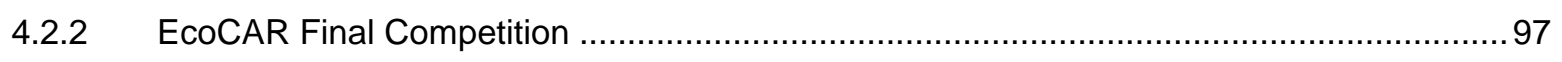

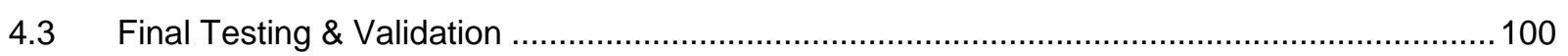

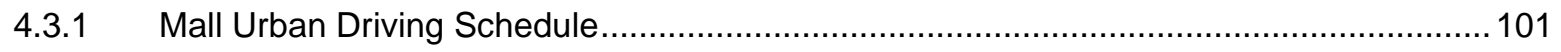

4.3.2 Route 19 Highway Fuel Efficiency Test ................................................................. 104

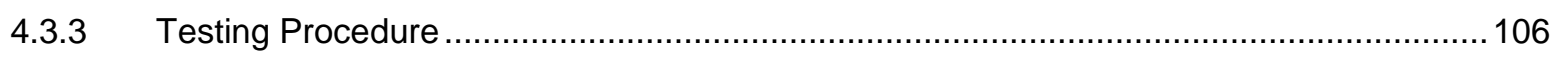

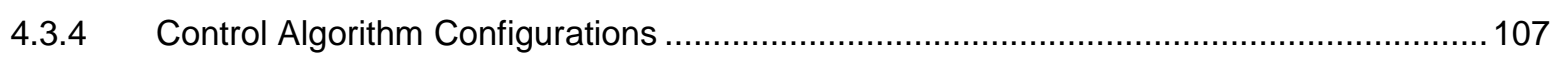

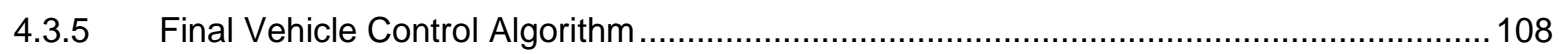

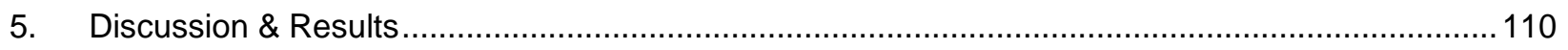

$5.1 \quad$ Fuel Efficiency \& Performance Results .................................................................... 110

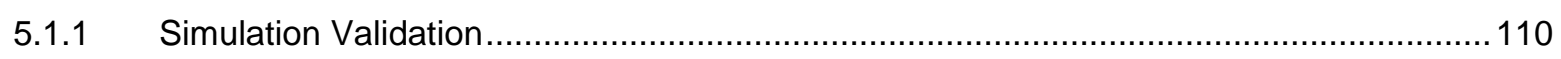

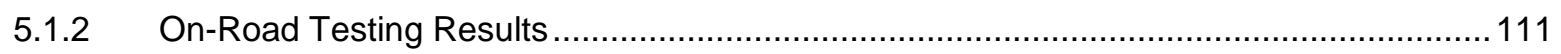

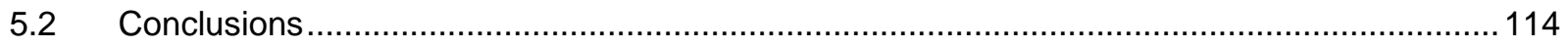

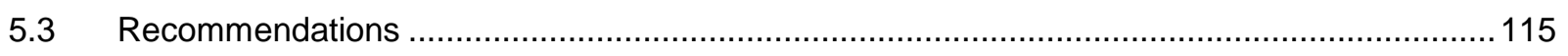

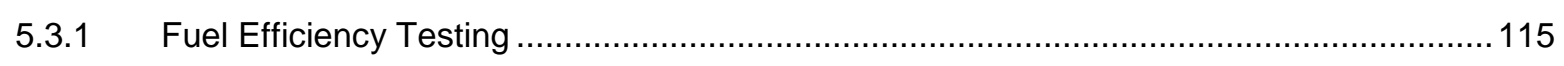

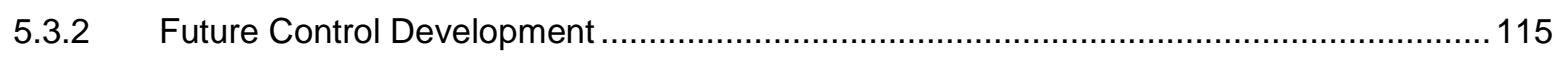

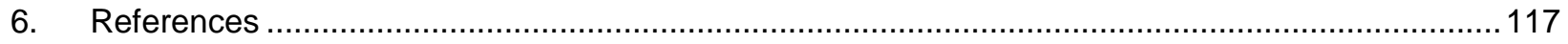




\section{List of Figures}

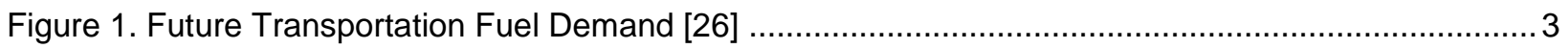

Figure 2. Transportation Fuel Demand: Personal vs. Commercial [26] ................................................. 4

Figure 3. Fuel Economy of New Light-Duty Vehicles [26] ............................................................ 5

Figure 4. Worldwide Light-Duty Vehicle Fleet [26] ....................................................................... 12

Figure 5. First Generation Honda IMA Hybrid System Layout [38] ................................................... 17

Figure 6. First Generation Toyota Hybrid System [45] ..................................................................... 18

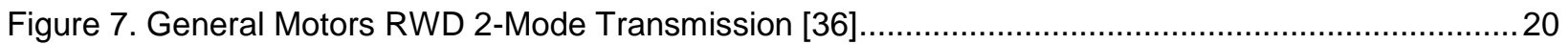

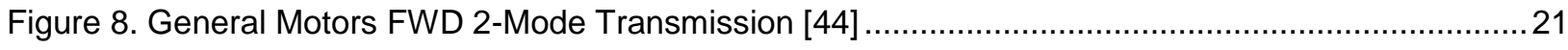

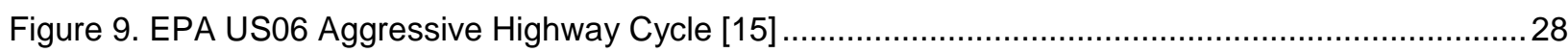

Figure 10. High Voltage Battery Current During US06 Cycle [16] ..........................................................28

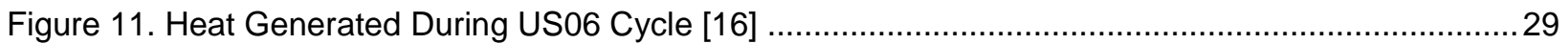

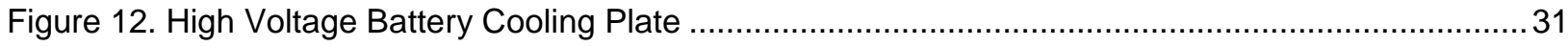

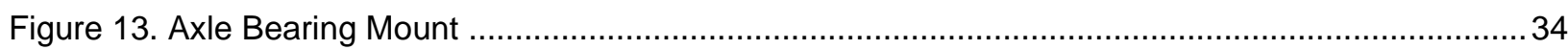

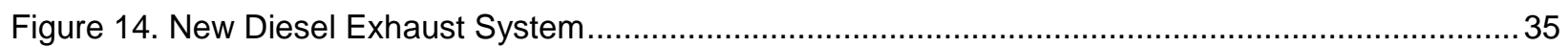

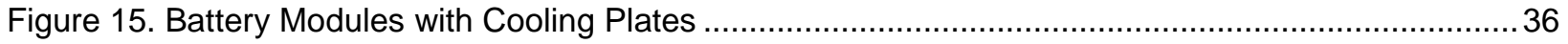

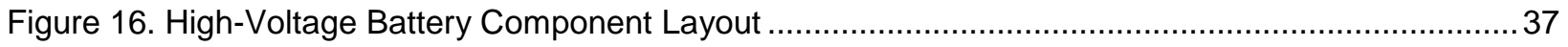

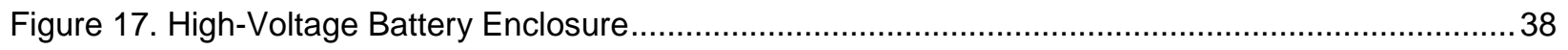

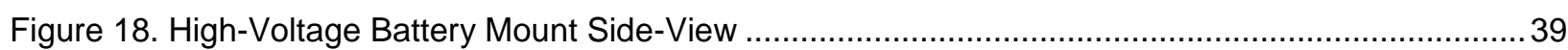

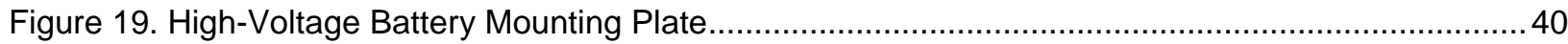

Figure 20. High-Voltage Battery Mount Installed In Vehicle Model .................................................... 40

Figure 21. Transmission Adapter Bolt Hole Orientation ................................................................... 42

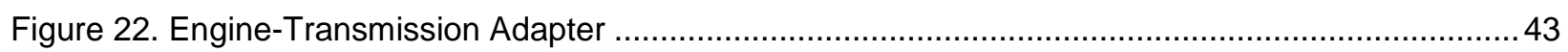

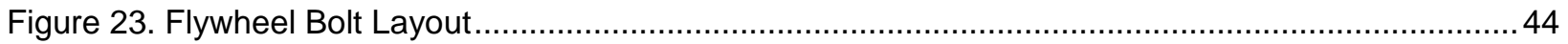

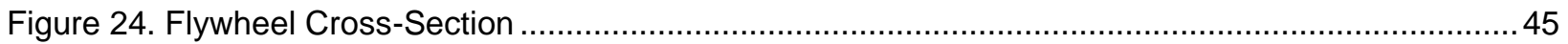

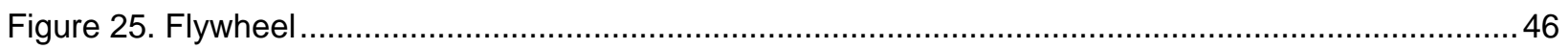

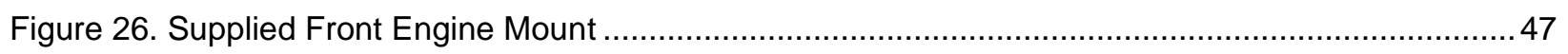

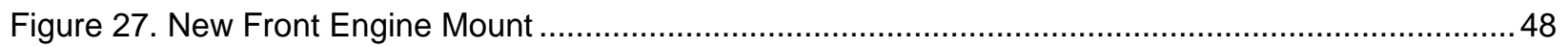

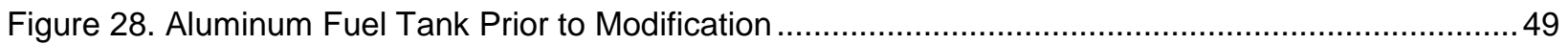

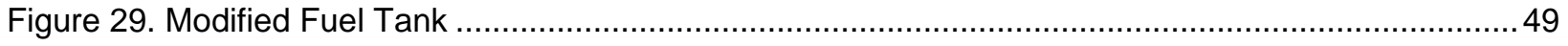

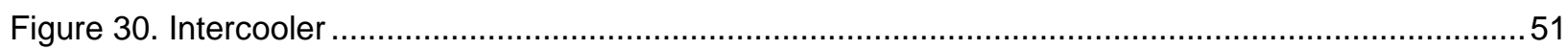

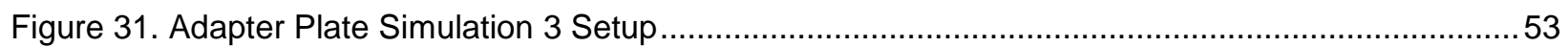

Figure 32. Von Mises Stress for Adapter Plate Simulation 3 …....................................................... 54

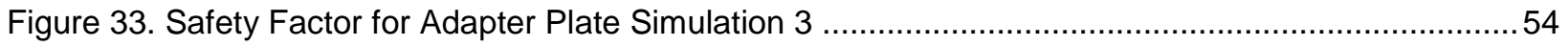

Figure 34. Von Mises Stress for Adapter Plate Simulation 4 ........................................................... 55

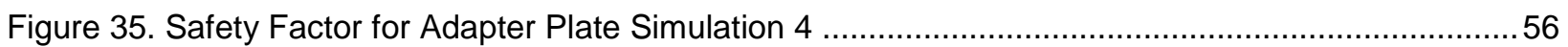




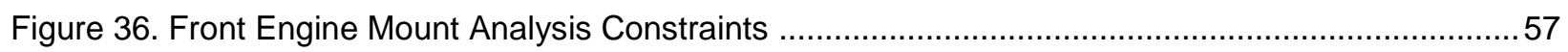

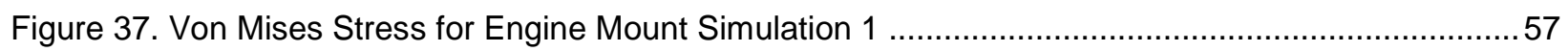

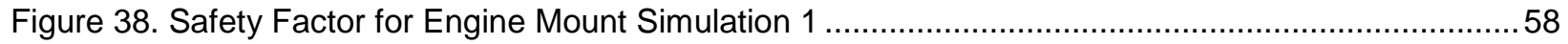

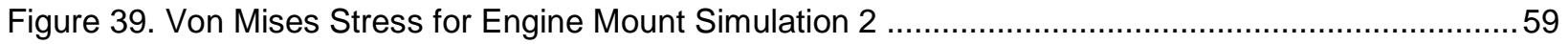

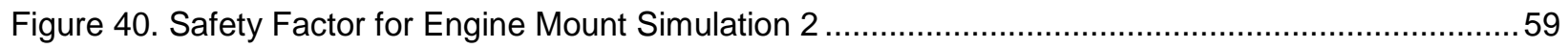

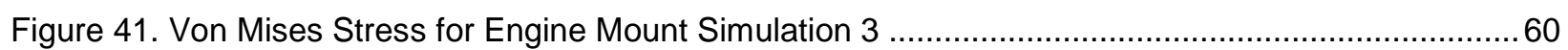

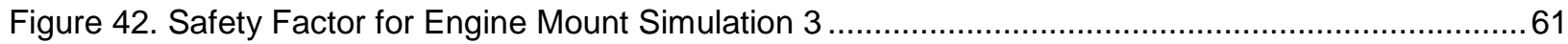

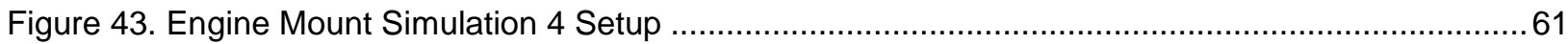

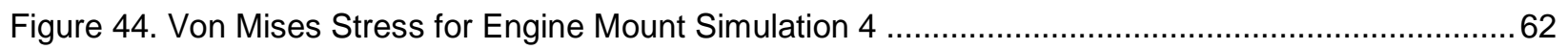

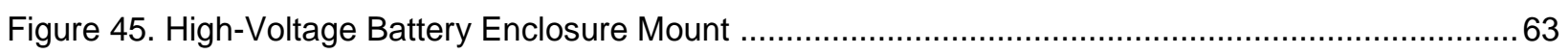

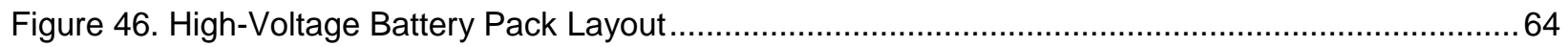

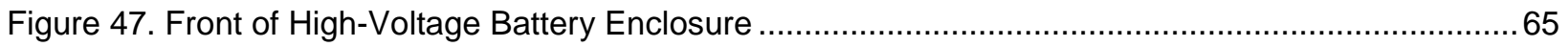

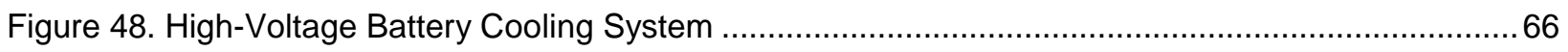

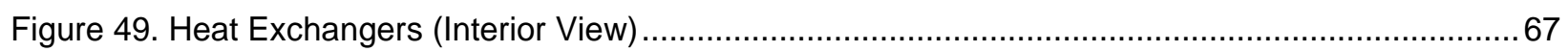

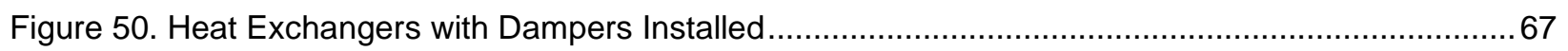

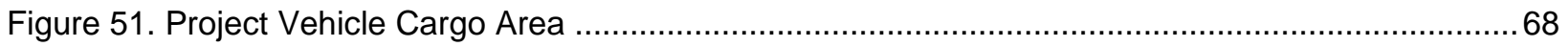

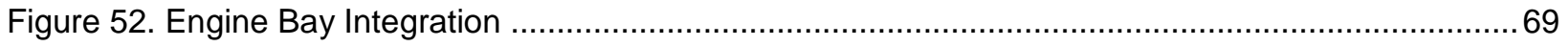

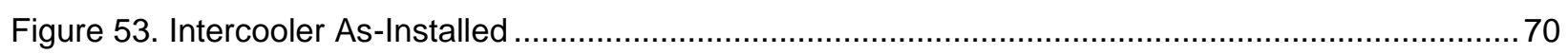

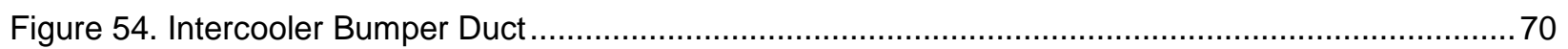

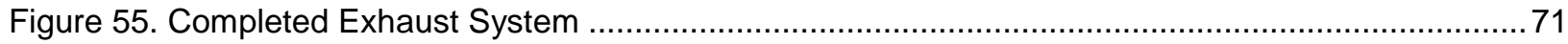

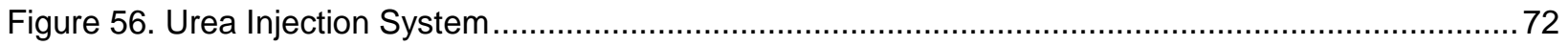

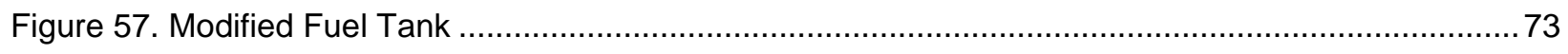

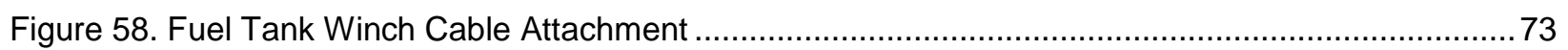

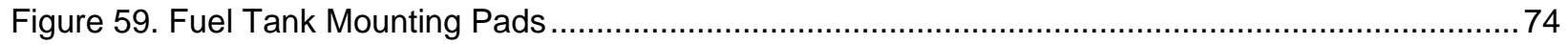

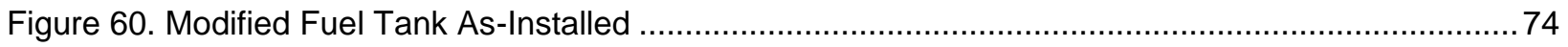

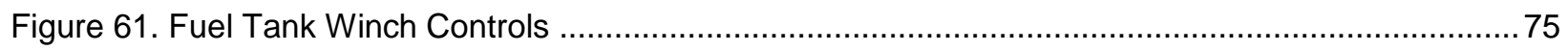

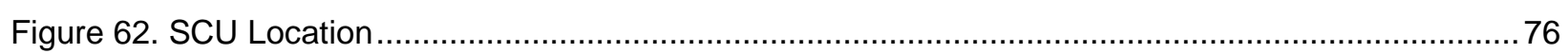

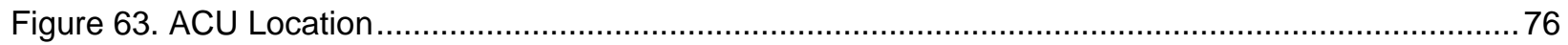

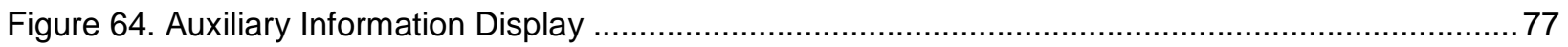

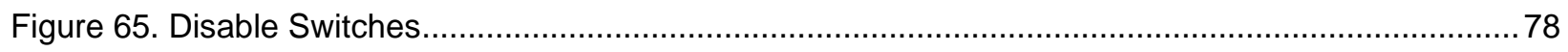

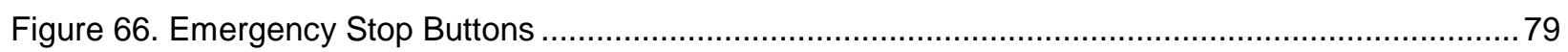

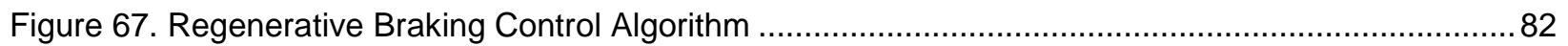

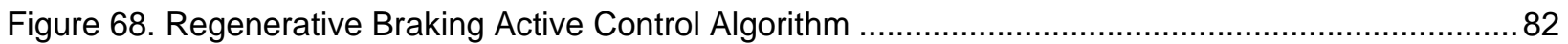

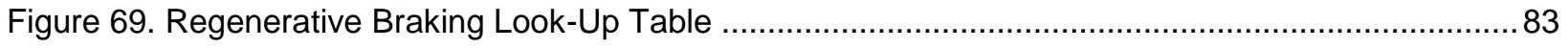

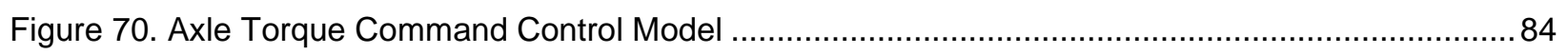

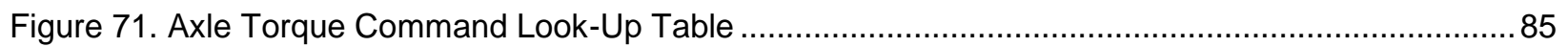

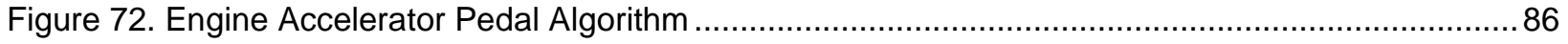




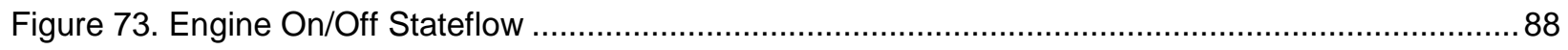

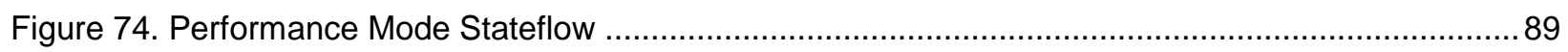

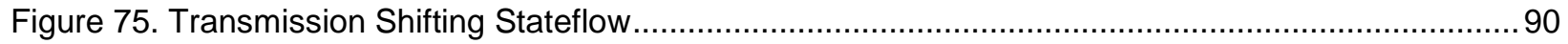

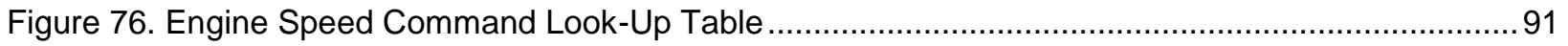

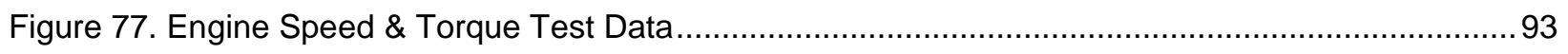

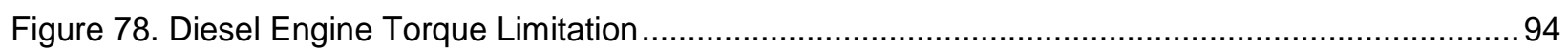

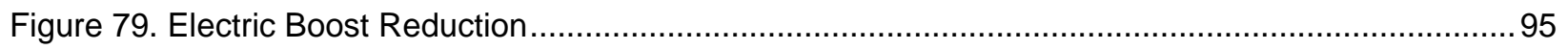

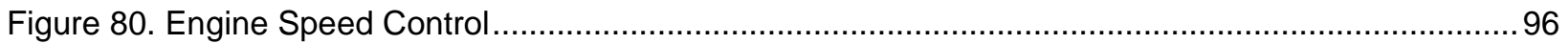

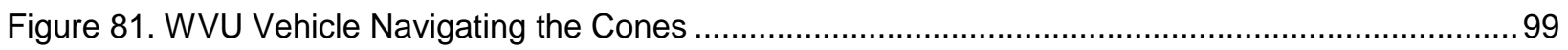

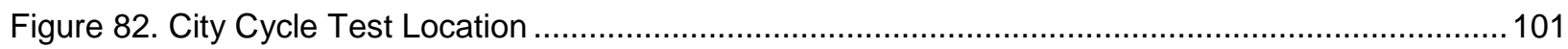

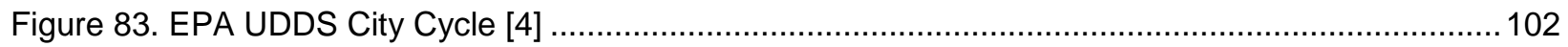

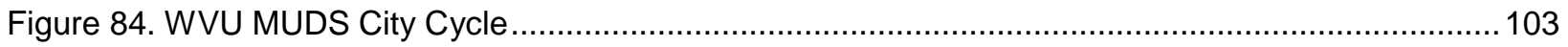

Figure 85. Highway Cycle Test Location ..................................................................................... 104

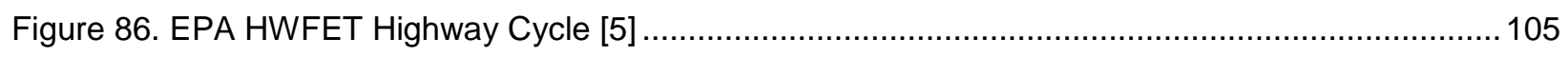

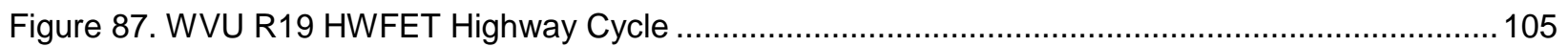




\section{List of Tables}

Table 1. EPA Light-Duty FTP-75 Tier 1 Emissions Standards [51] ................................................ 6

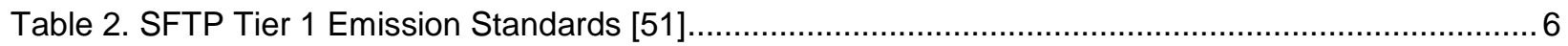

Table 3. EPA Light-Duty FTP-75 Tier 2 Emissions Standards [52] .................................................. 7

Table 4. SFTP Tier 2 Emissions Standards [50] ....................................................................... 7

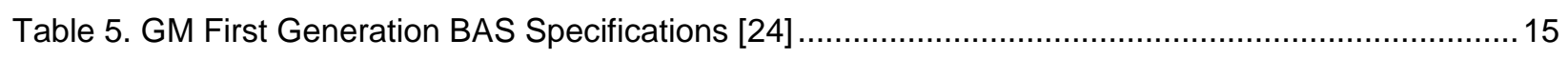

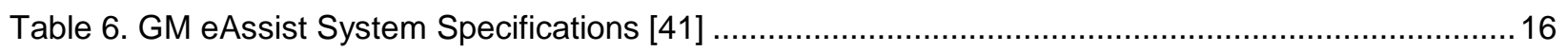

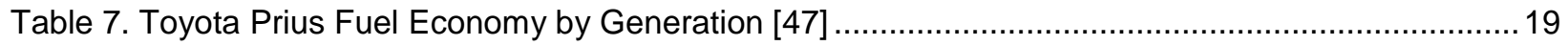

Table 8. 2-mode Fuel Efficiency Improvements [36] …....................................................................20

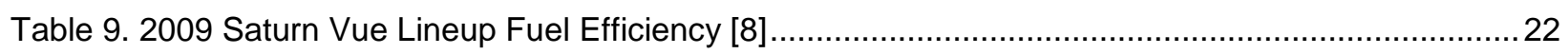

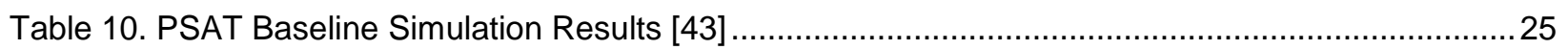

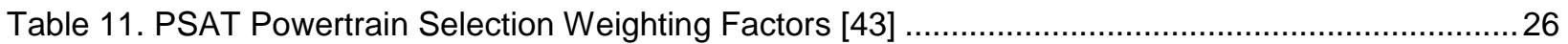

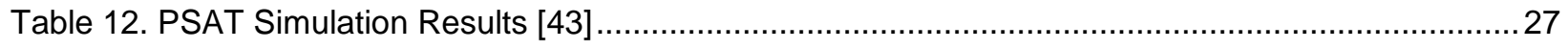

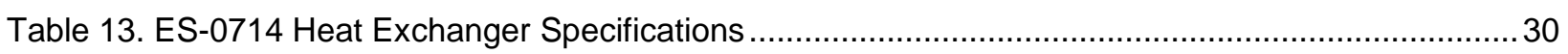

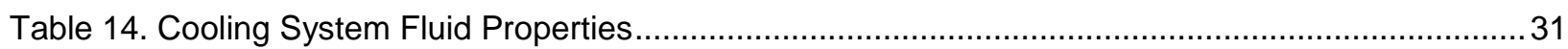

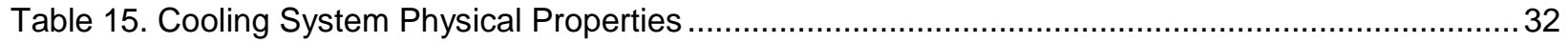

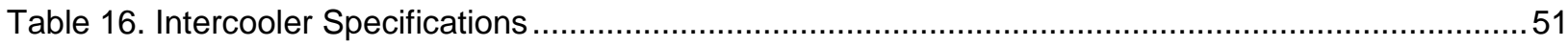

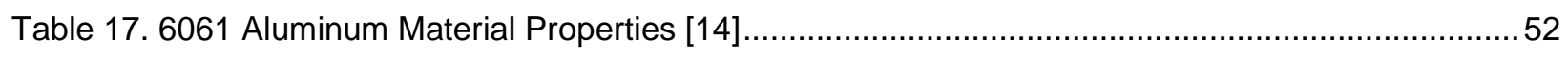

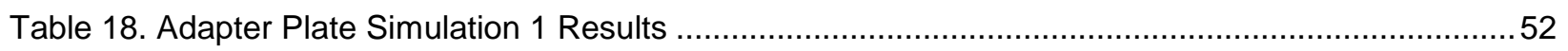

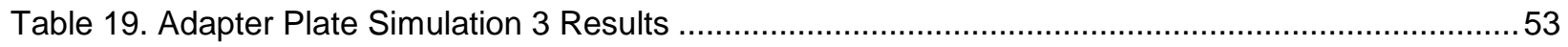

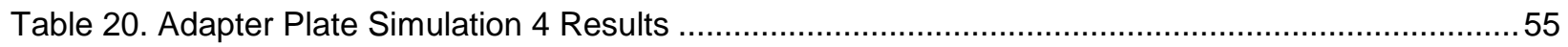

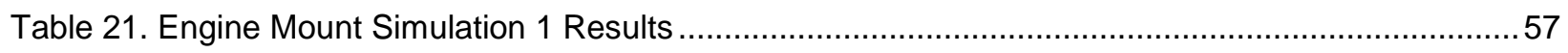

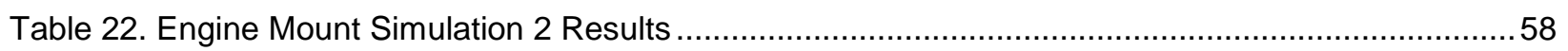

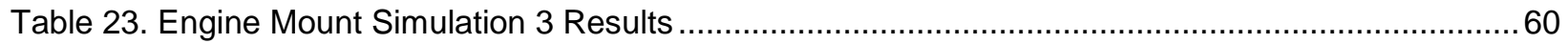

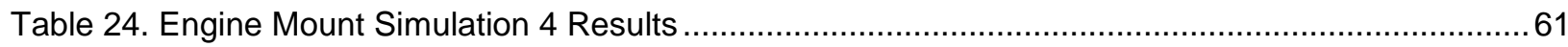

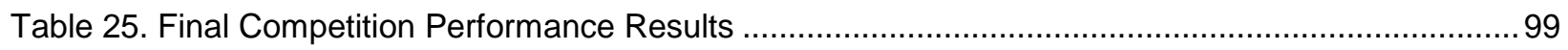

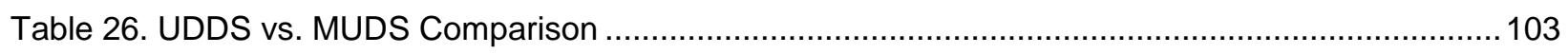

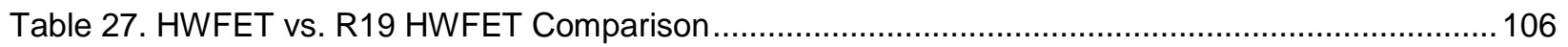

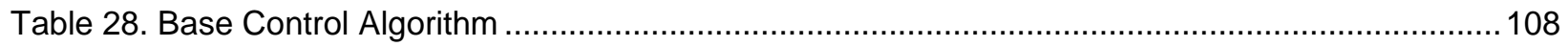

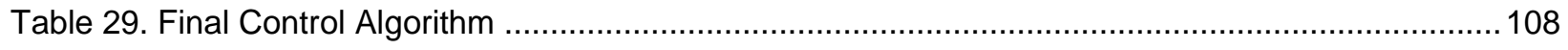

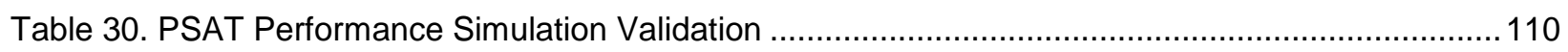

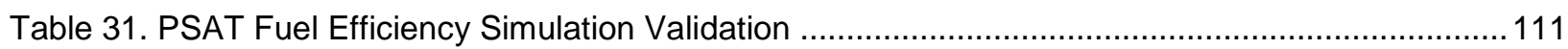

Table 32. On-Road Performance Test Results ...........................................................................111

Table 33. Acceleration Improvement with Full Engine Power ......................................................... 112

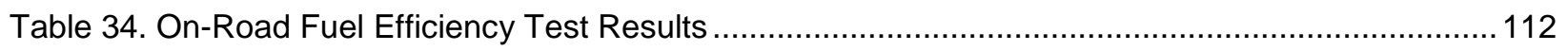

Table 35. Project Vehicle Fuel Economy Comparison .................................................................. 113

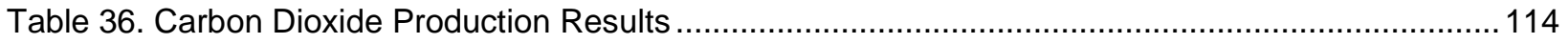




\section{Nomenclature}

\begin{tabular}{|c|c|}
\hline$A$ & Amperage (Amps) \\
\hline$A / C$ & Air Conditioning \\
\hline$A C$ & Alternating Current \\
\hline ACU & After-treatment Control Unit \\
\hline ANL & Argonne National Laboratory \\
\hline APP & Accelerator Pedal Position \\
\hline ATV & All-Terrain Vehicle \\
\hline BAS & Belt Alternator/Starter \\
\hline $\mathrm{BCM}$ & Body Control Module \\
\hline BMS & Battery Management System \\
\hline $\mathrm{BP}$ & British Petroleum \\
\hline BPP & Brake Pedal Position \\
\hline BTU & British Thermal Unit \\
\hline c & Minor Loss Coefficient \\
\hline CAN & Controller Area Network \\
\hline CFM & Cubic Feet Per Minute \\
\hline $\mathrm{CH}_{4}$ & Methane \\
\hline CNG & Compressed Natural Gas \\
\hline $\mathrm{CO}$ & Carbon Monoxide \\
\hline $\mathrm{CO}_{2}$ & Carbon Dioxide \\
\hline CUV & Crossover-Utility Vehicle \\
\hline CV & Constant Velocity \\
\hline DC & Direct Current \\
\hline$D_{h}$ & Hydraulic Diameter \\
\hline DI & Direct Fuel Injection \\
\hline DOC & Diesel Oxidation Catalyst \\
\hline DOE & Department of Energy \\
\hline DPF & Diesel Particulate Filter \\
\hline ECM & Engine Control Module \\
\hline ECU & Electronic Control Unit \\
\hline EDS & Electrical Distribution System \\
\hline EIA & Energy Information Agency \\
\hline EPA & Environmental Protection Agency \\
\hline E-REV & Extended-Range Electric Vehicle \\
\hline ESS & Energy Storage System \\
\hline
\end{tabular}




\begin{tabular}{|c|c|}
\hline EV & Electric Vehicle \\
\hline EVT & Electrically Variable Transmission \\
\hline$f$ & Friction Coefficient \\
\hline $\mathrm{FE}$ & Fuel Economy \\
\hline FEA & Finite Element Analysis \\
\hline FTP & Federal Test Procedure \\
\hline FWD & Front-Wheel-Drive \\
\hline g & Acceleration Due To Gravity or Gram Mass \\
\hline gal & Gallon \\
\hline GHG & Greenhouse Gas Emissions \\
\hline GM & General Motors Corporation \\
\hline gpm & Gallons-Per-Minute \\
\hline $\mathrm{HC}$ & Hydrocarbon Emissions \\
\hline $\mathrm{HCHO}$ & Formaldehyde \\
\hline $\mathrm{HCP}$ & Hybrid Control Processor \\
\hline HEV & Hybrid-Electric Vehicle \\
\hline hp & Horsepower \\
\hline HVIL & High-Voltage Interlock Loop \\
\hline HWFET & Highway Fuel Efficiency Test \\
\hline IMA & Integrated Motor Assist \\
\hline k & Surface Roughness \\
\hline $\mathrm{kg}$ & Kilogram Mass \\
\hline $\mathrm{km}$ & Kilometer \\
\hline $\mathrm{kN}$ & Kilonewton \\
\hline kph & Kilometers-Per-Hour \\
\hline kW & Kilowatt \\
\hline lb & Pound (Weight or Force) \\
\hline LNG & Liquefied Natural Gas \\
\hline mi. & Mile \\
\hline $\mathrm{mm}$ & Millimeter \\
\hline $\mathrm{mpg}$ & Miles-Per-Gallon \\
\hline mpgge & Miles-Per-Gallon Gasoline Equivalent \\
\hline $\mathrm{mph}$ & Miles-Per-Hour \\
\hline MUDS & Mall Urban Driving Schedule \\
\hline $\mathrm{N}-\mathrm{m}$ & Newton-Meter \\
\hline $\mathrm{N}_{2}$ & Diatomic Nitrogen \\
\hline NHTSA & National Highway Transportation Safety Administration \\
\hline $\mathrm{NiMH}$ & Nickel-Metal Hydride \\
\hline
\end{tabular}




$\begin{array}{ll}\text { NMHC } & \text { Non-Methane Hydrocarbon } \\ \text { NMOG } & \text { Non-Methane Organic Gas } \\ \text { NOX }_{\text {X }} & \text { Oxides of Nitrogen } \\ \text { OECD } & \text { Organization for Economic Cooperation and Development } \\ \text { OPEC } & \text { Organization of Petroleum Exporting Countries } \\ \text { ORSE } & \text { On-Road Safety Evaluation } \\ \text { P } & \text { Density } \\ \text { PEU } & \text { Petroleum Energy Usage } \\ \text { PHEV } & \text { Plug-In Hybrid-Electric Vehicle } \\ \text { PM } & \text { Particulate Matter } \\ \text { PSAT } & \text { Powertrain System Analysis Toolkit } \\ \text { PSi } & \text { Pounds-Per-Square Inch } \\ \text { R19 HWFET } & \text { Route 19 Highway Fuel Efficiency Test } \\ \text { RBDS } & \text { Regenerative Braking Disabling Switch } \\ \text { RTA } & \text { Rear Traction Assist } \\ \text { RWD } & \text { Rear-Wheel-Drive } \\ \text { SCU } & \text { Supervisory Control Unit } \\ \text { SCR } & \text { Selective Catalytic Reduction } \\ \text { SFTP } & \text { Supplemental Federal Test Procedure } \\ \text { SOC } & \text { State-Of-Charge } \\ \text { SUV } & \text { Sport-Utility Vehicle } \\ \text { TCM } & \text { Transmission Control Module } \\ \text { THC } & \text { Total Hydrocarbon Emissions } \\ \text { TPIM } & \text { Traction Power Inverter Module } \\ \mu & \text { Viscosity } \\ \text { UDDS } & \text { Urban Dynamometer Driving Schedule } \\ \text { V } & \text { Volts } \\ \text { VTEC } & \text { Variable Valve Timing and Lift Electronic Control } \\ \text { WV DOT } & \text { West Virginia Department of Transportation } \\ \text { WVU } & \text { West Virginia University } \\ & \end{array}$




\section{Introduction \& Objectives}

\subsection{Introduction}

The world's oil reserves are limited. While all of the oil held below the surface of the earth will never run out, the amount of oil that is economically and practically feasible to extract is finite. It is projected that oil production around the world will halt by the end of this century [1]. This is a problem because currently the world uses oil at a rate of around 88 million barrels per day. The United States alone consumes about 19 million barrels per day [3]. Of this, $70 \%$ is used specifically for transportation. If petroleum remains the primary source for transportation fuel for the next 90 years and production suddenly ends, the consequences would be disastrous. Many essential everyday functions rely on transportation. Food would not arrive to the market, coal would stay at the mine site instead of fueling the combustor at the power plant, and emergency vehicles would stay parked in the garage.

Groups like the U.S. Energy Information Agency (EIA), British Petroleum (BP), and Oak Ridge National Laboratory have been working to increase awareness by publishing reports describing current and future energy usage. Of particular interest are data regarding how much imported oil the United States consumes and how much we pay for it. About $50 \%$ of the oil consumed in the United States is imported. In 2010, the U.S. spent about $\$ 175$ billion on imported oil, with over $40 \%$ going to Organization of Petroleum Exporting Countries (OPEC) members and another 15\% going to non-OPEC Middle Eastern nations [2].

The United States government has steadily been increasing fuel economy requirements for new on-road vehicles in an effort to reduce the nation's oil consumption and, ultimately, our dependence on oil sourced from unstable Middle Eastern countries. This has caused automobile manufacturers to develop and produce more fuel efficient vehicles. In order to produce these fuel efficient vehicles, the manufacturers have started developing alternatives to the conventional powertrain consisting of an internal combustion engine connected to a transmission that drives the wheels.

The United States Department of Energy (DOE) has been trying to facilitate the design of alternative vehicles for more than 20 years. Since 1987, the U.S. DOE has been holding advanced vehicle technology competitions in cooperation with the major U.S. vehicle manufacturers to allow engineering students from across the United States, Canada, and Mexico the opportunity to help further the development of these new technologies. West Virginia University has built a 2-mode diesel-powered hybrid vehicle to compete in EcoCAR: The NeXt Challenge, sponsored by the DOE. By replacing the gasoline engine with a small diesel engine and installing a compound-split hybrid transaxle, the proposed project vehicle was expected to achieve much improved fuel efficiency while emitting lower levels of greenhouse gases. The research discussed in this thesis involved developing the powertrain control algorithm for the project vehicle and conducting on-road fuel efficiency and performance testing. 
As a graduate research assistant working for the project, the author was involved in all aspects of the vehicle design process including mechanical design, component selection, and integration. While the research focus of the work presented here was the development and validation of the powertrain control algorithm, the background work performed to produce the project vehicle has been included to provide a clear description of the project vehicle, its capabilities, and its limitations. This document will discuss the design and construction of the project vehicle in addition to detailing the powertrain control algorithm and on-road testing performed through the research.

\subsection{Research Objectives}

The goal of this research was to develop a unique powertrain control algorithm for a dieselpowered compound-split hybrid crossover utility vehicle built in conjunction with the university's participation in the EcoCAR competition and evaluate the fuel consumption and greenhouse gas emissions benefits that can be achieved compared to existing non-hybrid, gasoline-powered CUVs. Within the scope of the research, goals pertaining to the powertrain control algorithm were defined:

- Implement a novel diesel hybrid-electric powertrain architecture through the use of the GM frontwheel-drive 2-mode compound-split transaxle

- Develop a safe, efficient, and robust powertrain control algorithm to take full advantage of the capabilities of the 2-mode hybrid architecture

- Include engine on/off functionality, regenerative braking, and electric-only drive

- Maintain high energy efficiency without degrading vehicle performance

- Develop detailed on-road test plans

- Test multiple control strategies to determine how to most efficiently propel the project vehicle

- Conduct rigorous testing to validate the design of the project vehicle in terms of fuel efficiency, emissions, and performance

- Validate the accuracy of the computer simulations of the project vehicle 


\section{Literature Review}

\subsection{Petroleum Energy Usage In Transportation}

It has been well-documented that the world's supply of crude oil is finite. Current projections show that world oil production will likely begin to decline sharply before the year 2050 with production essentially ceasing by the year 2100 [1]. Over the next 25 years, petroleum consumption by the transportation sector in the United States is projected to increase from around 14 million barrels per day in 2011 to 17 million barrels per day, an increase of $21 \%$ [2]. The transportation sector accounts for about $70 \%$ of the total petroleum usage in this country. To understand the scale of the petroleum energy requirement of the United States, Figure 1 is an ExxonMobil projection of the worldwide transportation fuel demand through the year 2040 [26].

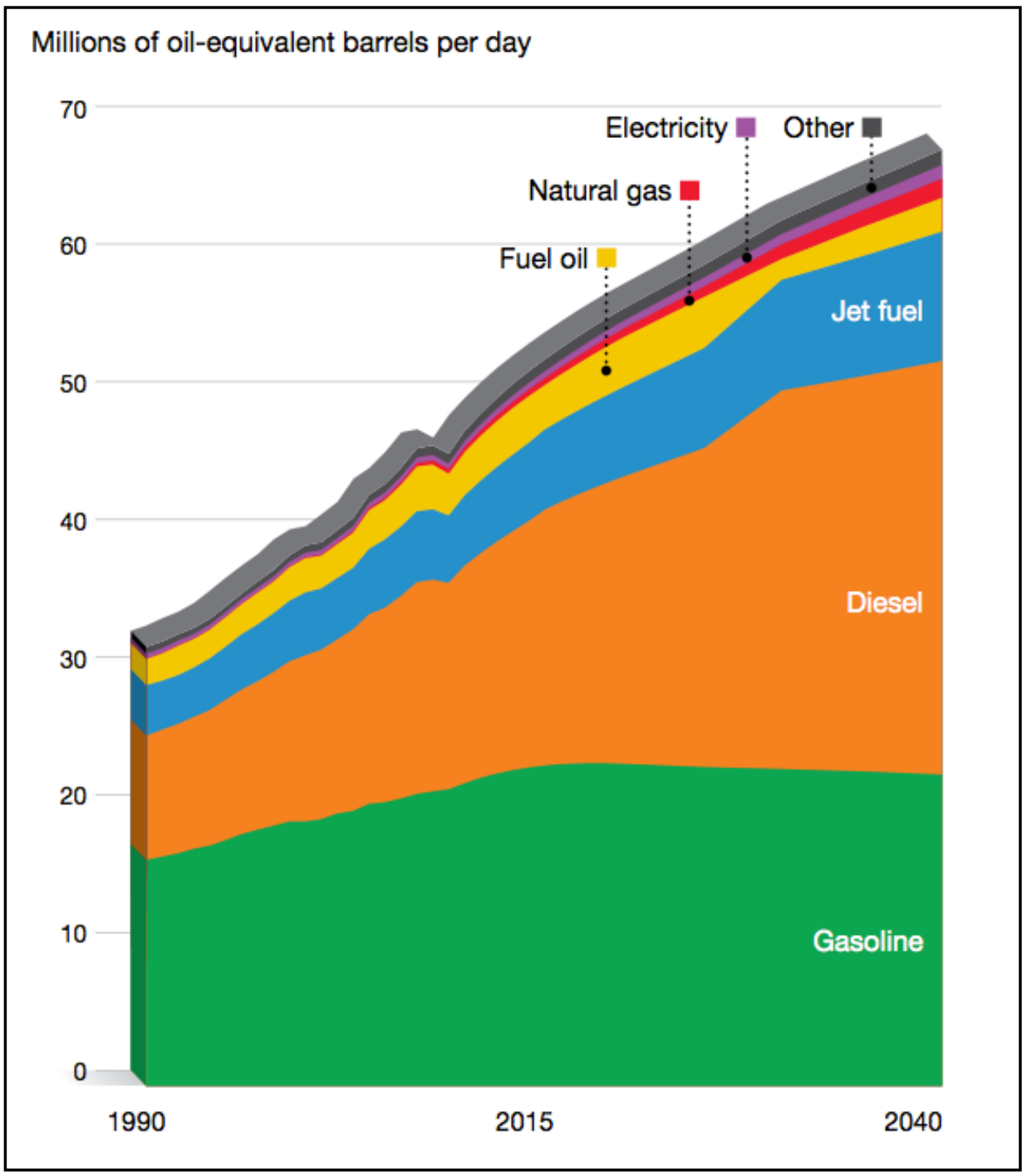

Figure 1. Future Transportation Fuel Demand [26] 
Today, worldwide petroleum consumption totals around 48 million barrels per day with the United States accounting for nearly $30 \%$ [26]. The projections show that gasoline consumption is going to settle into a constant 20 million barrels of oil per day, roughly $10 \%$ less than the amount consumed today. Diesel fuel demand, however, is expected to increase by $85 \%$ over the next three decades. ExxonMobil predicts that heavy-duty vehicles will be utilized more heavily in the coming years and although future heavy-duty diesel engines will be more efficient, road congestion is expected to become an issue [26]. Figure 2 displays how the commercial sector (right) is predicted to dominate transportation petroleum energy usage in the future. Note that the Commercial sector includes aviation, marine, and rail as well as over-the-road and off-road heavy-duty vehicles.

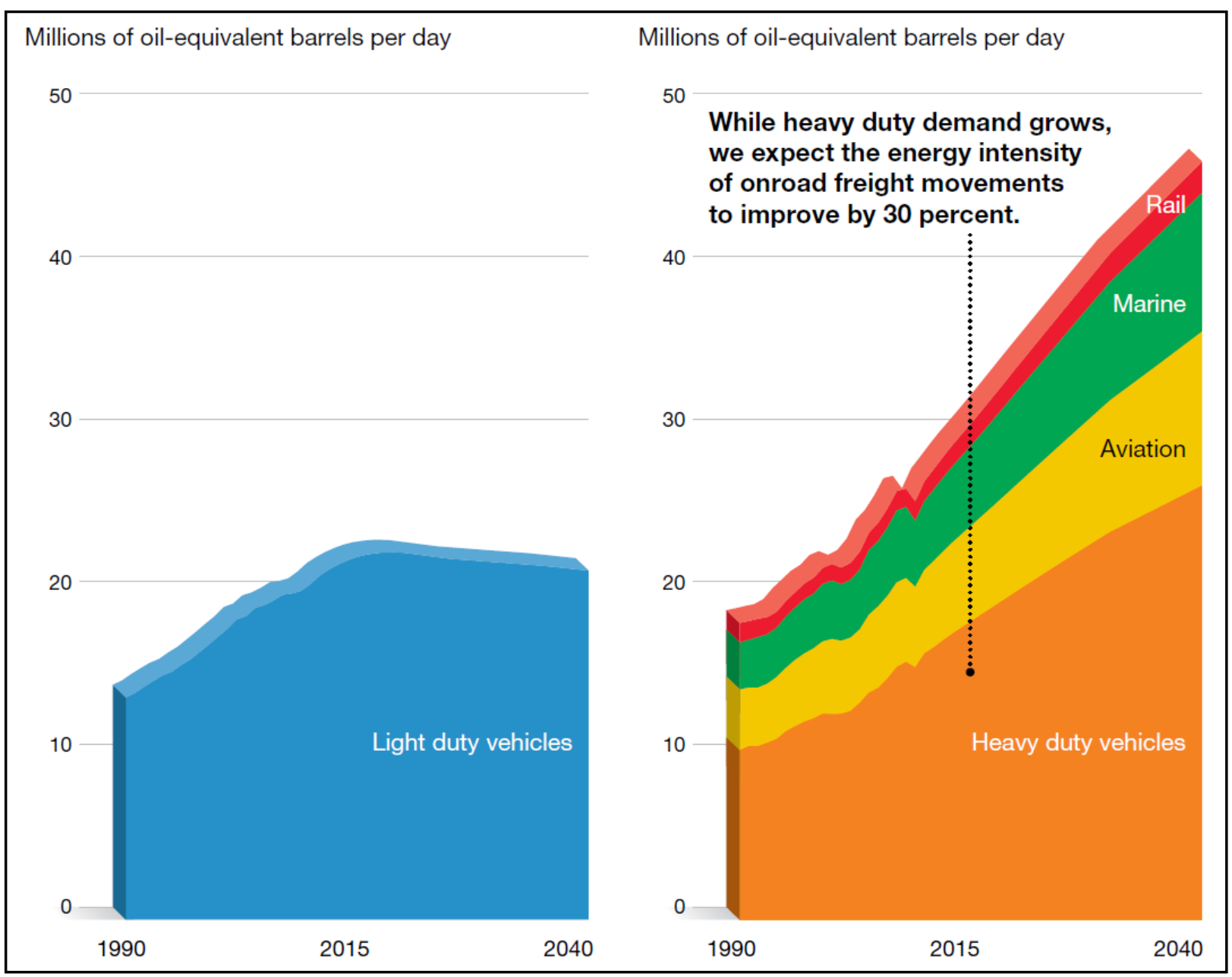

Figure 2. Transportation Fuel Demand: Personal vs. Commercial [26]

The commercial sector is expected to grow so rapidly due to development in non-OECD nations including China [26]. In spite of the number of vehicles comprising the global light-duty fleet nearly doubling to 1.6 billion by the year 2040, the amount of petroleum consumed by light-duty personal vehicles (left) is predicted to begin a gradual decline around the year 2015. This is due to a predicted increase in the average fuel efficiency of new model light-duty vehicles and the increased development 
and market proliferation of alternative vehicles such as hybrid-electric and full electric vehicles. Figure 3 displays the projected average fuel economy of new vehicles in the year 2040 [26].

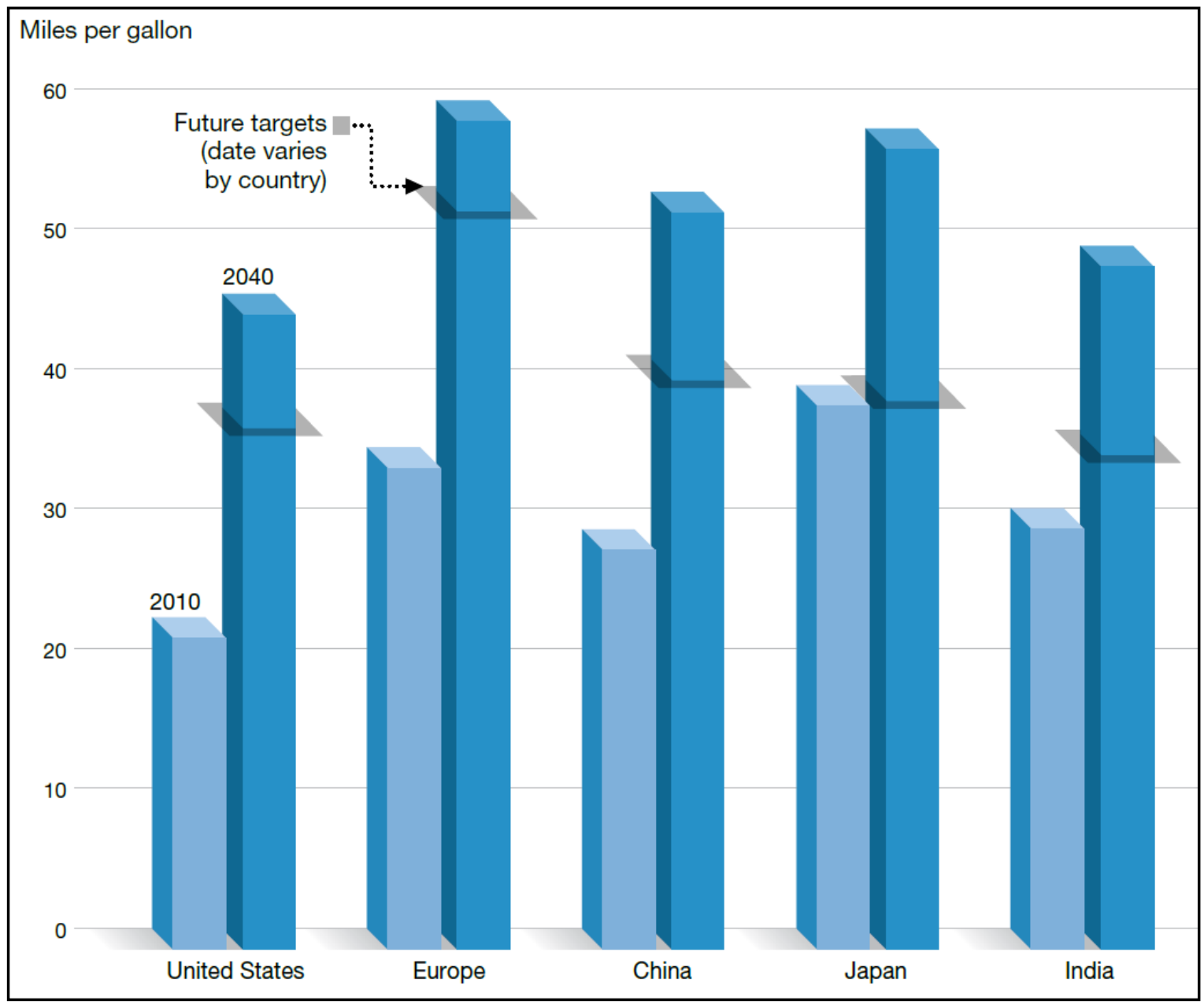

Figure 3. Fuel Economy of New Light-Duty Vehicles [26]

Currently, the average fuel economy of new light-duty vehicles is around $27 \mathrm{mpg}$ and ExxonMobil predicts that the average will increase to $48 \mathrm{mpg}$ by the year 2040 . This is due to an increase in the number of hybrid vehicles on the road and the implementation of strong, lightweight materials in constructing automobiles [26].

\subsection{Emissions Regulations}

Since the Clean Air Act was passed in 1970, the United States Environmental Protection Agency has been regulating emissions from mobile and stationary sources in an attempt to reduce air pollution. The Clean Air Act of 1970 established the first set of standards and limits for exhaust emissions from automobiles. The EPA was established the same year to enforce this new set of regulations.

Over the years, amendments have been made to the Clean Air Act including revisions made in 1990 regulating toxic emissions and ozone-depleting compounds including oxides of nitrogen ( $\mathrm{NO}_{\mathrm{x}}$ [ [48]. 
Toxic pollutants are considered those that pose potential risks to humans and the environment. Examples of regulated toxic pollutants include benzene, formaldehyde, naphthalene, and phosphorus. In Title III of the 1990 amendments, toxic compounds are defined as those that cause cancer, reproductive dysfunctions, neurological disorders, and genetic mutations [49].

Currently, the EPA regulates exhaust emissions for every type of on- and off-road vehicle including passenger cars, heavy-duty trucks, and locomotives. Each class of vehicle has its own unique set of standards and limits. Light-duty vehicles are defined as those with a gross vehicle weight rating less than $8500 \mathrm{lb}$ [50]. Beginning in 1991, the EPA adopted a scale for rating the emission levels produced by new vehicles. These Tier 1 standards were phased in between 1994 and 1997, giving manufacturers four model years to comply. The Tier 1 standards were concerned with emissions of hydrocarbons (unburned fuel), carbon monoxide, $\mathrm{NO}_{\mathrm{X}}$, and particulate matter (PM). The hydrocarbon emissions were divided into non-methane (NMHC) as well as total (THC). Table 1 lists the EPA Tier 1 emission standards for new light-duty vehicles. Note that all emissions values are listed in $\mathrm{g} / \mathrm{mi}$ [51].

Table 1. EPA Light-Duty FTP-75 Tier 1 Emissions Standards [51]

\begin{tabular}{|r|c|c|c|c|c|c|}
\hline & THC & NMHC & CO & $\begin{array}{c}\text { NO }_{\mathbf{x}} \\
\text { (Diesel) }\end{array}$ & $\begin{array}{c}\text { NO }_{\mathbf{x}} \\
\text { (Gasoline) }\end{array}$ & PM \\
\hline$<\mathbf{5 0 , 0 0 0 m i . / 5}$ yrs. & 0.41 & 0.25 & 3.4 & 1.0 & 0.4 & 0.08 \\
\hline$>\mathbf{1 0 0 , 0 0 0 m i . / 1 0 ~ y r s . ~}$ & - & 0.31 & 4.2 & 1.25 & 0.6 & 0.10 \\
\hline
\end{tabular}

The Tier 1 standards required that the vehicles be in compliance when new and after having been in-use for 100,000 miles or ten years. The standards for older vehicles were less stringent than for the new vehicles. The emissions were measured while driving the vehicles over the EPA's FTP-75 schedule. Beginning in the year 2000, the EPA instituted a supplemental federal test procedure (SFTP) for certifying new vehicles. This new procedure included the EPA's aggressive highway test cycle (US06) as well as its urban cycle with air conditioning operating (SC03). Table 2 lists the Tier 1 SFTP standards for lightduty vehicles. Note that the $\mathrm{NMHC}+\mathrm{NO}_{x}$ emissions are the weighted sum of these emissions from the FTP-75, US06, and SC03 test cycles with all values being listed in $\mathrm{g} / \mathrm{mi}$ [51].

Table 2. SFTP Tier 1 Emission Standards [51]

\begin{tabular}{|r|c|c|c|}
\hline & \multirow{2}{*}{$\begin{array}{c}\text { NMHC+NO } \\
\text { (Weighted) }\end{array}$} & \multicolumn{2}{|c|}{ CO } \\
\cline { 3 - 4 } & & US06 & SC03 \\
\hline$<\mathbf{5 0 , 0 0 0 m i . / 5}$ yrs. & 1.48 & 9.0 & 3.0 \\
\hline$>\mathbf{1 0 0 , 0 0 0 m i . / 1 0 ~ y r s . ~}$ & 2.07 & 11.1 & 3.7 \\
\hline
\end{tabular}

The EPA adopted a new set of emissions standards at the end of 1999 . The new Tier 2 standards were more descriptive than the previous Tier 1 standards with the addition of classification bins for new vehicle emissions. While the test procedure was the same for Tier 2 as in Tier 1, NOx standards 
were no longer fuel-specific, THC emissions were replaced with non-methane organic gas (NMOG) emissions, and formaldehyde $(\mathrm{HCHO})$ was added to the list of regulated emissions. The Tier 2 emissions standards were phased in between 2004 and 2009. Table 3 lists the EPA Tier 2 FTP-75 emissions standards. Note that all values are listed in $\mathrm{g} / \mathrm{mi}$ [52].

Table 3. EPA Light-Duty FTP-75 Tier 2 Emissions Standards [52]

\begin{tabular}{|c|c|c|c|c|c|c|c|c|c|c|}
\hline & \multicolumn{5}{|c|}{$<\mathbf{5 0 , 0 0 0} \mathbf{~ m i} . / 5$ years } & \multicolumn{5}{c|}{$>\mathbf{1 2 0 , 0 0 0}$ mi./15 years } \\
\cline { 2 - 11 } & NO $_{\mathbf{x}}$ & NMOG & CO & PM & HCHO & NO & NMOG & CO & PM & HCHO \\
\hline Bin 11 & 0.60 & 0.195 & 5.0 & - & 0.022 & 0.90 & 0.28 & 7.3 & 0.12 & 0.032 \\
\hline Bin 10 & 0.40 & 0.125 & 3.4 & - & 0.015 & 0.60 & 0.156 & 4.2 & 0.08 & 0.018 \\
\hline Bin 9 & 0.20 & 0.075 & 3.4 & - & 0.015 & 0.30 & 0.09 & 4.2 & 0.06 & 0.018 \\
\hline Bin 8 & 0.14 & 0.100 & 3.4 & - & 0.015 & 0.20 & 0.125 & 4.2 & 0.02 & 0.018 \\
\hline Bin 7 & 0.11 & 0.075 & 3.4 & - & 0.015 & 0.15 & 0.09 & 4.2 & 0.02 & 0.018 \\
\hline Bin 6 & 0.08 & 0.075 & 3.4 & - & 0.015 & 0.10 & 0.09 & 4.2 & 0.01 & 0.018 \\
\hline Bin 5 & 0.05 & 0.075 & 3.4 & - & 0.015 & 0.07 & 0.09 & 4.2 & 0.01 & 0.018 \\
\hline Bin 4 & - & - & - & - & - & 0.04 & 0.07 & 2.1 & 0.01 & 0.011 \\
\hline Bin 3 & - & - & - & - & - & 0.03 & 0.055 & 2.1 & 0.01 & 0.011 \\
\hline Bin 2 & - & - & - & - & - & 0.02 & 0.01 & 2.1 & 0.01 & 0.004 \\
\hline Bin 1 & - & - & - & - & - & 0 & 0 & 0 & 0 & 0 \\
\hline
\end{tabular}

Bins 9-11 expired in 2006 as they were implemented during the phase-in process only. All lightduty cars were required to meet Tier 2 Bin 8 standards by model year 2007 with all light-duty vehicles including trucks meeting the standards by 2009 [50]. Similar to the Tier 1 test procedure, Tier 2 certification included a supplemental test to simulate more extreme driving situations. The Tier 2 SFTP certification was not divided into bins. Again, $\mathrm{NMHC}+\mathrm{NO}_{x}$ was a weighted sum of the emissions measured during the FTP-75, US06, and SC03 test cycles. Table 4 lists the standards for Tier 2 SFTP emissions. All values are listed in $\mathrm{g} / \mathrm{mi}[50]$.

Table 4. SFTP Tier 2 Emissions Standards [50]

\begin{tabular}{|c|c|c|c|}
\hline \multicolumn{2}{|c|}{ US06 } & \multicolumn{2}{c|}{ SC03 } \\
\hline NMHC+NOx & CO & NMHC+NOx & CO \\
\hline 0.14 & 8.0 & 0.2 & 2.7 \\
\hline
\end{tabular}

Unlike Tier 1 standards, Tier 2 SFTP standards have no provision for vehicle age or mileage. Tier 2 SFTP standards were set to be equivalent to the Tier 1 standard minus $35 \%$ of the difference between the Tier 1 and Tier 2 FTP-75 standards. 


\subsection{Unconventional Light-Duty Vehicle Types}

Automobiles have been built dating back as far as the 17th century. The first automobile to utilize an Otto-cycle engine was built in 1886 by Karl Benz of Germany. The Benz-Patent Motorwagen is considered the first "modern automobile" by the fact that it was intentionally designed to be self-propelled and not pulled by horses. The three-wheeled Motorwagen featured a state-of-the-art single cylinder Ottocycle internal combustion engine producing $2 / 3 \mathrm{hp}$ [20]. The Otto-cycle internal combustion engine went on to become the standard power generator for automobiles and continues to be so to this day. However, the availability issues associated with crude oil and the harmful emissions resulting from the combustion of petroleum-derived fuels have led to increasing interest in alternative methods for propelling automobiles.

\subsubsection{Gasoline Engine Alternatives}

Gasoline engines have been used in everything from 1:10 scale remote control cars to lawn care equipment, boats, airplanes, and passenger vehicles. However, concerns regarding the operation of gasoline-powered internal combustion engines have driven engineers worldwide to develop suitable alternatives.

\subsubsection{Compression-Ignition Engines}

Around the same time as developmental work was being performed on Otto-cycle gasoline engines, Rudolf Diesel was working on an alternative internal combustion engine design. In contrast to the spark-ignited gasoline engine, Diesel's proposed heat engine used only the heat caused by compressing air to ignite the fuel. United States Patent number 608,845 was filed on August 9th, 1898 for Diesel's engine. The patent described in great detail how this new engine was designed to operate and how it differed from the gasoline engines of the day. The spark ignition source was replaced by a fuel supply valve, now known as a fuel injector, used to initiate the combustion process. The pistoncylinder assembly in Diesel's engine provided sufficient compression to raise the in-cylinder temperature past the fuel's auto-ignition temperature, meaning that combustion would begin as soon as fuel was introduced into the combustion chamber [19].

A notable advantage compression-ignition engines hold over conventional spark-ignited engines

is higher compression. Spark-ignited gasoline engines cannot tolerate compression ratios high enough to auto-ignite the gasoline in the cylinder because this uncontrolled ignition, known as knock, causes damage to the different mechanical components of the engine [21]. However, this is the same principal upon which compression-ignition diesel engines operate. For this reason, compression-ignition engines allow considerably higher compression ratios. Where an average spark-ignited engine may have a compression ratio of up to around 11:1, compression-ignition engines can tolerate compression ratios as high as 24:1. This is advantageous because a higher compression ratio produces more work output for the same amount of fuel energy consumed, increasing both potential power and thermal efficiency [21]. 
In addition, diesel fuel contains more energy per gallon than gasoline. Where gasoline has an energy content of roughly $125,000 \mathrm{BTU} / \mathrm{gal}$, diesel fuel increases energy content to around $138,700 \mathrm{BTU} / \mathrm{gal}$. Light-duty vehicles equipped with compression-ignition diesel engines typically achieve $20-40 \%$ better fuel efficiency than similar gasoline-powered vehicles [22].

Today, diesel engines are used almost exclusively in heavy-duty over-the-road and off-road equipment such as class 8 tractors and locomotives. This is likely due to the torque potential and efficiency provided by the high compression ratio of compression-ignition engines. Light-duty diesel engines are slowly gaining popularity with the car-buying public, but diesel has yet to reach the light-duty mainstream. Over the past decade, light-duty diesel vehicles only account for about 2-3\% of all light-duty vehicles sold in the United States [22].

\subsubsection{Natural Gas}

With the discovery of vast natural gas reserves in the United States including the Marcellus Shale formation located under Pennsylvania, Ohio, New York, and West Virginia, the automotive industry will have more fueling options for new vehicles in the future. Natural gas can be combusted in spark-ignited and compression-ignited engines with minimal modifications. Like gasoline, natural gas requires an ignition source such as a spark to begin combustion. Natural gas has a higher octane rating than traditional gasoline so an engine designed to run on natural gas can have a higher compression ratio than a comparable gasoline engine. Similar to compression-ignition engines that run on diesel fuel, the higher compression ratio allowed by natural gas increases the efficiency of the engine [23]. In transportation, natural gas is stored either as a compressed gas (CNG) or a liquid (LNG). CNG is the more popular form of natural gas used in transportation due to LNG requiring refrigeration to maintain its liquefied state.

In addition to the increased efficiency of natural gas engines, the combustion of natural gas also produces fewer harmful exhaust emissions than the combustion of gasoline. It should be noted that the combustion of natural gas does produce higher levels of methane gas $\left(\mathrm{CH}_{4}\right)$ which, while not contributing to smog, does act as a greenhouse gas. Depending on the design of the engine, natural gas has the potential to reduce carbon monoxide emissions by up to $97 \%$, $\mathrm{NO}_{\mathrm{x}}$ could be reduced by up to $60 \%$, and non-methane hydrocarbon emissions could be reduced by as much as 75\% [23]. However, CNG contains roughly $1 / 4$ the energy in gasoline per gallon meaning that more fuel would need to be stored onboard to maintain a vehicle's range between refills. These large high pressure storage vessels add to the price of CNG vehicles. Similar to light-duty diesel vehicles, CNG vehicles typically cost between $\$ 3,500$ and $\$ 6,000$ more than equivalent gasoline vehicles [23].

Currently, there is only one new model light-duty vehicle sold in the United States that runs on CNG. The Honda Civic Natural Gas (formerly GX) is designed to run exclusively on CNG and is the only sedan sold in this country that runs on natural gas. Chevrolet is planning a CNG Silverado 2500HD that will be capable of running on either CNG or gasoline to be on-sale later this year. Ram has begun selling a CNG 2500 heavy-duty pickup similar in concept to the system in the CNG Silverado. However, there is 
another class of unconventional vehicles that outsells natural gas and diesel-powered light-duty vehicles year after year.

\subsubsection{Hybrid Vehicles}

A hybrid vehicle is defined as any vehicle that utilizes two or more forms of energy storage for producing propelling power [25]. The popular light-duty hybrid vehicles on-sale today such as the Toyota Prius and Honda Insight utilize a spark-ignited gasoline engine for on-board power generation and supplement the engine with electric motors for propelling the vehicle. Hybrid vehicles are designed to reduce the fuel consumption and emissions generated by the transportation sector by reducing the amount of petroleum products consumed.

The major advantage a hybrid vehicle holds over a conventional vehicle is the ability to recapture otherwise wasted energy used to slow the vehicle during braking and store that energy for use in propelling the vehicle at a later time. In a hybrid-electric vehicle this energy is stored in a high-voltage battery [25]. Another advantage of incorporating powerful electric motors in the powertrain is the ability to turn the engine on and off quickly. This functionality allows hybrid vehicles to turn their engines off when the vehicle is stationary, thereby saving fuel that would otherwise be wasted while idling the engine. Depending on the size of the electric motor, some hybrid vehicles are even capable of electric-only drive with the engine turned off [25].

\subsubsection{Series Hybrids}

HEVs can be classified based on how the electric motors and engine are arranged in the powertrain. A series hybrid uses only the electric motor to drive the wheels with the engine driving an electric generator used to recharge the high voltage battery. Series hybrids require larger high voltage batteries than other hybrids because propulsion comes solely from the electric motor [25]. Currently the only commercially available series hybrid light-duty vehicles for sale in the United States are the limited production Fisker Karma and the Chevrolet Volt, although others are under development.

An advantage to the series configuration is the ability to operate the engine independent of the desired axle torque requested by the driver. This allows the engine to be operated in states of maximum efficiency with little throttling and limited transient operation [28]. Another advantage to the series hybrid layout is the ability to operate the vehicle with the engine off for extended periods of time depending on the state of charge of the high voltage battery. This is the reason that the batteries in both the Karma and the Volt are capable of being charged from a standard household electrical receptacle. These plug-in hybrid-electric vehicles are each capable of travelling from 20-40 miles on a full charge without turning the engine on [28].

The major drawback to a series powertrain configuration is that the conversion efficiency of the generator cannot be bypassed. In the event that the engine is running and the vehicle is in motion, all of the power generated by the engine must first be converted to electricity before reaching the wheels. Where a typical transmission is around $90-95 \%$ efficient at transferring engine power to the wheels, the 
conversion efficiency of a generator in a series hybrid is rarely this high and there are losses associated with charging and discharging the high voltage battery [33].

\subsubsection{Parallel Hybrids}

A parallel hybrid has the engine and electric motors arranged in such a way that propelling power can be provided by any combination of the engine or electric motors. The parallel powertrain layout is the most popular due to the ability to draw power from the engine and electric motors depending upon driving conditions to maintain maximum vehicle energy efficiency [25]. This allows the installation of smaller, lighter battery packs in parallel hybrids compared to those found in series hybrids and full electric vehicles. Most of the hybrid vehicles on the road today are parallel hybrids.

In a parallel hybrid configuration, the engine, the electric motor, or a combination of both can be used to propel the vehicle. This eliminates the losses associated with constantly converting the mechanical energy produced by the engine to electrical energy through the generator by allowing the engine to directly propel the vehicle. Typically, parallel hybrids rely on the electric motors for acceleration during transient low-speed vehicle operation and use the engine to propel the vehicle during periods of sustained vehicle speed. In general, parallel hybrids are more efficient during highway driving than series hybrids with the opposite being true for city driving [33].

\subsubsection{Full Electric Vehicles}

While the hybrid vehicles described previously incorporate electrical machines to provide propelling power, they all still rely on internal combustion engines for on-board power production through the combustion of fossil fuel. In addition to petroleum-derived fuels and natural gas, automobile manufacturers have been considering the idea of using only electricity to provide vehicle propelling power. At the dawn of the $20^{\text {th }}$ Century, electric vehicles were preferred because the earliest internal combustion engines tended to backfire due to low quality fuel, scaring any horses that may be nearby. These early electrics were generally used as "city cars" for running errands around town because they lacked the power to achieve speeds higher than $20 \mathrm{mph}$. Early electric vehicles generally allowed driving ranges on a full charge of between 25 and 40 miles [18].

Thanks to advances in automobile design and battery technology, today's EVs are designed to be capable of achieving highway speeds with ranges of at least 100 miles between charges [29]. According to EV manufacturer Tesla, their Roadster model is capable of a range of 220 miles. Assuming an EV consumes $1 \mathrm{kWh}$ of energy every 3 miles, the cost to recharge the high voltage battery at the national average rate of $11.7 \mathrm{c} / \mathrm{kWh}$ would come out to $3.9 \mathrm{\phi} / \mathrm{mile}$ [30]. By comparison, a conventional vehicle that achieves an average fuel economy of $28 \mathrm{mpg}$ at a fuel price of $\$ 3.80 /$ gallon would cost $13.57 \mathrm{\phi} / \mathrm{mile}$ to operate. At $50 \mathrm{mpg}$, the operational cost would be $7.6 \mathrm{\$} / \mathrm{mile}$, roughly double that of the EV.

While electric vehicles consume no fuel, produce no emissions while driving, and cost considerably less to operate travelling down the road, they have yet to reach the popularity of hybrids. This is due to the range anxiety stigma associated with operating EVs. Charging times for the large 
batteries found in PHEVs and EVs can be as long as 11 hours using a standard 110/120 V electrical receptacle [28]. Consumers are afraid of being stranded with a depleted battery and no way to recharge it. This is the major advantage hybrid vehicles hold over full electric vehicles.

\subsubsection{Future Light-Duty Vehicle Market Trends}

Since the introduction of the Echo-based first generation Toyota Prius in 2000, more than one million Toyota Prius models have been sold in the United States with the worldwide total eclipsing four million. The number of diesel-powered and CNG-fueled vehicles sold in the United States is negligible compared to the total light-duty vehicles sold, and this trend is expected to continue. According to the EIA, there were 128 million new cars sold in the United States in 2011. Of those, 1.5 million were hybridelectrics, 1.03 million were diesel vehicles, and 30,000 were natural gas vehicles [27]. Figure 4 is a chart of the projected composition of the worldwide light-duty vehicle fleet through the year 2040 [26].

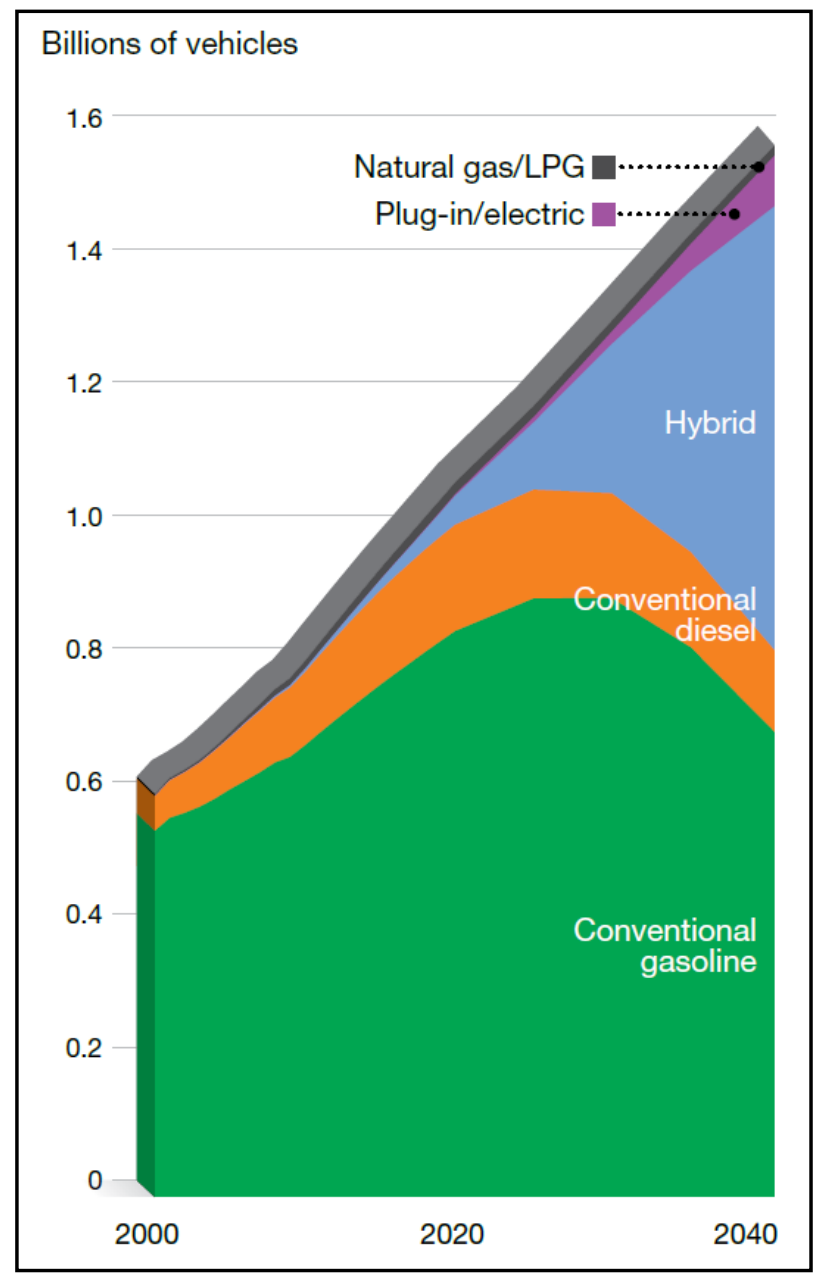

Figure 4. Worldwide Light-Duty Vehicle Fleet [26]

The chart illustrates how hybrid vehicles are projected to comprise around 35\% of the light-duty vehicle fleet by the year 2040. It also depicts the declining market shares of diesel-powered and 
gasoline-powered vehicles from $98 \%$ today down to $50 \%$ in 2040 with only $35 \%$ of the new vehicles sold being conventionally powered. This sharp decline is projected due to increasingly stringent fuel economy and emissions regulations. Natural gas and electric vehicles are expected to continually increase to around $5 \%$ of the global fleet in 2040 [26].

\subsection{Automotive Battery Technology}

A major concern among consumers considering purchasing hybrids and EVs is the durability and safety of their high voltage systems. Detractors often cite battery replacement costs as a reason not to purchase HEVs and EVs. While a battery replacement in a Toyota Prius costs around $\$ 4,000$, the frequency with which replacements occur is about one in 40,000 vehicles [32]. Battery technology has advanced over the past decade to the point that there are multiple viable options for automobile manufacturers when selecting what type of batteries to use in new hybrid vehicles.

\subsubsection{Lead-Acid}

Lead-acid batteries can be found in almost every light-duty vehicle on the road today. Commonly used for engine starting, lead-acid batteries have been proven durable and stable over billions of on-road miles in the past century. Lead-acid batteries are the least expensive automotive battery technology currently available. In addition, lead-acid batteries are more resistant to voltage drop when cold compared to other battery technologies. However, there are limitations to lead-acid batteries in hybrid applications [31].

The reason that lead-acid batteries work so well as starting batteries is that current is only drawn from the battery at high rates for a limited time while the starter motor is spinning the engine. Lead-acid batteries cannot withstand long periods of current draw before becoming unstable. The major disadvantage of lead-acid batteries, however, is low energy density. A lead-acid battery large enough to store the energy required by today's HEVs would be too heavy to be feasible [31].

\subsubsection{Nickel-Metal Hydride (NiMH)}

Nickel-metal hydride batteries were the most popular battery technology being used in new hybrid vehicles until recently. There was a time when all hybrid vehicles sold in the United States utilized NiMH batteries for electrical energy storage. With higher energy density than lead-acid batteries, NiMH batteries can be sized appropriately to fit well into passenger vehicles without adding as much mass as a similarly sized lead-acid battery pack [31].

The Toyota Prius utilized NiMH batteries from the beginning and those battery packs have proven durable over the lifetime of the vehicles. According to Toyota, the battery replacement rate for the extremely popular second generation Prius was $0.003 \%$ [32]. However, Toyota has recently replaced the $\mathrm{NiMH}$ batteries in their hybrids with new lithium-ion units. Currently, NiMH batteries are available in every Honda hybrid model as well as the full-size pickup and SUV hybrids built by General Motors. 
$\mathrm{NiMH}$ batteries have been known to generate significant heat when operated at high temperatures, indicating an internal inefficiency that wastes energy that could otherwise be used to propel the vehicle. They are also known to generate hydrogen gas under certain circumstances which must be avoided to eliminate the chance of an explosion [32]. While NiMH batteries were the standard in HEV high voltage battery packs, lithium-ion battery technology has been increasingly implemented in new hybrids and EVs.

\subsubsection{Lithium-Ion}

Lithium-ion batteries are the current state-of-the-art in hybrid vehicle electrical energy storage. This style of battery has been used successfully in laptop computers and cellular phones for years. Recently, larger lithium-ion batteries have been developed for use in electrified vehicles, displacing $\mathrm{NiMH}$ batteries formerly used in vehicles such as the Toyota Prius and Ford Escape Hybrid.

Of the three technologies discussed, lithium-ion batteries have the highest specific energy meaning that a battery pack with a given energy storage capacity would be lighter and physically smaller than a NiMH or lead-acid battery of equivalent capacity. For this reason, lithium-ion batteries are currently the most ideal technology for use in alternative automotive applications [31]. However, lithiumion batteries must be closely monitored and controlled to maintain the battery pack at a safe temperature. If lithium-ion batteries are allowed to get above roughly $60^{\circ} \mathrm{C}$, reactions will begin to occur spontaneously inside the battery modules until the temperature rises to the point that the batteries could catch on fire or explode [31]. This uncontrolled discharging was the cause for laptop computer fires in the past.

\subsubsection{Safety Concerns}

Recently, the Chevrolet Volt has drawn attention to the danger surrounding high-voltage batteries used in automobiles. Following side-impact crash testing performed by the National Highway Traffic Safety Administration (NHTSA) a Chevrolet Volt caught on fire three weeks after the test with the wrecked vehicle sitting in a lot outside of the NHTSA facility. The fire was investigated and the cause was found to be that coolant had leaked out of the battery's liquid cooling system due to a frame member piercing the side of the T-shaped battery pack located between the front seats. The leaked coolant seeped into the high-voltage battery and created short circuits inside the battery pack leading to elevated temperatures and the eventual fire [34]. GM subsequently recalled every Volt that had been sold to prevent this from occurring again. NHTSA has since revised their post-testing procedure to include draining the fuel tank and discharging any batteries installed in wrecked test vehicles. According to NHTSA there have been no reported incidents involving battery fires in electrified automobiles [35].

\subsection{Production Hybrid Systems}

Today's hybrid-electric vehicles can be classified according to their level of hybridization or the degree to which electrical energy is used for propulsion. Different hybrid powertrains are designed to 
utilize fuel energy and electrical energy at different rates under certain driving conditions but each design has limitations on how much power the engine or electric motors can provide to propel the vehicle. Systems that rely mostly on the engine for propelling power are referred to as "mild hybrids" while systems that are capable of a more even split between engine power and electric motor power are called "strong hybrids." A mild hybrid system typically utilizes a small electric motor/generator used to assist the engine during acceleration and cruising, but the electric motor alone typically cannot power the vehicle. Strong hybrids utilize larger electric machines typically capable of powering the vehicle on electricity alone [25]. Examples of mild hybrid architectures include GM's Belt Alternator/Starter system and Honda's Integrated Motor Assist (IMA) system. Strong hybrid systems include GM's 2-mode and Toyota's Hybrid Synergy Drive.

\subsubsection{GM's Belt Alternator/Starter}

\subsubsection{Generation I}

General Motors first developed the BAS system to be installed in the 2007 Saturn Vue Green Line hybrid CUV and the 2007 Saturn Aura Green Line hybrid sedan. The first-generation BAS system consisted of a 2.4 liter four cylinder gasoline engine with an electric motor/generator driven off of the engine crankshaft via a rubber belt. Table 5 lists the specifications of the first generation BAS system in the 2007 Vue Green Line [24].

Table 5. GM First Generation BAS Specifications [24]

\begin{tabular}{|r|c|}
\hline Engine Type & $2.4 \mathrm{~L}$ Gasoline \\
\hline Engine Power & $127 \mathrm{~kW}$ \\
\hline Engine Torque & $220 \mathrm{~N}-\mathrm{m}$ \\
\hline Electric Motor Power & $>4 \mathrm{~kW}$ \\
\hline Electric Motor Torque & $>60 \mathrm{~N}-\mathrm{m}$ \\
\hline Battery Type & $\mathrm{NiMH}$ \\
\hline Battery Voltage & $36 \mathrm{~V}$ \\
\hline
\end{tabular}

The first generation system was only available with a modified 4T45-E conventional four speed automatic transaxle. Modifications included adding an auxiliary transmission fluid pump to maintain pressure in the automatic transmission when the engine was not running to avoid transmission slippage when pulling away from a stop as well as other minor changes to reduce rolling resistance during coastdown and regenerative braking [24]. An advantage of the BAS system was its ease of integration into vehicles constructed on an assembly line. The $36 \mathrm{~V}$ battery enclosure housed the hybrid system control hardware and the motor/generator mounted in place of a conventional alternator on the front of the engine minimizing hybrid-specific work during final assembly [24]. 
The BAS system was capable of engine-off idling and regenerative braking. In addition, the electric motor/generator provided supplemental torque during acceleration and cruising, reducing the amount of fuel consumed by the engine during these events. In the 2007 Saturn Vue Green Line, the BAS system increased city fuel economy by $23 \%$ and increased highway fuel economy by $19 \%$ over the base 2007 Saturn Vue model. In addition, the Vue Green Line accelerated from 0-60 mph one second faster than the base Vue [24]. The first generation BAS system was available on the discussed Saturn hybrid models as well as the Chevrolet Malibu hybrid model. General Motors discontinued its BAS system after the 2010 model year.

\subsubsection{Generation II (eAssist)}

General Motors launched its second generation BAS system, renamed eAssist, in the 2012 Buick LaCrosse and Regal eAssist models. The eAssist system was an evolution of the original BAS system maintaining the original system's layout and functions. Table 6 lists the specifications for the eAssist system in comparison to the original BAS system [41].

Table 6. GM eAssist System Specifications [41]

\begin{tabular}{|r|c|c|}
\hline & BAS & eAssist \\
\hline Engine Type & $2.4 \mathrm{~L}$ Gasoline & $2.4 \mathrm{~L} \mathrm{DI}$ Gasoline \\
\hline Engine Power & $127 \mathrm{~kW}$ & $136 \mathrm{~kW}$ \\
\hline Engine Torque & $220 \mathrm{~N}-\mathrm{m}$ & $233 \mathrm{~N}-\mathrm{m}$ \\
\hline Electric Motor Power & $>4 \mathrm{~kW}$ & $>14 \mathrm{~kW}$ \\
\hline Electric Motor Torque & $>60 \mathrm{~N}-\mathrm{m}$ & $>60 \mathrm{~N}-\mathrm{m}$ \\
\hline Battery Type & $\mathrm{NiMH}$ & Li-lon \\
\hline Battery Voltage & $36 \mathrm{~V}$ & $115 \mathrm{~V}$ \\
\hline
\end{tabular}

The 2.4 liter engine in the eAssist system had direct injection and higher compression than the previous BAS engine (11.2:1 vs. 10.4:1). The new lithium-ion battery was both smaller and lighter than the NiMH battery used in the first generation system [41]. GM's eAssist system utilized a modified 6T40 six speed automatic transaxle in place of the four speed unit in the first generation BAS system. The new transmission was already equipped to allow for low-drag coasting requiring only the addition of an auxiliary oil pump and a new torque converter seal for use in eAssist applications [41].

The new eAssist system retained the engine-off idling and regenerative braking capabilities of the previous BAS system as well as provided supplemental torque during acceleration and cruising. However, due to the increased power of the electric motor/generator and the addition of a wide ribbed belt, the eAssist system was capable of momentary electric-only drive while the engine was started [41]. According to road load calculations performed by GM powertrain engineers, the new eAssist system could provide $33 \%$ improved city fuel economy and $20 \%$ improved highway fuel economy compared to a 
standard vehicle [41]. Currently, eAssist is available on the Buick Regal and LaCrosse eAssist models as well as the new Chevrolet Malibu Eco.

\subsubsection{Honda's Integrated Motor Assist}

Honda's Integrated Motor Assist system debuted on the 1999 Insight model equipped with a 1.0 liter three cylinder engine producing $50 \mathrm{~kW}$ and an electric motor producing an additional $10 \mathrm{~kW}$ [38]. Honda's mild hybrid IMA system is similar to General Motors' BAS/eAssist system in that it utilizes an electric motor to provide additional torque during acceleration to reduce the fuel consumed by the engine during transient operation. However, where the GM systems located the motor/generator at the front of the engine and connect it to the crankshaft via a rubber belt, Honda's IMA system located the electric motor between the engine and transmission with the motor directly connected to the engine's crankshaft. Figure 5 is a drawing illustrating the placement of the electric motor in the IMA system [38].

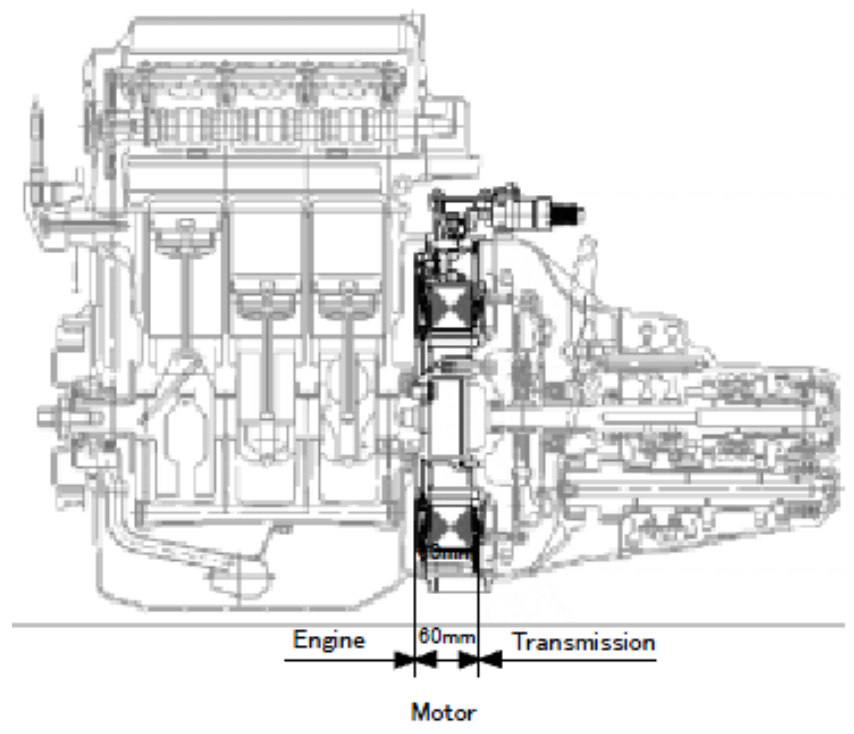

Figure 5. First Generation Honda IMA Hybrid System Layout [38]

By attaching the rotor of the electric motor directly to the engine's crankshaft, there were no bearings in the $60 \mathrm{~mm}$ wide electric motor. The three cylinder engine was selected for its minimal mechanical losses to improve the energy efficiency of the powertrain further. Combined with the 6.5 Ah $\mathrm{NiMH}$ battery pack and cooling system for the electric motor, the entire IMA system in the first generation Honda Insight weighed less than $80 \mathrm{~kg}$ [38].

Over the years, the basic architecture of the IMA system has remained unchanged. The system has been updated and installed behind four cylinder engines in the Civic and six cylinder engines in the Accord. The electric motors have increased to $15 \mathrm{~kW}$ in recent iterations as well [39]. The latest iteration of the IMA system is capable of engine start/stop and regenerative braking similar to the GM BAS/eAssist systems. IMA is also capable of low speed electric-only propulsion through the use of cylinder deactivation via Honda's Variable Valve Timing and Lift Electronic Control (VTEC) system. Because the 
electric motor rotor is connected directly to the engine's crankshaft, the engine is required to rotate any time the vehicle is in motion. Using VTEC, the intake and exhaust valves in the engine are held open to reduce pumping losses during electric-only driving [40].

While GM's eAssist is only available with a six speed automatic transaxle, Honda offers its IMA system in front of conventional automatics, continuously variable transmissions, and manual transmissions in the case of the CRZ model [42].

\subsubsection{Toyota's Hybrid Synergy Drive}

Toyota's Prius model has become synonymous with the word "hybrid" as it relates to automobiles. Toyota's hybrid system, marketed today as "Hybrid Synergy Drive," is a strong hybrid system capable of regenerative braking, engine start/stop, and electric-only drive. Introduced in 1997 based on the Echo model, the Toyota Prius has become the most popular alternative vehicle in the world with millions having been sold [45]. The basis of the Toyota hybrid system was a single planetary gear set that was used to split input power between a $43 \mathrm{~kW} 1.5$ liter Atkinson cycle engine and a $30 \mathrm{~kW}$ electric motor. The third element of the planetary gear set was connected to a generator for charging the high-voltage battery. Figure 6 is a schematic of the Toyota hybrid system [45].

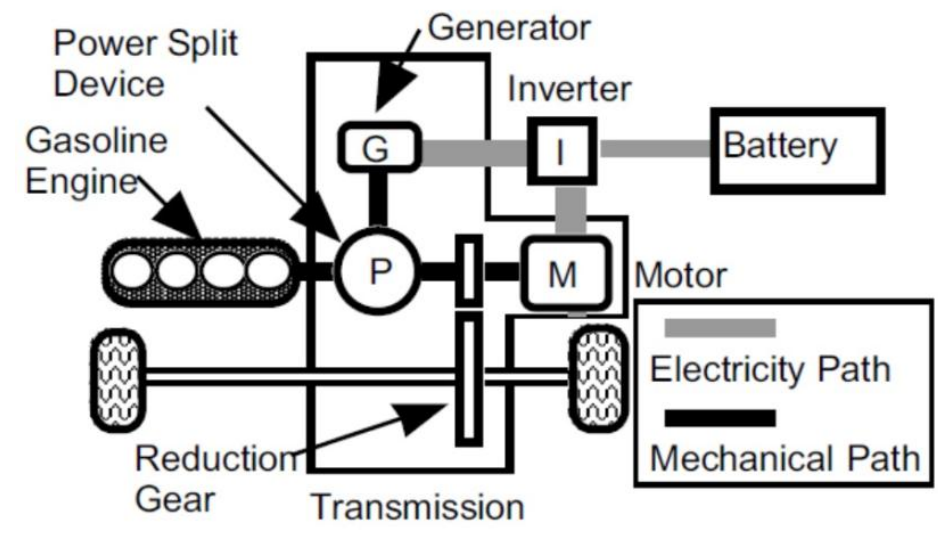

Figure 6. First Generation Toyota Hybrid System [45]

Halfway through the first generation, Toyota increased the power output of the engine to $53 \mathrm{~kW}$ and the electric motor to $33 \mathrm{~kW}$. This was done to improve the performance of the vehicle so that it would be better received in the United States and Europe [45]. The second generation Prius debuted in 2003 featuring distinctive Kammback styling and a more powerful hybrid system. Engine power was increased to $57 \mathrm{~kW}$ and the electric motor was increased to $50 \mathrm{~kW}$. Beginning in 2007, the Toyota hybrid system was offered in other Toyota models including the Camry and Highlander crossover utility vehicle.

The current generation model of the Toyota Prius was introduced in 2009. Changes over previous iterations included an increase in engine displacement from 1.5 liters to 1.8 liters. While the basic powertrain configuration remained unchanged aside from a gearing update, the engine and electric 
motor were up-rated again. The 1.8 liter Atkinson cycle engine now produced $73 \mathrm{~kW}$ and the electric motor produced $60 \mathrm{~kW}[46]$.

While each generation of the Toyota Prius produced more power than previous versions, the fuel efficiency of the Prius model has continued to improve. Table 7 lists the EPA fuel economy test results for each of the three Prius generations [47].

Table 7. Toyota Prius Fuel Economy by Generation [47]

\begin{tabular}{|r|c|c|c|}
\hline & Gen. 1 & Gen. 2 & Gen. 3 \\
\hline Engine Power & $53 \mathrm{~kW}$ & $57 \mathrm{~kW}$ & $70 \mathrm{~kW}$ \\
\hline EPA City Fuel Economy & $42 \mathrm{mpg}$ & $48 \mathrm{mpg}$ & $51 \mathrm{mpg}$ \\
\hline EPA Highway Fuel Economy & $41 \mathrm{mpg}$ & $45 \mathrm{mpg}$ & $48 \mathrm{mpg}$ \\
\hline EPA Combined Fuel Economy & $41 \mathrm{mpg}$ & $46 \mathrm{mpg}$ & $50 \mathrm{mpg}$ \\
\hline
\end{tabular}

\subsubsection{GM's 2-mode}

The General Motors 2-mode system was a strong hybrid system similar to Toyota's Hybrid Synergy Drive system in that there are two electric motors and an engine connected to the wheels through a planetary gear set. However, unlike the Toyota system, GM originally began working on a 2mode electrically variable transmission (EVT) to be used in heavy-duty buses in 2003 in an effort to improve stop-and-go fuel economy while maintaining similar acceleration performance [36].

GM's light-duty 2-mode utilized three planetary gear sets (two in the cancelled front-wheel drive 2-mode) and a collection of hydraulically-actuated clutches inside the transmission that are engaged and released at different times to allow the transmission to operate in one of two EVT modes as well as four fixed gear ratios via the planetary gear sets. A $300 \mathrm{~V} \mathrm{NiMH}$ battery system was utilized for electrical energy storage in both the RWD and FWD applications. The major advantage the 2-mode transmission held over the 1-mode EVT system in the Toyota Prius was its ability to provide high power as well as increased fuel economy [36].

\subsubsection{Rear-Wheel-Drive}

The rear-wheel-drive 2-mode hybrid transmission is available in full-size pickups and sport utility vehicles sold by Chevrolet, GMC, and Cadillac. The vehicles offered with the 2-mode transmission include the Chevrolet Silverado 1500, Chevrolet Tahoe, GMC Sierra 1500, GMC Yukon, and Cadillac Escalade. The rear-wheel-drive 2-mode transmission was designed to handle the larger $\mathrm{V}-8$ engines offered in these vehicles while maintaining towing capacity. Figure 7 is a schematic stick diagram of GM's rear-wheel-drive 2-mode hybrid transmission [36]. 


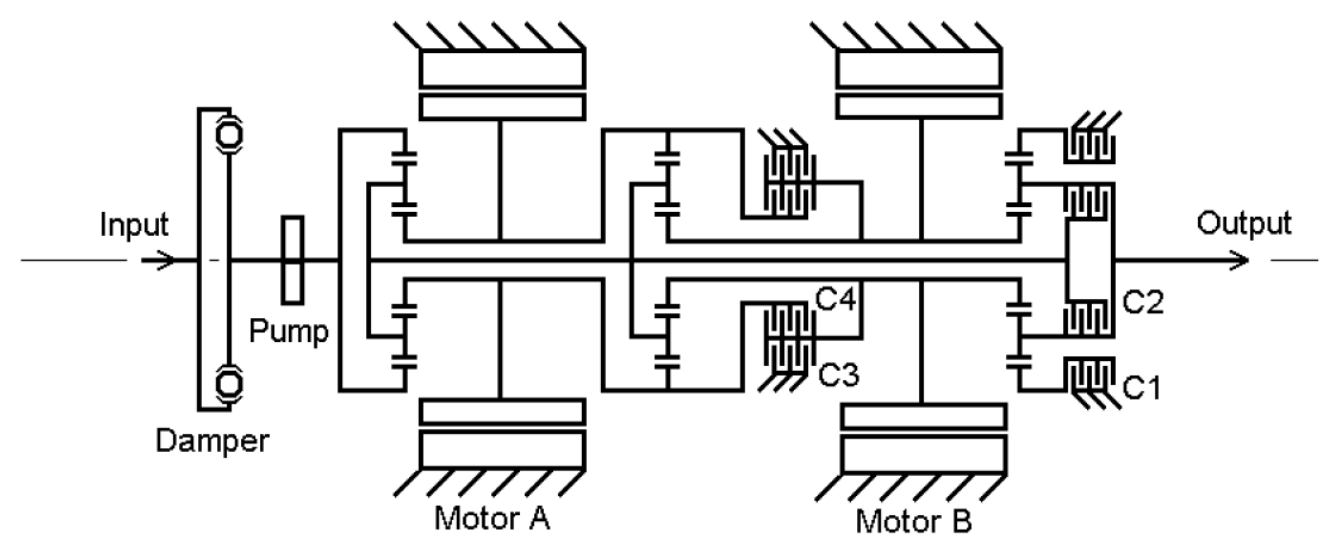

Figure 7. General Motors RWD 2-Mode Transmission [36]

Torque input comes from the V-8 engine transferred through the torsional damper designed to reduce engine shudder during engine starting and stopping. The pump pressurizes the transmission fluid for cooling the electric motors and actuating the hydraulic clutches labeled C1 through C4. These clutches are used for shifting the transmission between EVT modes as well as producing the four fixed gear ratios that are used during high-load situations such as grade climbing and towing.

Each vehicle is equipped with an Atkinson cycle 6.0 liter V-8 capable of producing $332 \mathrm{hp}$ with the electric motors in the transmission producing $80 \mathrm{hp}$ each. This powertrain configuration is available in both two- and four-wheel-drive vehicles [6]. The three planetary gear set design of the GM 2-mode makes it possible to maintain each vehicle's $5300 \mathrm{lb}$ towing capacity while also improving fuel economy during both city and highway driving. Table 8 displays the fuel efficiency improvements afforded by the 2mode transmission installed in a RWD Chevrolet Tahoe SUV [36].

Table 8. 2-mode Fuel Efficiency Improvements [36]

\begin{tabular}{|r|c|c|c|}
\hline & Tahoe RWD & 2-mode Tahoe RWD & \% Improvement \\
\hline EPA City Fuel Economy & $14 \mathrm{mpg}$ & $21 \mathrm{mpg}$ & $50 \%$ \\
\hline EPA Highway Fuel Economy & $20 \mathrm{mpg}$ & $22 \mathrm{mpg}$ & $10 \%$ \\
\hline
\end{tabular}

The $50 \%$ improvement in city fuel economy is due to the 2-mode's ability to propel the vehicle using only the electric motors when pulling away from a stop up to a speed of $30 \mathrm{mph}$. Additionally, the 2-mode Tahoe Hybrid, as well as all of the other full-size truck hybrids equipped with the 2-mode transmission, turns its engine off when the vehicle slows to a stop and is capable of providing up to $100 \%$ of the braking torque via the electric motors during regenerative braking [36]. On the highway, a 10\% fuel economy improvement is due to the ability of the 2-mode to provide an electric boost for up to 10 seconds when accelerating or climbing a grade. This electric boost supplements the engine power and reduces the transient operation of the engine, thus reducing the fuel consumed by the engine [6]. 


\subsubsection{Front-Wheel-Drive}

Similar to the RWD 2-mode transmission, GM developed a FWD 2-mode variant to be installed in the 2009 Saturn Vue 2-mode Hybrid with a 3.6 liter spark-ignited engine. The FWD 2-mode was designed to be installed in place of the contemporary six-speed automatic transaxle used across GM's brands. In packaging the 2-mode system for use in FWD applications, one of the three planetary gear sets was eliminated. The FWD 2-mode transaxle still utilized four hydraulic clutches to select the EVT modes and four fixed gear ratios. Figure 8 is a schematic stick diagram of the front-wheel-drive 2-mode transmission [44].

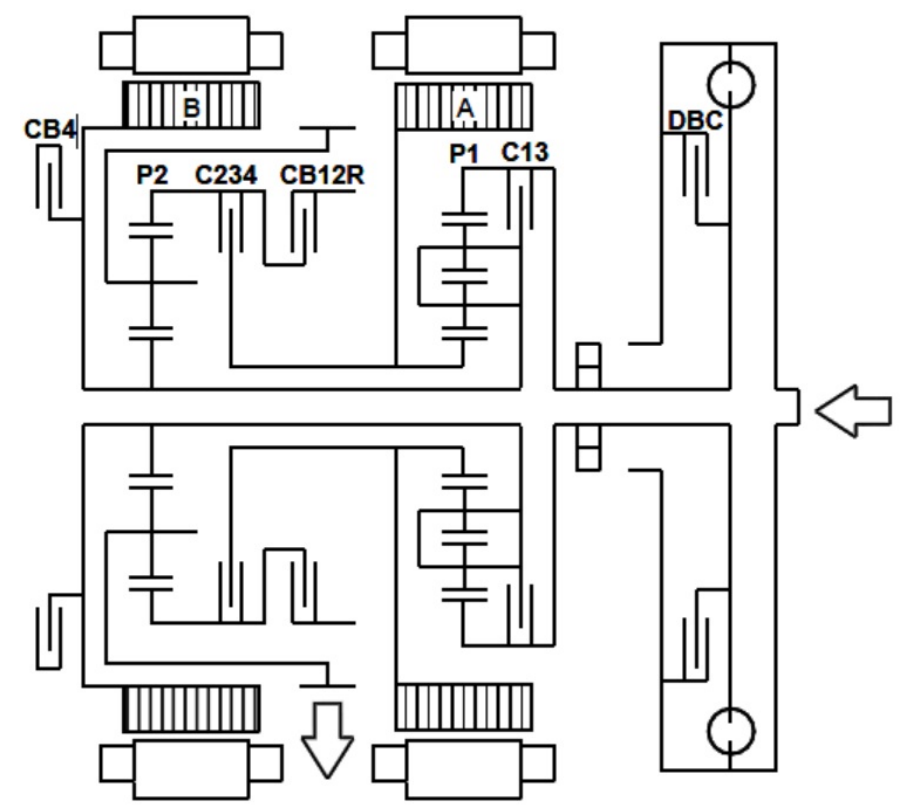

\section{Figure 8. General Motors FWD 2-Mode Transmission [44]}

While eliminating the third planetary gear set reduced the torque capacity of the FWD 2-mode transmission, the FWD version maintained all of the hybrid functionality of the RWD 2-mode. The electric motors were designed using concentrated windings to minimize the required physical size of the motors to produce the desired output torque. This electric motor design was capable of being scaled up or down depending on what engine was in the vehicle. The FWD 2-mode system was designed to be used behind gasoline and diesel engines displacing from 2.0 to 3.6 liters [44].

While the FWD 2-mode Vue was never released to the public, development was nearly complete when the EPA performed its standard fuel economy testing on the 2-mode Vue Hybrid. As can be seen in Table 9, the 2-mode 2009 Saturn Vue equipped with the 3.6 liter V-6 engine achieved EPA combined fuel economy of $28 \mathrm{mpg}$, a $47 \%$ improvement over the non-hybrid 3.6 liter Vue [8]. While the BAS Vue Hybrid with the 2.4 liter engine also returned combined fuel economy of $28 \mathrm{mpg}$, this system produced half of the power of the 2-mode. Compared with the base 2.4 liter Vue, the BAS system improved combined fuel economy by $27 \%$ [8]. 
Table 9. 2009 Saturn Vue Lineup Fuel Efficiency [8]

\begin{tabular}{|c|c|c|c|c|c|c|}
\hline \multicolumn{4}{|c|}{2009 Saturn Vue FWD Lineup } & \multicolumn{3}{c|}{ EPA Fuel Economy Ratings } \\
\hline Model & Engine & Hybrid & Hybrid Type & City MPG & Highway MPG & Combined MPG \\
\hline Base XE & 2.4 I-4 & N & - & 19 & 26 & 22 \\
\hline XR & 3.6 V-6 & N & - & 17 & 24 & 19 \\
\hline Hybrid & 2.4 I-4 & Y & BAS & 25 & 32 & 28 \\
\hline 2-mode Hybrid & 3.6 V-6 & Y & 2-mode & 27 & 30 & 28 \\
\hline
\end{tabular}




\section{Background: Vehicle Design Process}

The vehicle design and implementation process consumed over two years of the project. This chapter will discuss in great detail the modeling, design, and integration activities performed to produce the completed project vehicle. While the author was involved in a majority of the activities discussed in this chapter, the research focus of this thesis is detailed in Chapter 4.

\subsection{Simulation \& Modeling}

The first phase of the project involved deciding what vehicle architecture and components would be used to construct the project vehicle. These decisions were made based on simulation models built to represent the different hybrid architectures. The author was not involved in activities performed during the simulation and modeling stage of the project so all credit for the simulation and modeling work must be given to the team that performed the work. The majority of the information presented in this section has been collected from progress reports written during this phase of the project.

The team had the option of building either a series or parallel HEV, a PHEV, an extended-range electric vehicle (E-REV) or a full electric vehicle (EV). On-board power generation options included spark-ignited engines fueled by E85 ethanol (a mixture of 85 percent ethanol and 15 percent gasoline), compression-ignited engines fueled by B20 biodiesel (a mixture of 80 percent number 2 ultra-low sulfur diesel fuel and 20 percent biodiesel) and hydrogen fuel cells donated from GM's Chevrolet Equinox Fuel Cell Electric Vehicle program. PSAT was used for simulation and modeling of the different vehicles.

\subsubsection{Proposed Hybrid Strategies}

The decision was made to build a hybrid-electric vehicle instead of a fuel cell vehicle or pure EV due to the complexity of implementing either of these architectures. By retaining a more conventional powertrain layout consisting of an internal combustion engine and transmission, there would be fewer vehicle modifications required to construct the proposed project vehicle. Three possible HEV architectures were explored: the GM 2-mode electrically variable transmission, a belted alternator/starter with rear traction assist (BAS+RTA), and a parallel plug-in hybrid-electric vehicle (PHEV). Each architecture was simulated using different combinations of engines and batteries to determine which powertrain configuration provided the best balance between reduced emissions, improved fuel efficiency, and vehicle performance potential [43].

\subsubsection{2-Mode}

In 2008, the front-wheel-drive GM 2-mode system was still under development, but GM was able to provide the team a PSAT model of the 2-mode electrically variable transmission for simulation. Of the three proposed hybrid strategies, the 2-mode system was considered by the project team to be the easiest to mechanically integrate due to the packaging of the 2-mode transmission with the electric 
motors being housed inside the automatic transmission case. The proposed 2-mode architecture required a high-voltage battery exceeding $300 \mathrm{~V}$ to drive the electric motors in the transmission. A $320 \mathrm{~V}$ lithium-ion battery system supplied by A123 Systems was specified for use in the proposed 2-mode vehicle.

A major advantage the proposed 2-mode architecture held over the others during the selection process was its ease of integration. With most of the major components housed in a conventional transmission-sized package, it was decided that the 2-mode architecture would produce the most seamless integration. The lone disadvantage realized during the selection process of the 2-mode system was the possibility of a challenging control algorithm development process due to the system's complexity and functions [43].

\subsubsection{BAS+RTA}

WVU had past experience constructing a through-the-road parallel hybrid vehicle in the Challenge $X$ advanced vehicle technology competition. However, unlike the previous effort the new project vehicle would utilize lithium-ion batteries for electrical energy storage instead of the capacitors used in the past. With the similarities between the 2005 Chevrolet Equinox used during Challenge $X$ and the 2009 Saturn Vue, many of the lessons learned while designing and building the Equinox could be applied if another BAS vehicle were built.

The proposed BAS+RTA system would utilize an $18 \mathrm{~kW}$ motor/generator for providing engine starting and electric boost to aid the engine during acceleration. A single $55 \mathrm{~kW}$ induction motor would be installed between the rear wheels to provide further electric boost as well as regenerative braking with a gear reduction installed after the rear traction motor to prevent over-revving. A $280 \mathrm{~V}$ lithium-ion battery system would provide electrical energy storage.

The major advantage the BAS+RTA system held over the others was WVU's familiarity with the architecture and the issues associated with it. In addition, the high combined power output of the electric motors would help maintain vehicle performance. However, there were inherent inefficiencies associated the BAS system and its ability to provide regenerative energy for charging the high-voltage battery using only the rear wheels. Also, the mechanical integration of a BAS+RTA powertrain would likely be more difficult than with the 2-mode system [43].

\subsubsection{Parallel PHEV}

The final proposed hybrid architecture was similar to the BAS+RTA design although it eliminated the engine-driven motor/generator and included a more powerful high-voltage battery pack. The L20 battery system provided by A123 Systems would be the basis for this design that would include a plug for charging the vehicle from a standard $110 / 120 \mathrm{~V}$ wall receptacle. At typical speeds, the engine would be turned off with all propelling power being provided by the $55 \mathrm{~kW}$ rear traction motor. At high vehicle speeds or when the battery was depleted to a set level, the engine would be turned on and continue driving the front wheels of the vehicle through a conventional automatic transaxle. 
The proposed parallel PHEV architecture would produce integration issues similar to the BAS+RTA system. However, this system would also produce the slowest vehicle performance due its lower combined power output compared to both the 2-mode and BAS+RTA architectures.

\subsubsection{Engines Considered}

The project team only considered gasoline engines that were capable of running on both traditional 87 octane gasoline and E85 ethanol. The two four-cylinder gasoline engines seriously considered displaced 1.6 and 1.8 liters respectively. The 1.6 liter Ecotec engine produced $105 \mathrm{hp}$ and $111 \mathrm{lb}$-ft of torque and the 1.8 liter Ecotec engine made $140 \mathrm{hp}$ and $129 \mathrm{lb}$-ft of torque. Both engines utilized variable valve timing and featured 10.5:1 compression ratios. Both of these engines were sourced from GM's European Opel division [43].

In addition to the spark-ignited engines, the use of small diesel engines from Opel was also explored. Two four-cylinder diesel engines were considered: a 1.3 liter out of the 2008 Corsa model and a 2.0 liter from the 2008 Vectra. Both of these engines featured variable valve timing, variable geometry turbochargers, and direct diesel injection. The 1.3 liter variant produced $90 \mathrm{hp}$ and $148 \mathrm{lb}$-ft of torque while the 2.0 liter engine produced $158 \mathrm{hp}$ and $258 \mathrm{lb}$-ft of torque.

\subsubsection{Simulation Method}

The PSAT software included models to represent the different components considered including the engines, transmissions, batteries, and the vehicle body. PSAT was capable of building a complete vehicle model using any combination of powertrain components and simulating that vehicle model over a specified driving cycle. The results of the PSAT simulations included fuel efficiency information, hybrid battery status, and control system-related information. PSAT would simulate all vehicle functions including transmission gear, engine on/off status, and high-voltage battery current and plot all of this information for review following each simulation.

The first step in the simulation process involved simulating an unmodified 2009 Saturn Vue over the EPA's city and highway driving cycles as well as testing the acceleration performance of the base vehicle model. This was done to validate the PSAT model compared to the real-world testing results for a 2.4L base model Saturn Vue. Table 10 displays a comparison between the PSAT simulation results and the actual test data [43].

Table 10. PSAT Baseline Simulation Results [43]

\begin{tabular}{|r|c|c|c|}
\hline & Actual & PSAT & \% Difference \\
\hline Acceleration 0-60 mph & $10.6 \mathrm{sec}$ & $10.8 \mathrm{sec}$ & $1.89 \%$ \\
\hline Acceleration $\mathbf{5 0 - 7 0} \mathbf{~ m p h}$ & $5 \mathrm{sec}$ & $5.5 \mathrm{sec}$ & $10.00 \%$ \\
\hline Combined Fuel Economy & $28.3 \mathrm{mpgge}$ & $28.25 \mathrm{mpgge}$ & $-0.18 \%$ \\
\hline
\end{tabular}


The PSAT model of the base vehicle differed by less than $2 \%$ in terms of fuel efficiency and $0-60$ $\mathrm{mph}$ acceleration. The difference of 0.5 seconds in the $50-70 \mathrm{mph}$ acceleration simulation was in part due to the PSAT driver model. During simulation, it was discovered that the driver model parameters could potentially affect the vehicle's ability to follow the different test schedules. By adjusting the gains in the driver model by $15 \%$, the driver's ability to match the test cycle varied by up to $5 \%$ [43].

Once the baseline was determined in PSAT, the different proposed hybrid architectures were simulated. The results of these simulations were weighted with greater importance placed on fuel efficiency and emissions. Table 11 lists the different simulation results and the weighting factors applied to each [43].

Table 11. PSAT Powertrain Selection Weighting Factors [43]

\begin{tabular}{|c|c|c|c|}
\hline & $\begin{array}{c}\text { Minimum Performance } \\
\text { Criteria }\end{array}$ & Final Design Target & $\begin{array}{l}\text { Weighting } \\
\text { Factor }\end{array}$ \\
\hline $\begin{array}{l}\text { Fuel Economy, CAFE } \\
\text { Unadjusted, Combined }\end{array}$ & 32 mpgge & 35 mpgge & .21 \\
\hline WTW Petroleum Use & $\leq 0.77 \mathrm{kWh} / \mathrm{km}$ & $\leq 0.40 \mathrm{kWh} / \mathrm{km}$ & .21 \\
\hline WTW GHG Emissions & $\leq 244 \mathrm{~g} / \mathrm{km}(392 \mathrm{~g} / \mathrm{mi})$ & $\leq 150 \mathrm{~g} / \mathrm{km}(242 \mathrm{~g} / \mathrm{mi})$ & .21 \\
\hline Tailpipe Emissions & EPA Tier II Bin 5 & EPA Tier II Bin 5 & .09 \\
\hline Range & $\geq 200 \mathrm{mi}$ & $\geq 350 \mathrm{mi}$ & 0.01 \\
\hline Towing Capacity & $\geq 680 \mathrm{~kg}$ & $\geq 700 \mathrm{~kg}$ & .07 \\
\hline Acceleration (0-60 mph) & $\leq 14 \mathrm{sec}$ & $8.0 \mathrm{sec}$ & 0.09 \\
\hline Acceleration (50-70 $\mathrm{mph}$ ) & $\leq 10 \mathrm{sec}$ & $4.6 \mathrm{sec}$ & 0.07 \\
\hline Vehicle Mass & $\leq 2268 \mathrm{~kg}(5000 \mathrm{lb})$ & < $1979 \mathrm{~kg}$ (4363 lb) & 0.03 \\
\hline Cargo Capacity & $0.83 \mathrm{~m}^{3}$ & $0.83 \mathrm{~m}^{3}$ & 0.01 \\
\hline
\end{tabular}

Using these weighting factors, each of the three proposed hybrid powertrain architectures was simulated with up to twelve different combinations of engines and high-voltage batteries. The highestscoring configurations for each hybrid architecture were all compared with the 1.3 liter diesel engine and 2-mode electrically variable transmission scoring the highest. Table 12 lists the results of the preliminary PSAT simulations [43]. 
Table 12. PSAT Simulation Results [43]

\begin{tabular}{|c|c|c|c|c|}
\hline & & 2-Mode & BAS+RTA & PHEV \\
\hline UDDS FE & mpgge & 38.05 & 29.17 & 31.55 \\
\hline HWFET FE & mpgge & 38.23 & 33.23 & 40.35 \\
\hline Combined FE & mpgge & 38.13 & 30.87 & 34.98 \\
\hline WTW PEU & kWh/km & 0.30 & 0.37 & 0.53 \\
\hline WTW GHG & $\mathrm{g} / \mathrm{km}$ & 89.54 & 106.88 & 164.47 \\
\hline $\mathrm{CO}_{2}$ Emissions & $\mathrm{g} / \mathrm{mi}$ & 0.465 & 0.465 & - \\
\hline Range & mi & 269 & 222 & 252 \\
\hline Towing Accel. & sec & 7.3 & 6.7 & 5.8 \\
\hline $0-60 \mathrm{mph}$ & sec & 8.4 & 8.3 & 13.1 \\
\hline $50-70 \mathrm{mph}$ & sec & 4.3 & 4.1 & 7.4 \\
\hline Weight & lbs & 4363 & 4307 & 5005 \\
\hline Cargo Capacity & $\mathrm{m}^{3}$ & 0.79 & 0.83 & 0.79 \\
\hline \multicolumn{2}{|c|}{ Passenger Capacity } & 5 & 5 & 5 \\
\hline \multicolumn{2}{|c|}{ Final Score } & 89.9 & 66.4 & 70.9 \\
\hline
\end{tabular}

\subsubsection{Preliminary PSAT Simulation Results}

Following the simulations of the different models, the combination of the GM 2-mode transaxle, 1.3 liter diesel engine, and A123 Systems battery pack provided predicted city/highway fuel economy of $38.05 / 38.23$ mpgge with an overall EPA combined fuel economy of 38.13 mpgge. The PSAT simulation produced a $0-60 \mathrm{mph}$ acceleration time of 8.4 seconds, a $50-70 \mathrm{mph}$ acceleration time of 4.3 seconds, and a 60-0 mph braking distance of 150 feet. These performance numbers were deemed acceptable and this design achieved the best fuel economy of the twelve different 2-mode configurations tested so it was selected as the design the project team would build and validate.

\subsubsection{Battery Cooling Thermal Analysis}

Before the university could receive the selected $\mathrm{A} 123$ battery system, thermal analysis needed to be performed and approved by engineers at A123 Systems. The battery thermal analysis began with simulating the proposed vehicle over the EPA's aggressive highway driving US06 test cycle using PSAT. Figure 9 is a trace of the US06 supplemental federal test procedure [15]. 


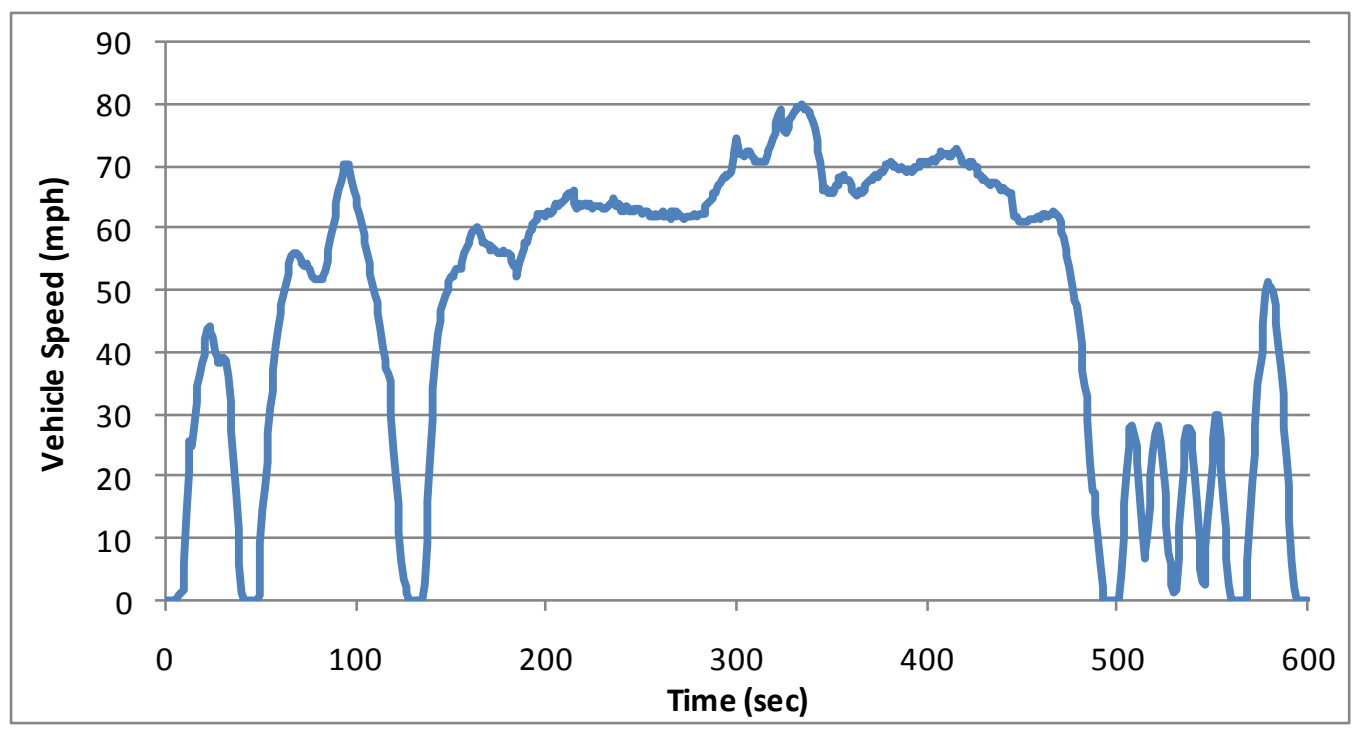

Figure 9. EPA US06 Aggressive Highway Cycle [15]

The EPA developed the US06 test cycle to more accurately simulate actual highway driving in the United States. This aggressive test schedule produces a maximum speed of $80.3 \mathrm{mph}$ with an average speed of $48.37 \mathrm{mph}$ [15]. The US06 cycle was used for the battery thermal analysis because it represented an extreme case with high speeds and aggressive acceleration and braking events, thereby heavily taxing the high-voltage battery system. PSAT had the capability of reporting the total current flowing into and out of the high-voltage battery over the US06 cycle. Figure 10 is a plot of the current flow for the high voltage battery simulated across the US06 cycle [16].

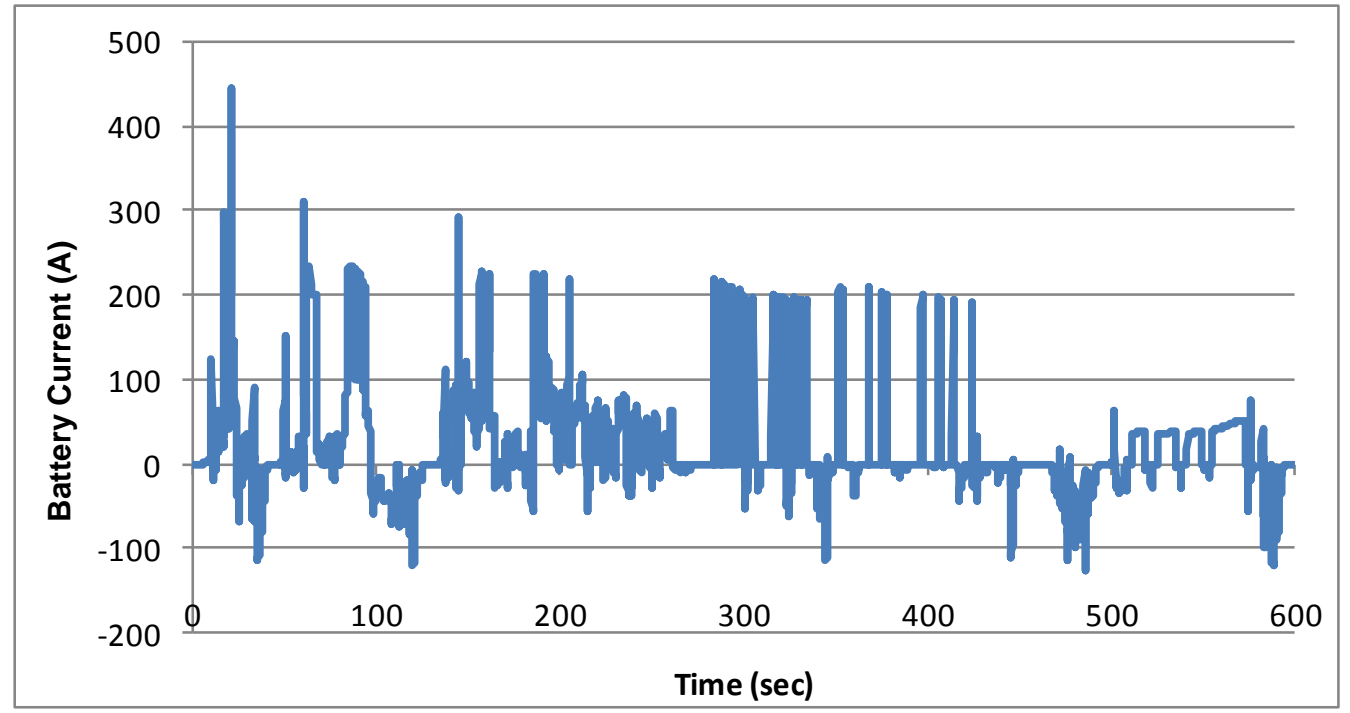

Figure 10. High Voltage Battery Current During US06 Cycle [16]

The vehicle requested the most current from the high voltage battery during periods of acceleration when the electric motors in the 2-mode transmission provided an electric boost. Negative 
currents represent periods of regenerative braking. Using this current data, the total heat energy was calculated according to:

$$
P_{\text {Heat }}=\text { Current }^{2} \times \text { Resistance }
$$

The total resistance of the four modules comprising the high-voltage battery was $0.120 \Omega$ and the average current from the PSAT simulation was $60.9 \mathrm{~A}$ producing an average heat generation of $445 \mathrm{~W}$. The maximum instantaneous heat generation was calculated to be $23.67 \mathrm{~kW}$. Figure 11 is a plot of the heat generated by the high voltage battery over the US06 test cycle [16].

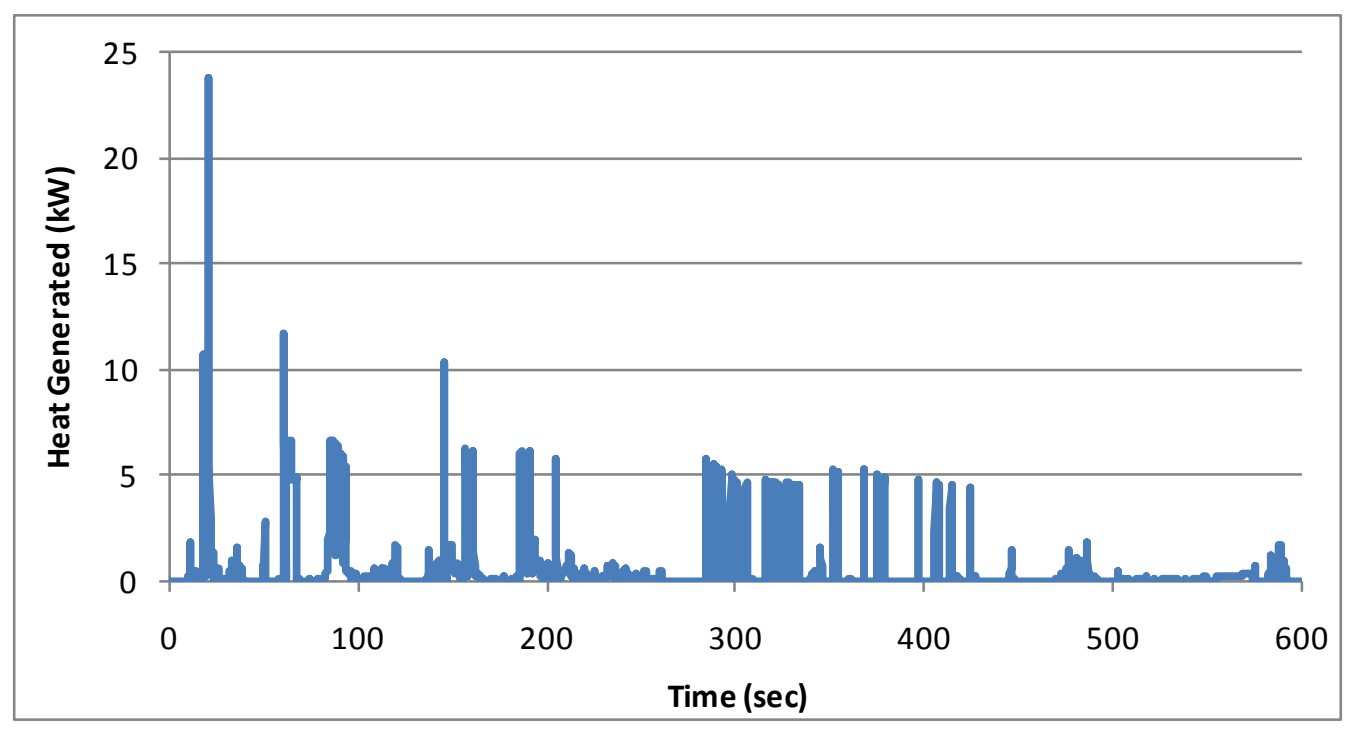

Figure 11. Heat Generated During US06 Cycle [16]

According to the PSAT simulation results, the cooling system would need to be capable of dissipating heat at a rate of no less than $445 \mathrm{~W}$. More cooling capacity was desired as the vehicle would be tested at the GM Desert Proving Ground outside of Yuma, Arizona in the Summer of 2010. The selected A123 battery modules were designed to be cooled by conduction to liquid cooling plates through metallic fins and straps lining the sides of the modules. The proposed cooling system consisted of two liquid cooling plates, each responsible for dissipating the heat from two battery modules at a minimum average rate of $222.5 \mathrm{~W}$.

\subsubsection{Heat Exchanger Selection}

An ambient temperature of $45^{\circ} \mathrm{C}\left(113^{\circ} \mathrm{F}\right)$ was assumed during the design of a suitable heat exchanger to simulate a Summer day in the Arizona desert. A heat exchanger was selected that provided the necessary cooling capacity to maintain the high voltage battery at temperatures below $50{ }^{\circ} \mathrm{C}$ under extreme driving conditions like those simulated in the US06 test cycle. A Lytron ES-0714 liquid-air 
heat exchanger was selected for its ability to exceed the performance requirements and its small overall size. Table 13 lists the specifications of the Lytron heat exchanger.

\section{Table 13. ES-0714 Heat Exchanger Specifications}

\begin{tabular}{|r|c|}
\hline Height & $214 \mathrm{~mm}$ \\
\hline Width & $458 \mathrm{~mm}$ \\
\hline Depth & $79 \mathrm{~mm}$ \\
\hline Core and Fin Material & Aluminum \\
\hline Maximum Temperature & $205^{\circ} \mathrm{C}$ \\
\hline Fluid Volume & $508 \mathrm{~mL}$ \\
\hline Pressure Drop & $31 \mathrm{kPa}$ \\
\hline
\end{tabular}

This heat exchanger featured a single inlet and a single exit with provisions for mounting two electric fans to pull cool air through the core. The selected fans were designed to move air at a rate of 440 CFM through the heat exchanger. Assuming a coolant flow rate of 3.5 gallons per minute (gpm), the total heat rejection rate from the Lytron heat exchanger was calculated to be $562.65 \mathrm{~W}$ [16]. This heat exchanger could reject heat at a rate over $100 \mathrm{~W}$ more than the requirement, leaving extra cooling capacity in the event that the batteries and ambient temperature ever got over $45^{\circ} \mathrm{C}$.

\subsubsection{Cooling System Design}

The cooling plates each consisted of one inlet and one outlet with a meandering channel connecting the two ports. A coolant channel was designed to be milled in the aluminum plates that maximized the cooling capacity of the plates while producing minimal pressure drop from inlet to outlet. The coolant channel had a rectangular cross-section and included $1290^{\circ}$ corners and a fill port located along the top edge. This fill port was also used to help bleed air from the cooling system. Figure 12 is a drawing of the cooling plate illustrating the coolant channel design. 


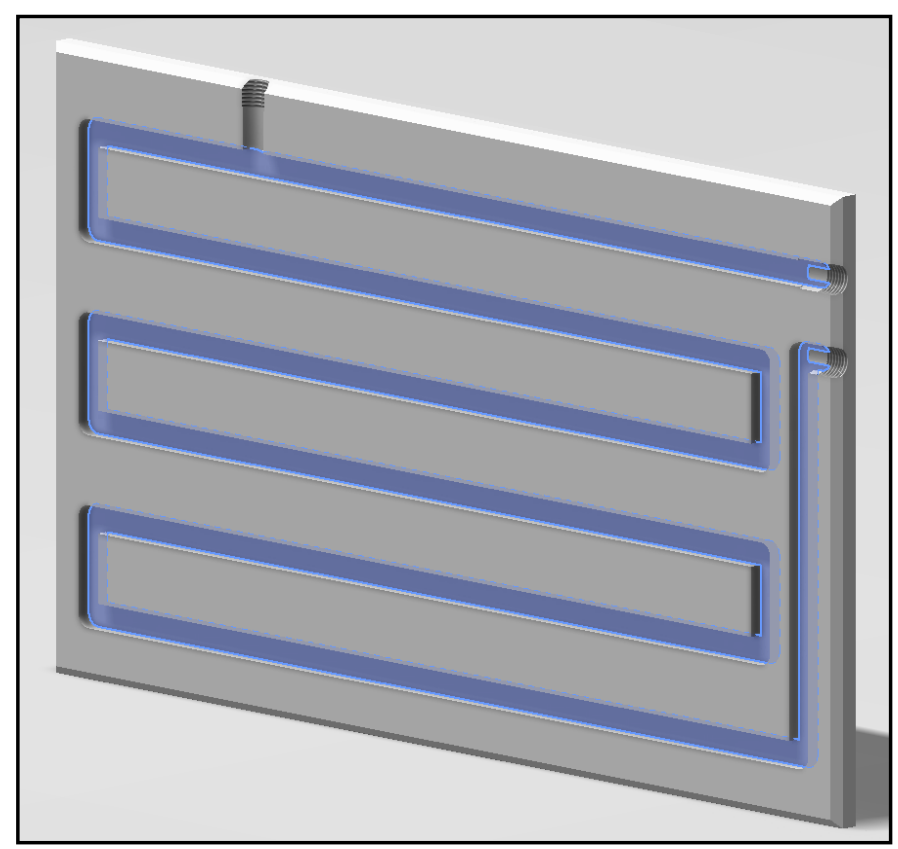

Figure 12. High Voltage Battery Cooling Plate

The fill port was the vertical tapped hole along the top edge of the plate. The top port on the right edge was the inlet with the outlet below. The length of each channel was 2 meters. To construct one cooling plate, two aluminum halves with this channel cut into them were welded together. Each plate was designed to be installed between two battery modules inside the high voltage battery enclosure. The coolant to be used for the battery cooling system was a mixture of $50 \%$ water and $50 \%$ ethylene glycol. This coolant had a density $(\rho)$ of $1077 \mathrm{~kg} / \mathrm{m}^{3}$ with a dynamic viscosity $(\mu)$ of 2.8 centipoise.

The two cooling plates were designed to be plumbed in parallel with a single pump driving the liquid cooling system. The remaining piping between the pump, heat exchanger, and cooling plates was assumed to contain ten $90^{\circ}$ bends constructed using stainless steel piping. The steel piping system was expected to be around 7.25 meters in length. Table 14 lists the fluid flow characteristics of the liquid cooling system.

Table 14. Cooling System Fluid Properties

\begin{tabular}{|r|c|c|}
\hline & Aluminum Cooling Plates & Steel Piping \\
\hline Hydraulic Diameter $\left(\mathbf{D}_{\mathbf{h}}\right)$ & $0.0168 \mathrm{~m}$ & $0.0127 \mathrm{~m}$ \\
\hline Roughness $(\mathbf{k})$ & $0.001 \mathrm{~mm}$ & $0.0015 \mathrm{~mm}$ \\
\hline Friction Coefficient $(\mathbf{f})$ & 0.01025 & 0.0082 \\
\hline Minor Loss Coefficient $(\mathbf{c})$ & 1.3 & 0.3 \\
\hline Number of $\mathbf{9 0} \mathbf{0}^{\circ}$ Bends & 12 & 10 \\
\hline Length & $2 \mathrm{~m}$ & $7.25 \mathrm{~m}$ \\
\hline
\end{tabular}


This information was used to calculate the total pressure drop in the system as well as the required volumetric flow rate to be provided by the coolant pump. The equivalent lengths of the cooling plates and piping were found according to:

$$
L_{\text {Equivalent }}=\text { ActualLength }+C \times \frac{D_{h}}{f}
$$

Using the equivalent lengths for the different components, the total head loss in meters was calculated:

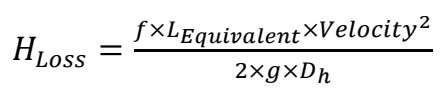

Finally, the pressure drop for the piping and cooling plates was calculated using:

$$
P_{\text {Loss }}=H_{\text {Loss }} \times \rho \times \mathrm{g}
$$

Table 15 lists the pressure drop for the different components as well as the entire system.

\section{Table 15. Cooling System Physical Properties}

\begin{tabular}{|r|c|c|}
\hline & Aluminum Cooling Plates & Stainless Steel Piping \\
\hline Equivalent Length & $27.57 \mathrm{~m}$ & $11.96 \mathrm{~m}$ \\
\hline Head Loss & $0.415 \mathrm{~m}$ & $1.19 \mathrm{~m}$ \\
\hline Pressure Drop & $3.10 \mathrm{psi}$ (Two Cooling Plates Plus Piping) \\
\hline Total Pressure Drop & $7.10 \mathrm{psi}$ (Including Heat Exchanger) \\
\hline
\end{tabular}

This information was used to select a coolant pump for the cooling system. The pump needed to be able to maintain a flow rate of at least 3.5 gallons per minute while producing 10 psi of pressure, enough pressure to overcome the $7.10 \mathrm{psi}$ pressure drop through the cooling system. Shurflo Pumps model number 2088-514-500 was selected for its ability to operate under these conditions as well as its compatibility with $50 \%$ ethylene glycol coolant.

\subsection{Mechanical Design}

By the end of the vehicle design process, the project vehicle would include myriad components not originally installed at the factory including high-voltage batteries, electric motors, a new engine, onboard computers, a redesigned exhaust system, after-treatment devices, a new fuel tank, modified suspension components, safety devices, and the list goes on. However, installing new components requires designing new mounts and analyzing them for strength and longevity before implementation. 


\subsubsection{Required Design Work}

The proposed compound-split hybrid-electric vehicle architecture required that many new mounts and enclosures for the engine and battery be designed and analyzed. Parts relating to mounting the engine and high-voltage battery pack were required to achieve a minimum factor of safety greater than 2 . To aid in the design of different components and mounts, the university had access to full 3-D models of the 2009 Saturn Vue as well as models of the 1.3 liter diesel engine and 2-mode transmission. Using these models the battery enclosure, front engine mount, transmission adapter, and axle bearing mount were all designed. A student version of Autodesk Inventor Professional was utilized for all design and simulation work. This CAD package was selected for its high feature content and intuitive layout.

\subsubsection{Axle Bearing Mount}

Front-wheel-drive vehicles are commonly constructed in such a way that the engine occupies the passenger side of the engine compartment with the transmission behind it on the driver's side. The transmission has two axle shafts to transmit the output torque to the wheels. Because of the offset location of the transmission in the vehicle, the axle shaft between the transmission output and the front passenger side wheel is very long with a constant velocity (CV) coupling in the middle to allow for suspension travel. In order to prohibit the shaft from rotating eccentrically at random, a bearing is placed before the $\mathrm{CV}$ joint and this bearing is supported by a mount bolted to the block or oil pan of the engine.

In order to begin this design, a suitable mounting location on the engine needed to be chosen. The 1.3 liter engine had provisions low on the block on the side facing the vehicle's firewall for mounting a conventional belt-driven air conditioning compressor. However, the 2-mode Vue arrived with a highvoltage electric air conditioning compressor to allow the passenger compartment to be cooled during engine-off operation. It was decided to retain the electric air conditioning compressor and mount it on top of the engine, allowing the use of the existing air conditioning compressor mounting bolt holes for installing the new axle bearing mount.

Taking measurements of both the engine block and the axle shaft bearing housing, a wedgeshaped mount was designed. The angle of the wedge was critical to keep the axle shaft properly oriented and level where it entered the transmission. Figure 13 is an image of the designed axle bearing mount. 


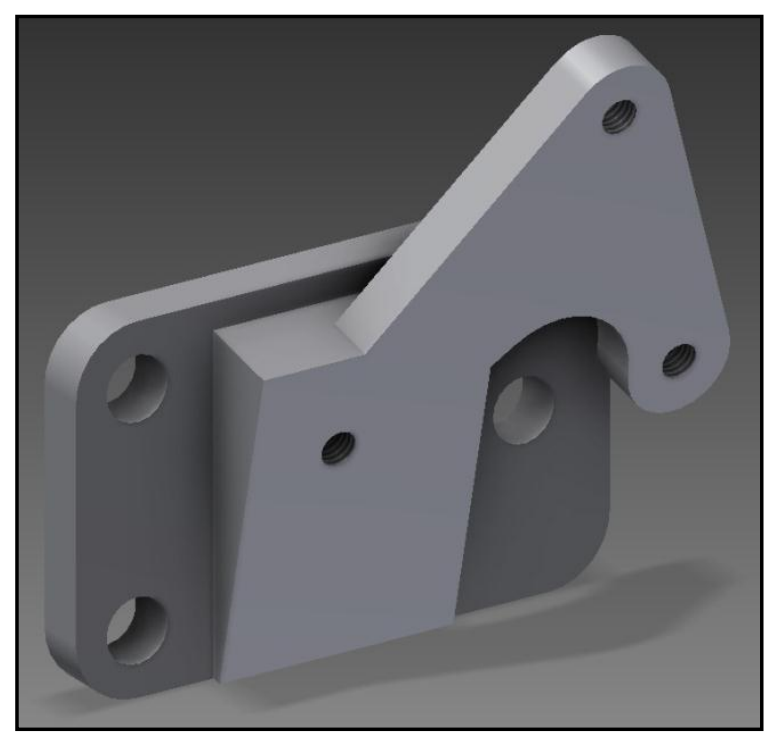

Figure 13. Axle Bearing Mount

The rectangular flat plate was bolted to the engine block and the angled triangular piece had three tapped holes for attaching the axle bearing housing. The angle of the triangular piece was designed to be $12.8^{\circ}$ as this was the angle of the stock axle bearing mount in the 3-D CAD model. The actual part was machined in two separate pieces and welded together to form the desired angle. This part, as well as all of the machined parts discussed in Section 3.2.1, was constructed by Morgantown Machine \& Hydraulics, Inc. located on Goshen Road just outside of Morgantown.

\subsubsection{Exhaust System}

Similar to the engine mounts, a new exhaust system was required for integrating the new diesel engine into the project vehicle. The production Saturn Vue was only offered with gasoline engines and the exhaust system included one three-way catalyst for each cylinder bank with the exhaust streams merging and passing through a pair of mufflers before exiting at the rear of the vehicle below the rear bumper cover. However, none of the production exhaust system was retained in the project vehicle.

For the diesel engine, the exhaust system required different components for removing pollutants from the exhaust to meet the emissions standards set by the EPA. A passive diesel oxidation catalyst (DOC) was installed directly after the turbocharger's turbine exit followed by a diesel particulate filter. The DOC was employed to reduce emissions of unburned hydrocarbons $(\mathrm{HC})$ and carbon monoxide $(\mathrm{CO})$ and the DPF was intended to remove particulate matter from the exhaust. Between the DOC and DPF were ports for measuring the exhaust gas pressure and temperature. The pressure reading was used to detect high exhaust back-pressure caused by a clogged or partially clogged DPF. In the case of high exhaust back-pressure before the DPF, the diesel engine ECU would inject more fuel into the cylinders so that the unburned fuel would be oxidized in the DOC and increase the exhaust gas temperature to greater than $600{ }^{\circ} \mathrm{C}$ to burn the PM captured in the DPF [11]. 
Following the DOC/DPF, a selective catalytic reduction (SCR) system was installed in order to reduce the emission of harmful oxides of nitrogen. $\mathrm{NO}_{x}$ reacts with different organic compounds in the atmosphere to produce ground level ozone or smog, acid rain, and other products harmful to humans and the environment [12]. The SCR system included another temperature sensor, a urea injector, and the catalyst itself. For the SCR system to function properly, liquid urea needed to be injected into the exhaust stream prior to the SCR catalyst. The catalyst needed to be above $200{ }^{\circ} \mathrm{C}$ for the reaction to occur properly. When the exhaust temperature was below $200^{\circ} \mathrm{C}$ before the SCR catalyst, the injector needed to be turned off so that raw urea would not be emitted into the atmosphere. When functioning properly, the SCR system would convert the input $\mathrm{NO}_{x}$ and urea into diatomic nitrogen $\left(\mathrm{N}_{2}\right)$ and water [13].

With these components included in the exhaust system as well as the turbocharger, the new exhaust system did not require a dedicated muffler to eliminate engine exhaust noise from entering the passenger compartment. The DOC was bolted directly to the turbine outlet of the turbocharger. Figure 14 is a photograph of the complete exhaust system, excluding the DOC, removed from the vehicle.

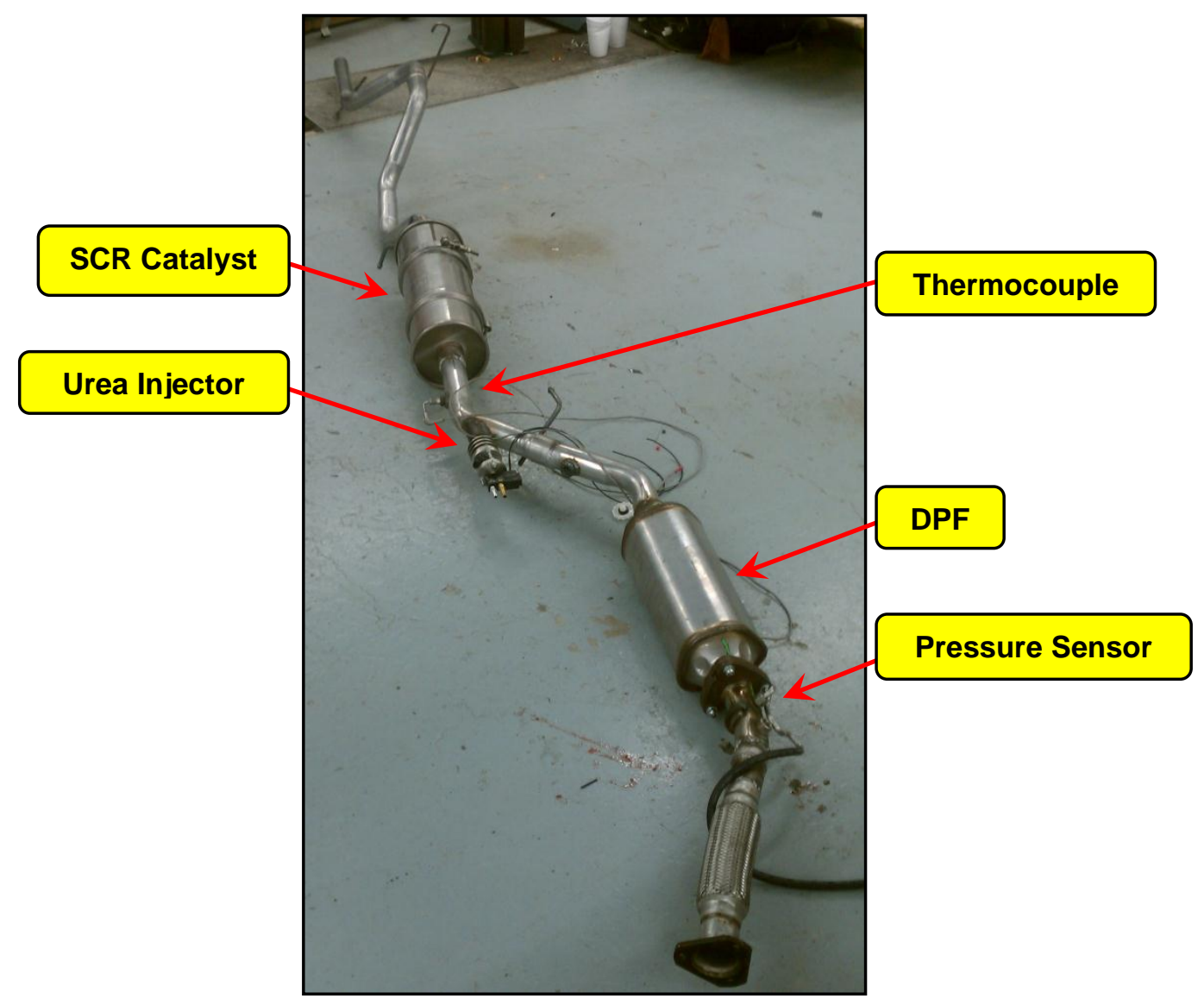

Figure 14. New Diesel Exhaust System

At the foreground are the temperature and pressure sensors used by the diesel engine ECU for determining when a DPF regeneration was needed. The first major component is the DPF followed by the thermocouple used to measure exhaust temperature prior to the SCR catalyst, the other major 
component. The urea injector was aimed directly at the inlet of the SCR catalyst to eliminate any urea getting trapped on the walls of the exhaust tubing and not mixing with the exhaust gas stream. The tubing was bent after the SCR catalyst to route around the fuel tank and rear sub-frame. The entire system was installed in the vehicle using conventional rubber exhaust system hangers. A single exhaust outlet was located below the bottom of the rear bumper cover offset to the passenger side.

\subsubsection{High-Voltage Battery Enclosure}

As well as models of the vehicle and all of its components, 3-D models of all of the components necessary to construct the high-voltage battery system including the individual modules, the battery management system (BMS) computer, and the contactor circuitry were also available. Using a model of the cargo area of the vehicle, the battery enclosure was designed such that it would securely house all the components and physically fit inside the project vehicle. The battery enclosure needed to be completely sealed and isolated from the passenger compartment to eliminate any chance of harmful gases generated inside the battery enclosure getting into the cabin air. In addition, the pack needed to be able to withstand $20 \mathrm{~g}$ frontal and side impacts as well as an $8 \mathrm{~g}$ downward impact without rupturing or becoming so deformed as to damage the battery modules inside.

The components necessary to construct the $330 \mathrm{~V}$ battery system included the lithium-ion battery modules, the BMS, and the electrical distribution system (EDS) including the main battery contactors mounted on a dedicated base with a dielectric composite cover that needed to be retained for safety when working inside the battery enclosure. The team was charged with designing a cooling system for the battery pack that needed to be approved by the engineers at $\mathrm{A} 123$ before the battery modules would be shipped to the school. Once the designed liquid cooling system design was approved, the new battery enclosure could be designed to house all the battery components as well as the aluminum cooling plates.

Inside the high-voltage battery enclosure, the battery modules were to be bolted to the base plate and the liquid cooling plates were placed between the modules. The cooling plates were held in place by pressure from the surrounding battery modules to ensure maximum contact between the battery modules and the cooling plates facilitating conduction heat transfer. Figure 15 is a drawing of the modules and cooling plates as they were arranged inside the high-voltage battery enclosure.
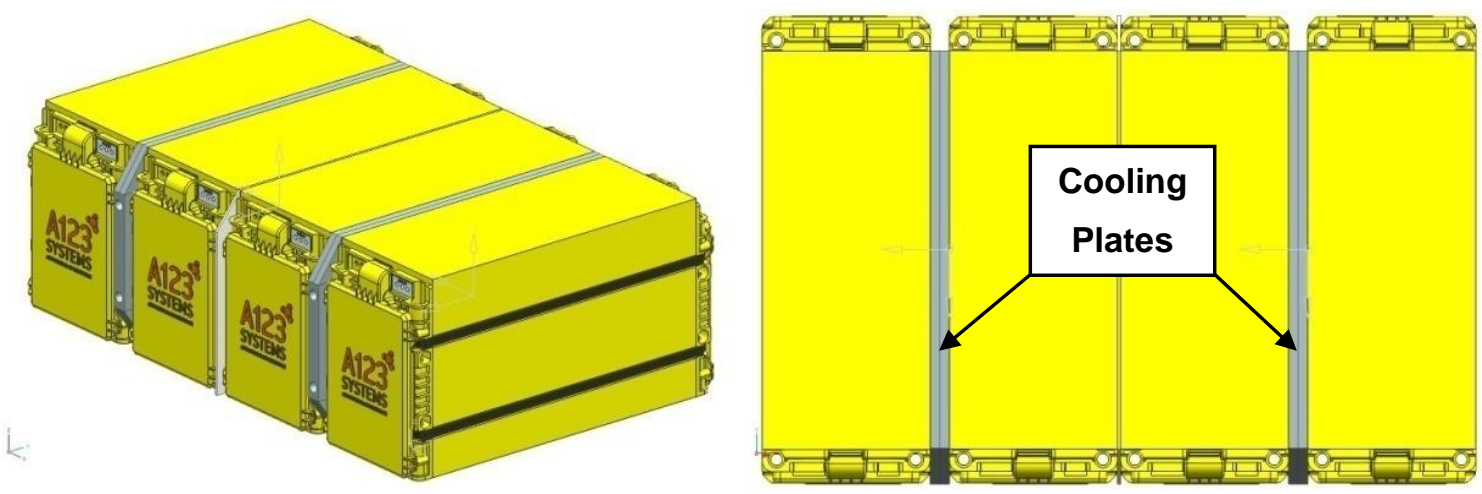

Figure 15. Battery Modules with Cooling Plates 
The four battery modules were intended to be cooled by two liquid cooling plates plumbed in parallel from a single pump located outside of the battery enclosure. Each cooling plate was responsible for dissipating the heat from two battery modules. The width of this arrangement of battery modules and cooling plates dictated the interior width of the high-voltage battery enclosure. A tight fit was desired inside the enclosure so that the outboard battery modules also made contact with the walls of the enclosure, further increasing the amount of conduction heat transfer potential.

The next step in the design process involved locating the different components used to monitor and control the high-voltage battery modules including the BMS and EDS as well as two quick-blow fuses, one installed between modules 2 and 3 and one installed on the positive line before it exited the battery enclosure. To mount these components and keep them isolated from the heat generated by the battery modules, a partition was implemented inside the enclosure. Figure 16 is a drawing of the proposed layout of the components inside the high-voltage battery enclosure.

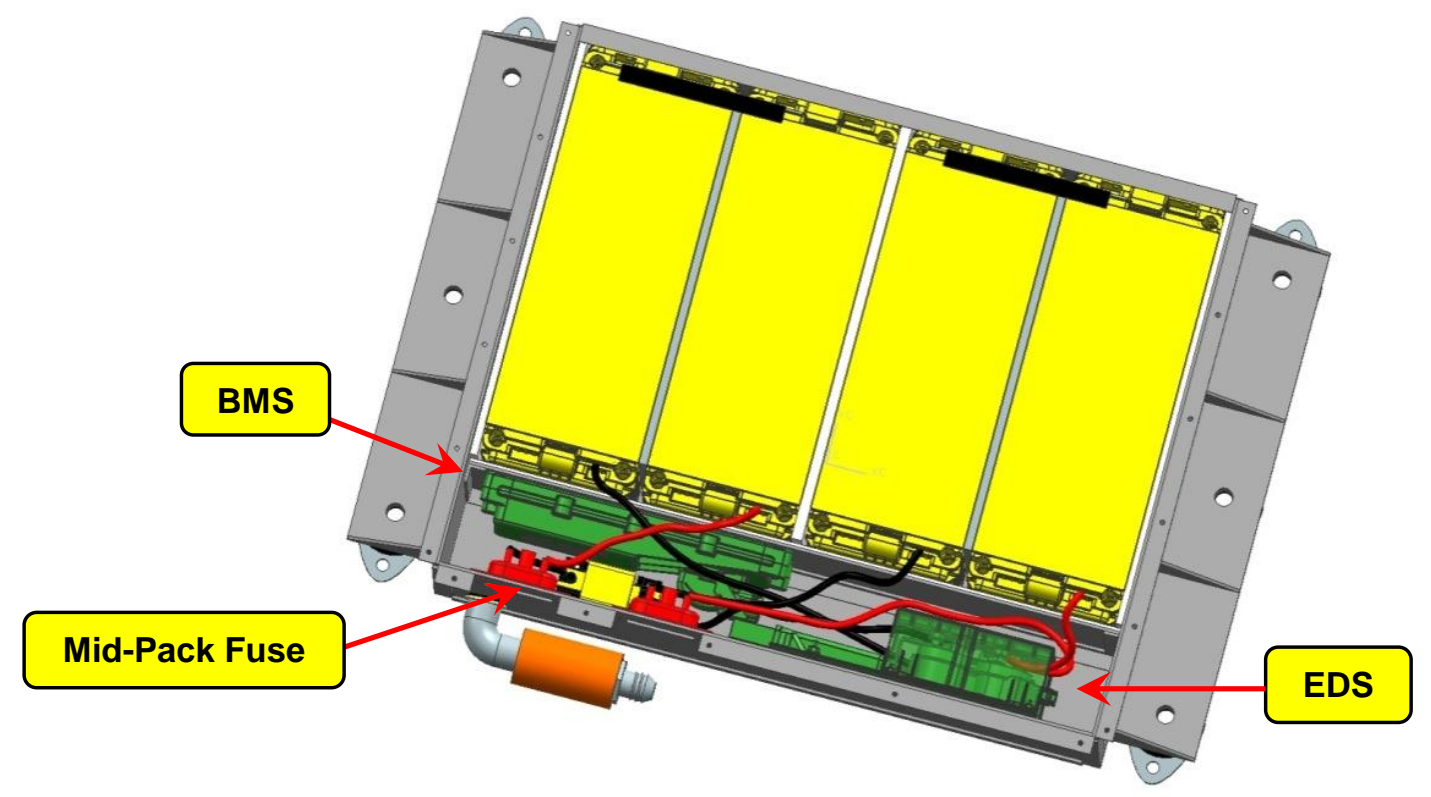

Figure 16. High-Voltage Battery Component Layout

The battery modules are illustrated in yellow at the top of the figure. The modules were numbered 1-4 left-to-right. The partition can be seen behind the battery modules with the EDS and BMS illustrated in green. The figure also shows the high voltage wiring of the battery pack with positive lines in red and negative lines in black. The yellow fuse at the bottom of the figure is the mid-pack fuse located between battery modules 2 and 3 .

With all the components located inside the high-voltage battery enclosure, the exterior dimensions could be set. The intent was to design the enclosure with as little empty space as possible to maintain cargo capacity in the project vehicle. Figure 17 is a drawing of the high-voltage battery enclosure installed into a 3-D model of the project vehicle. 


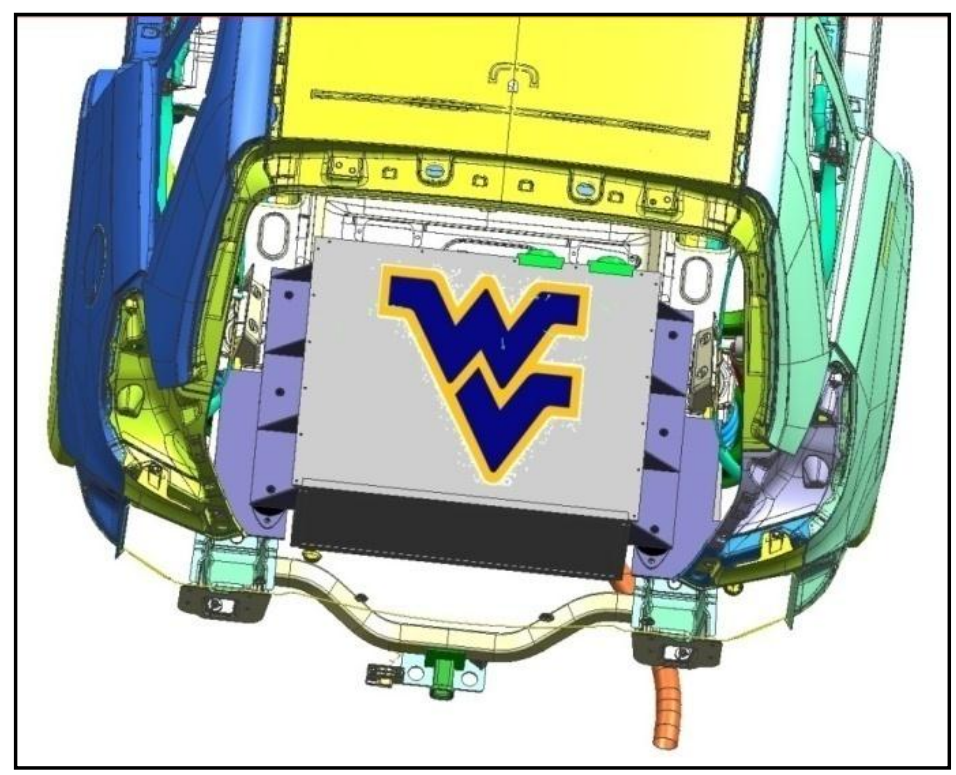

Figure 17. High-Voltage Battery Enclosure

Once installed, the new high-voltage battery enclosure would require that the floor of the cargo area in the rear of the vehicle be raised about six inches. Cutting out the floor to mount the battery lower in the vehicle would have helped to maintain cargo capacity but this modification was deemed impractical given the time constraints of the project deadline schedule. In addition, maintaining the original floor would help reduce road and wind noise. By mounting the high-voltage battery below the original floor level, the enclosure would have been exposed to moisture and road debris kicked up under the project vehicle which would be undesirable as well.

To save weight, the high-voltage battery enclosure was designed to be constructed entirely of aluminum. The battery enclosure needed to meet certain strength requirements to be implemented into the project vehicle. Discussion of the high-voltage battery enclosure strength analysis can be found in "wvuEssDesign V4FIN" which was submitted to A123 Systems for approval on April 15, 2010. This document discusses in great detail the mechanical design and analysis of the different components comprising the high-voltage battery enclosure [37].

\subsubsection{High-Voltage Battery Mount}

To install the high-voltage battery enclosure into the project vehicle, a mounting plate needed to be designed to securely fix the enclosure to the frame and body of the vehicle. Because the supplied 2mode Vue arrived with a $300 \mathrm{~V} \mathrm{NiMH}$ battery pack installed behind the rear seats, there were existing mounting points in the cargo area of the project vehicle that could be used for installing the new highvoltage battery enclosure. Some of these mounting points were originally used for installing a spare tire in non-hybrid versions of the Saturn Vue, but the 2-mode hybrid did not come with a spare tire to make room for the original high-voltage battery. 
Using the CAD model of the vehicle body, measurements were taken for locating the ten existing mounting points in the floor pan that would be used for installing the new high-voltage battery mounting plate. The contour of the floor was also measured as the mounting points existed on four different planes. Once the dimensions of the vehicle body were known, the mounting locations for the highvoltage battery enclosure were finalized so that they did not interfere with any of the mounting points for the battery mounting plate. Figure 18 is a profile drawing illustrating the different levels required for the battery mount to properly attach to the vehicle floor.

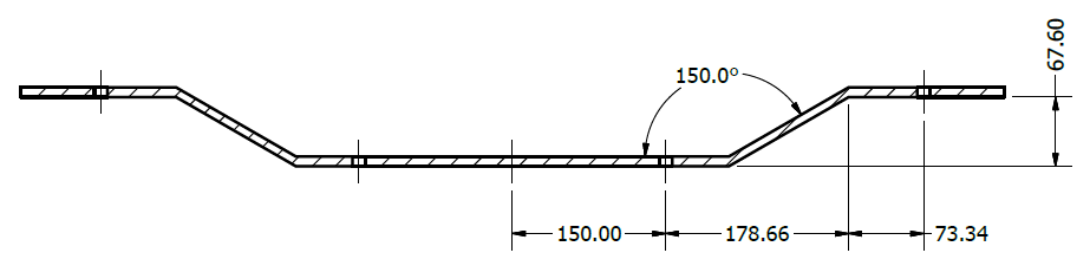

SECTION A-A

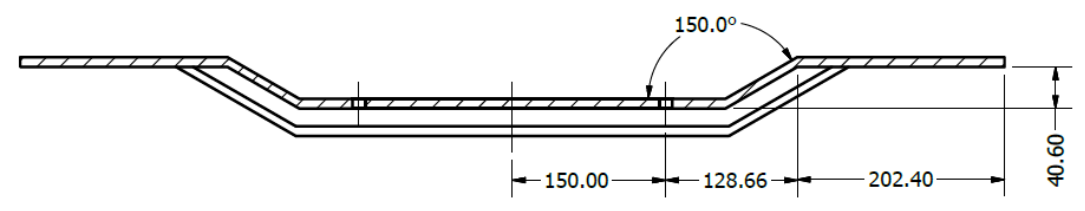

SECTION B-B

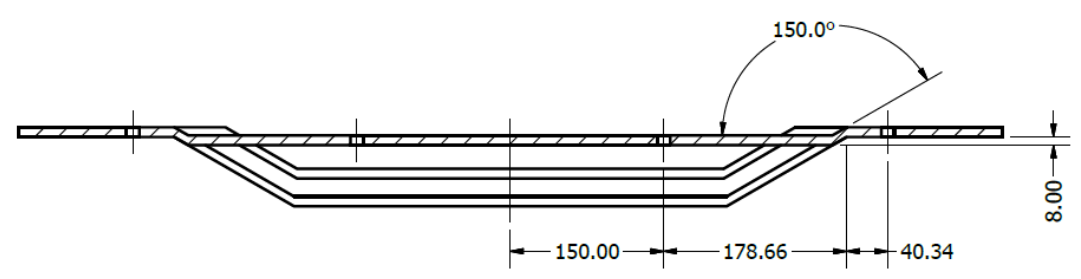

SECTION C-C

Figure 18. High-Voltage Battery Mount Side-View

The high-voltage battery enclosure was designed to be mounted using six rubber-isolated pads. The mounting pads bolted to the mounting plate using two bolts each and were arranged with the middle mount on both sides rotated $90^{\circ}$ so that all of the pads would fit on the mounting plate. Figure 19 is an image of the designed high-voltage battery mount. 


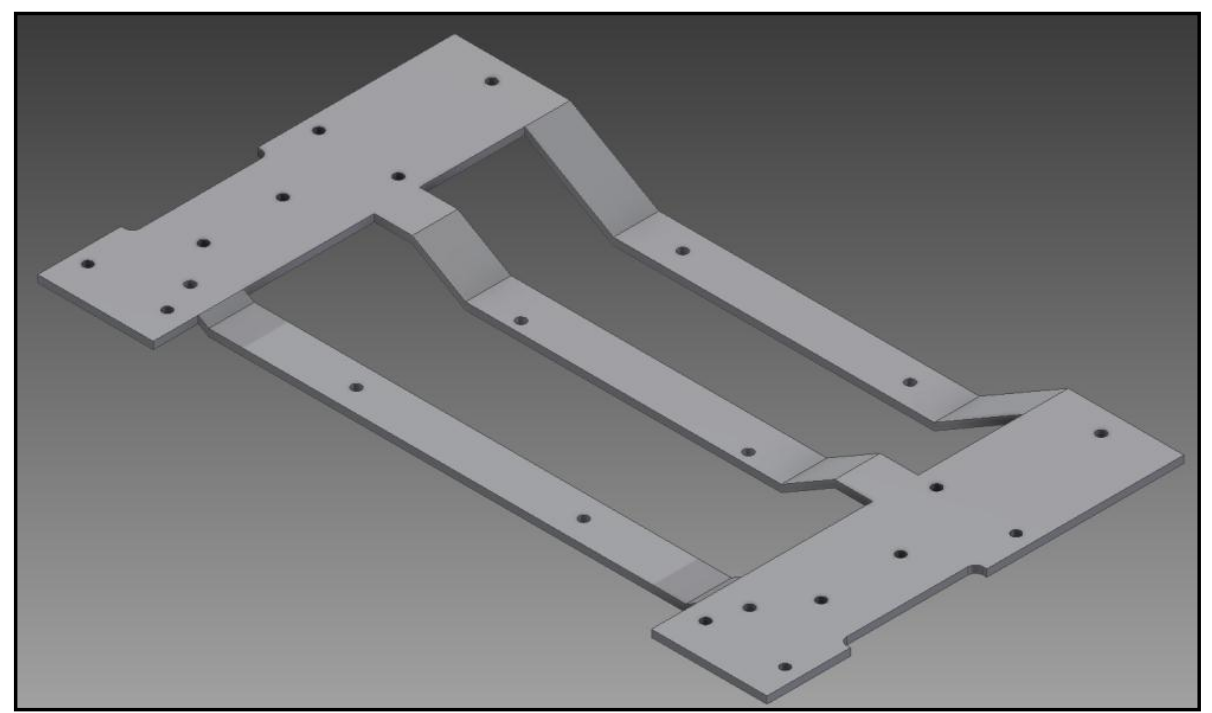

Figure 19. High-Voltage Battery Mounting Plate

The mounting plate was designed to be constructed from 3/8" 6061 aluminum. The mounting pad bolt holes were threaded and tapped for M14-sized bolts with the remaining holes drilled through to attach the mounting plate to the ten threaded studs installed in the vehicle from the factory. Figure 20 is an image of the mounting plate as it was intended to be installed in the project vehicle to illustrate the orientation of the rubber battery enclosure mounts. The figure also illustrates the locations of the various mounting points used to install the battery mounting plate in the cargo area of the project vehicle.

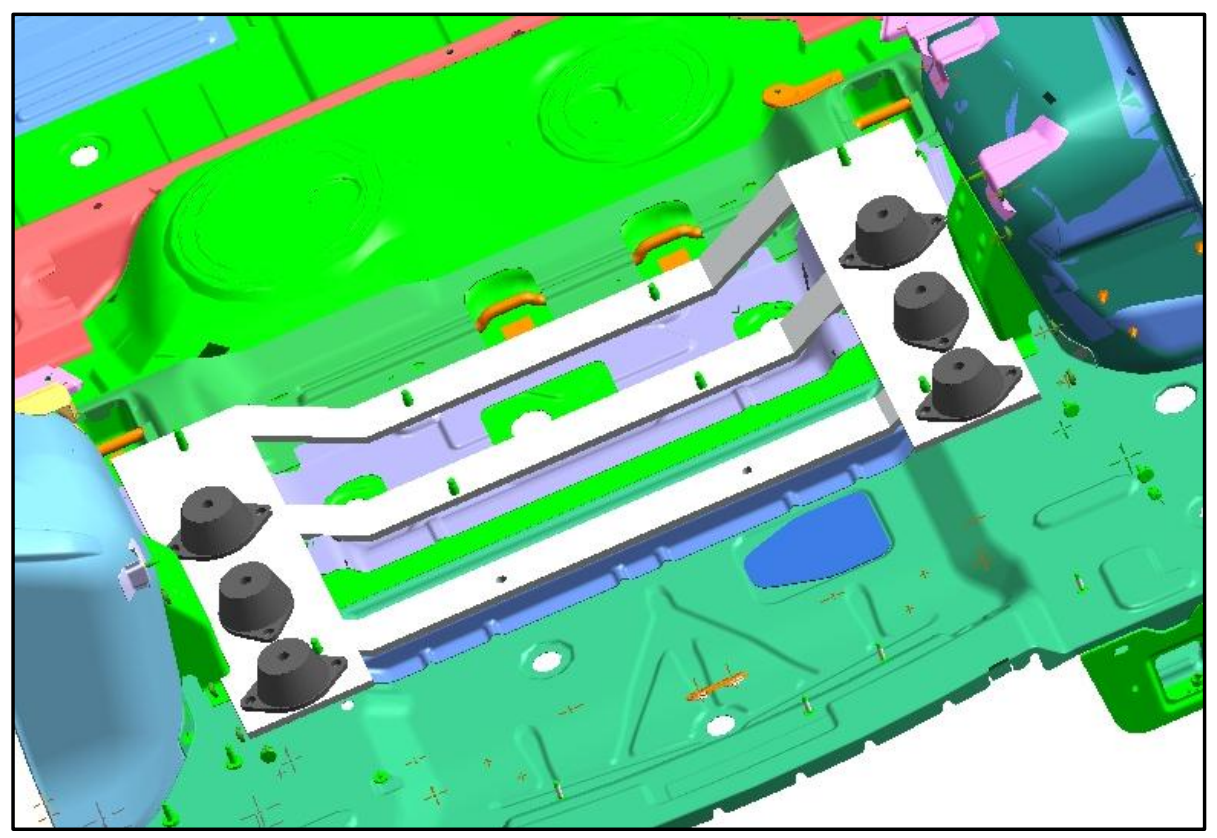

Figure 20. High-Voltage Battery Mount Installed In Vehicle Model 
All ten mounting points were utilized using nuts and bolts sized M12 with the two at the front of the mounting plate also used to install supports for a firewall that was installed to separate the highvoltage battery from the passenger compartment.

\subsubsection{Transmission Adapter}

The 2-mode transmission and 1.3 liter diesel engine were not designed to be mated together and no bolt holes between the engine and transmission directly lined up. This required the design of an engine-transmission adapter with bolt holes corresponding to those in the engine block and transmission case. In addition to physically bolting the transmission to the engine, proper alignment of the two components was of the utmost importance. The input shaft of the 2-mode transmission needed to be in perfect alignment with the engine crankshaft centerline to ensure there would be no bending moment applied to either. Additionally, any eccentric offset between the two would result in vibrations being transmitted into the vehicle cabin as well as a fatigue load being applied to the transmission input shaft resulting in premature failure.

The design of the transmission adapter began with taking measurements from 3-D CAD models of both the 2-mode transmission and 1.3 liter diesel engine. A polar coordinate system was setup for measuring the locations of the different bolt holes with the origin being set at the crankshaft/input shaft rotational axis. The linear distance from the rotational axis was measured in millimeters and the angular location of the bolt hole from level was measured in degrees. The CAD models also illustrated which holes in the adapter would need to be threaded and which would need to be through-holes. Bolt sizes were determined from the CAD models as well.

Using Autodesk Inventor, the locations of all the bolt holes were drawn first to begin laying out the physical geometry of the transmission adapter. During this step, it was discovered that one bolt from the engine and one bolt from the transmission interfered with one another. A bolt shear analysis was performed and it was concluded that these two bolts could be safely omitted from the final assembly as the transmission retained six M10-sized attaching bolts and one M12 bolt and the engine retained two M12 and two M14 bolts. Figure 21 is one of four technical drawings illustrating the locations of the different holes in the transmission adapter. 


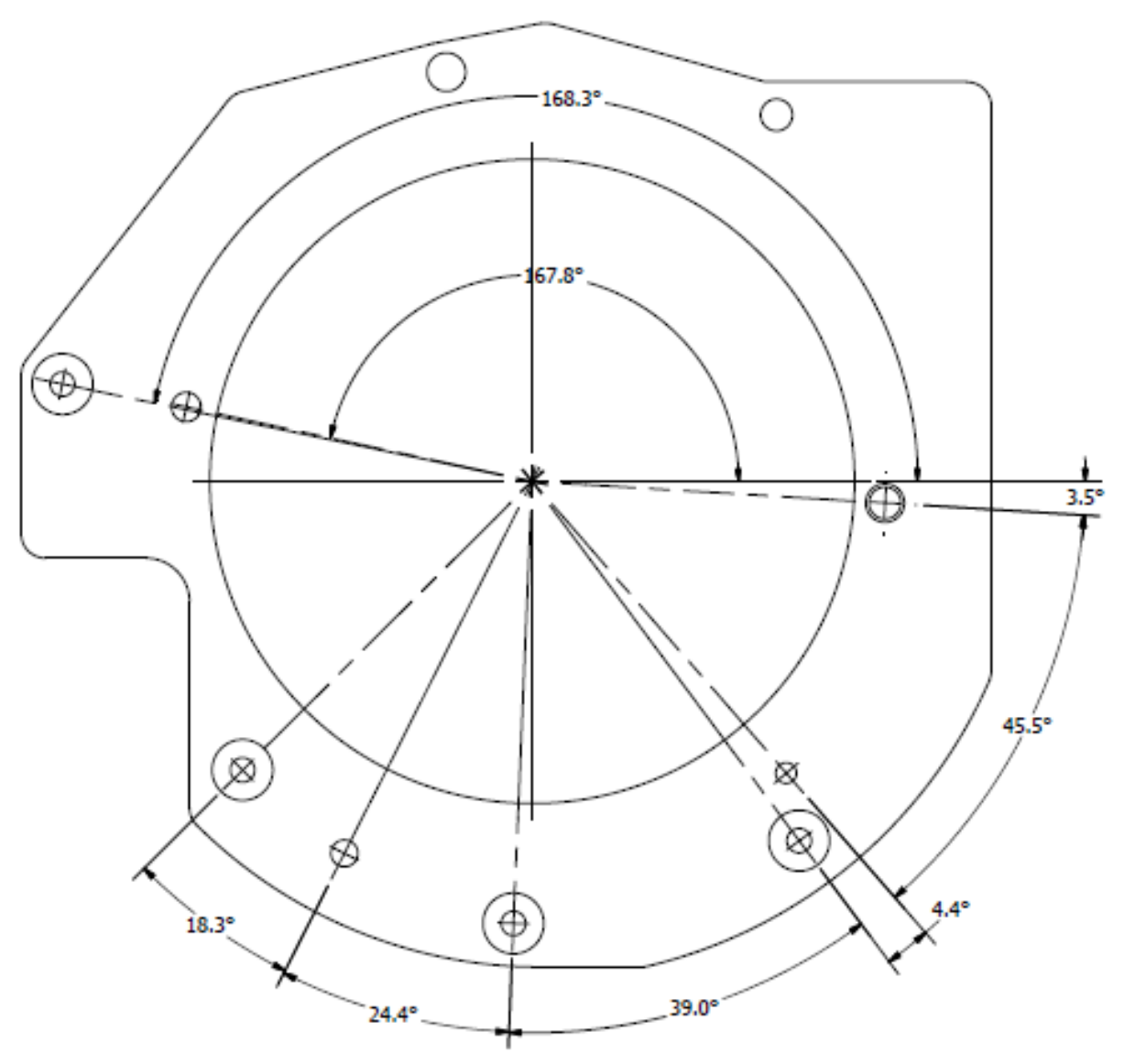

Figure 21. Transmission Adapter Bolt Hole Orientation

This drawing shows the angular locations of some of the different holes required in the enginetransmission adapter. Other drawings were generated that specified the distance each hole was from the center as well as the size of each hole and whether it was threaded or not. After the bolt holes for the engine and transmission were laid out and verified, the overall shape of the adapter plate was designed. Figure 22 is an image of the designed adapter plate viewed from the transmission mounting face. 


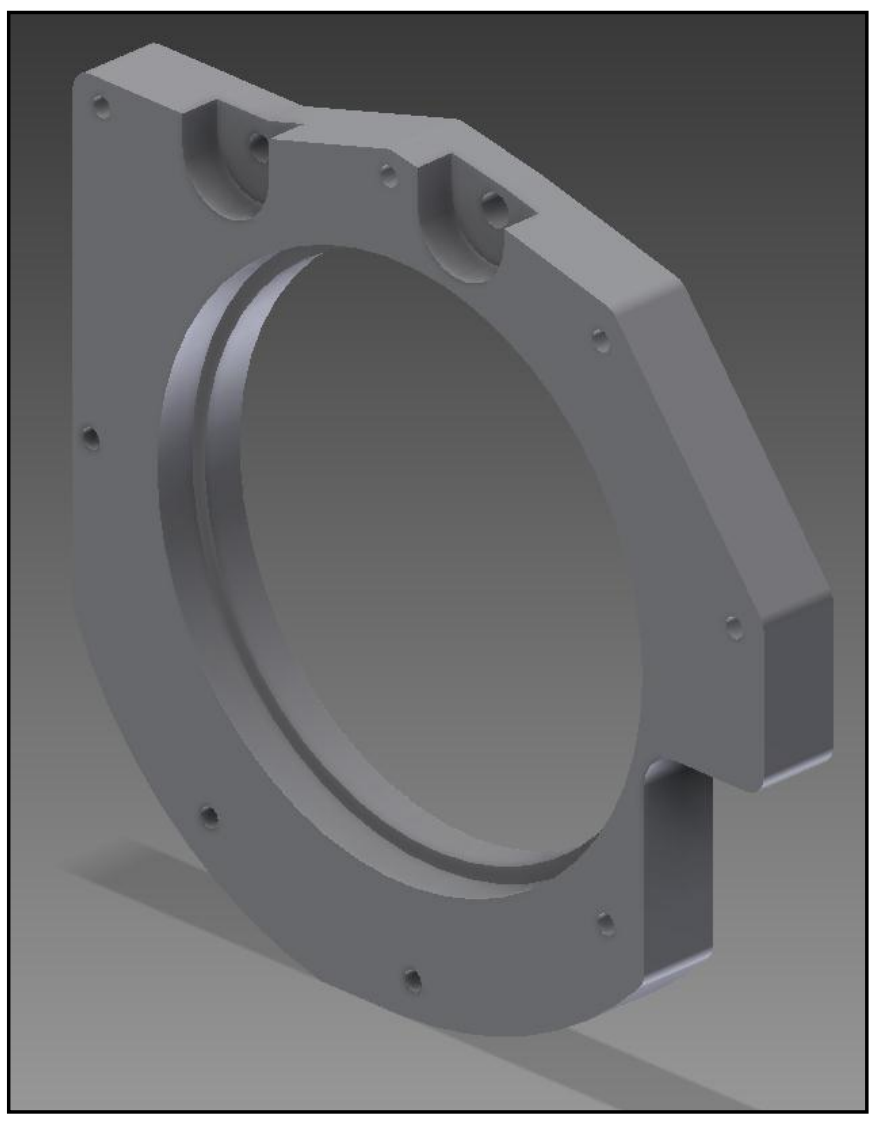

Figure 22. Engine-Transmission Adapter

The outside shape of the adapter was designed to follow the shape of the mating face of the 2mode transmission as the crankcase of the 1.3 liter diesel engine was considerably smaller than that of the stock 3.6 liter V-6. The inside diameter had a recess to accommodate the two lower bolts attaching the engine to the adapter due to the small block of the diesel engine. This inside diameter was selected to allow sufficient clearance for the flywheel and torsional damper to rotate freely. The cut out of righthand edge was made to clear the passenger side transmission output shaft. The adapter was designed to be $40 \mathrm{~mm}$ thick to properly engage the torsional damper on the 2-mode transmission input shaft based on the width of the flywheel. Discussion of the transmission adapter strength analysis can be found in Section 3.2.2 of this document.

\subsubsection{Flywheel}

Although the diesel engine was shipped with a flywheel already installed, the torsional damper required for connecting the engine to the 2-mode transmission would not bolt to it. In order to properly mate the diesel engine and 2-mode transmission, a new flywheel needed to be designed. Similar to the transmission adapter, properly sizing the flywheel was essential to ensure smooth operation of the engine and to protect both the engine and 2-mode transmission from damaging eccentricity. 
Because the 3-D CAD model of the 1.3 liter diesel engine did not include a flywheel, the new flywheel was designed by measuring the original once the engine was shipped to WVU. The bolt holes for attaching the flywheel to the crankshaft snout were located first. The eight holes were equally spaced about a $63 \mathrm{~mm}$ diameter circle centered at the axis of rotation. A smaller offset key was used to properly locate the flywheel on the crankshaft. The torsional damper attached to the flywheel using four bolts located on a $250 \mathrm{~mm}$ diameter circle centered at the axis of rotation. Figure 23 is a drawing illustrating the locations of the bolt holes required in the flywheel. All diameters are given in millimeters.

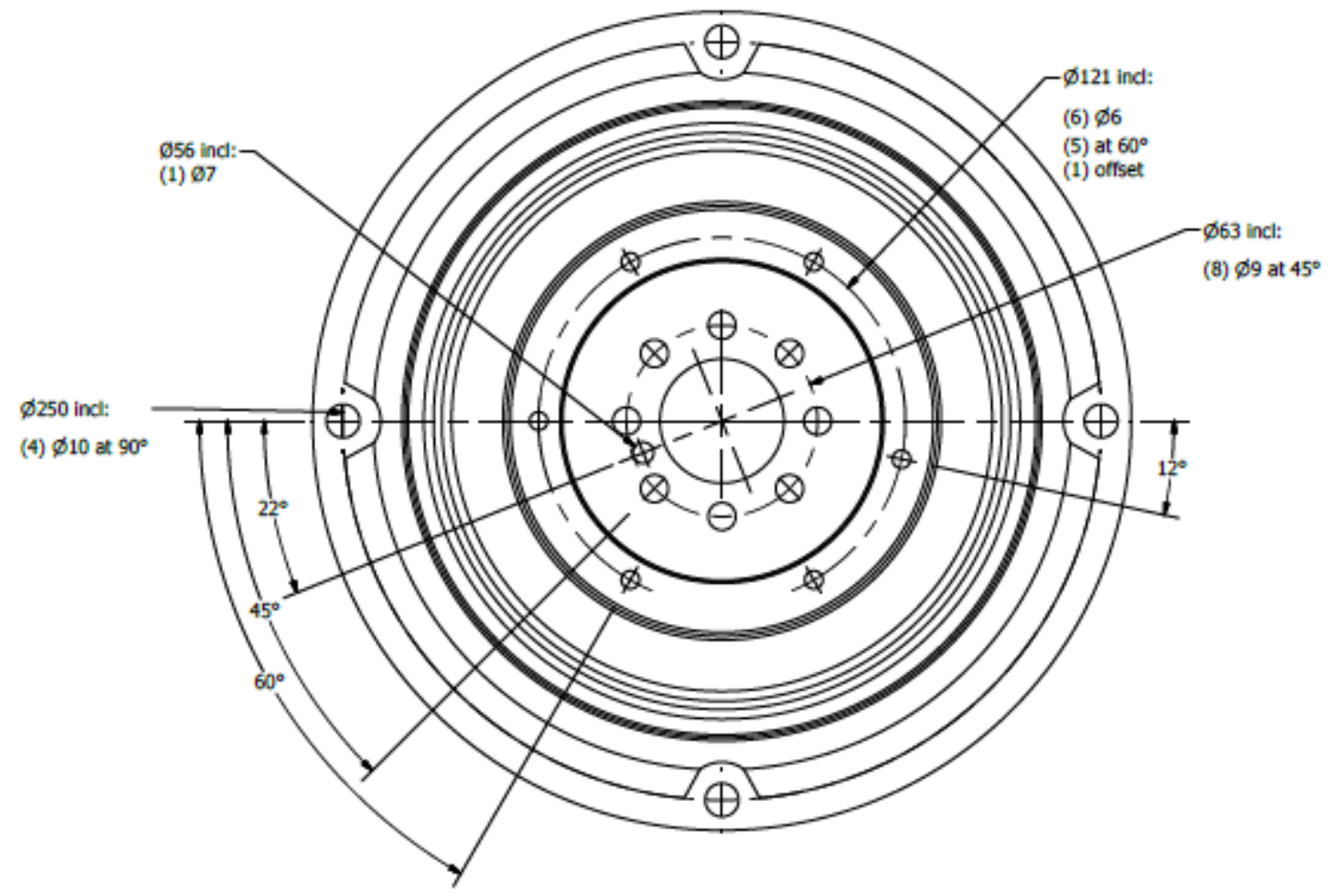

Figure 23. Flywheel Bolt Layout

The 1.3 liter diesel engine utilized a stamped steel inductive pick-up wheel riveted to the flywheel to track the orientation of the engine. An induction sensor in the engine block sent pulses to the engine ECU used for fuel injection timing. After removing the pick-up wheel from the stock flywheel, the contour of the front face of the flywheel could be designed. The flywheel needed to mimic the shape of the induction wheel as closely as possible to eliminate any chance of the pick-up wheel vibrating and sending a false reading to the ECU. Exact measurements of the induction wheel were taken and the overall shape of the face of the flywheel was determined. Figure 24 is a drawing showing the cross-sectional shape of the flywheel including dimensions. The overall thickness was set at just under $52 \mathrm{~mm}$ to properly locate the torsional damper on the splined input shaft of the 2-mode transmission. 


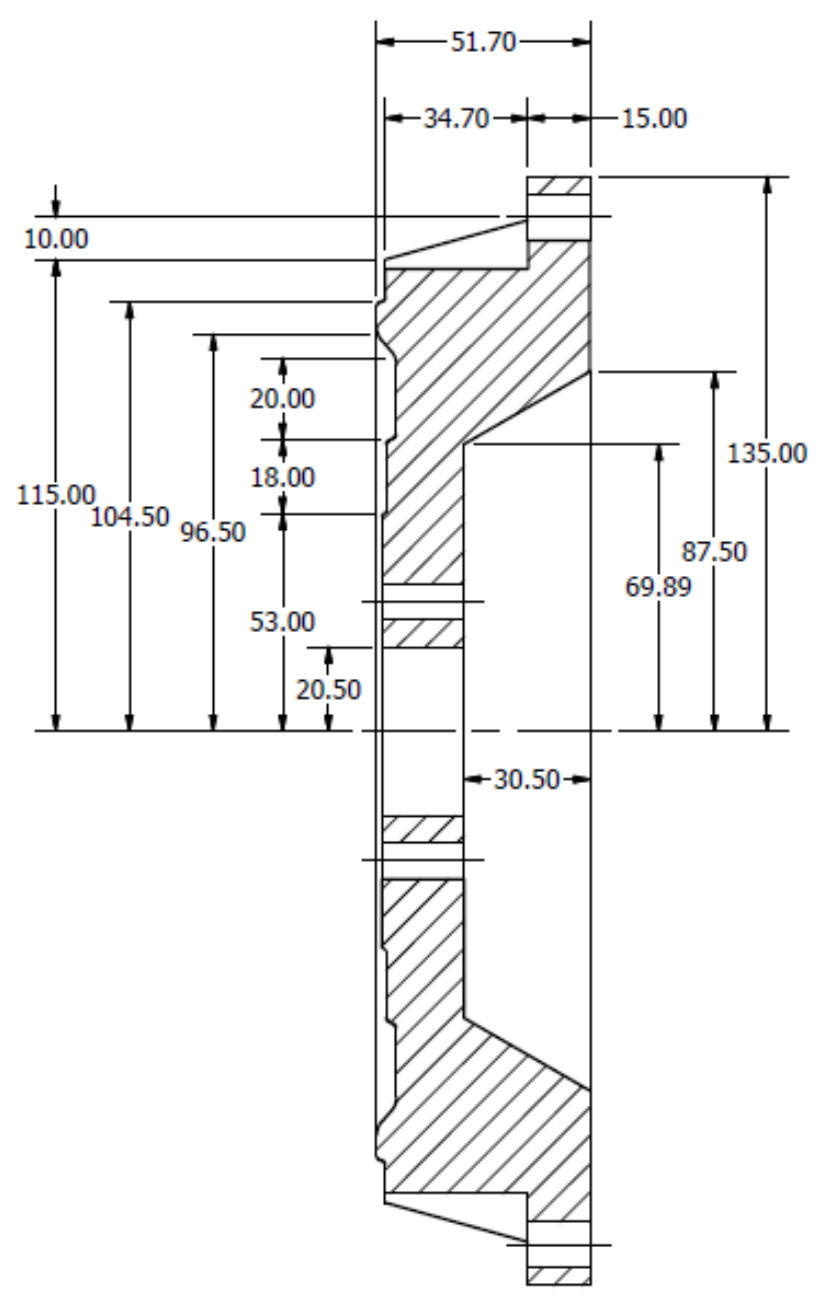

Figure 24. Flywheel Cross-Section

With the critical dimensions set, the only remaining design parameter was the overall weight of the flywheel and torsional damper. The original flywheel and clutch assembly weighed 32lb. This was the target weight for the new flywheel and torsional damper assembly. After weighing the torsional damper, the flywheel target weight was around 13lb. The flywheel was designed to be machined from SAE 4140 steel with a density of $7.85 \mathrm{~g} / \mathrm{cm}^{3}$ [14]. Using the calculated volume provided by the Autodesk Inventor software, material was removed from the transmission side of the flywheel until the calculated mass of the flywheel and torsional damper matched as closely as possible the mass of the original flywheel and clutch assembly. Figure 25 is a drawing of the new flywheel. 


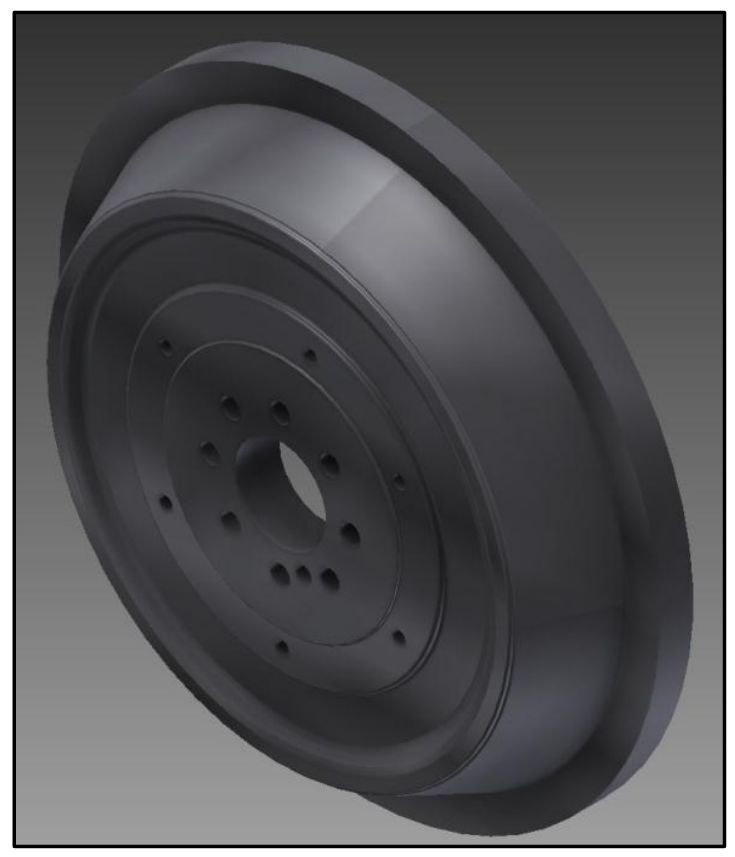

Figure 25. Flywheel

The figure illustrates the flywheel when viewed from the engine side. The new flywheel was heavier than the target weight, weighing $21.7 \mathrm{lb}$. The required geometry of the flywheel did not allow any more material to be removed from the design. When installed, the induction pick-up was installed between the flywheel and engine crankshaft with an offset dowel in the crankshaft ensuring that both the pick-up and flywheel were installed in the correct position.

\subsubsection{Front Engine Mount}

The front of the engine is defined in this context as the side with the accessory belt drive perpendicular to the axis of crankshaft rotation. Because the 1.3 liter diesel engine was never intended to be installed in the 2009 Saturn Vue, a new front engine mount was required to secure it to the passenger side frame rail. Fortunately, the other mounts for securing the powertrain in the vehicle required no modifications as the remaining three mounting points attached to the 2-mode transmission case which was originally installed in the vehicle. The diesel engine arrived with mounts and components for installation into a 2008 Opel Corsa 1.3 CDTi and the supplied front engine mount was used as a basis for the design of a new mount for installation into the project vehicle. Figure 26 is a photograph of the engine mount shipped with the engine. 


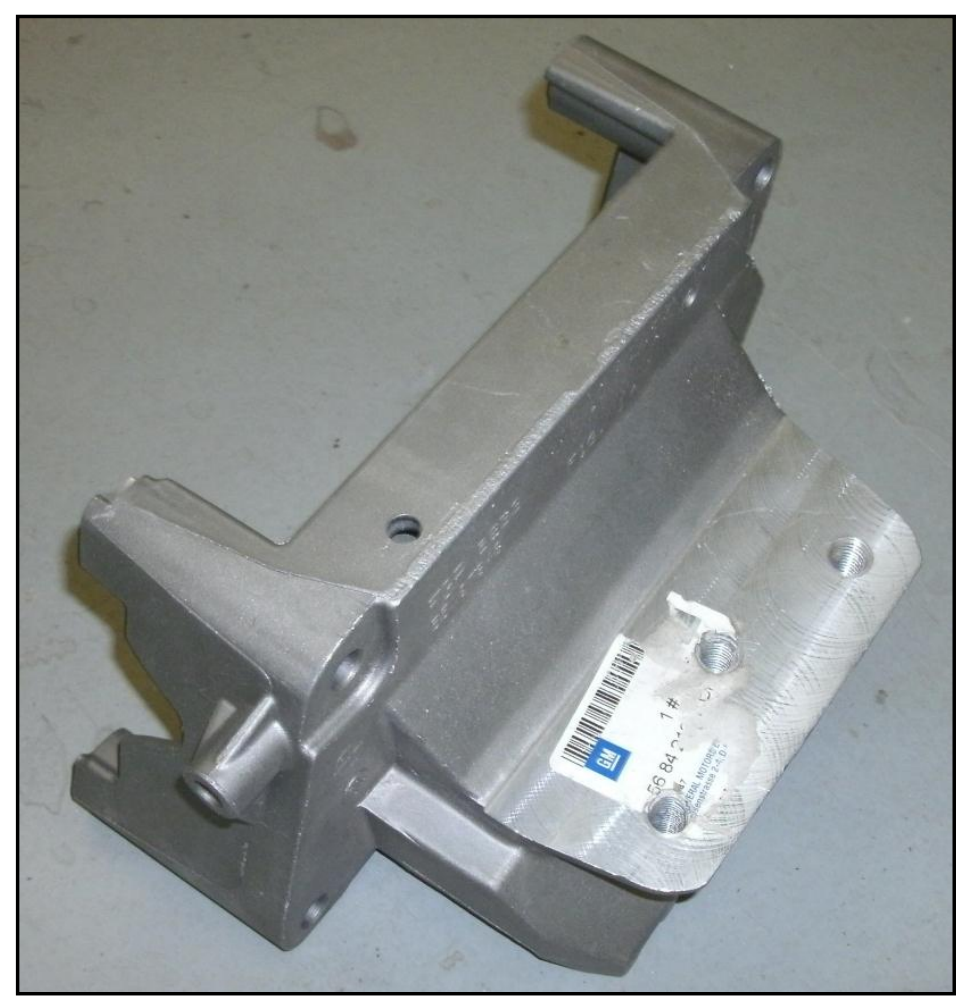

Figure 26. Supplied Front Engine Mount

The four posts on the opposite side of the mount sat flush against the front of the diesel engine's block and the three bolt holes on the protruding mounting pad in the foreground were used to attach the engine mount to the frame mount in an Opel Corsa. However, the frame mount installed in the 2009 Saturn Vue project vehicle did not line up with this front engine mount. In addition, the frame mount in the Saturn only used two bolts instead of three.

The front engine mount design process began with measuring the length and location of the four posts that attached to the engine block. Once this geometry was established, the location of the mounting points for the frame mount in the Vue needed to be determined. This was accomplished using the supplied CAD models of the of the Saturn Vue and 1.3 liter diesel engine. The engine was fixed to the 2-mode transmission via the new adapter plate and the powertrain was then put into the CAD model of the vehicle and situated as it would be installed. Measurements were taken in the CAD software and the front mounting pad geometry was designed. Figure 27 is an image of the new front engine mount. 


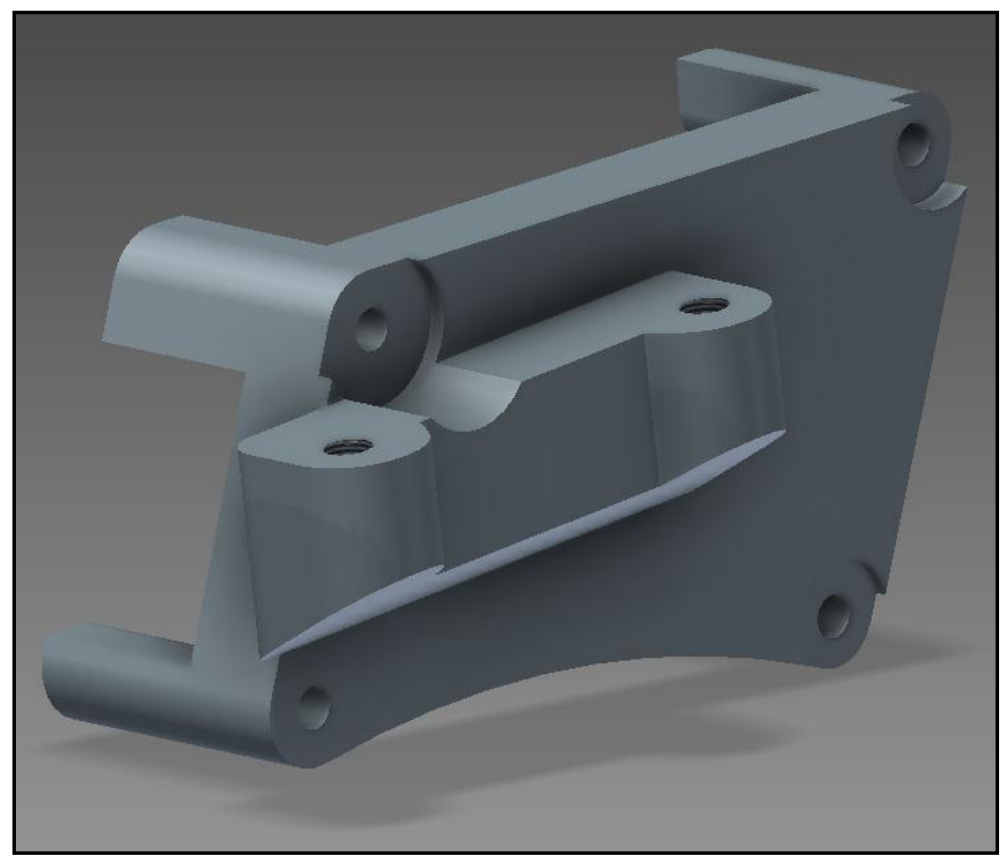

Figure 27. New Front Engine Mount

The mounting pad was raised up and moved to the left relative to the mounting pad on the supplied engine mount due to the higher frame rail location in the Saturn Vue compared to the Opel Corsa which was a compact car. This part was analyzed for strength prior to machining. Discussion of the front engine mount strength analysis can be found in Section 3.2.3 of this document.

\subsubsection{Fuel Tank}

A new fuel tank was designed for the project vehicle for two reasons. The stock composite fuel tank had a 16 gallon capacity but according to the simulations, the project vehicle could maintain a 200 mile range with an eight gallon fuel tank. Also, it was desired that the fuel tank be easily removed for onroad fuel economy testing where the tank could be weighed between tests. To aid in removal and installation of the full fuel tank, an electric winch was installed under the vehicle to raise and lower the fuel tank. A 12 gallon aluminum fuel tank was purchased and modified to fit in the project vehicle. Figure 28 is a photograph of the aluminum fuel tank as-purchased. 


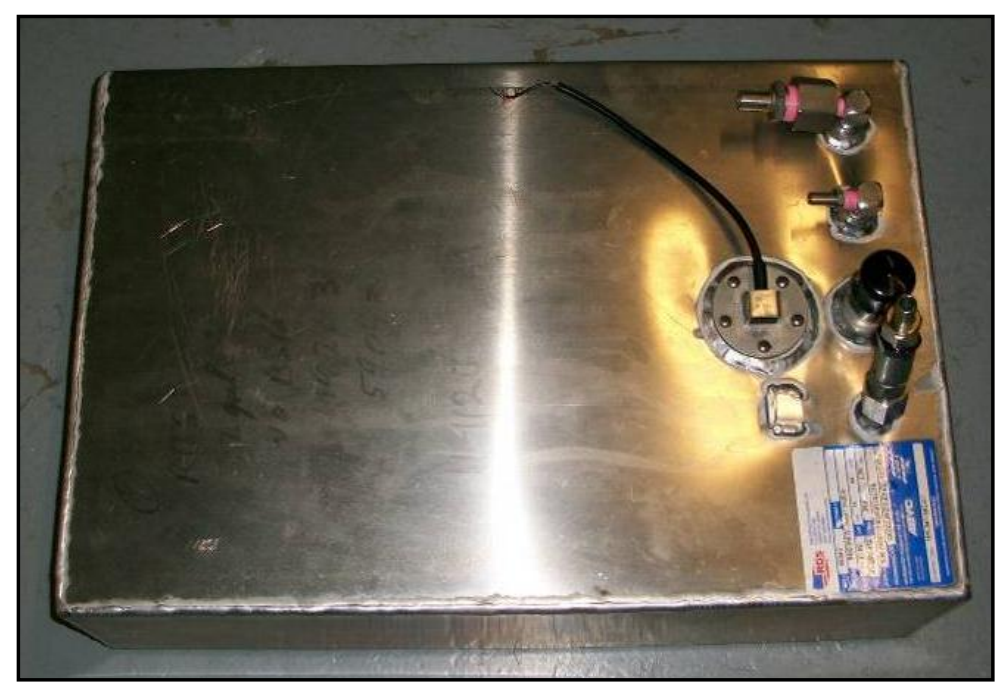

Figure 28. Aluminum Fuel Tank Prior to Modification

The purchased fuel tank included a fill port, a fuel level sensor, and fuel feed and return ports already installed. The tank was modified to fit in the location of the production tank. Ground clearance and exhaust routing were the two major concerns when the fuel tank was being designed and modified. The vehicle's minimum ground clearance was specified to be 5 inches to cope with the quality of roads found in and around Morgantown. For this reason, a 1 inch section was cut out of each side of the fuel tank to decrease its height, thereby increasing the vehicle's ground clearance. To make room for exhaust routing, the left side of the tank was reshaped to allow ample exhaust system clearance. Figure 29 is a drawing of the fuel tank after modifications.

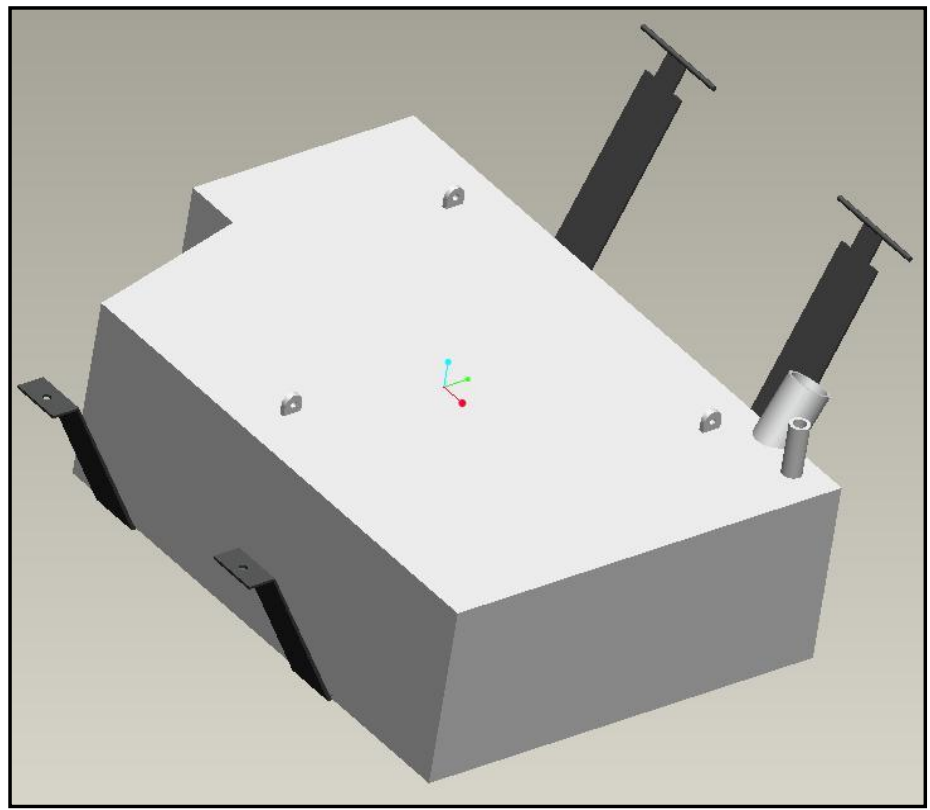

Figure 29. Modified Fuel Tank 
The fill port was moved to the side of the tank so that the fuel tank could be mounted closer to the underside of the vehicle. For safety, the fuel tank could not protrude below the vehicle frame rails. Three tabs were to be welded to the top of the tank for attaching the lift cable from the electric winch. Quickdisconnects for the fuel feed and return lines were to be installed at the front of the tank to further ease removal and installation.

In order to retain the ability to fill the fuel tank through the production fuel filler neck, the opening under the fuel filler cap was enlarged to accept the larger diesel fuel pump nozzle. After modifications, the new fuel tank held nine gallons. The fuel tank was analyzed for natural frequencies and the results of this analysis can be found in Section 3.2.4 of this document.

\subsubsection{Intercooler}

The diesel engine utilized a turbocharger to compress the intake air before it entered the combustion chambers. Turbocharging is common in compression-ignition engines to increase power output by allowing more fuel to be injected while maintaining the proper equivalence ratio [21]. However, the temperature of the intake air increases when it is compressed in the turbocharger, reducing its density and effectively negating the benefits of the turbocharger. While the heating of the intake air may not be an issue at low boost levels, the turbocharger on the 1.3 liter diesel engine was capable of producing 18 psi of boost which could significantly heat the intake air. This necessitated the design and installation of a heat exchanger, known as an intercooler, in the intake system after the turbocharger compressor.

There are two major types of intercoolers available: air-to-air and water-to-air. An air-to-air intercooler uses only air flowing across the heat exchanger to cool the intake air passing through it. A water-to-air intercooler utilizes a liquid coolant to cool the intake air similar to refrigerant coils in an air conditioning system. An advantage of a water-to-air setup is that the intercooler can be mounted anywhere on the vehicle whereas an air-to-air intercooler must be installed in a location that gets good air flow typically at the front of the vehicle. However, water-to-air intercooler systems require the addition of a coolant pump and piping and another heat exchanger for removing heat from the coolant mounted elsewhere in the vehicle. An air-to-air intercooler system is less complex in that it only requires one heat exchanger. Water-to-air intercoolers are typically used in high performance vehicles with most production turbocharged vehicles implementing air-to-air systems so an air-to-air intercooler was designed for use in the project vehicle.

The design of the intercooler began with selecting a mounting location and measuring the available space. By the time the intercooler was designed, the project vehicle had arrived at WVU so all measurements were taken by hand. In order to ensure maximum airflow through the intercooler, a location in front of the engine radiator behind the front bumper was selected. Taking measurements, the maximum size of the intercooler was 16 in. tall, 24 in. wide, and 2 in. deep.

Using this maximum size information, the required size was calculated with the aid of technical support at Bell Intercoolers. According to the Bell engineers, the minimum flow rate in cubic feet per minute (CFM) required through the intercooler core was equivalent to 1.5 times the rated power output of 
the engine in horsepower. The diesel engine produced $90 \mathrm{hp}$, resulting in a minimum flow rate of 135 CFM through the intercooler. The Bell engineers also stated that the intercooler core should be as thin as possible to improve the overall cooling efficiency. With this information, intercooler core \#A200075090 was selected. Table 16 lists the specifications for the designed intercooler.

\section{Table 16. Intercooler Specifications}

\begin{tabular}{|r|c|}
\hline Length & 9.00 in. \\
\hline Height & 7.50 in. \\
\hline Width & 2.00 in. \\
\hline Flow Rate & 161.6 CFM \\
\hline
\end{tabular}

The selected intercooler provided a maximum flow rate greater than what the 1.3 liter diesel engine required. The dimensions refer to the size of the heat exchanger core and not the inlet and outlet tanks. The inlet and outlet ports were 2 inches in diameter and the required size of the intercooler would facilitate installation in multiple locations. Figure 30 is a photograph of the intercooler.

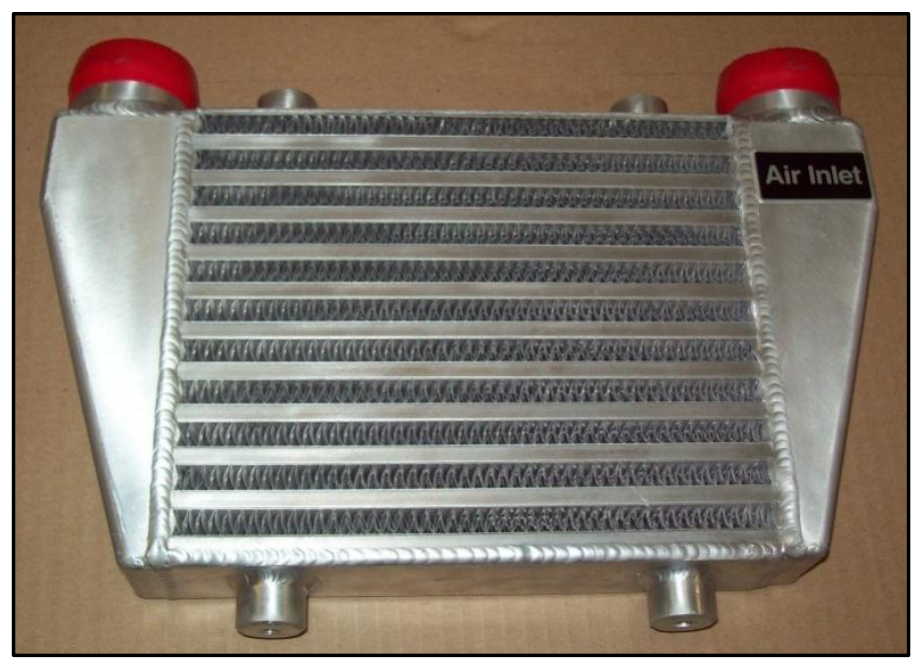

Figure 30. Intercooler

The inlet and outlet ports were oriented in the same direction so that the intercooler could be installed offset to one side of the project vehicle to simplify and shorten the plumbing for the intake system. Bell included multiple tapped mounting locations so that the mounting scheme could be designed once the intercooler arrived.

\subsubsection{Transmission Adapter Strength Analysis}

The engine-transmission adapter plate was analyzed for strength using Autodesk Inventor's finite element analysis (FEA) package for various load cases. The adapter was designed to be machined from 6061 aluminum. The material properties used for 6061 aluminum are shown in Table 17 [14]. 
Table 17. 6061 Aluminum Material Properties [14]

\begin{tabular}{|r|c|}
\hline Density & $2.70 \mathrm{~g} / \mathrm{cm}^{3}$ \\
\hline Yield Strength & $276 \mathrm{MPa}$ \\
\hline Ultimate Tensile Strength & $310 \mathrm{MPa}$ \\
\hline Young's Modulus of Elasticity & $68.9 \mathrm{GPa}$ \\
\hline Shear Modulus & $26.0 \mathrm{GPa}$ \\
\hline Poisson's Ratio & 0.330 \\
\hline
\end{tabular}

For the first four simulations, impact forces were analyzed. The engine and transmission were assumed to weigh $318 \mathrm{~kg}(700 \mathrm{lb})$ combined and an impact acceleration of $20 \mathrm{~g}$ was simulated to model the forces exerted on the part in the event of a collision with a solid object. The part was held stationary and a force of $43 \mathrm{kN}$ was applied to each of the 14 bolt holes with each force oriented in the same direction. Simulation 1 applied this load vertically pulling down on the bolt holes. The FEA results for Adapter Plate Simulation 1 are listed in Table 18.

\section{Table 18. Adapter Plate Simulation 1 Results}

\begin{tabular}{|r|c|}
\hline Maximum Von Mises Stress & $57.08 \mathrm{MPa}$ \\
\hline Minimum Safety Factor & 4.82 \\
\hline
\end{tabular}

Adapter Plate Simulation 2 had the forces vertically pulling up on the bolt holes producing the same results. These two simulations produced a minimum factor of safety of 4.82 , more than double the minimum required factor of safety of 2 .

Adapter Plate Simulation 3 applied the force on the bolt holes at a 45 degree angle pointing down and toward the rear of the vehicle to simulate a curb or pothole impact with the vehicle in motion. This situation was analyzed because it was believed to be a condition that would be encountered during normal driving. Figure 17 displays the setup for Adapter Plate Simulation 3. The bolt holes are highlighted in light blue and the yellow arrows represent some of the applied forces. 


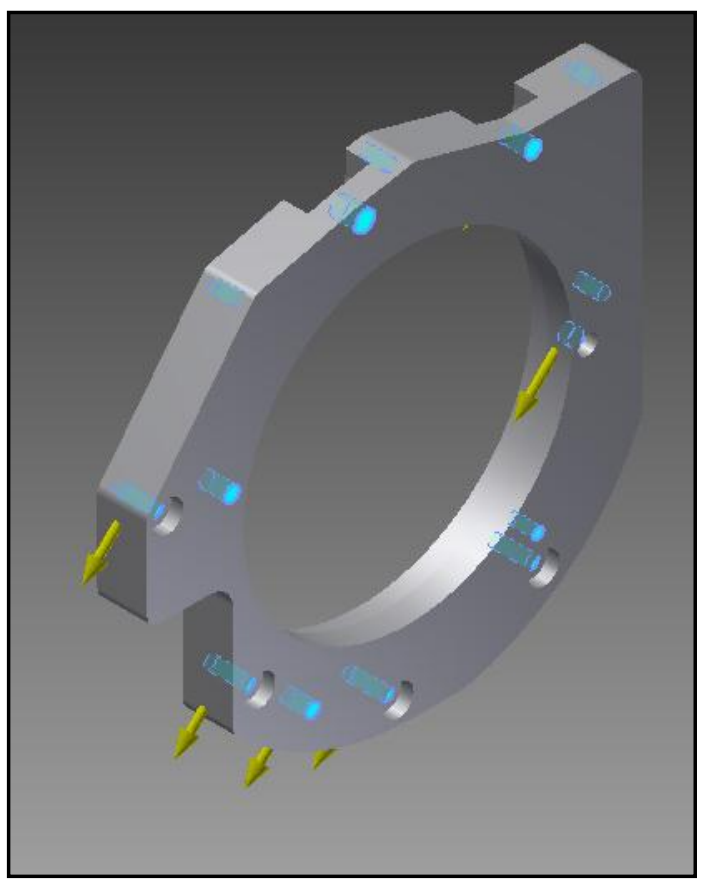

Figure 31. Adapter Plate Simulation 3 Setup

Table 19 lists the FEA results for Adapter Plate Simulation 3.

\section{Table 19. Adapter Plate Simulation 3 Results}

\begin{tabular}{|r|c|}
\hline Maximum Von Mises Stress & $37.16 \mathrm{MPa}$ \\
\hline Minimum Safety Factor & 7.4 \\
\hline
\end{tabular}

Adapter Plate Simulation 3 produced a factor of safety of 7.4 , nearly four times the minimum requirement. Figure 32 displays the locations of the maximum and minimum Von Mises stresses for Simulation 3. Most of the plate was under stresses less than $5 \mathrm{MPa}$. The point with the maximum stress concentration was a location where a bolt hole for the engine came close to the surface of the inner radius of the opening in the plate. In the actual part, this bolt hole broke through the surface during machining due to this close tolerance caused by the size difference between the crankcase dimensions of the stock 3.6 liter gasoline engine and the 1.3 liter diesel engine. 


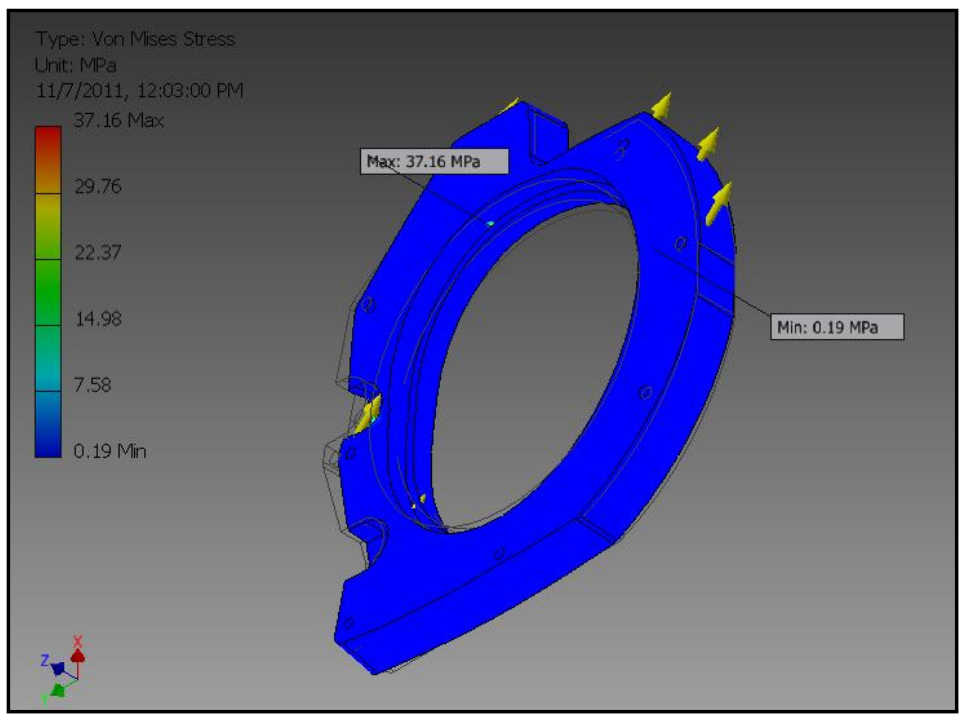

\section{Figure 32. Von Mises Stress for Adapter Plate Simulation 3}

Figure 33 displays the factor of safety for every point on the adapter plate. Again, the critical point was where the engine bolt hole is near the surface of the inner radius. Otherwise, the rest of the part had a factor of safety of over 10 .

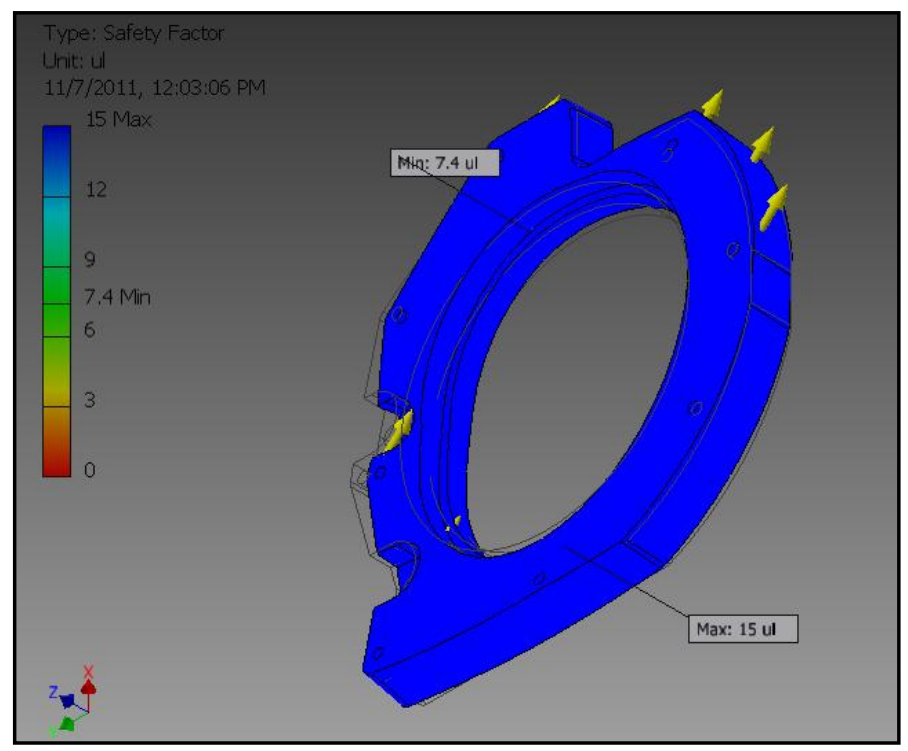

\section{Figure 33. Safety Factor for Adapter Plate Simulation 3}

Adapter Plate Simulation 4 applied the force only in the x-direction toward the front of the vehicle to simulate a collision with an immovable object or another vehicle. This condition was required to be simulated to get the GM engineers overseeing the design of the components to approve the design before it could be implemented into the project vehicle. Table 20 lists the FEA results for Adapter Plate Simulation 4. 


\section{Table 20. Adapter Plate Simulation 4 Results}

\begin{tabular}{|r|c|}
\hline Maximum Von Mises Stress & $54.99 \mathrm{MPa}$ \\
\hline Minimum Safety Factor & 5 \\
\hline
\end{tabular}

Adapter Plate Simulation 4 produced a factor of safety of 5 , over two times the minimum requirement. Figure 34 displays the Von Mises stress for Simulation 4 . Similar to the previous simulations, the point of the maximum Von Mises stress of $54.99 \mathrm{MPa}$ was where the engine bolt hole is close to the inner radius surface. The remainder of the plate experienced stresses less than $10 \mathrm{MPa}$.

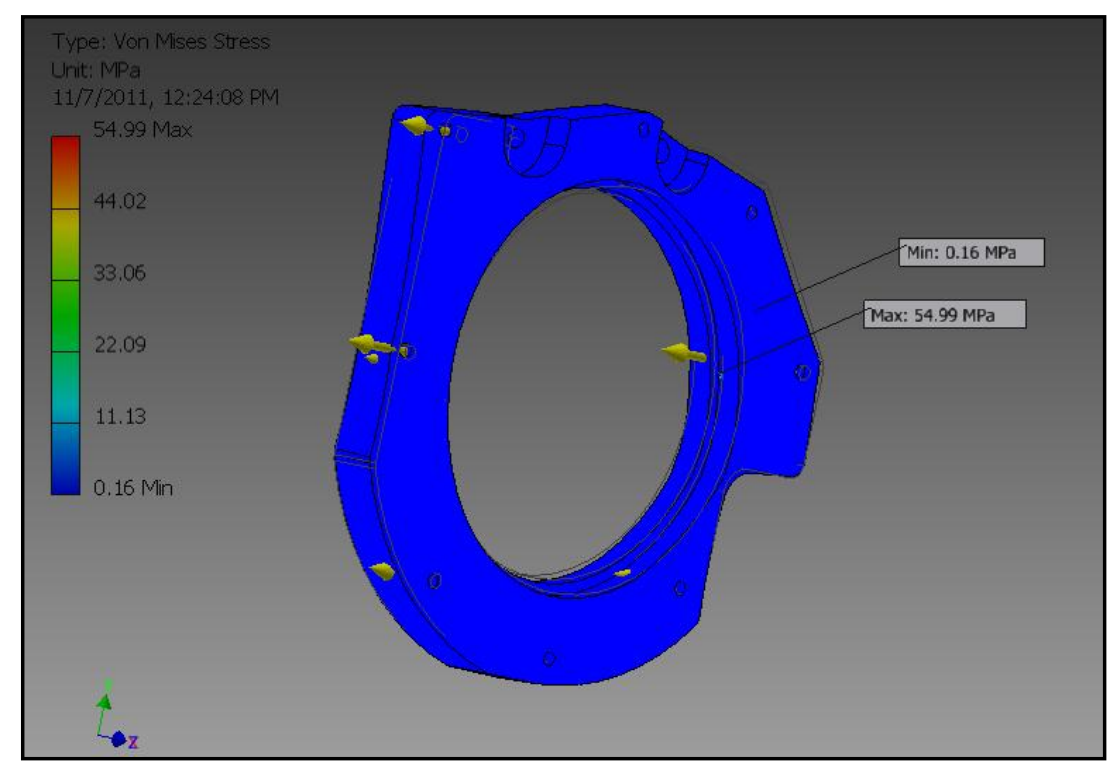

\section{Figure 34. Von Mises Stress for Adapter Plate Simulation 4}

Figure 35 displays the factor of safety results for Adapter Plate Simulation 4. In this orientation, the engine bolt hole that comes near to the surface of the inner radius can be seen below the minimum flag. 


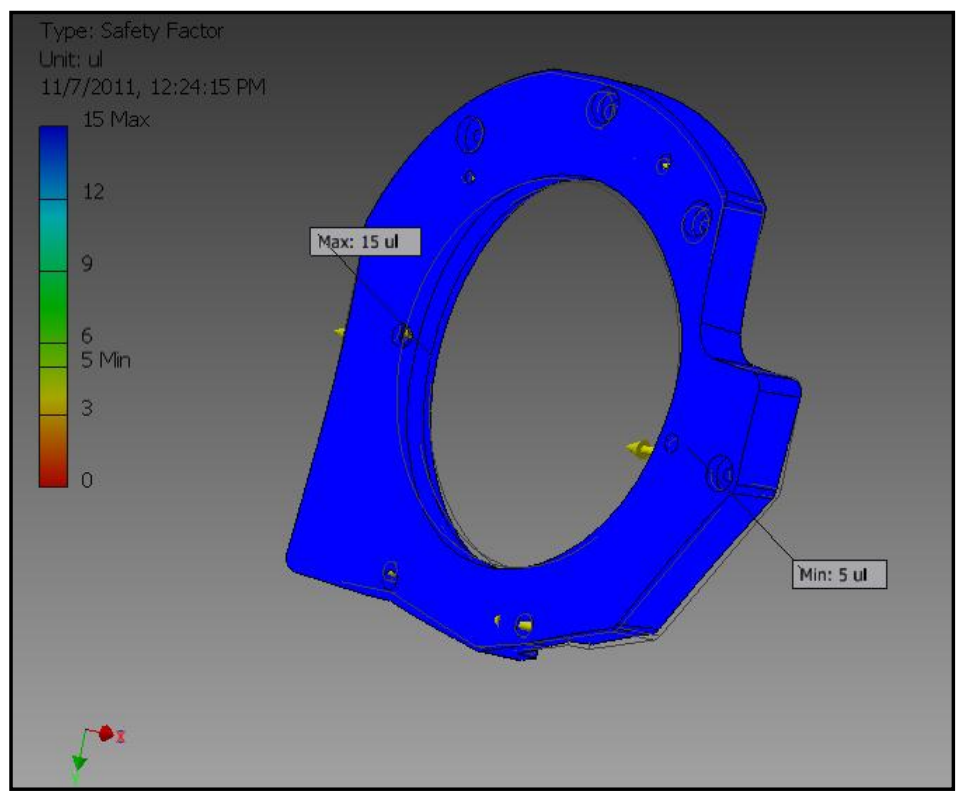

Figure 35. Safety Factor for Adapter Plate Simulation 4

Adapter Plate Simulation 5 simulated a torque being applied to the plate in the case where the engine is producing maximum torque but the transmission resists spinning. All bolt holes were fixed and a moment of $400 \mathrm{~N}-\mathrm{m}$, double the maximum torque output from the diesel engine, was applied to the inside of the plate. This resulted in a safety factor of 15 or greater for every point on the plate and thus was not an extreme case.

After performing these simulations, the minimum observed factor of safety was 4.82 encountered in Adapter Plate Simulations 1 and 2. This is more than double the minimum requirement. The adapter was stronger than needed because the physical geometry of the part dictated the design. The $40 \mathrm{~mm}$ adapter thickness was a critical dimension to properly engage the input shaft of the 2-mode transmission in the torsional damper bolted to the crankshaft of the engine. The $40 \mathrm{~mm}$ thickness was the reason that the transmission adapter exceeded the minimum factor of safety of 2 for every load case. Were the part ever redesigned, material could be removed from non-critical areas to reduce mass while maintaining an acceptable factor of safety.

\subsubsection{Front Engine Mount Strength Analysis}

The front engine mount was also analyzed for strength using Autodesk Inventor's FEA package for various load cases. The engine mount was designed to be machined from 6061 aluminum. The material properties used for 6061 aluminum are shown in Table 17 [14]. The front engine mount was analyzed under load cases similar to those used for simulating the transmission adapter in the previous section. For every simulation, the mount was constrained at the four bolt holes used to attach it to the engine block as well as the mating faces between the front engine mount and the engine block. Figure 36 displays the constraints used for the simulations. 


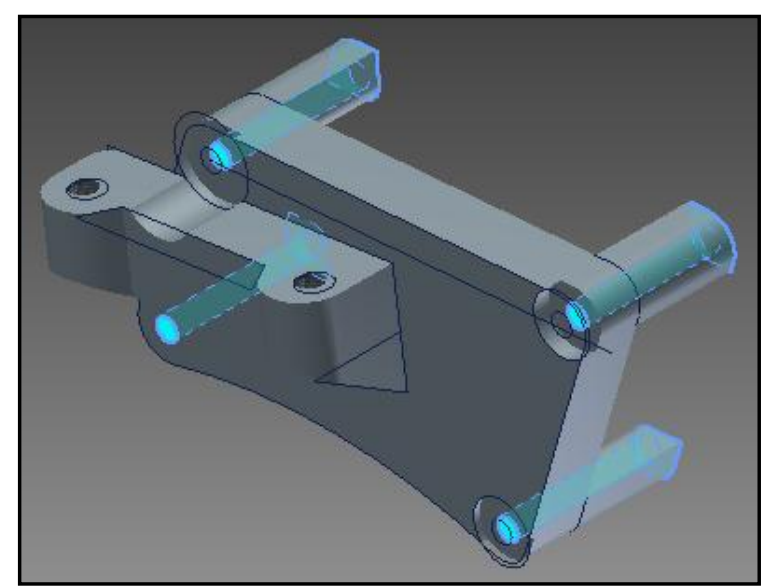

\section{Figure 36. Front Engine Mount Analysis Constraints}

Engine Mount Simulation 1 involved applying a vertical force upward on two bolt mounting pad used to attach the front engine mount to the frame of the project vehicle via a rubber-isolated mount. An acceleration of $8 \mathrm{~g}$ was used to simulate an extreme vertical impact such as driving over a parking block or high curb. Again, the entire weight of the engine and transmission $(318 \mathrm{~kg})$ was used, producing a total vertical force of $25 \mathrm{kN}$. Table 21 lists the results of Engine Mount Simulation 1.

\section{Table 21. Engine Mount Simulation 1 Results}

\begin{tabular}{|r|c|}
\hline Maximum Von Mises Stress & $55.08 \mathrm{MPa}$ \\
\hline Minimum Safety Factor & 4.99 \\
\hline
\end{tabular}

Engine Mount Simulation 1 was not a critical case as the minimum factor of safety more than doubled the required minimum of 2 . Figure 37 displays the stress distribution in the front engine mount in Engine Mount Simulation 1.

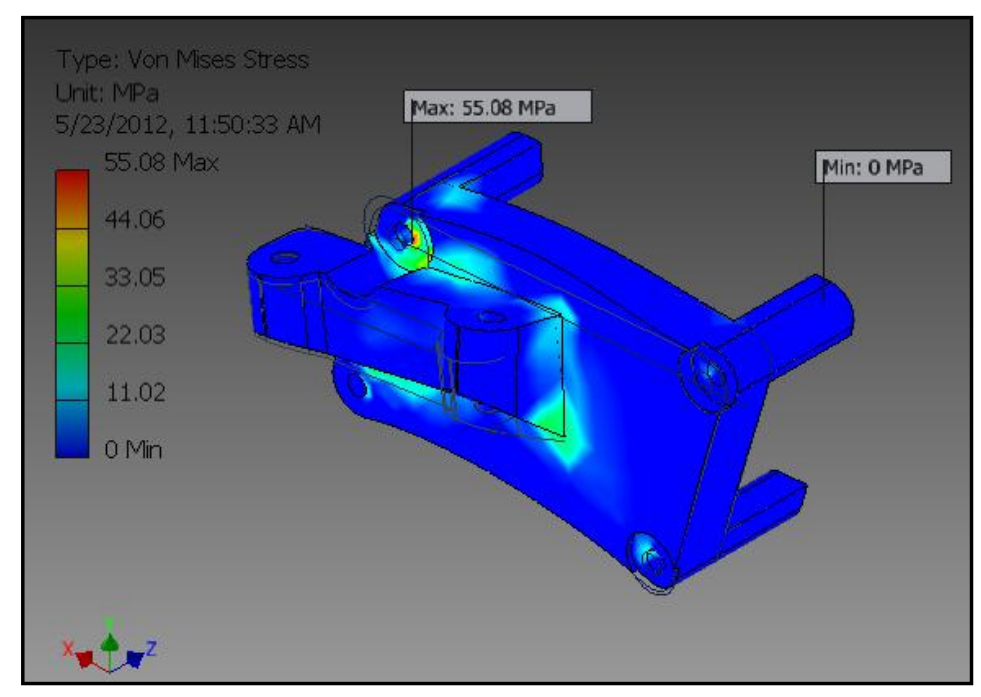

Figure 37. Von Mises Stress for Engine Mount Simulation 1 
The location of the maximum stress was at the edge of one of the upper mount-to-engine bolt holes. Most of the front engine mount was under stress less than $30 \mathrm{MPa}$. Figure 38 displays the factor of safety for every point on the front engine mount for Engine Mount Simulation 1. The front engine mount achieved a minimum factor of safety of 4.99 with the majority of the part exceeding 15 .

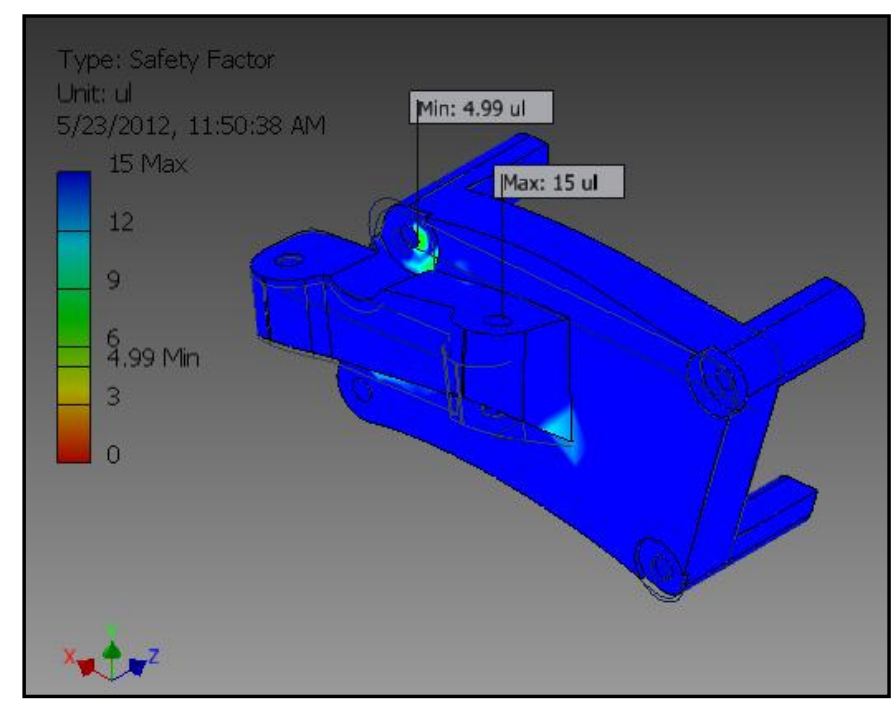

\section{Figure 38. Safety Factor for Engine Mount Simulation 1}

Engine Mount Simulation 2 involved simulating a collision with an immovable object. This was achieved by applying a $20 \mathrm{~g}$ impact force $(63 \mathrm{kN})$ only in the positive $\mathrm{x}$-direction. This condition was required to be simulated per the competition rules to get the GM engineers overseeing the design of the components to approve the design before it could be implemented into the project vehicle. Table 22 lists the FEA results for Engine Mount Simulation 2.

Table 22. Engine Mount Simulation 2 Results

\begin{tabular}{|r|c|}
\hline Maximum Von Mises Stress & $121.57 \mathrm{MPa}$ \\
\hline Minimum Safety Factor & 2.26 \\
\hline
\end{tabular}

Engine Mount Simulation 2 would prove to be the critical case of those tested, producing a minimum factor of safety of 2.26. Figure 39 displays the stress distribution in the front engine mount in Engine Mount Simulation 2. 


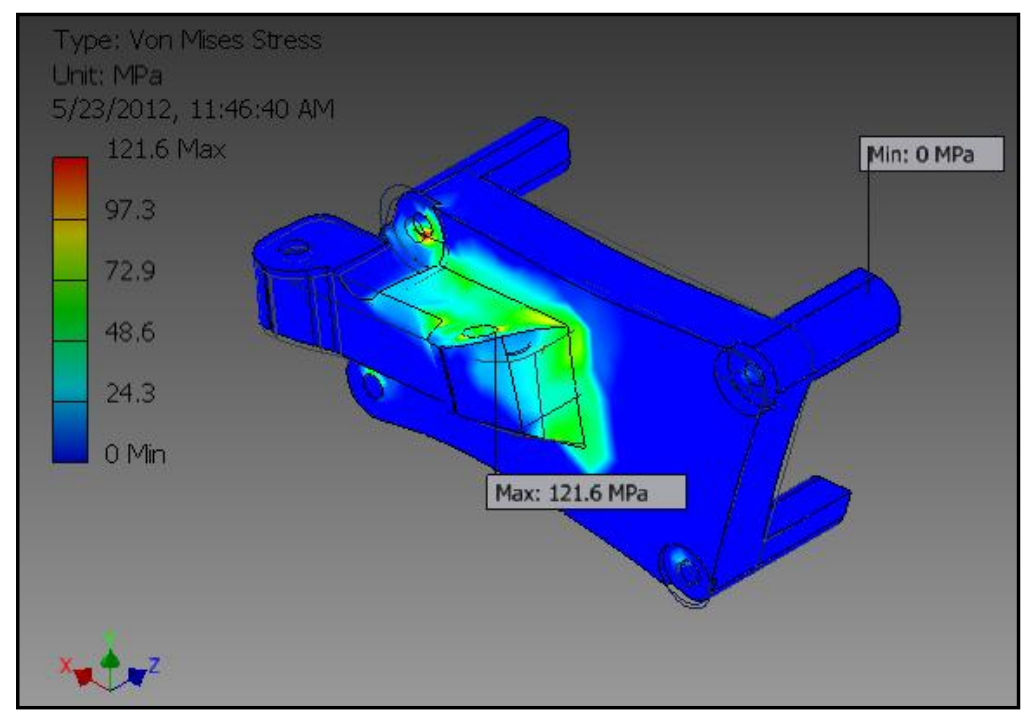

\section{Figure 39. Von Mises Stress for Engine Mount Simulation 2}

For Engine Mount Simulation 2, the stress was concentrated in the area where the mount-toframe mounting pad connected to the main vertical body of the front engine mount. With the $90^{\circ}$ angle between the two surfaces, this stress concentration was expected but could not be avoided due to the geometry of the rubber-isolated frame mount. To minimize this stress concentration, the lower surface of the mounting pad was designed to attach to the main body at a $45^{\circ}$ angle. Figure 40 displays the factor of safety for Engine Mount Simulation 2.

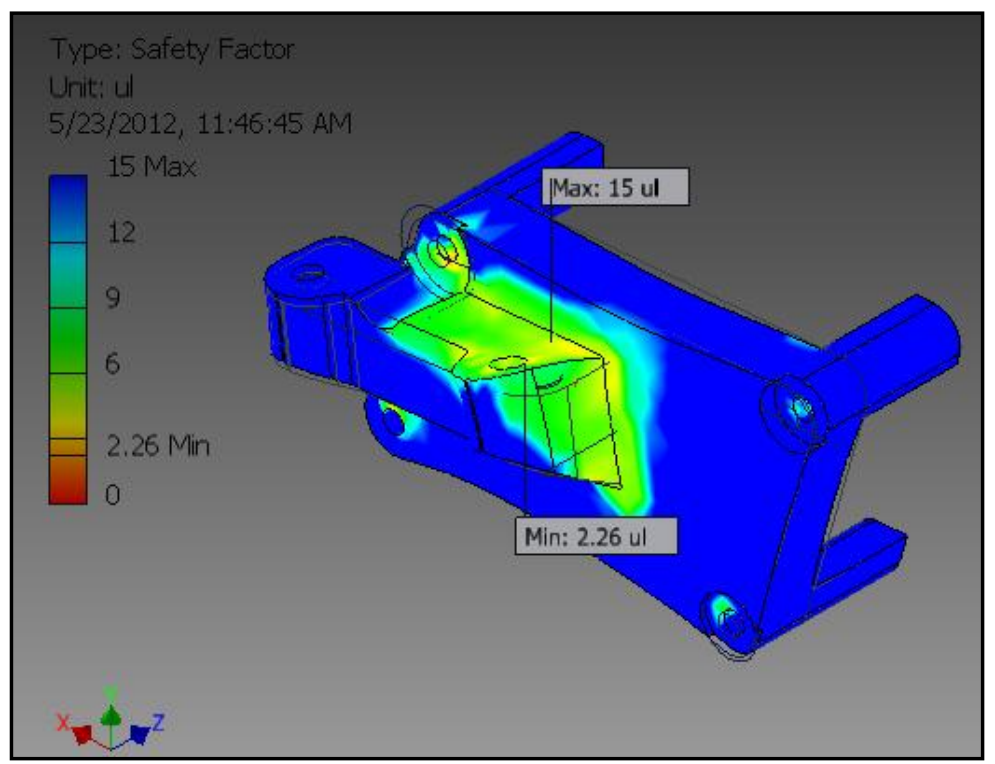

\section{Figure 40. Safety Factor for Engine Mount Simulation 2}

The minimum factor of safety of 2.26 was located at one of the frame-to-mount bolt holes. Similar to the stress distribution, the factor of safety of the mounting pad and the surrounding area indicated that this was the critical region of the front engine mount. While the main body of the front engine mount 
achieved a factor of safety of over 15, the mounting pad area averaged a factor of safety between 4 and 6. However, the minimum factor of safety exceeded the lower limit set by the competition organizers.

Engine Mount Simulation 3 involved applying the same $63 \mathrm{kN}$ force on the frame mounting pad at a $45^{\circ}$ angle. The force was aimed down toward the rear of the vehicle. Table 23 lists the FEA results for Engine Mount Simulation 3.

Table 23. Engine Mount Simulation 3 Results

\begin{tabular}{|r|c|}
\hline Maximum Von Mises Stress & $100.53 \mathrm{MPa}$ \\
\hline Minimum Safety Factor & 2.74 \\
\hline
\end{tabular}

This load case did not prove to be the critical case as it produced a minimum factor of safety of 2.74. However, this simulation was performed to investigate the effect of changing the angle of the $20 \mathrm{~g}$ impact force. While multiple angles were tested, Engine Mount Simulation 3 represents the most extreme case of those tested. Figure 41 displays the stress distribution for Engine Mount Simulation 3.

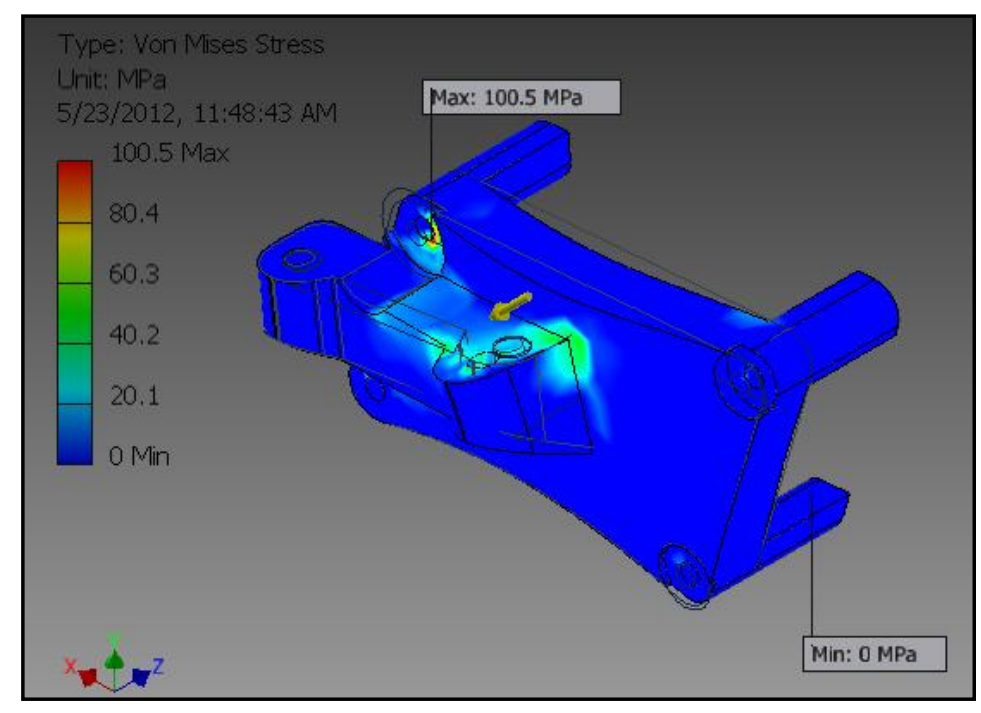

\section{Figure 41. Von Mises Stress for Engine Mount Simulation 3}

Similar to Engine Mount Simulation 1, the location of the maximum stress was the rear-most upper engine-to-mount bolt hole. Stress concentration again occurred where the frame mounting pad attached to the main body of the engine mount. However, the majority of the part was under stress less than $20 \mathrm{MPa}$. Figure 42 displays the factor of safety for Engine Mount Simulation 3. Similar to Engine Mount Simulation 2, lower factors of safety occurred around the area of the frame mounting pad. 


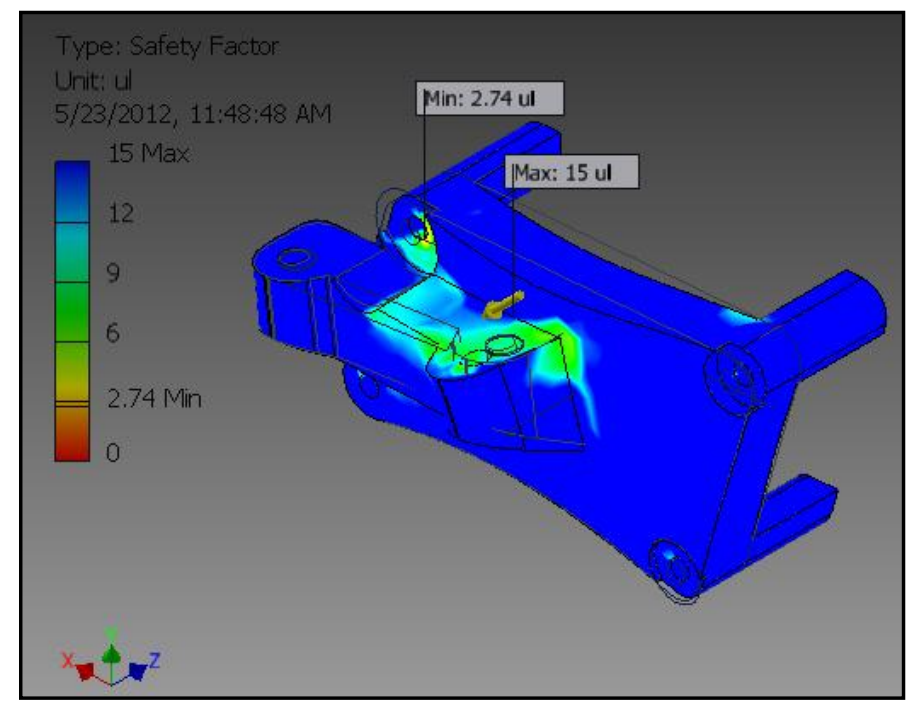

\section{Figure 42. Safety Factor for Engine Mount Simulation 3}

For Engine Mount Simulation 4, the engine-to-mount bolt holes were unconstrained and a moment of $400 \mathrm{~N}-\mathrm{m}$, double the maximum torque of the diesel engine, was applied to the mount. In addition, the total weight of the engine and transmission $(3.2 \mathrm{kN})$ was applied to the mount. This simulation was performed to verify that the front engine mount was capable of withstanding moment loads in the event that the engine and 2-mode transmission were producing maximum torque at the same time. Figure 43 shows the load setup for Engine Mount Simulation 4.

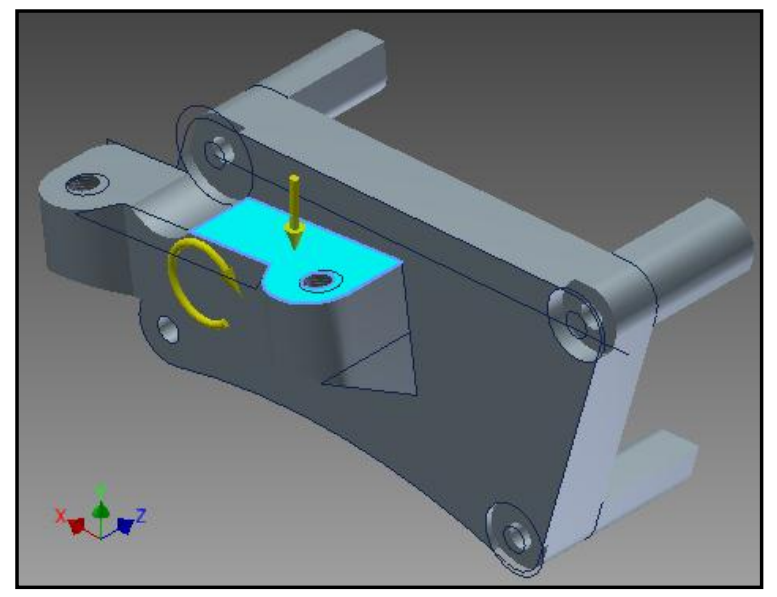

Figure 43. Engine Mount Simulation 4 Setup

Table 24 lists the FEA results for Engine Mount Simulation 4.

Table 24. Engine Mount Simulation 4 Results

\begin{tabular}{|r|c|}
\hline Maximum Von Mises Stress & $35.30 \mathrm{MPa}$ \\
\hline Minimum Safety Factor & 7.79 \\
\hline
\end{tabular}


Producing a minimum factor of safety of 7.79 , this did not prove to be a critical case. Figure 44 displays the stress distribution for Engine Mount Simulation 4.

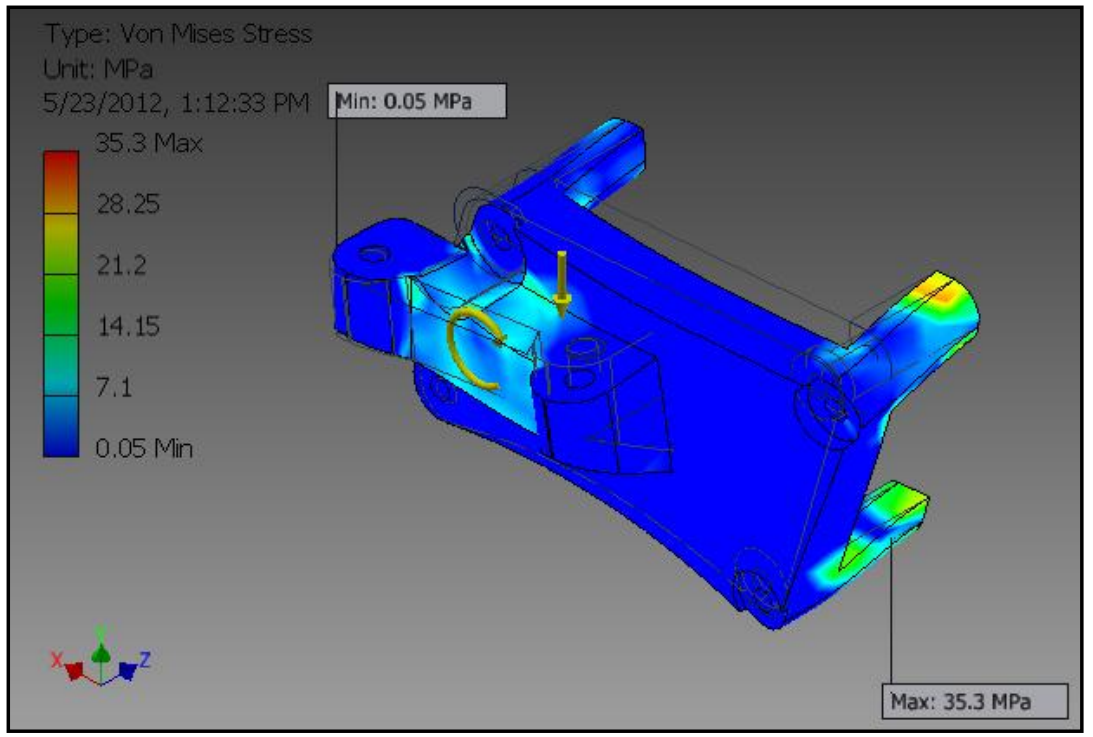

\section{Figure 44. Von Mises Stress for Engine Mount Simulation 4}

For this load case, the stress was mostly concentrated in the stand-offs attaching the mount to the engine block. However, the maximum stress of $35.3 \mathrm{MPa}$ was the lowest of all of the simulations. Aside from the location of the maximum stress, the factor of safety exceeded 15 for the majority of the part.

Through all of the simulations performed, the front engine mount proved to be well-designed and more than strong enough to function as-intended for the life of the project vehicle. The critical load case encountered in Engine Mount Simulation 2 involved a $20 \mathrm{~g}$ deceleration resulting from a frontal impact with a solid object. However, the resulting minimum factor of safety of 2.26 exceeded the minimum requirement and the design was approved and implemented into the project vehicle. The load cases examined for the front engine mount were extreme compared to the conditions the part would be subjected to as-installed. Similar to the transmission adapter, the mass of the front engine mount could be reduced through the removal of material from non-critical areas.

\subsubsection{Fuel Tank Frequency Analysis}

The modified fuel tank was analyzed for possible natural frequencies using ANSYS. This analysis was performed to verify that the sides of the aluminum fuel tank would not undergo displacements large enough to stress the welds to the point of failure in the event that a natural frequency was ever introduced. The lowest natural frequency was found to be around $460 \mathrm{~Hz}$ according to the ANSYS analysis. The maximum speed of the diesel engine was known to be $5000 \mathrm{rpm}$ or $83.3 \mathrm{~Hz}$ so the engine could not produce this natural frequency. The case examined was driving over highway rumble strips at a speed of $70 \mathrm{mph}$. 
The rumble strip frequency analysis was performed assuming the vehicle was traversing a West Virginia interstate at the posted speed limit. According to the West Virginia Department of Transportation (WV DOT), milled rumble strips on interstate highways are placed 5 inches apart with each indentation being 7 inches wide and between $1 / 2$ and 5/8 inches deep [17]. This would produce a frequency of one undulation per foot of vehicle movement. Were the vehicle travelling at a constant $70 \mathrm{mph}$ over WV DOT rumble strips, the fuel tank would experience a frequency of $102.67 \mathrm{~Hz}$, well below its $460 \mathrm{~Hz}$ natural frequency. For reference, a frequency of $460 \mathrm{~Hz}$ would be achieved if the vehicle were travelling at 313.6 mph which was mechanically impossible for the project vehicle to achieve. In addition, the presence of fuel inside the tank would aid in damping any frequencies imparted on the fuel tank.

\subsection{Components \& Integration}

Once the overall designs of the project vehicle and the compound-split hybrid architecture were finalized, the university acquired the 2009 Saturn Vue base vehicle in the Fall of 2009. Integration of new components and development of the control algorithm began soon afterward and by May of 2010, all major hardware components were installed in the vehicle.

\subsubsection{A123 Systems Battery Pack}

The new high-voltage battery was the first major component installed in the project vehicle. The battery pack consisted of four A123 Systems 25s2p modules connected in series. Each module consisted of 503.3 volt cells, two strings of 25 series cells connected in parallel. The new pack was located below the rear load floor behind the rear seats. Before the high-voltage battery enclosure could be integrated into the project vehicle, the high-voltage battery mount needed to be installed. Figure 45 is a photograph of the high-voltage battery enclosure mount installed in the project vehicle.

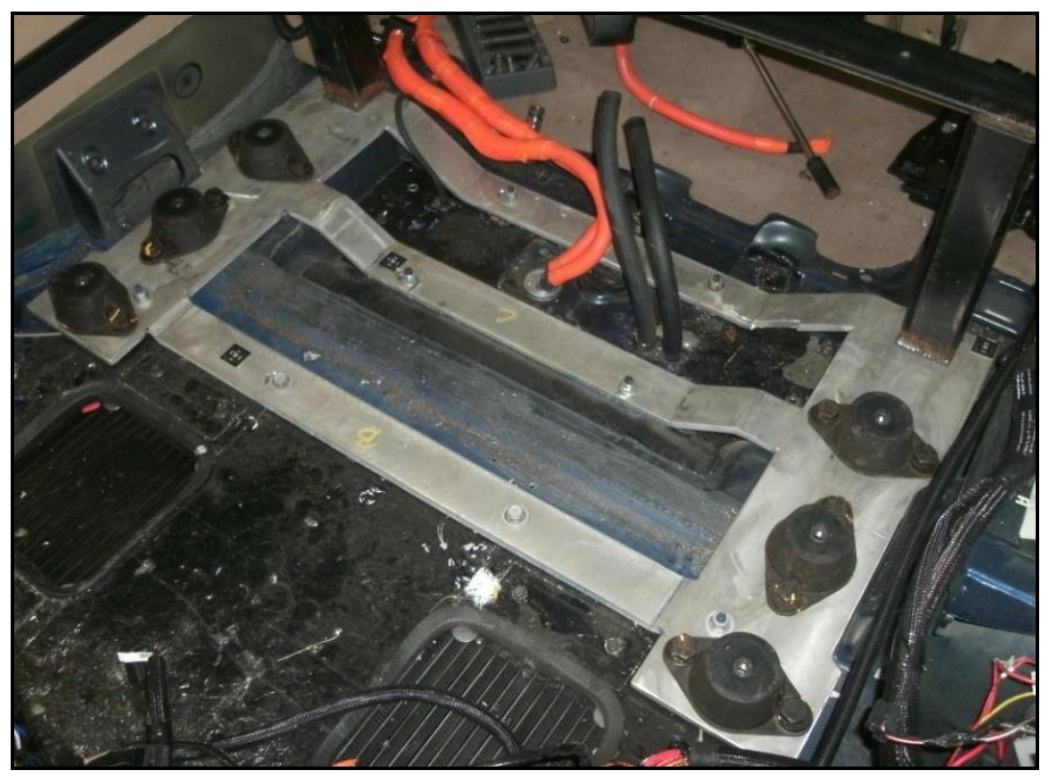

Figure 45. High-Voltage Battery Enclosure Mount 
The photograph was taken from the rear of the vehicle, through the opened lift-gate. The highvoltage battery enclosure bolted to the mount using the six black rubber mounting points shown in the figure. Once the enclosure was installed in the project vehicle, the various components comprising the high-voltage battery pack were installed including the four battery modules and the control components supplied by $\mathrm{A} 123$ Systems. The high-voltage battery pack was cooled by a liquid cooling system consisting of two cooling plates plumbed in parallel with a recirculation pump mounted to the vehicle's rear sub frame below the floor. Figure 46 shows the layout of the modules inside the battery enclosure and the locations of the liquid cooling plates.

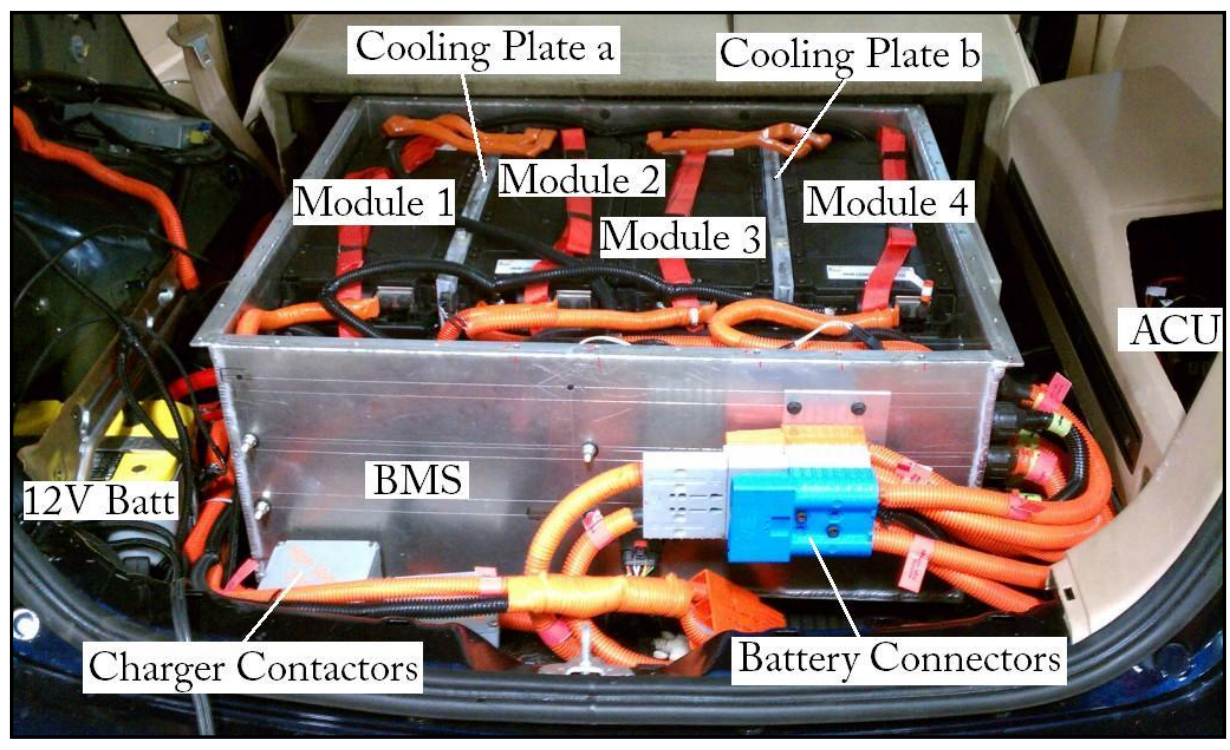

Figure 46. High-Voltage Battery Pack Layout

Each cooling plate cooled the two adjacent battery modules. A temperature sensor was attached to the surface of the left cooling plate to monitor the battery pack temperature to prevent overheating. Behind the battery connectors inside the enclosure were the battery pre-charge and main contactors. These were controlled by the BMS which determined whether the high-voltage battery pack was in a suitable state to be connected to the vehicle based on the integrity of the high-voltage interlock loop $(\mathrm{HVIL})$, the presence of a ground fault, and the state of charge (SOC) of the battery. If the vehicle was in a safe state, the hybrid control processor (HCP) would send a message to the BMS to close the main battery contactors and energize the high-voltage bus when the ignition key was turned to the Run position.

The after-treatment control unit (ACU) in the figure was a new controller installed to control the diesel exhaust after-treatment system. This computer also acted as a CAN communication gateway between the BMS and the HCP. The ACU was installed behind the rear wheel housing on the passenger side of the vehicle, underneath an interior panel. A conventional $12 \mathrm{~V}$ automotive battery was installed on the opposite side of the cargo area behind the other interior panel which was removed in the photograph. 
This $12 \mathrm{~V}$ battery supplied voltage to the conventional $12 \mathrm{~V}$ circuits in the project vehicle such as the interior and exterior lighting and the radio.

The HVIL was a low-voltage circuit that ran through all the high-voltage components in the vehicle. This circuit also ran through different safety devices in the vehicle including the inertia switch which acted as a crash sensor, the two emergency stop buttons installed in the vehicle, the under-hood hybrid system safety cover, and the battery's mid-pack disconnect (blue battery connector). The grey battery connector was the direct link between the high-voltage battery and the inverter module located at the front of the vehicle in the engine bay which inverted the high-voltage DC battery current to AC current to drive the electric motors in the 2-mode transmission. The charger contactors were always closed during normal vehicle operation. When the vehicle was powered down, these contactors would open to isolate the vehicle from the high-voltage battery. The function of these contactors was to keep the vehicle isolated from the battery during on-plug charging when the high-voltage battery's main contactors must be closed.

The orange battery connector was for the high-voltage battery charger located on the front of the battery enclosure directly behind the rear seats. A charger supplied by Brusa was installed in the vehicle to maintain the high-voltage battery SOC during development of the control strategy. There were periods during the design process when the engine was not capable of running or not installed in the vehicle. Once the project vehicle was fully functional, the on-board charger would be unnecessary because the engine and regenerative braking function would supply enough power to charge the high-voltage battery and maintain a safe SOC. Figure 47 is a photograph of the front of the high-voltage battery enclosure.

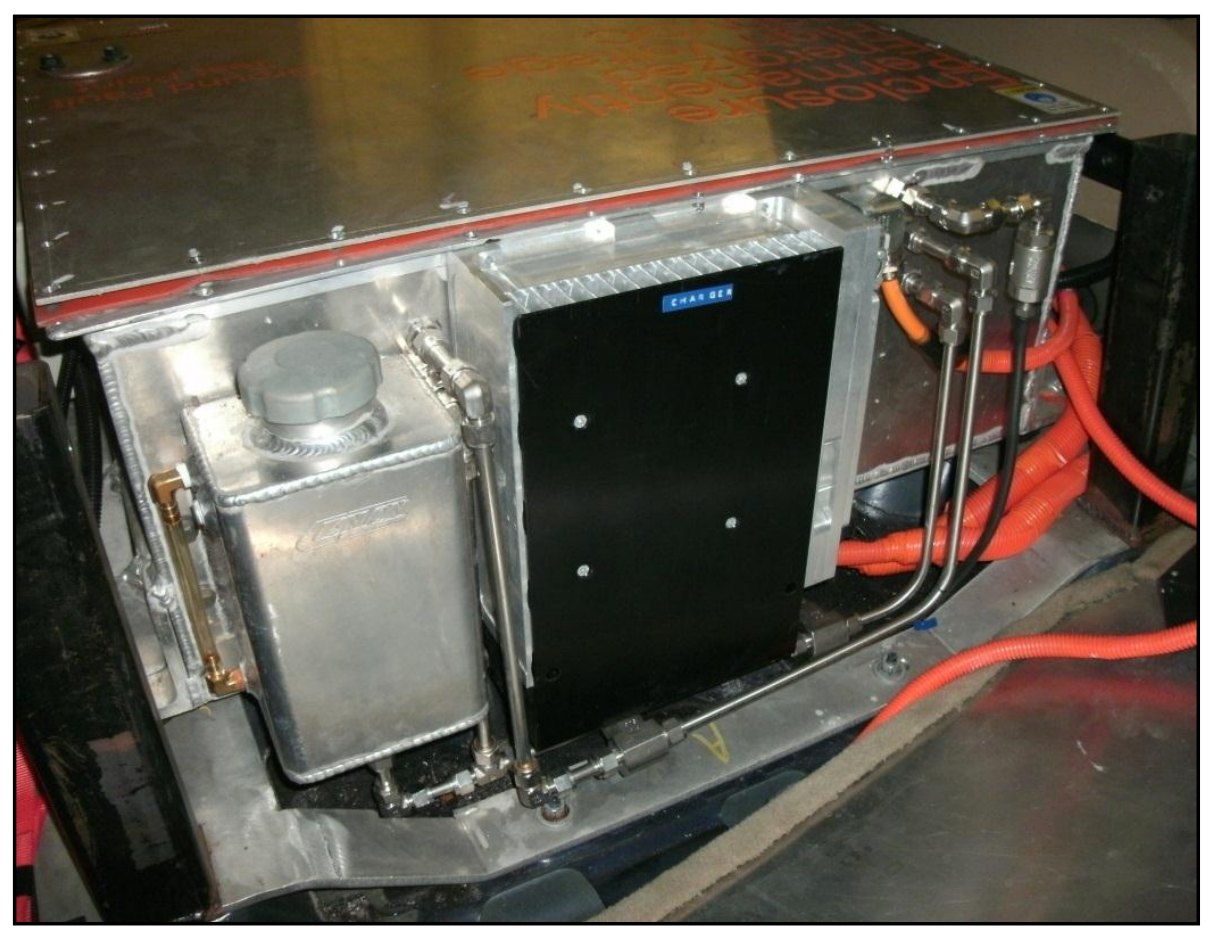

Figure 47. Front of High-Voltage Battery Enclosure 
The Brusa NLG-513 battery charger was bolted to the front of the enclosure with the overflow tank for the liquid cooling system mounted to the left. An aluminum firewall was fabricated to isolate all of the high-voltage components from the passenger compartment. This firewall attached to the two black steel posts on either side of the high-voltage battery enclosure in the photograph. The rear seats rested against this firewall when installed and upright. From this angle, the plumbing for the two cooling plates inside the battery enclosure can also be seen. The coolant lines from the cooling plates merged underneath the Brusa charger and ran through the floor to the coolant pump mounted under the vehicle. To dissipate the heat from the cooling system, two heat exchangers were installed in the floor under the battery enclosure. Figure 48 is a photograph of the cooling system components mounted to the bottom of the vehicle.

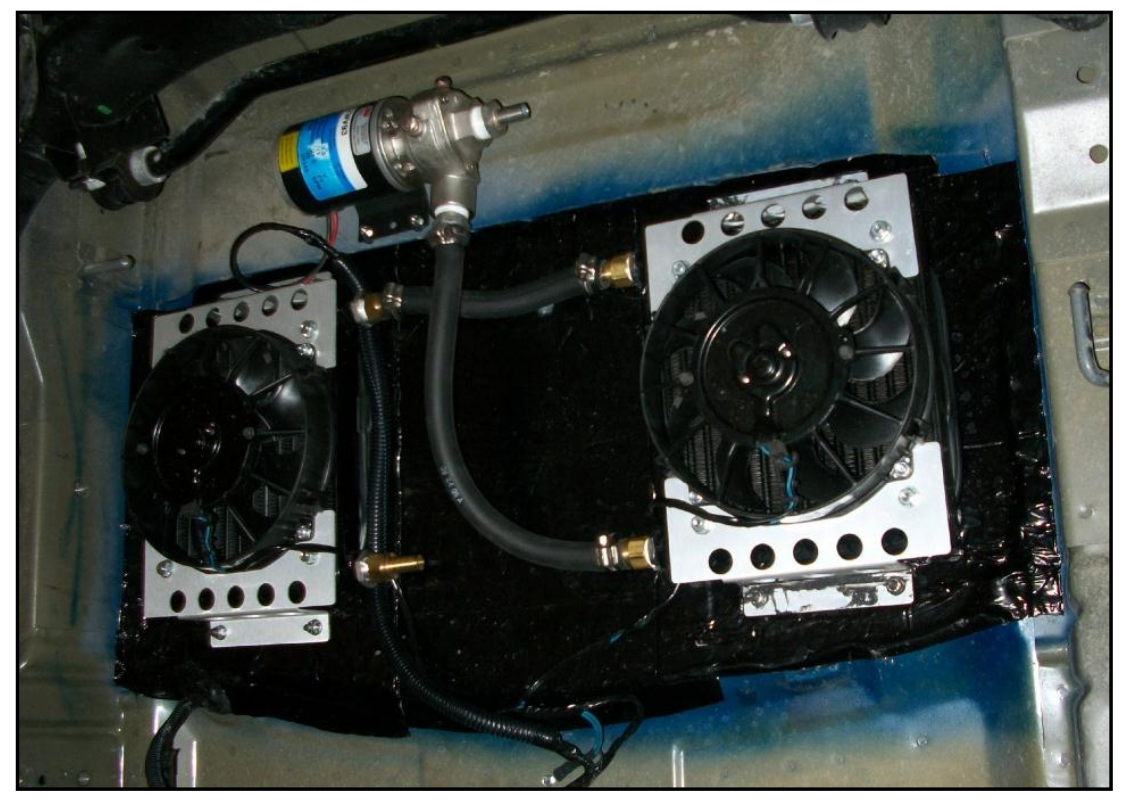

Figure 48. High-Voltage Battery Cooling System

The $12 \mathrm{~V}$ Dayton coolant pump was rated to flow 20 gallons per minute. The hot coolant from the cooling plates entered the left heat exchanger through the disconnected port. The coolant flowed out the left heat exchanger directly into the right heat exchanger before entering the coolant pump to be pumped back into the cooling plates. The electric fans pulled air from the interior of the vehicle through the heat exchangers. The coolant pump was relocated after this photograph was taken, but the system functioned in the same manner. Figure 49 is a photograph of the heat exchangers as they appear from inside the vehicle. 


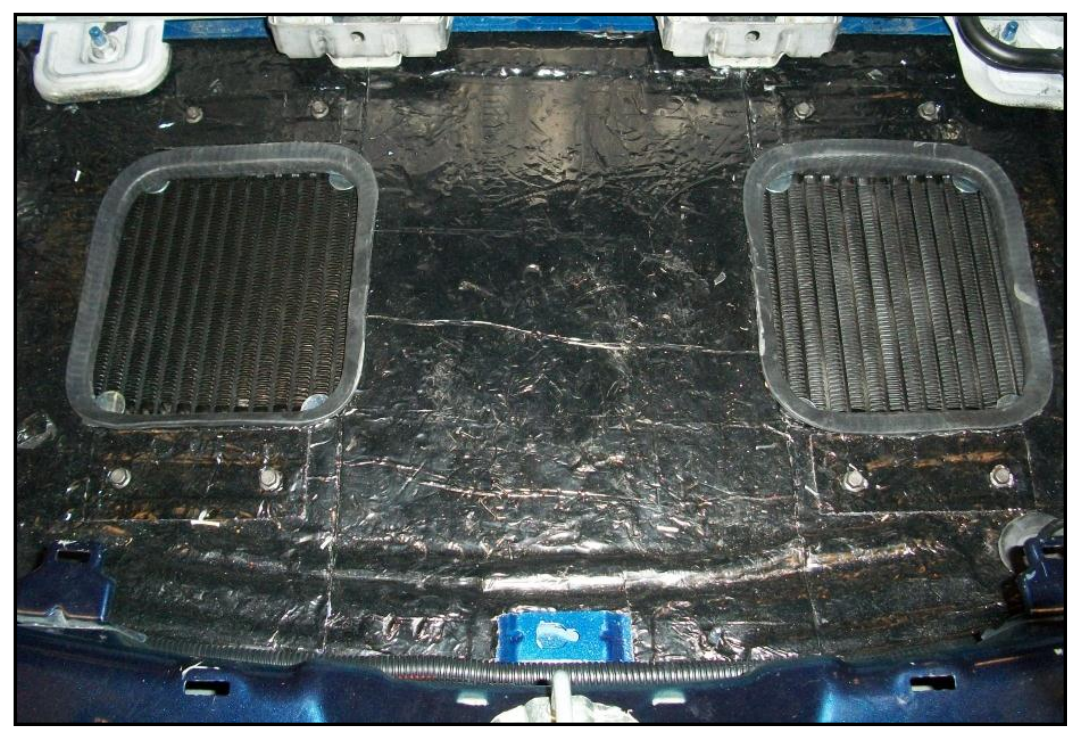

Figure 49. Heat Exchangers (Interior View)

Two holes were cut in the floor of the cargo area of the vehicle and rubber seals were applied to the edges of the holes. The heat exchangers were bolted to the floor and the high-voltage battery enclosure was installed over the heat exchangers. A four inch gap was left between the bottom of the high-voltage battery enclosure and the floor to allow sufficient airflow underneath the enclosure to reach the heat exchangers. In order to eliminate any chance of water, exhaust gas, or road debris from entering the vehicle through the heat exchangers, dampers were installed over the cooling fans. Figure 50 is a photograph of the heat exchanger dampers.

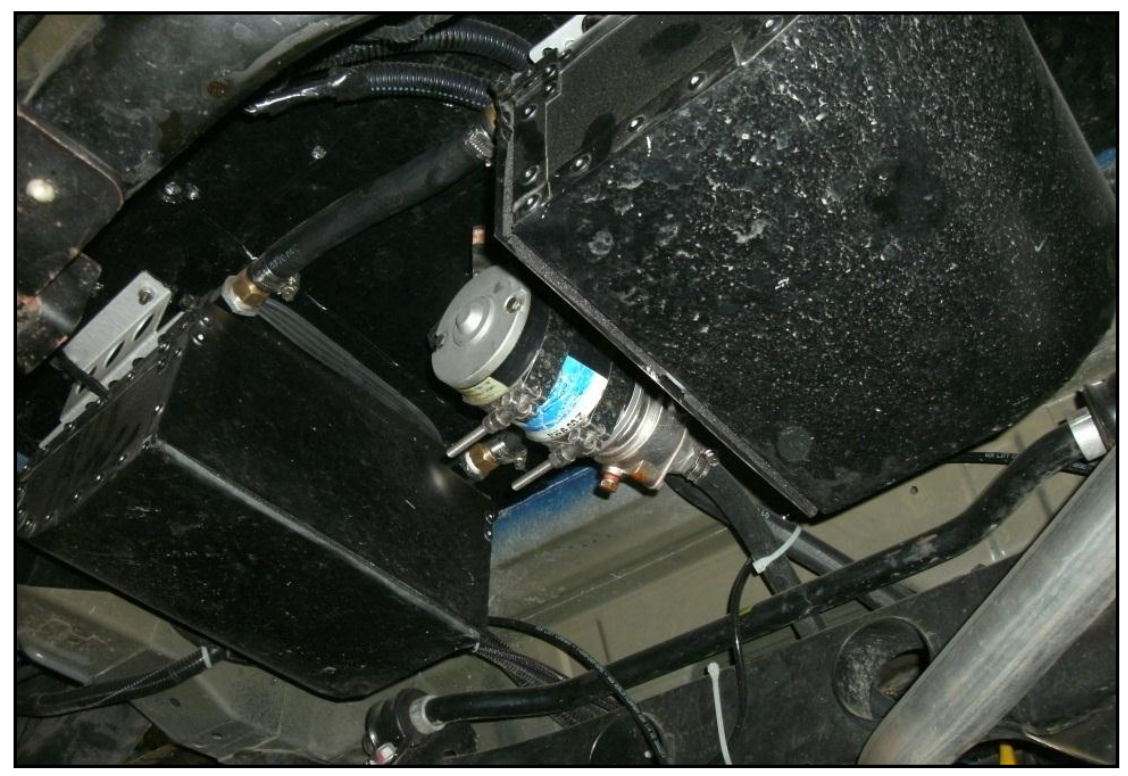

Figure 50. Heat Exchangers with Dampers Installed 
The dampers were constructed of thin gauge steel and riveted together. Flapper doors were installed with hinges at the top so that air could escape when the fans were turned on. The doors opened inward toward the center of the vehicle. Rubber gaskets around the flapper door openings sealed the dampers when the fans were off. The coolant pump was relocated in between the heat exchangers to make room for the electric winch used to raise and lower the fuel tank.

To maintain the cargo-carrying capability of the project vehicle, an aluminum cover was designed to sit on top of the high-voltage battery enclosure. This cover served two purposes: to protect the highvoltage battery and other components installed in the rear of the vehicle and hide these components from view. The battery cover was upholstered with carpeting matching the color of the carpet originally installed in the project vehicle. Figure 51 is a photograph of the cargo area of the vehicle with the battery cover installed.

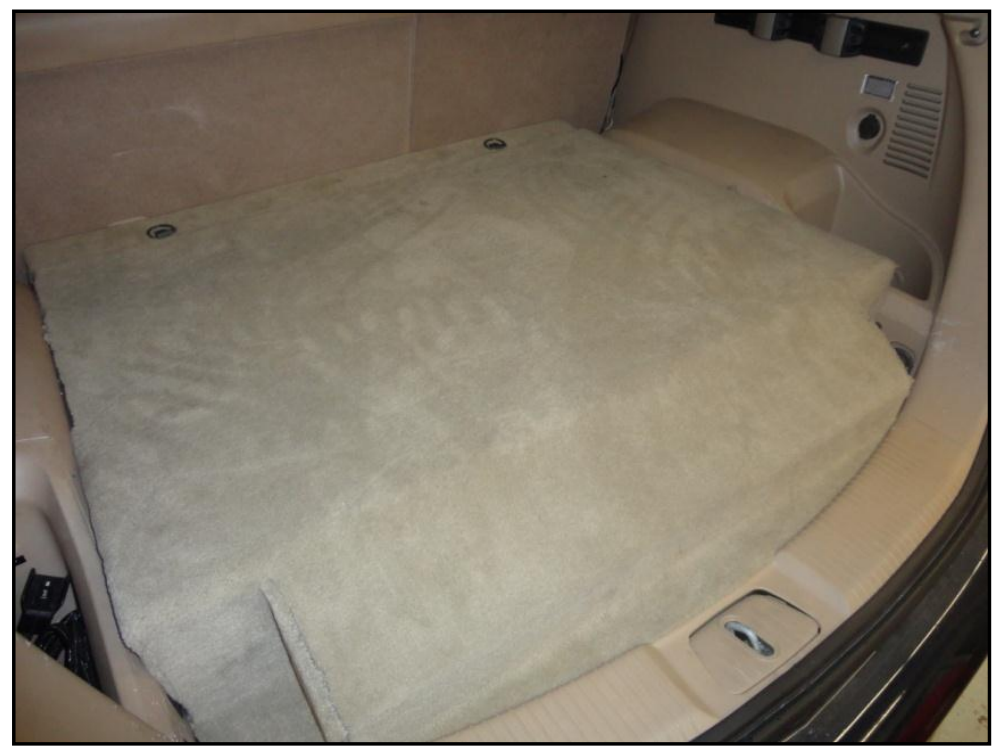

Figure 51. Project Vehicle Cargo Area

\subsubsection{GM 1.3 Liter Turbocharged Diesel Engine}

The diesel engine was the second major powertrain component installed in the project vehicle. The four cylinder 1.3 liter turbocharged diesel engine came from the European Opel division of General Motors and was originally installed in the 2008 Corsa model. Once the transmission adapter, front engine mount, and new flywheel were designed and machined, the diesel engine was installed in the project vehicle. Figure 52 is a photograph showing the locations of major components under the hood of the project vehicle. 


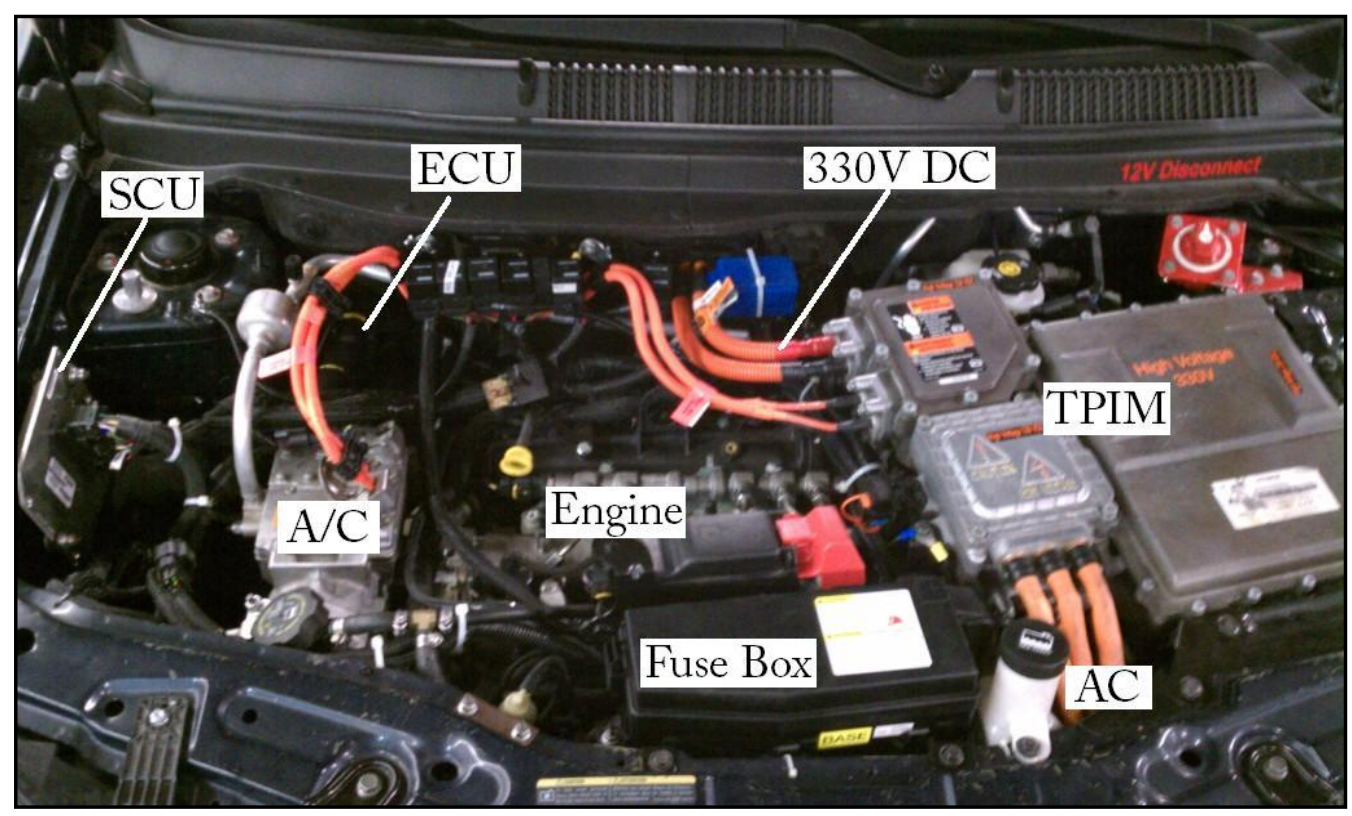

Figure 52. Engine Bay Integration

The engine was mounted transversely in the passenger side of the engine bay with the 2-mode transmission located to the right of the engine, under the Transmission Powertrain Inverter Module (TPIM). The TPIM controlled the power electronics to invert $330 \mathrm{~V}$ DC supplied by the lithium-ion battery to $275 \mathrm{~V} \mathrm{AC}$ to drive the two electric motors in the 2-mode transmission and to charge the high-voltage battery when the electric motors generated power during engine-on operation and through regenerative braking. Behind the TPIM was a disconnect switch for the $12 \mathrm{~V}$ electrical system. The air conditioning compressor was mounted to the left of the engine, just in front of the diesel engine's electronic control unit (ECU). Located on the inside of the passenger side fender was the supervisory control unit (SCU) which implemented the powertrain control algorithm and handled CAN communication between the engine, 2mode transmission, and high-voltage battery controllers. All of the orange wiring carried high-voltage.

The intercooler for the turbocharged diesel engine was initially intended to be installed in front of the radiator and condenser for the air conditioning system behind the front bumper. However, the decision was made to install the intercooler in front of the passenger side front wheel as this area was large enough and would allow equivalent airflow to the original location while decreasing the length of the required intake plumbing, thereby reducing the pressure drop from the turbocharger compressor outlet to the engine's intake manifold. Figure 53 is a photograph of the intercooler as it was installed in the project vehicle. 


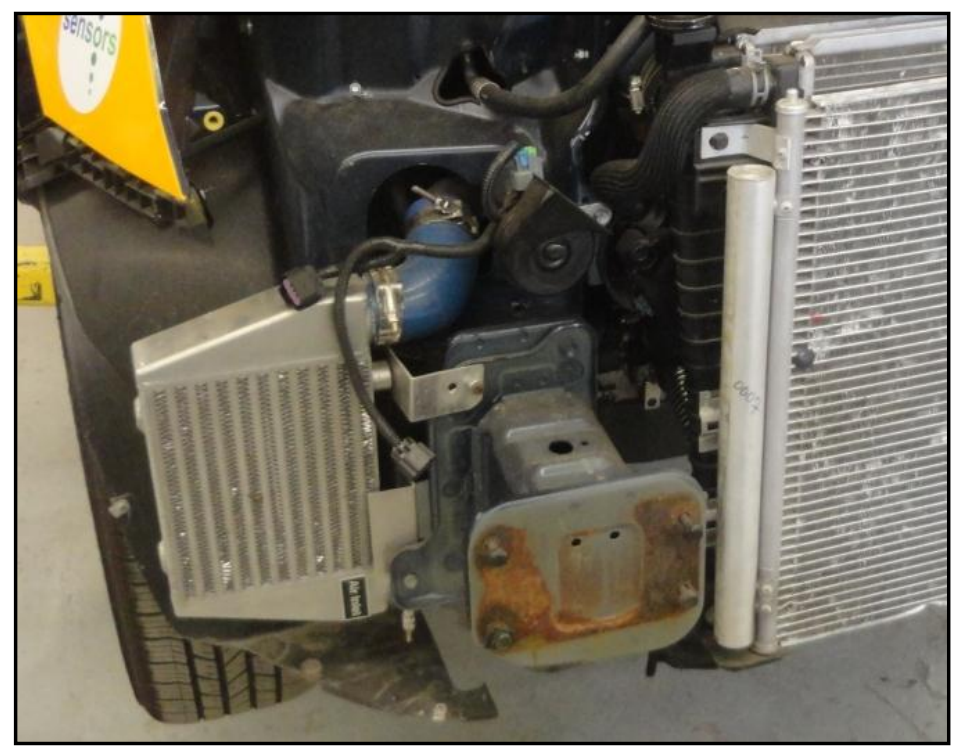

Figure 53. Intercooler As-Installed

To ensure that the intercooler received adequate airflow, the stock front bumper was replaced with the bumper designed for the 2009 Saturn Vue Redline model. This new bumper included large air intake ducts located directly in front of the intercooler. These ducts were enlarged and new grilles were designed and installed to maximize the airflow potential to the intercooler. Figure 54 is a photograph of the new air duct created for the intercooler. The intercooler can be seen through the grille. A matching opening was made on the driver's side of the front bumper to maintain aesthetic symmetry.

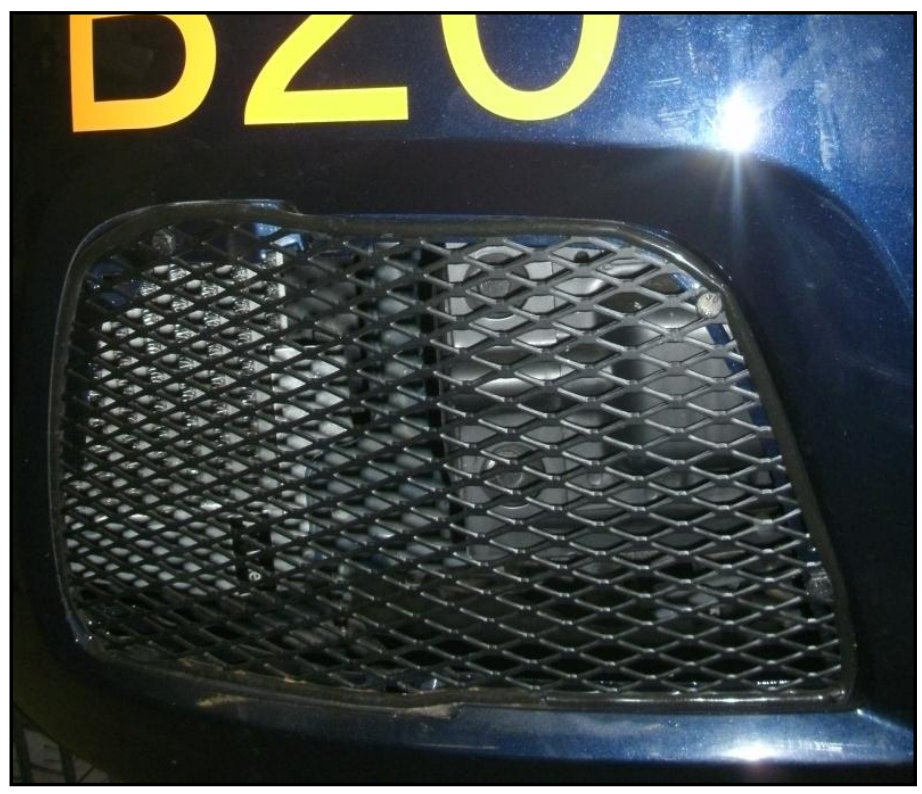

Figure 54. Intercooler Bumper Duct 


\subsubsection{Exhaust \& After-treatment Systems}

The new exhaust system was designed on the project vehicle and constructed one piece at a time starting at the engine. Once the routing of the exhaust tubing and the locations of the different components of the after-treatment system were set, the entire system was welded and tested for leaks. This was done by sealing one end of the system and pressurizing the system using compressed air. With the exhaust system pressurized, a mixture of soap and water was sprayed on the welds, causing any air leaks to produce bubbles. The exhaust system was required to be leak-free so that the after-treatment system would be as effective as possible. Completely sealing the exhaust system involved re-welding any leaks and testing the system again until no more leaks were present.

With the exhaust system free of leaks, final installation of the exhaust and after-treatment systems commenced. The exhaust system was installed using conventional rubber exhaust hangers. In the area where the exhaust was routed around the fuel tank, the fuel tank was wrapped with insulating material to prevent the exhaust from heating the diesel fuel inside the fuel tank. In addition, heat shields were installed on the bottom of the vehicle body above the locations of the DPF and SCR. Figure 55 is a photograph of the exhaust system as it was installed under the project vehicle.

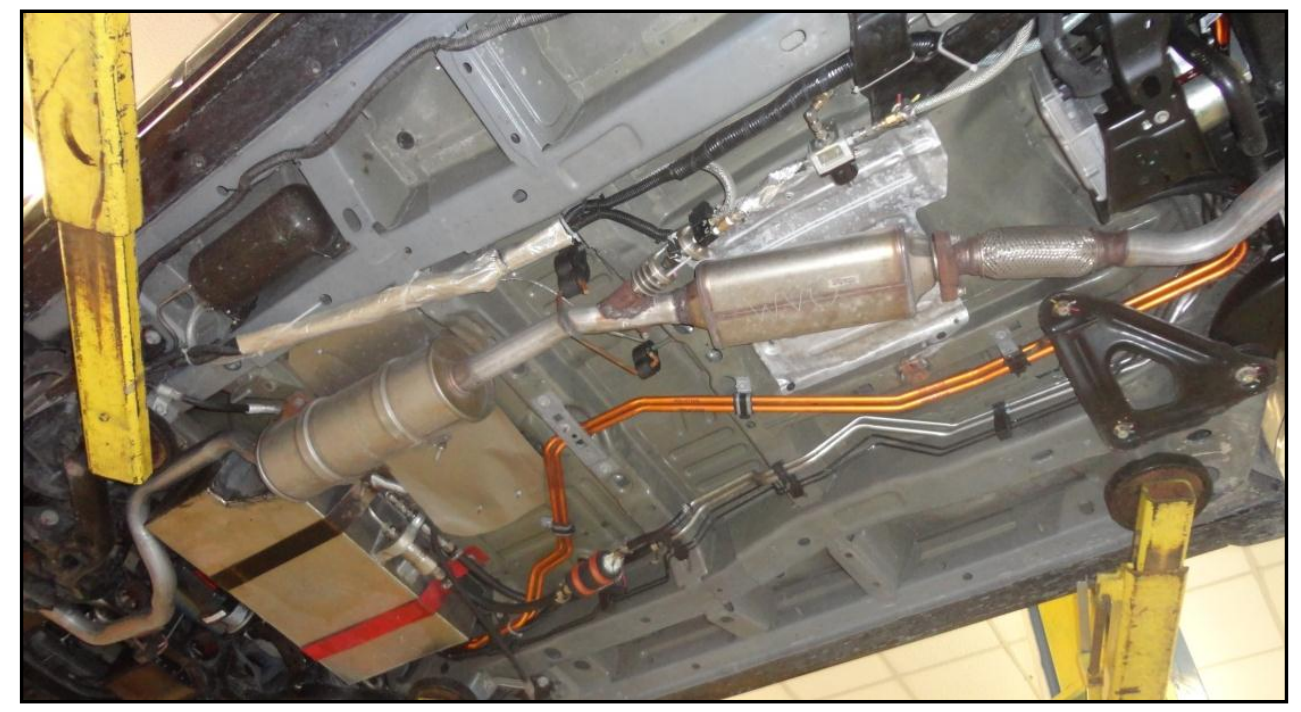

Figure 55. Completed Exhaust System

The urea injector for the selective catalytic reduction system can be seen installed ahead of the SCR catalyst. This injector was controlled by the after-treatment control unit installed inside the project vehicle. Using input from the thermocouple installed just ahead of the injector, the ACU would determine a urea dosing rate based on the engine speed, engine load, and exhaust temperature. Figure 56 is a close-up photograph of the urea injector and thermocouple. 


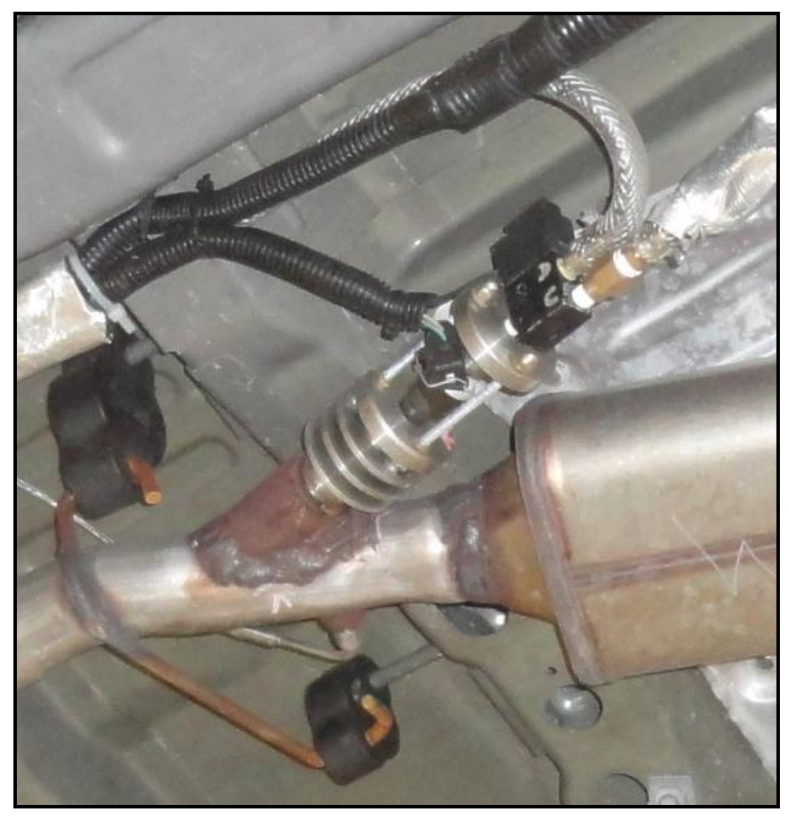

Figure 56. Urea Injection System

A urea storage tank was installed under the hood of the project vehicle. The urea system included an electric urea pump and a pressure regulator to limit the pressure delivered to the urea injector to no more than $60 \mathrm{psi}$. The urea injection system also included an air compressor and pressurized air tank that were used to clean the urea injector after shutting the vehicle down. Once the ignition key was turned to the off position, the ACU would command a solenoid in the urea injector plumbing to switch from the urea circuit to the air circuit, sending air pressurized to 90 psi through the injector to clean out any residual urea deposited inside. This was to prevent the urea injector from becoming clogged by crystallized urea were the project vehicle ever parked for an extended period of time. A pressure switch installed in the air storage tank would turn on the compressor and maintain a constant 90 psi inside the tank at all times.

\subsubsection{Fuel Tank}

Stainless steel tubing was bent to form the fuel feed and return lines that were permanently attached to the ports in the aluminum fuel tank. To maintain the ground clearance of the project vehicle, the bottom of the fuel tank was raised one inch by cutting a section out of each side of the tank. Additionally, a portion of the rectangular fuel tank was removed to allow ample room for the exhaust system to route toward the rear of the vehicle. Figure 57 is a photograph of the completed fuel tank. 


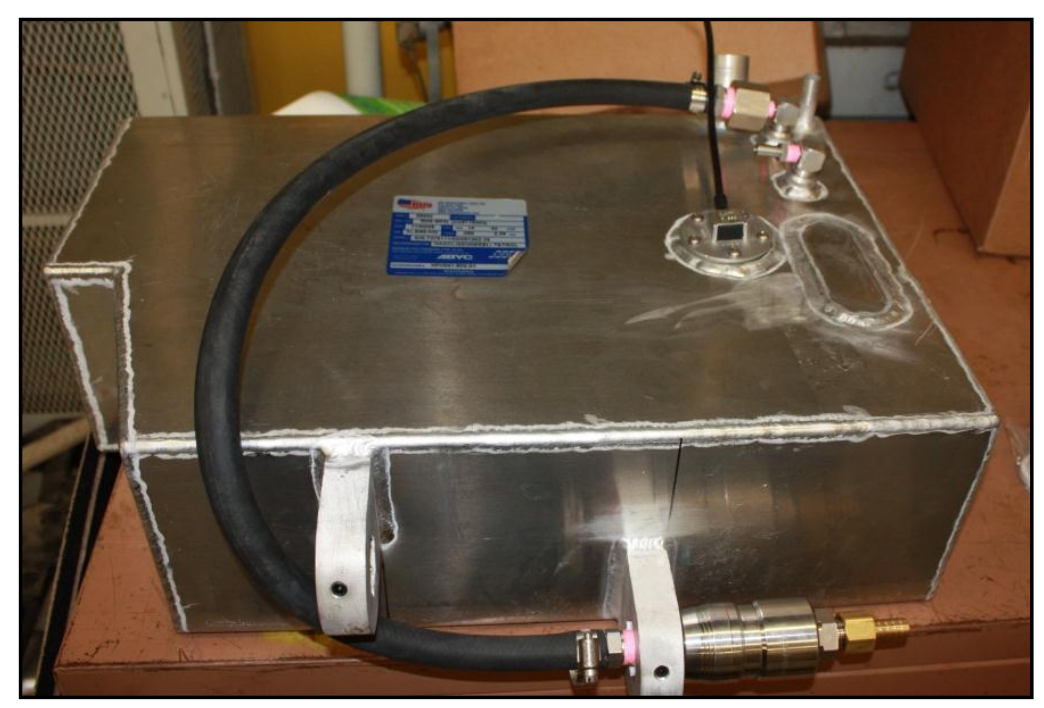

Figure 57. Modified Fuel Tank

Mounting points for the quick disconnects for the fuel feed and return lines were installed on the front of the fuel tank. The photograph was taken before all modifications were completed regarding fuel line plumbing and winch cable attachment. The lift cable from the electric winch attached to the fuel tank using a single attachment point located above the center of gravity of the fuel tank to maintain stability during removal and installation. This attachment point was located inside a depression in the top of the fuel tank to make room for the pulley bolted to the vehicle underbody over which the winch cable was routed. Figure 58 is a photograph illustrating the final configuration of the fuel line plumbing and cable attachment scheme.

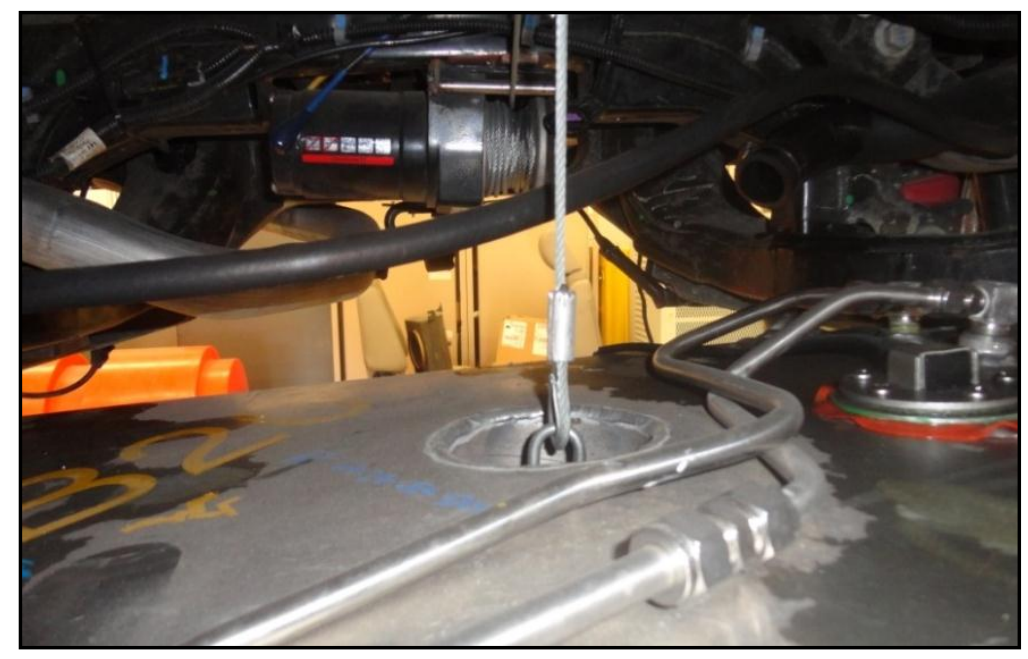

Figure 58. Fuel Tank Winch Cable Attachment

In order to install the new fuel tank in the project vehicle, a mounting system needed to be developed and implemented. In addition, the electric winch used to raise and lower the tank required a system of pulleys to lift the tank correctly. The first step in integrating the new fuel tank involved installing 
rubber bumpers on the bottom of the vehicle's body against which the fuel tank would be secured. Three rubber suspension bump stops were modified and bolted to the vehicle's underbody above the location where the fuel tank would be installed. Figure 59 is a photograph of the fuel tank mounting pads.

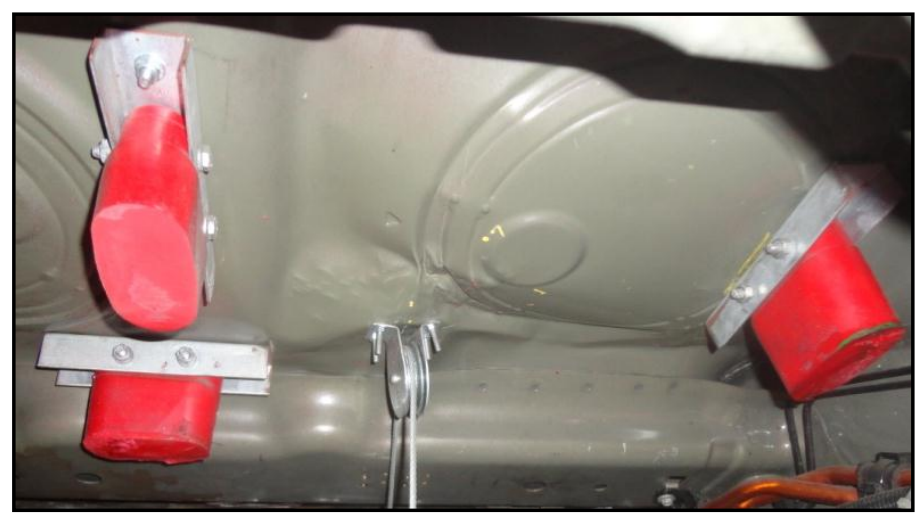

Figure 59. Fuel Tank Mounting Pads

Once the mounting pads were modified and installed, the electric winch and pulley system was designed. Because space above the fuel tank was limited, the winch was installed behind the fuel tank under the project vehicle and a pulley was installed above the center of gravity of the new fuel tank. The winch cable was routed over the pulley and attached to the fuel tank using a quick-disconnect. Once these were installed, the fuel tank was put in place and new fuel tank installation straps were bent to follow the shape of the fuel tank. Figure 60 is a photograph of the new fuel tank installed in the project vehicle.

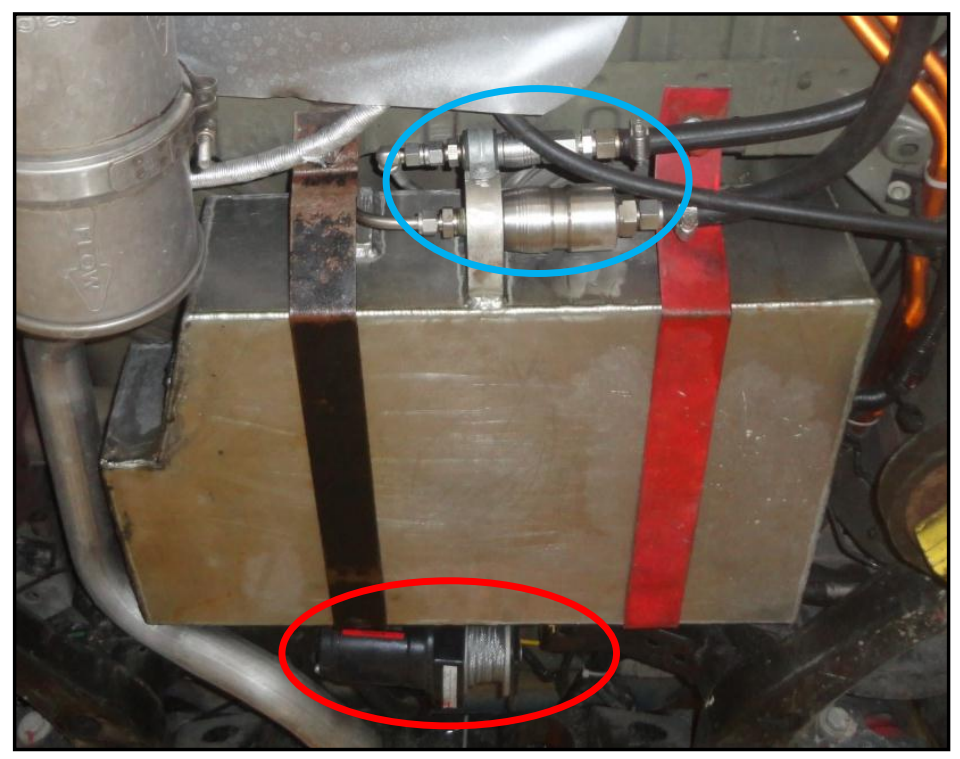

Figure 60. Modified Fuel Tank As-Installed

The electric winch is circled in red and the fuel line quick-disconnects are circled in blue. The exhaust was routed to the left of the fuel tank, around the modified corner. A switch to toggle the winch 
on and off was installed in the cargo area of the project vehicle and the control switch wiring was extended so that the winch could be operated from a safe distance when the vehicle was raised on a vehicle lift. Figure 61 is a photograph of the location of the winch power toggle and control cable.

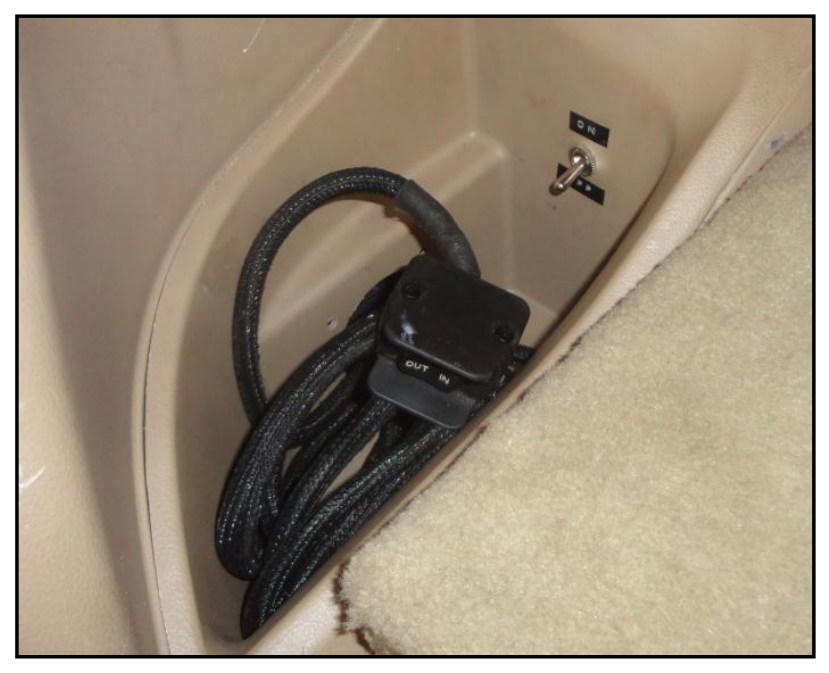

Figure 61. Fuel Tank Winch Controls

\subsubsection{Controllers}

Two new programmable electronic controllers were installed in the vehicle to implement the control algorithm written to control and monitor the operation of the compound-split hybrid powertrain. Supplied by Woodward/Mototron, the new controllers were capable of receiving analog voltage inputs as well as digital inputs and communicating with the project vehicle systems through CAN. The control modules were also capable of sending voltage signals to control relays to turn other components in the vehicle on or off. One of the new controllers was installed as a CAN gateway between the production vehicle's CAN network and the new diesel engine and the other controller served a similar purpose for the high-voltage battery system.

The supervisory control unit implemented the newly-developed powertrain control algorithm. Receiving accelerator and brake pedal inputs from the driver and using CAN information regarding vehicle speed and transmission status, the SCU would determine when to turn the engine on or off, the desired engine speed, and when to shift the transmission. This controller was installed between the two CAN networks in the production vehicle and the new CAN network installed for the additional control modules. Figure 62 is a photograph illustrating the location of the SCU under the hood of the project vehicle. 


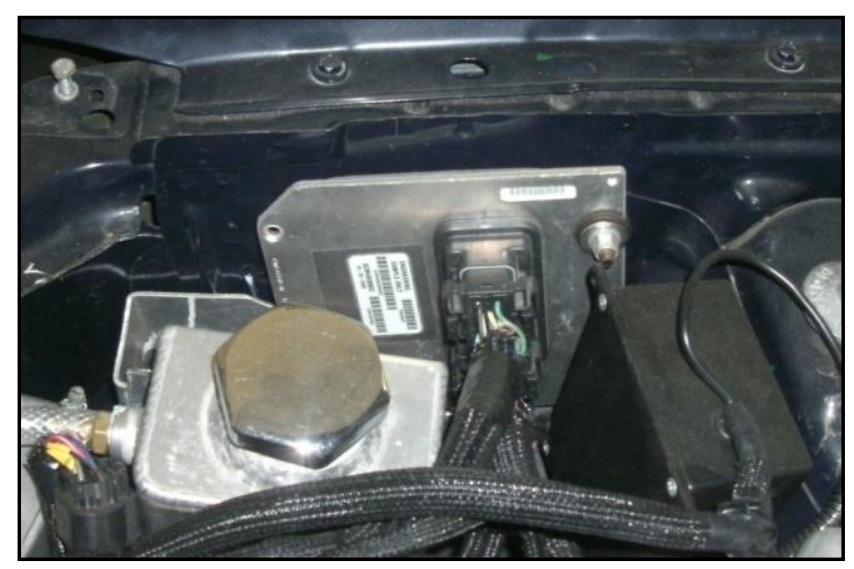

Figure 62. SCU Location

The SCU was installed on the inside of the passenger front fender just ahead of the shock tower. The Mototron controllers were water-tight facilitating installation in any location so the under-hood location was selected for its proximity to both the engine ECU and the two CAN buses installed in the project vehicle. The SCU was installed using rubber vibration damping mounts bolted directly to the body of the project vehicle. This location allowed easy access to the controller and offered protection from any road debris that may have entered the engine bay while driving.

The after-treatment control unit communicated with the high-voltage battery and also controlled the urea injection system in the exhaust. This controller was utilized as a CAN communication gateway between the high-voltage battery system and the rest of the vehicle. It was also used to control different relays for powering the fuel pump as well as the coolant pump and electric fans for the high-voltage battery's liquid cooling system. The ACU was installed behind the passenger side interior panel in the cargo area of the project vehicle. Figure 63 is a photograph of the ACU installed in the vehicle. The after-treatment control unit is circled in red.

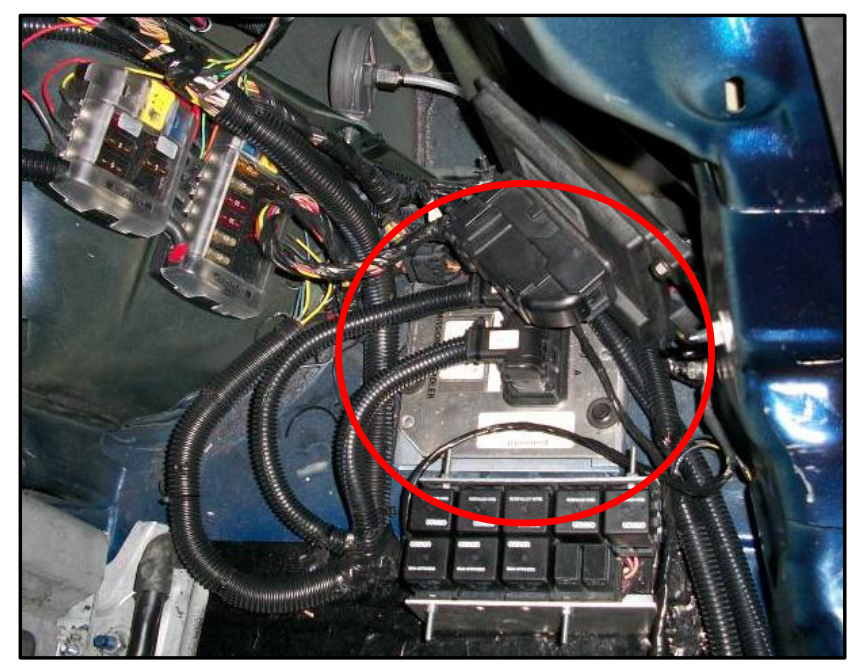

Figure 63. ACU Location 


\subsubsection{Safety Components}

\subsubsection{Information Displays}

In order to give the driver of the project vehicle important information regarding the state of the high-voltage system, auxiliary information displays were developed and installed. A seven inch screen was installed on top of the dashboard above the radio to display high-voltage battery information. The display was designed to show the state of charge and temperature of the high-voltage battery using Vector software. The large screen also displayed the presence of a ground fault being detected in the high-voltage system. All of the information displayed on the screen was read from the vehicle's CAN communication. Figure 64 is a photograph of the display screen as it was installed in the project vehicle.

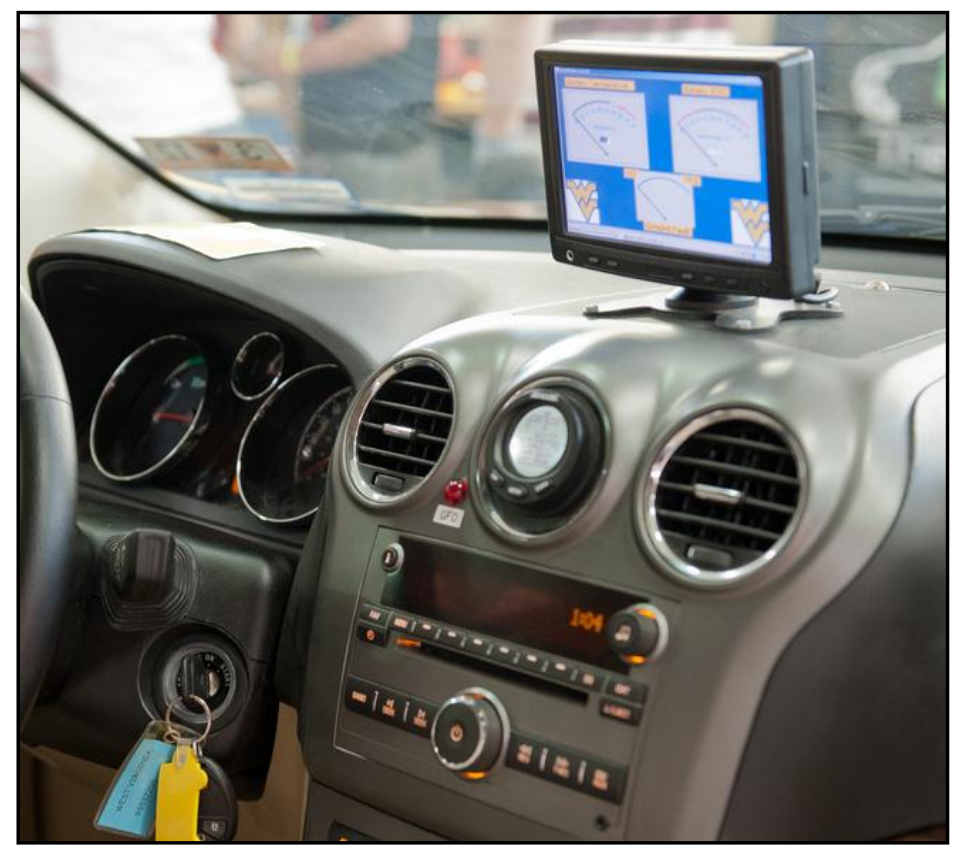

Figure 64. Auxiliary Information Display

The photograph also shows the location of the red ground fault detection warning light directly above the radio display. The presence of a ground fault could be very dangerous to any person in or around the project vehicle so a redundant warning system was implemented. A ground fault would occur if the high-voltage circuit were to ever short to ground which was the chassis of the project vehicle. The center air vent was eliminated and replaced with another display screen. The center vent display gave the driver information regarding instantaneous current flow into and out of the high-voltage battery as well as a GPS-based vehicle speed.

\subsubsection{Regenerative Braking \& After-treatment Disable Switches}

A toggle switch was installed within reach of the driver to disable regenerative braking. When the brake pedal was depressed, the powertrain control algorithm would request that a certain percentage of 
the braking torque be generated by one of the electric motors in the 2-mode transmission, converting the braking energy into electricity to be stored in the high-voltage battery. The remaining braking torque was supplied by the vehicle's conventional hydraulic disc brakes. A simple toggle switch was used to completely disable this blended braking so that all braking torque was applied by the vehicle's conventional brakes when the regenerative brake disable switch was activated.

Ammonia slip occurs when some or all of the urea that is injected into the exhaust is not consumed in the SCR process and allowed to exit the tailpipe. Unconsumed urea has the capability of destroying sensitive emissions testing equipment. If the operator of the emissions test detected ammonia in the exhaust emissions, the switch could be tripped, disabling the urea injector and all its associated components. Figure 65 is a photograph of both the regenerative braking and after-treatment disabling switches.

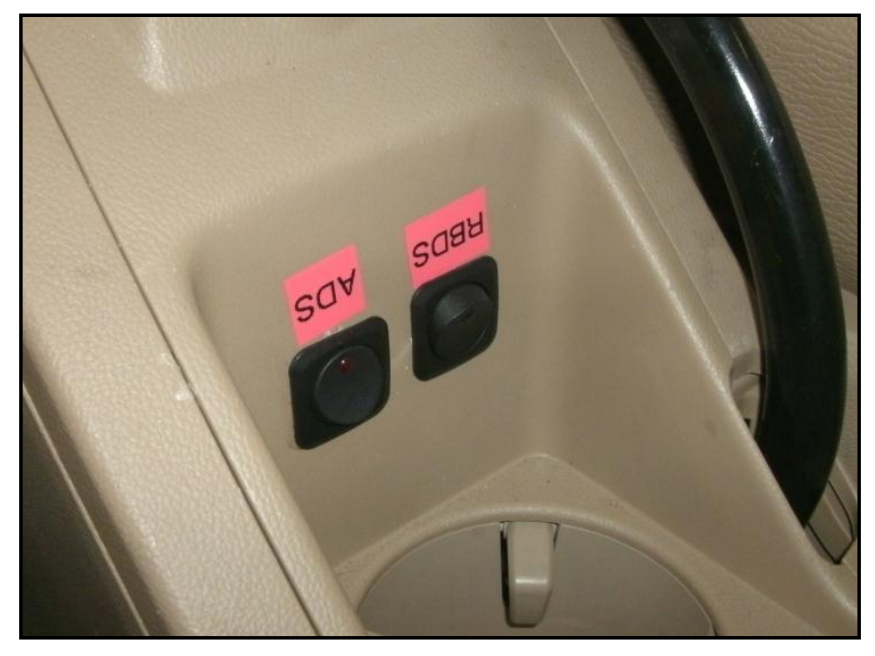

Figure 65. Disable Switches

Both of the disable switches were installed above the cup holder in the center console between the front seats in the project vehicle where the driver could have access while belted into the driver's seat. In the photograph, the after-treatment disable switch on the left is activated thereby disabling the urea injection system in the exhaust.

\subsubsection{Inertia Switch \& Emergency Stop Buttons}

As a prototype vehicle, it was desirable to have a method of quickly disabling the engine and high-voltage systems in the event of a fault. To accomplish this function, two emergency stop buttons were installed in the project vehicle. The emergency stop buttons were wired in such a manner that depressing one or both of them cut power to the engine ECU and fuel pump as well as breaking the highvoltage interlock circuit which would disable the entire high-voltage system and open the contactors in the lithium-ion battery pack.

One emergency stop button was installed on the passenger side quarter panel so that someone standing outside of the vehicle could disable the engine and high-voltage systems in the event of a fault. 
The other emergency stop button was installed to the left of the steering column within reach of the belted driver. These two emergency stop buttons were wired in series. Figure 66 is a pair of photographs of the two emergency stop buttons. The picture to the left shows the driver's emergency stop button with the exterior button shown on the right.

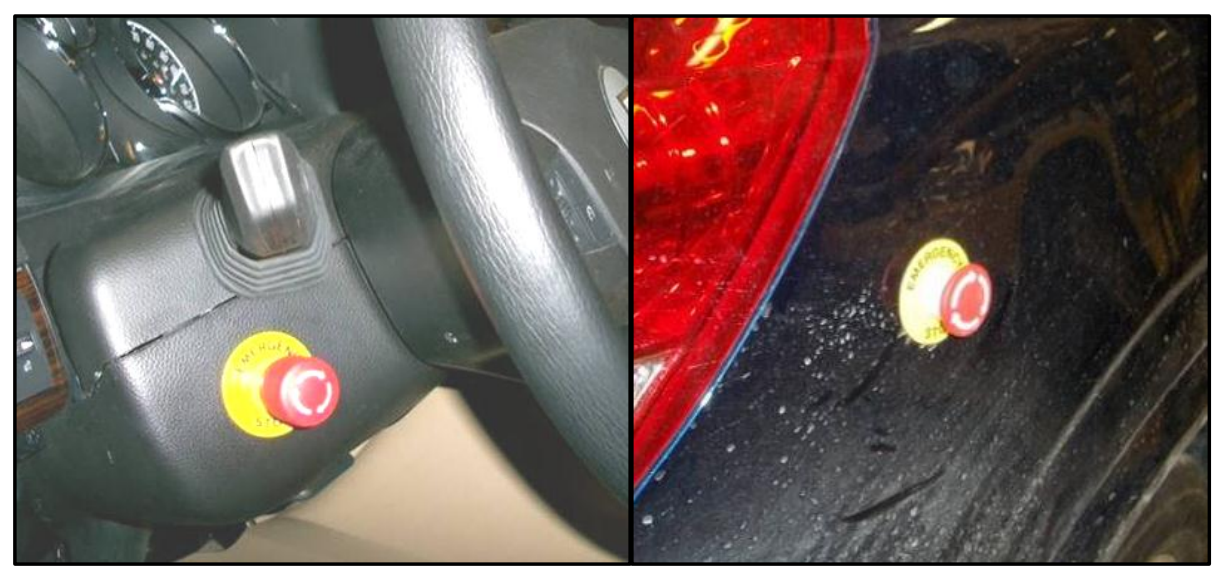

Figure 66. Emergency Stop Buttons

In addition to the emergency stop buttons, an inertia switch was installed to cut power to the engine ECU and fuel pump as well as disable the high-voltage system in the event that the vehicle were ever involved in a collision. This inertia switch was installed in series with the two emergency stop buttons so that tripping any of the three would perform the same function. The inertia switch was installed behind the dashboard above the front passenger foot well.

\subsubsection{Deviations from the Original Design}

Inevitably during the design and construction of the project vehicle, some components did not install as they were originally intended. This was partly due to designing many parts using an incorrect CAD model of the engine as well as not having the dimensions of some of the components beforehand. Working within a team of 25 or more required constant communication to keep the team informed on what had been designed and ordered and what tasks needed completed. However, this communication could break-down at times and, for instance, some of the designed components would be impossible to install where they were intended.

A single heat exchanger was initially specified for cooling the high-voltage battery but the purchased heat exchanger was not automotive-grade and included two fans that required $120 \mathrm{~V}$ AC so the split heat exchanger configuration discussed previously was designed and installed. The new automotive-grade heat exchanger array maintained the intended cooling area and produced a similar pressure drop to the original design.

The high-voltage battery was originally intended to be constructed using eight A123 12s8p modules. However, after the initial simulations were completed $A 123$ released the $25 s 2 p$ modules and offered to supply them because the specified high-voltage battery was within the 300-330 V range. The 
new modules were comparable to the previously selected modules but provided simplified packaging as only four of the $25 \mathrm{~s} 2 \mathrm{p}$ modules would be required to produce a $330 \mathrm{~V}$ battery. The decision was made to use the new battery $25 \mathrm{~s} 2 \mathrm{p}$ modules.

All of the brackets and mounts designed for the diesel engine were designed twice due to the initial use of an incorrect CAD model of the new engine. While a correct CAD model of the 1.3 liter diesel engine was eventually sourced, some parts of the engine were missing in the model. Once the engine was shipped to WVU, it was apparent that the $300 \mathrm{~V}$ air conditioning compressor supplied with the 2mode Saturn Vue could not be installed where it was originally intended. The CAD model of the diesel engine did not include the diesel oxidation catalyst that connected to the turbine outlet of the turbocharger and the electric air conditioning compressor interfered with the exhaust. A new mounting bracket was designed to install the compressor on top of the front engine mount. 


\section{Control Strategy Development \& Vehicle Testing}

With the design and construction of the project vehicle explained, the remaining sections of this document will detail the graduate research performed for this thesis. Through this research, a powertrain control strategy was developed to manage the operation of the diesel engine, high-voltage battery, and 2mode transmission installed in the project vehicle. The research was focused on developing a control algorithm designed to improve the fuel efficiency and reduce the $\mathrm{CO}_{2}$ emissions of the project vehicle through the implementation of engine on/off functionality, regenerative braking, and electric-only drive. Once the control algorithm was developed and implemented, the project vehicle was tested on-road for fuel efficiency, emissions, and performance.

\subsection{Powertrain Control Algorithm}

While the mechanical components of the project vehicle were being integrated, the control algorithm for the diesel hybrid-electric powertrain was being developed. This algorithm was implemented entirely through CAN communication between the newly installed SCU, the engine ECU, the HCP, the transmission control module (TCM), and the body control module (BCM).

\subsubsection{Powertrain State}

The first decision made within the powertrain control algorithm was determining whether the driver was attempting to accelerate or brake the project vehicle. This was determined based on the depression percentage of the brake pedal. If the brake pedal was not depressed, the powertrain control algorithm would enter the Propelling state. If the brake pedal position was above $0 \%$, the control algorithm entered the Braking state. These two powertrain states controlled the engine on/off function, engine torque, transmission shifting, regenerative braking, and the commanded axle torque.

\subsubsection{Braking Powertrain State}

The braking powertrain state controlled the amount of regenerative braking provided when the driver depressed the brake pedal. Based on the high-voltage battery SOC, vehicle speed, and brake pedal position (BPP) the regenerative braking control algorithm would calculate the required negative axle torque. Figure 67 illustrates the regenerative braking control algorithm. 


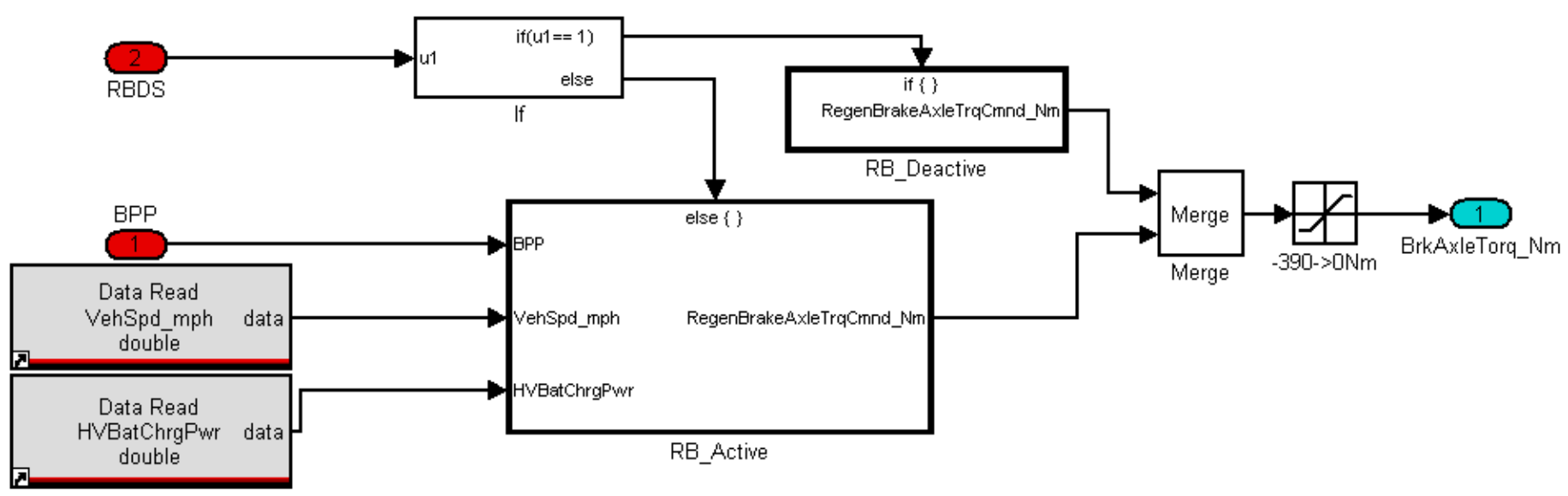

Figure 67. Regenerative Braking Control Algorithm

If the regenerative braking disable switch (RBDS) was activated, the algorithm would disable the regenerative braking function and command $0 \mathrm{~N}-\mathrm{m}$ of regenerative braking axle torque. Otherwise, the algorithm would enter the "RB_Active" subroutine where a desired regenerative braking axle torque was calculated. Figure 68 is a block diagram of the regenerative braking active subroutine.

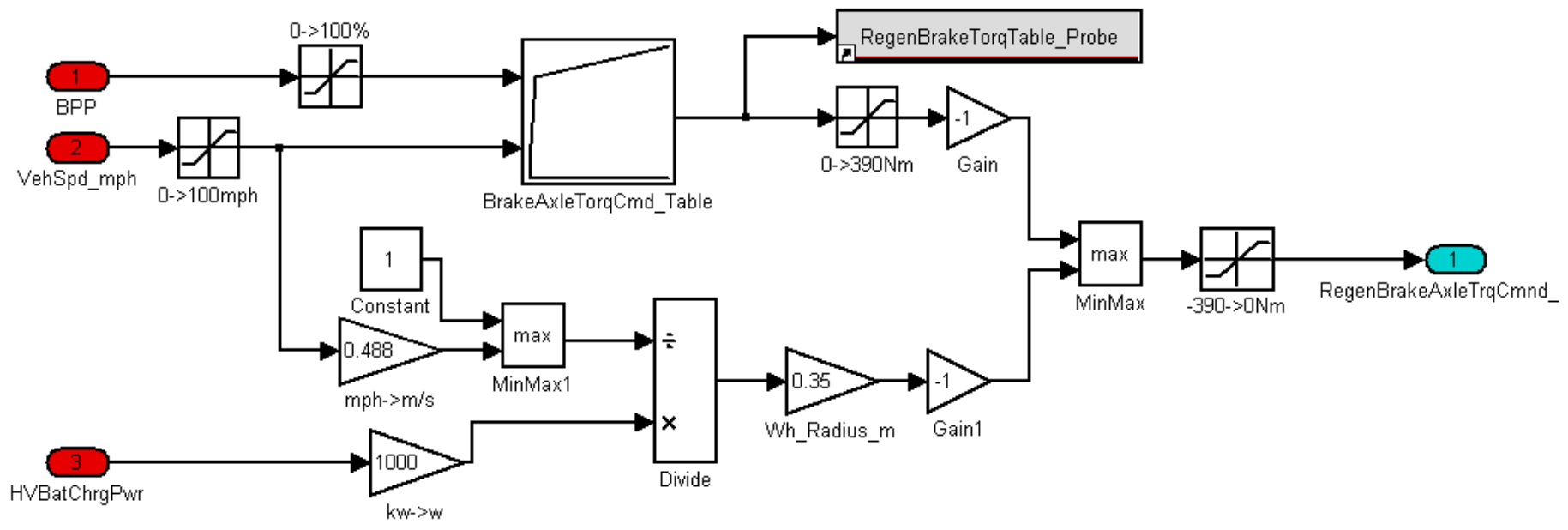

Figure 68. Regenerative Braking Active Control Algorithm

In the upper loop of the program, the BPP and vehicle speed were input into a look-up table to produce a desired regenerative braking axle torque. In the lower loop, the high-voltage battery state-ofcharge was used to provide extra regenerative braking in the event that the high-voltage battery was ever deeply discharged. Conversely, in the event that the high-voltage battery was fully charged, the lower loop would return $0 \mathrm{~N}-\mathrm{m}$. The results from the two loops were compared with the highest value being sent to the HCP. Note that the maximum value would represent the highest numerical value as braking axle torque was calculated using negative values. Figure 69 is a plot of the regenerative braking look-up table. 


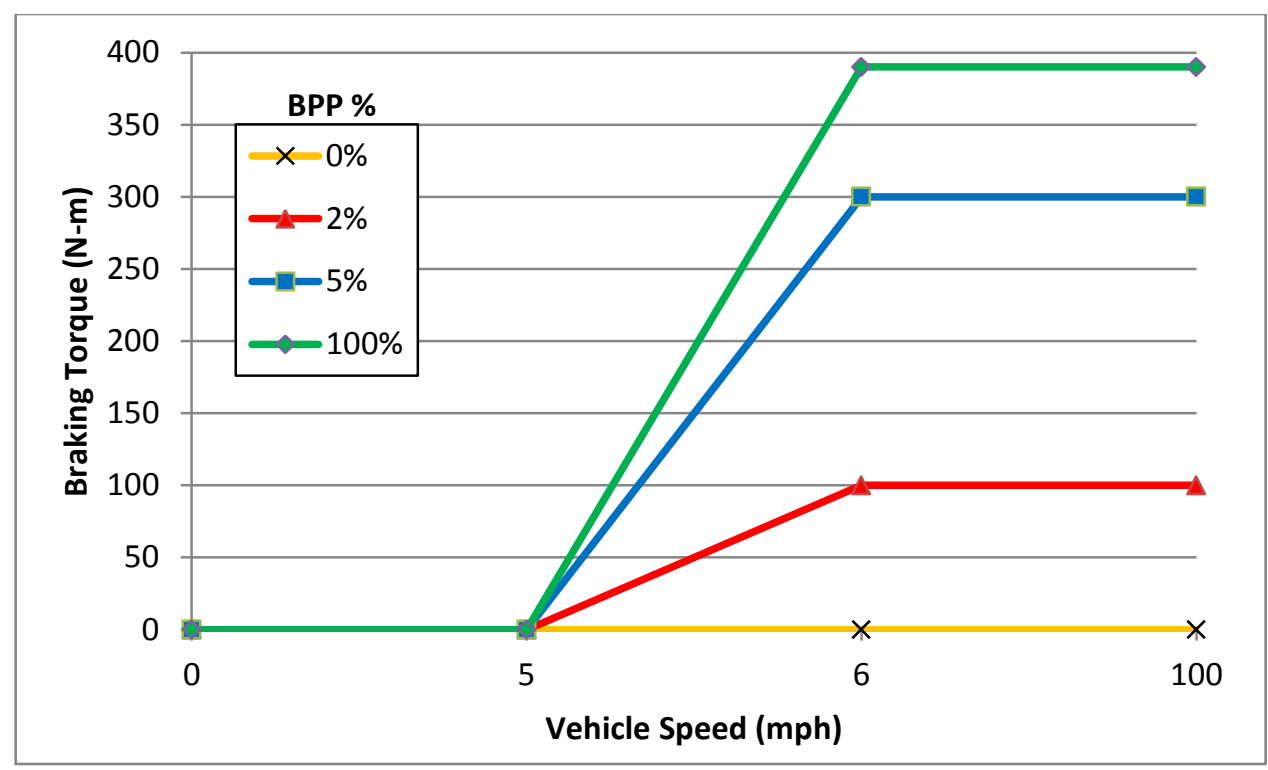

Figure 69. Regenerative Braking Look-Up Table

The colored lines represent lines of constant BPP. It was desired to request as much regenerative braking as possible to minimize energy wasted by the project vehicle's conventional hydraulic braking system. As the vehicle speed dropped below $6 \mathrm{mph}$, the amount of regenerative braking torque was ramped down to zero by the time the vehicle speed reached $5 \mathrm{mph}$. This was done once it was discovered that ramping out regenerative braking right before the vehicle came to a complete stop produced an uncomfortable lurch that would catch the driver off-guard and possibly cause the project vehicle to bump into another vehicle at a stop light. A maximum value of $-390 \mathrm{~N}-\mathrm{m}$ was selected as the maximum possible requested regenerative braking axle torque to protect the high-voltage system from currents above $150 \mathrm{~A}$.

\subsubsection{Propelling Powertrain State}

The propelling powertrain state controlled the amount of axle torque based on the accelerator pedal depression percentage. The propelling state in the powertrain control algorithm handled transmission shifting, engine on/off status, engine speed, and engine torque. The HCP would receive a total axle torque command from the SCU based on the accelerator pedal position (APP) and divide this value into a commanded engine torque and a commanded torque from the electric motors in the 2-mode transmission. The powertrain control algorithm did not directly modify the electric motor torque as no modifications were made to the program in the hybrid control processor. Control of the individual electric motors was performed by the HCP algorithm.

A two-dimensional look-up table was developed for directly translating driver accelerator pedal input to a requested amount of axle torque to be sent to the HCP. The SIMULINK control model written to determine the axle torque command can be seen in Figure 70. 


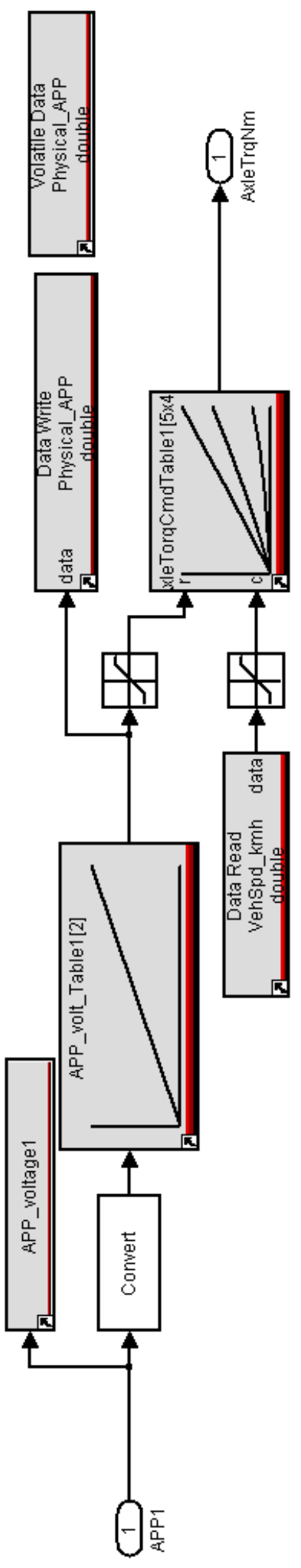

Figure 70. Axle Torque Command Control Model 
The voltage signal from the accelerator pedal was converted to a percentage in the first look-up table with this value written to the controller memory for use elsewhere in the control algorithm. This percentage, as well as the vehicle speed, was then fed into a second look-up table used to produce a commanded axle torque to be sent to the HCP. Figure 71 is a plot of the axle torque look-up table.

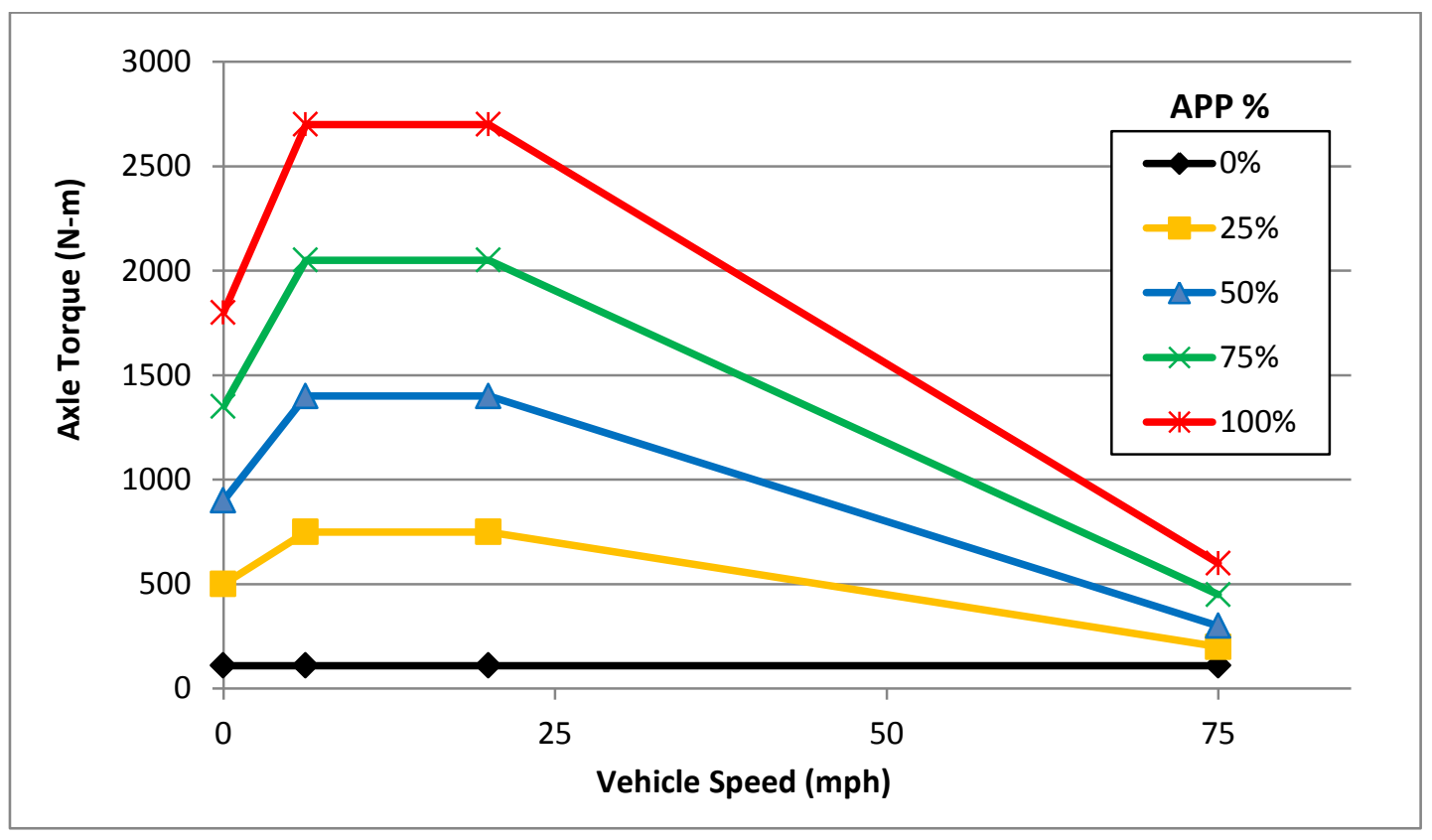

\section{Figure 71. Axle Torque Command Look-Up Table}

The colored lines in the figure represent lines of constant accelerator pedal position. Linear interpolation was used for APP values between those shown in the look-up table. Based on the vehicle speed in miles-per-hour and APP, a total commanded axle torque was selected and sent out via CAN to the HCP. At $0 \%$ APP, a constant creep torque of $80 \mathrm{~N}-\mathrm{m}$ was commanded at all times to maintain the ability of the vehicle to creep with no accelerator pedal application. This was done to mimic the behavior of a vehicle equipped with a conventional automatic transmission. At vehicle speeds above $75 \mathrm{mph}$, the commanded axle torque would remain at the value set for a vehicle speed of $75 \mathrm{mph}$. The HCP would then return a CAN message containing the requested engine torque to the SCU where this value was converted to a pair of voltage outputs simulating a conventional throttle-by-wire accelerator pedal that were then sent to the diesel engine ECU. Figure 72 displays the engine accelerator pedal subsystem. 


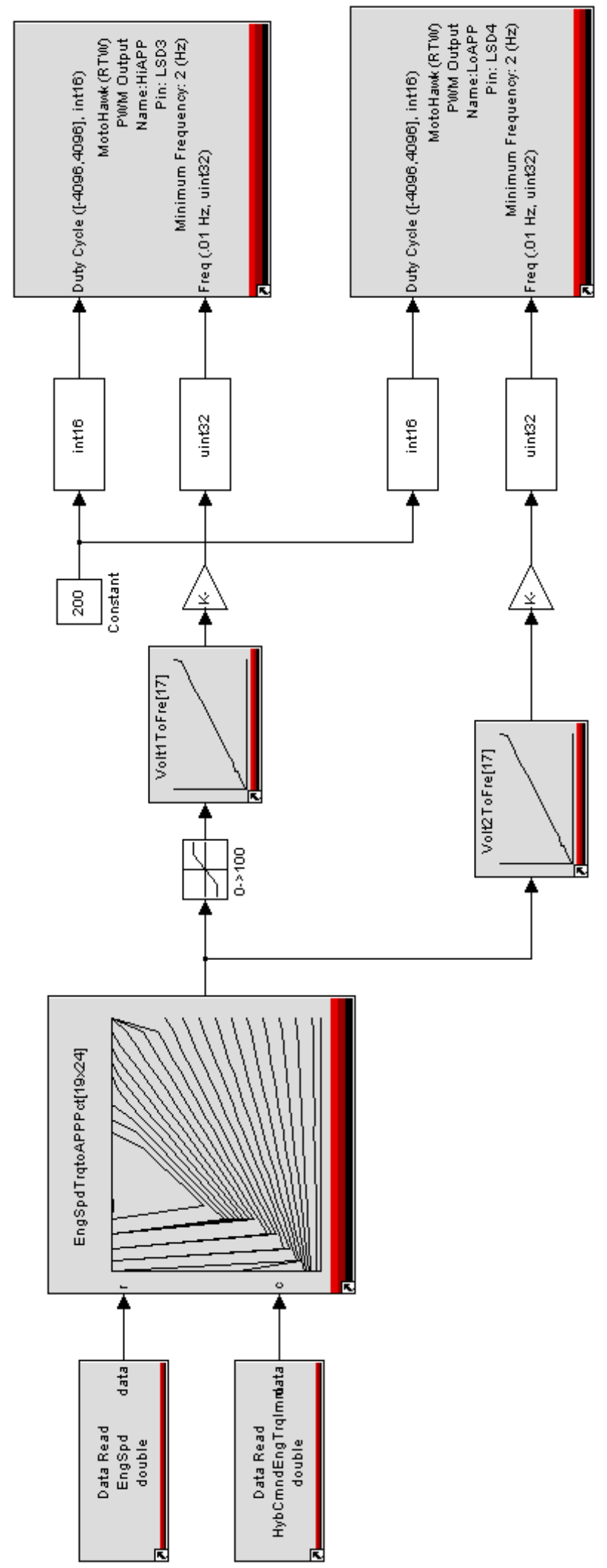

Figure 72. Engine Accelerator Pedal Algorithm 
The engine speed and commanded engine torque from the HCP were input into a 2-D look-up table to produce a simulated engine accelerator pedal position. The simulated engine APP was then converted into two separate voltages, one twice the value of the other. These two voltages were then output from the SCU and sent to the diesel engine ECU. The diesel engine ECU would interpret the voltage pair and increase or decrease the engine torque accordingly.

\subsubsection{Reverse}

If the gear selector were placed in Reverse, the control algorithm would enter Reverse mode. In reverse mode, the engine was always commanded off unless the high-voltage battery was severely discharged or overheated. A two-dimensional look-up table was developed to translate the percentage of depression of the accelerator pedal to a commanded axle torque. All axle torque was provided by the high-voltage battery and electric motors in the 2-mode transmission. There was no regenerative braking commanded while in reverse mode.

\subsubsection{Park \& Neutral}

With the gear selector placed in Park or Neutral, the powertrain control algorithm would not command axle torque regardless of the accelerator pedal input from the driver. While the SCU would receive voltage signals from the accelerator pedal, the algorithm sent out a constant commanded axle torque of $0 \mathrm{~N}-\mathrm{m}$. This was done as a safety feature to eliminate the chance of the project vehicle moving unexpectedly. Unless the battery was discharged below $20 \%$, the diesel engine was commanded off when the transmission was in Park or Neutral.

\subsubsection{Engine On/Off}

The ability for a hybrid vehicle to turn its engine off when not needed is one of the most effective methods used to reduce the vehicle's fuel consumption. In an attempt to maximize fuel efficiency, this function was incorporated into the project vehicle as well. The stateflow routine written to control the engine on/off function can be seen in Figure 73 on the next page. 


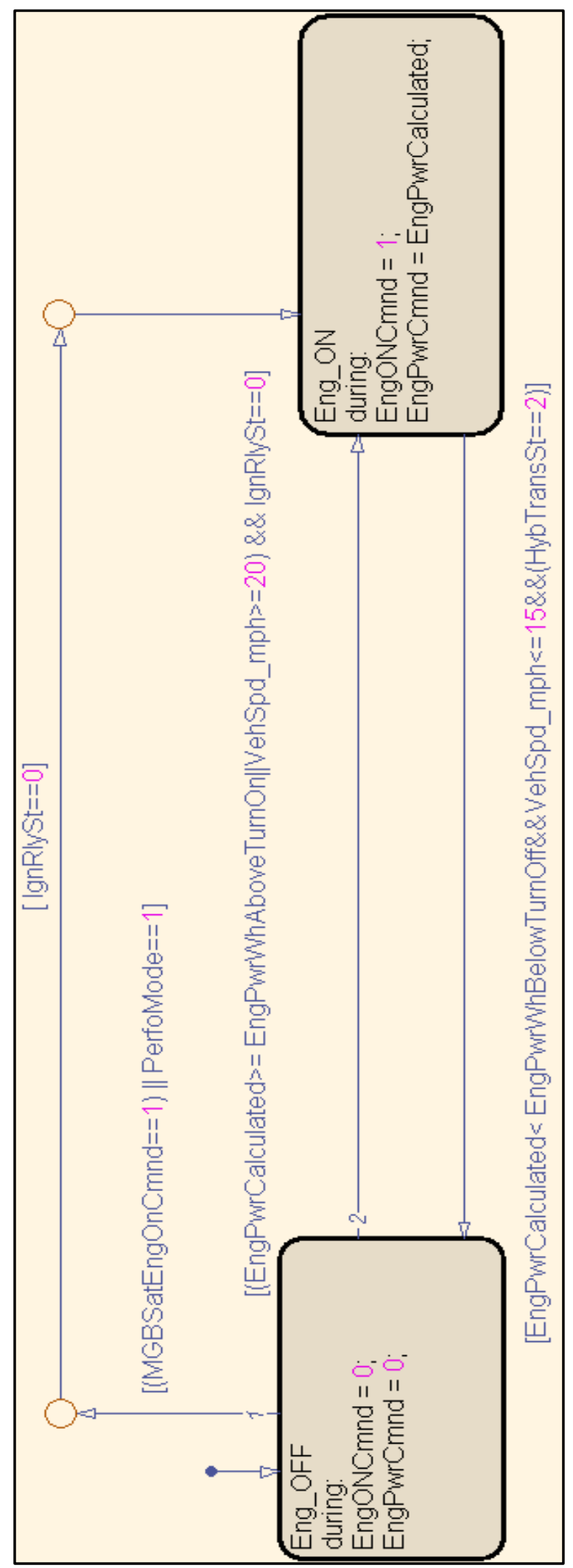

Figure 73. Engine On/Off Stateflow 
The engine on/off control algorithm was based on four criteria: vehicle speed, accelerator pedal position, high-voltage battery SOC, and transmission mode. The engine on/off function would use these four pieces of information while applying different degrees of priority to each. The lowest priority parameter for turning the engine on was the vehicle speed. Limits were set in the algorithm to turn the engine on and off when the vehicle reached set speeds. A $5 \mathrm{mph}$ hysteresis was used between the "on" and "off" vehicle speeds to keep the engine from continually turning on and off while cruising. For example, the engine would be commanded on when the vehicle speed was over $20 \mathrm{mph}$ and the engine would remain on until the vehicle speed dropped below $15 \mathrm{mph}$. The engine would not, under any circumstances, turn off until the vehicle speed dropped below the set value.

The next highest priority parameter for turning the engine on was the high-voltage battery SOC. This was done to protect the lithium-ion battery pack from being discharged too deeply. A target value for the SOC was set and the algorithm would command an increasing amount of power from the engine to charge the high-voltage battery as the SOC dropped further below the target. Once this power command was above a set value, the engine would turn on and remain on until the commanded engine power from the high voltage battery dropped below the set point. Conversely, once the high voltage battery SOC was above the set target, the engine power commanded to charge the battery was reduced.

Similar to the high-voltage battery SOC, the accelerator pedal position was also converted into a desired amount of engine power. This value was added to the power command from the high-voltage battery. This total power command was then compared to the set power command above which the engine would be turned on. There was also a "Performance Mode" that was enabled when the accelerator pedal was depressed past $80 \%$. If the driver depressed the accelerator pedal past $80 \%$, this would override all other parameters and the engine would be commanded on immediately. Figure 74 is the stateflow routine that determined whether to enable performance mode. The actual accelerator pedal position was referred to as "PhysicalAPP" in this stateflow.

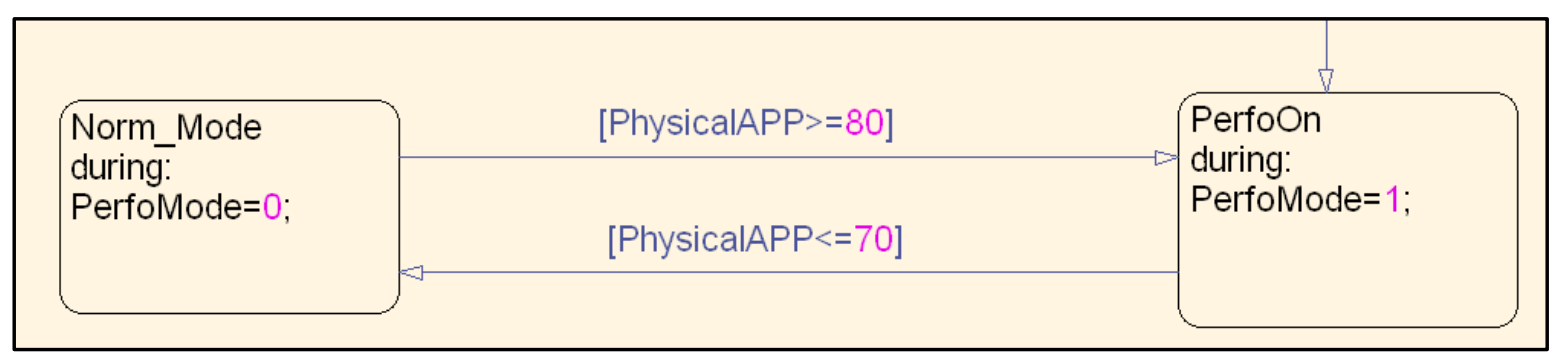

Figure 74. Performance Mode Stateflow

The design of the 2-mode transmission required that the engine be on before the transmission could be shifted from the low speed range (EVT mode 1) to the high speed range (EVT mode 2). Once in high range, the engine was required to remain on until the transmission was shifted back to low range. The transmission range was the highest priority parameter considered when turning the engine off. The engine would only turn off when the transmission was in EVT mode 1, Park, or Reverse. Under normal conditions, the engine would be commanded off when the transmission was in park or reverse. Only 
when the high voltage battery SOC was below $20 \%$ would the vehicle reverse or idle with the engine turned on.

\subsubsection{Transmission Shifting}

Unlike the engine on/off control, the transmission shift strategy was based exclusively on vehicle speed. On the recommendation of 2-mode engineers, the decision was made to only utilize the two EVT modes available from the 2-mode transmission as well as fixed gear ratio 2 which was used to shift between the two EVT modes. In the initial iteration of the control algorithm, the transmission shifted up from EVT mode 1 to EVT mode 2 when the vehicle speed reached $30 \mathrm{mph}$ and it would downshift back to EVT mode 1 once the vehicle speed dropped below $25 \mathrm{mph}$. A $5 \mathrm{mph}$ hysteresis was used to keep the transmission from repeatedly shifting between EVT modes while the vehicle cruised around the shift speeds. Figure 75 is the transmission stateflow shifting routine. Note that in this iteration, the upshift speed was raised to $35 \mathrm{mph}$.

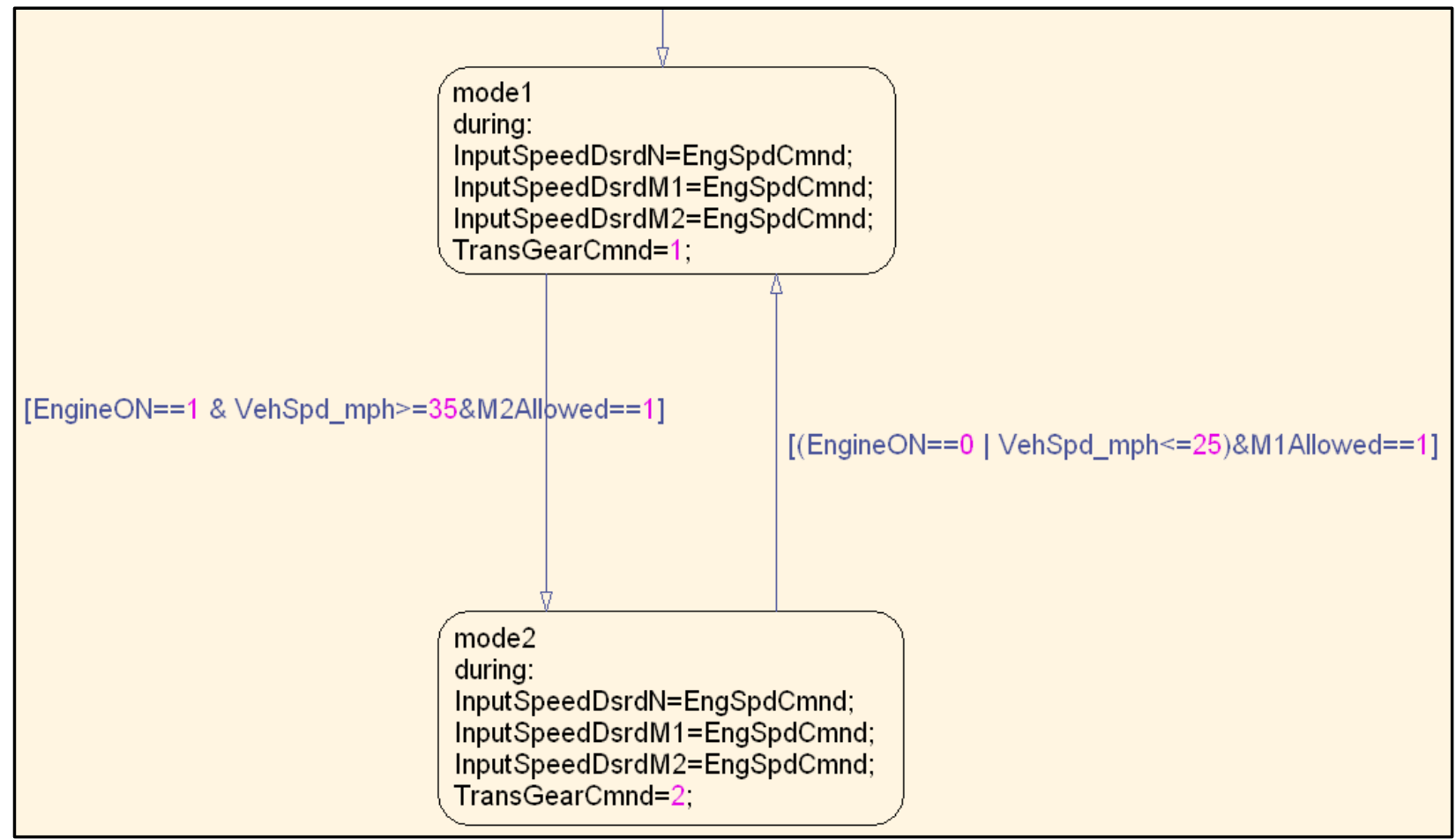

Figure 75. Transmission Shifting Stateflow

The transmission would remain in EVT mode 1 until the engine was on, the vehicle speed was greater than or equal to $35 \mathrm{mph}$, and the transmission control module broadcasted via CAN that a shift to EVT mode 2 was possible (M2Allowed==1). Only then would the state change from the top "mode 1" block down to the "mode 2" block. In the mode 2 state, the "TransGearCmnd" would change from 1 to 2 signaling a shift from EVT mode 1 to mode 2. In order for the transmission to downshift to EVT mode 1 , the TCM was required to broadcast that a shift to mode 1 was possible (M1Allowed==1). In addition, 
either the vehicle speed needed to drop below $25 \mathrm{mph}$ or the engine needed to be commanded off to allow the state to return to the mode 1 block.

To make the shift as smooth as possible, the engine speed was commanded to remain constant while the shift was performed. The engine was held at a speed of about $2500 \mathrm{rpm}$ which produced a speed ratio through the transmission of $1.88: 1$, the same ratio as fixed gear 2 . This produced a smooth EVT mode shift and helped protect the engine and 2-mode transmission from damaging drive train shocks. To shift the transmission to the desired EVT mode or fixed gear 2, a CAN message was generated by the control algorithm with a value of 1 corresponding to EVT mode 1 and 2 for EVT mode 2 . During the shift, the TCM would command fixed gear 2 automatically without any input from the SCU control algorithm.

\subsubsection{Engine Speed Control}

Similar to the transmission shift points, engine speed was controlled based solely on vehicle speed. Early in the vehicle design process, 2-mode engineers had recommended that the diesel engine not be allowed to spin slower than $1000 \mathrm{rpm}$, possibly due to a natural frequency or some other weakness inherent in the 2-mode transmission's design. For this reason, the minimum commanded engine speed allowed by the control algorithm was set at $1250 \mathrm{rpm}$. A two-dimensional look-up table was assembled translating the vehicle's linear speed in miles per hour to a commanded engine speed in revolutions per minute. Figure 76 is a chart of the two-dimensional engine speed look-up table.

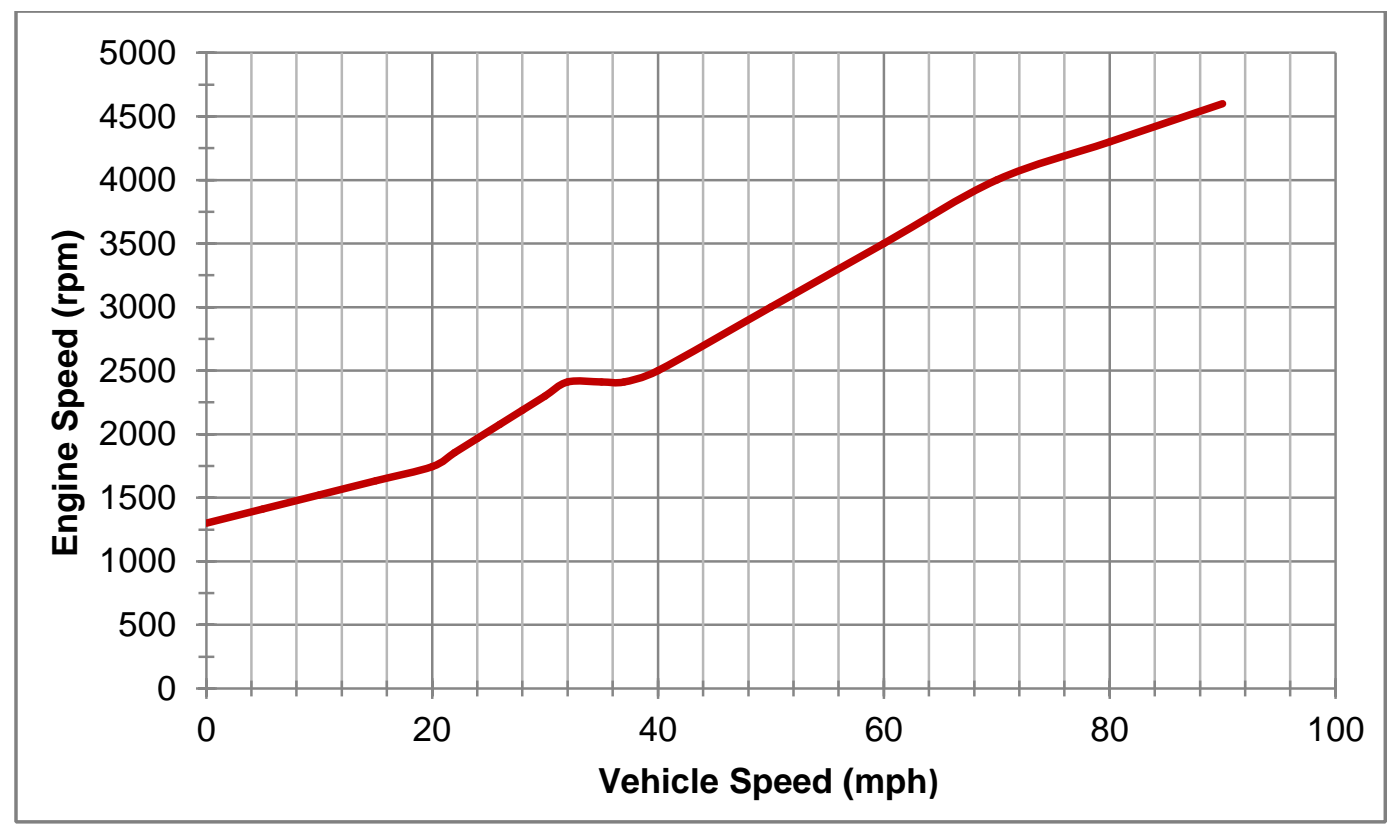

Figure 76. Engine Speed Command Look-Up Table

The minimum engine speed commanded was set at $1250 \mathrm{rpm}$ with this being the desired engine speed were the engine ever turned on with the vehicle at a standstill. The engine speed increased linearly as the vehicle speed increased to $20 \mathrm{mph}$. At that point, the engine speed was commanded to 
increase more rapidly in preparation for the shift between EVT mode 1 and EVT mode 2. As the vehicle speed increased to the set shift speed of $30 \mathrm{mph}$, the engine speed increased linearly to $2450 \mathrm{rpm}$. This engine speed was selected because it produced a speed ratio between the transmission input and output shafts of 1.88, the same ratio as fixed gear 2 [7]. This was done to make the shift between EVT mode 1 and EVT mode 2 as smooth as possible because fixed gear 2 was used to shift between the EVT modes.

Once the transmission was in EVT mode 2, the engine was required to be on until the transmission was downshifted back to mode 1 . In mode 2, the engine speed was linearly increased as the vehicle speed increased up to a vehicle speed of $90 \mathrm{mph}$ where the engine was commanded to run at $4600 \mathrm{rpm}$, the highest engine speed commanded by the control algorithm. At vehicle speeds higher than $90 \mathrm{mph}$, the engine speed was commanded to remain constant at $4600 \mathrm{rpm}$.

\subsubsection{Initial Testing}

Once the vehicle was fully assembled and deemed roadworthy, it was taken on multiple test drives around the Evansdale Campus with special attention being paid to throttle response, brake function, transmission shifting, and battery SOC. Initially, the vehicle was driven in EV mode only to validate the function of the high-voltage electrical systems. This required that speeds be kept below 30 mph because this was the selected shift speed for the 2-mode transmission. Regenerative braking was also verified at this time.

During EV testing, it was discovered that the A123 lithium-ion high-voltage battery system had a built-in safety feature to prohibit dangerously deep discharging. Once the high-voltage battery SOC dropped below $18 \%$ of full charge, the BMS would broadcast via CAN that the SOC was down to $0 \%$. When the HCP received this message, it would command the high-voltage battery contactors open and disable the diesel hybrid-electric powertrain. This required that an absolute lower limit for the highvoltage battery SOC be set in the control algorithm. A value of $25 \%$ was selected. If the high-voltage battery SOC ever dropped below $25 \%$, the diesel engine would be commanded on at all times to provide battery charging.

After the electric drive and braking systems were verified to be fully functional, engine testing began. First with the vehicle stationary in Park, the engine was commanded on and off through a calibration in the control algorithm using a laptop computer plugged into the CAN. The engine's response to a simulated accelerator pedal was measured by commanding engine torque and reading the CAN message displaying the actual input torque into the 2-mode transmission. Similar to a diesel-electric locomotive, the 2-mode transmission allowed the engine to be loaded using the electric motors. This allowed high engine torque to be commanded. However, it was during this phase of testing that an issue with the engine producing no more than $50 \%$ of its maximum rated torque was discovered. Fortunately, this condition improved during final fuel efficiency and performance testing. Figure 77 is a plot of engine torque and speed data recorded during this phase of testing. 


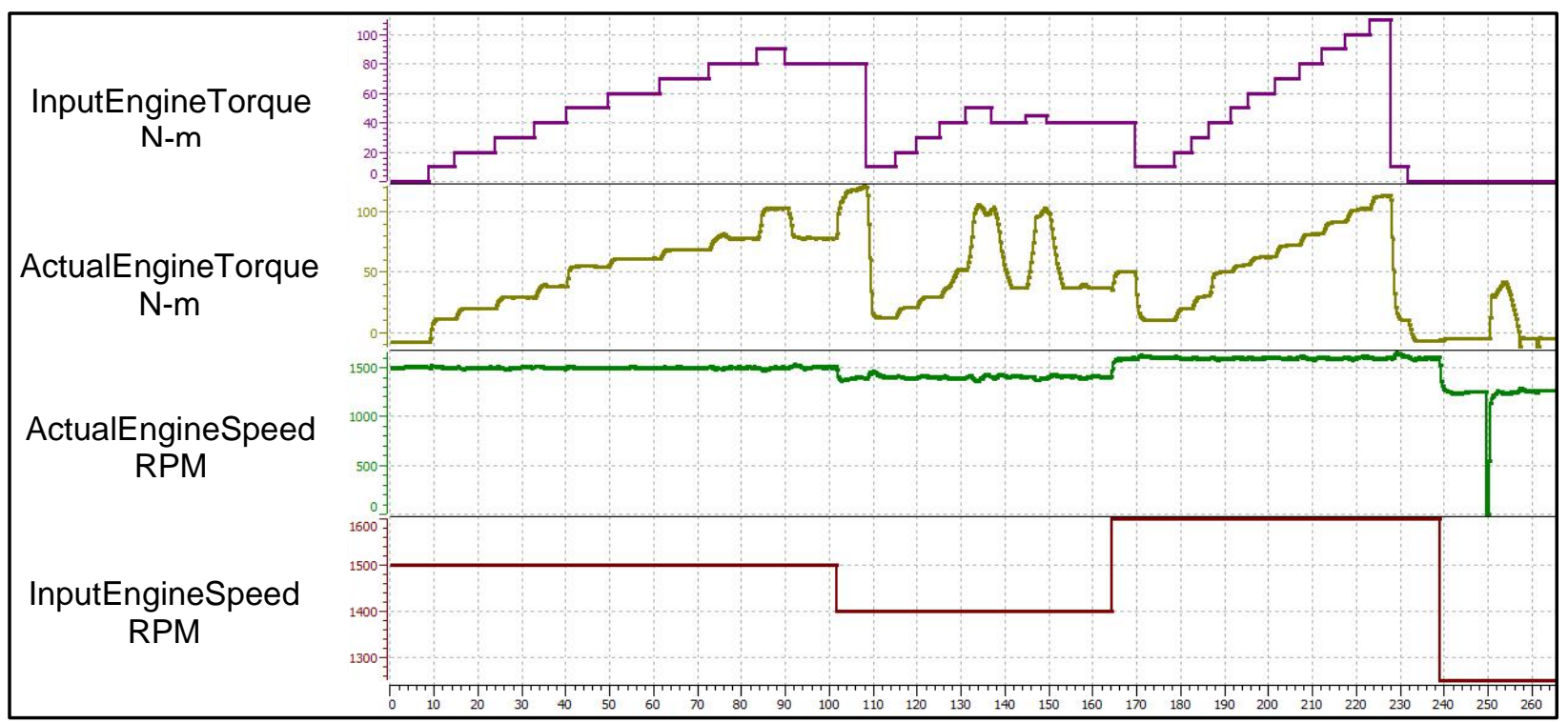

Figure 77. Engine Speed \& Torque Test Data

The purple trace at the top of the figure is the input torque requested using the calibration in the control algorithm. The light green line below it is the actual engine torque response. The highest torque value requested during this test was $90 \mathrm{~N}-\mathrm{m}$. Requesting an engine torque of $100 \mathrm{~N}-\mathrm{m}$ or higher resulted in the engine reverting to producing a constant $80 \mathrm{~N}$-m until the torque request dropped below $100 \mathrm{~N}-\mathrm{m}$. The dark red trace at the bottom of the figure represents the engine speed request with the green line above it being the actual engine speed response. The engine speed request was varied from $1500 \mathrm{rpm}$ to $1400 \mathrm{rpm}$ to $1600 \mathrm{rpm}$ to $1200 \mathrm{rpm}$ and the diesel engine essentially followed the request exactly. The duration of this test was around 280 seconds.

Another issue discovered during initial testing was the rough manner in which the diesel engine would turn off. The 2-mode transmission would use one of its electric motors to quickly stop the engine from rotating when the HCP commanded the engine off. During engine shutdowns, there were noticeable shutters transmitted into the passenger compartment by the diesel engine as it slowed down. The control strategy in production 2-mode vehicles included an active damping feature to make engine shutdowns smooth using a combination of engine and electric motor control. However, this feature was disabled for the 2-mode transmission in the project vehicle due to its complexity.

Engine issues notwithstanding, the project vehicle was deemed ready for on-road testing at speeds above $30 \mathrm{mph}$. This required shifting the 2-mode transmission into EVT mode 2 for the first time. Initial shift attempts were made by first commanding the transmission to shift through Neutral with a one second delay when shifting up or down between EVT mode 1 and EVT mode 2. This was done to minimize the chance of damaging the 2-mode transmission. Once the shift to EVT mode 2 through Neutral was achieved and the data thoroughly analyzed, the next step was shifting through Fixed Gear 2 between EVT mode 1 and EVT mode 2. Once this function was tested and deemed safe and reliable, the vehicle was ready to be fully tested and optimized. 


\subsection{Preliminary Testing}

During all test driving, CAN communication was monitored in real-time using the Vector CANCaseXL and CANoe software. This software allowed the user to view every message being sent over CAN as well as providing traces of selected messages so the user could quickly determine parameters such as high-voltage battery SOC, high-voltage current flow, vehicle speed, accelerator pedal position, commanded and delivered axle torque, high-voltage battery and power electronics temperatures, and transmission range. Another useful feature of the software was its ability to store and replay tests up to 45 minutes in length. The data collected could also be exported to Excel to be analyzed further.

\subsubsection{Preliminary Testing and Optimization}

During preliminary testing, the project vehicle was subjected to numerous on-road tests to verify the function of the different components and to ensure that the control algorithm was robust and free of errors. Although the diesel engine remained in a reduced power state, the vehicle performed reliably without issue during initial testing. Figure 78 is a plot illustrating the diesel engine's inability to produce more than $100 \mathrm{~N}-\mathrm{m}$ of torque during a test drive.

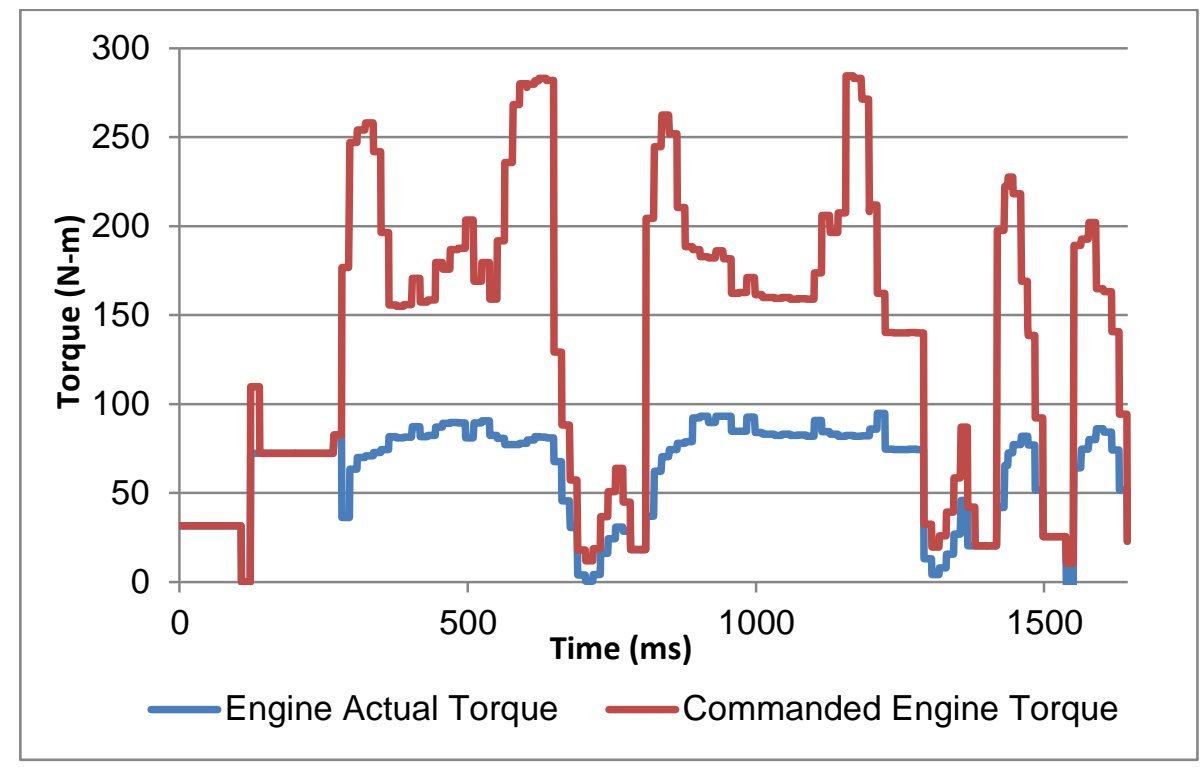

Figure 78. Diesel Engine Torque Limitation

Note that although the HCP would command over $200 \mathrm{~N}-\mathrm{m}$ of engine torque, the diesel engine never produced more than $100 \mathrm{~N}-\mathrm{m}$. However, at times when the HCP commanded less than $100 \mathrm{~N}-\mathrm{m}$, the diesel engine would follow the command.

Multiple attempts were made to smooth engine shutdowns, but none were entirely effective. The power to the diesel engine ECU was turned off during shutdowns to eliminate the chance that the ECU was injecting extra fuel in an attempt to keep the engine from stalling. The commanded engine torque 
during shutdowns was set to $0 \mathrm{~N}-\mathrm{m}$. The only change that had an effect was turning the engine off while the vehicle was travelling at speeds higher than $15 \mathrm{mph}$. At these speeds the engine shutdowns were still rough, but were less noticeable inside the passenger compartment.

With the engine producing half of its rated power, the project vehicle would sometimes have trouble climbing long grades. This was due to the electric motors having to provide more power to propel the vehicle and thus commanding more current from the high-voltage battery. The 2-mode transmission itself was designed to only allow a few seconds of sustained electric boost when ascending a grade at high speeds to protect the electric motors, power electronics, and high-voltage battery from overheating [6]. As stated in SAE Paper 2010-01-0826, the electric assist would be ramped out after a few seconds of sustained high load operation and would only return upon the driver reapplying the accelerator pedal [6]. This was the same behavior exhibited by the project vehicle when climbing hills with the engine operating in its reduced power state. Figure 79 is a plot of the vehicle speed, accelerator pedal position, and high-voltage battery current recorded during an acceleration test illustrating the reduction in electric boost after about ten seconds.

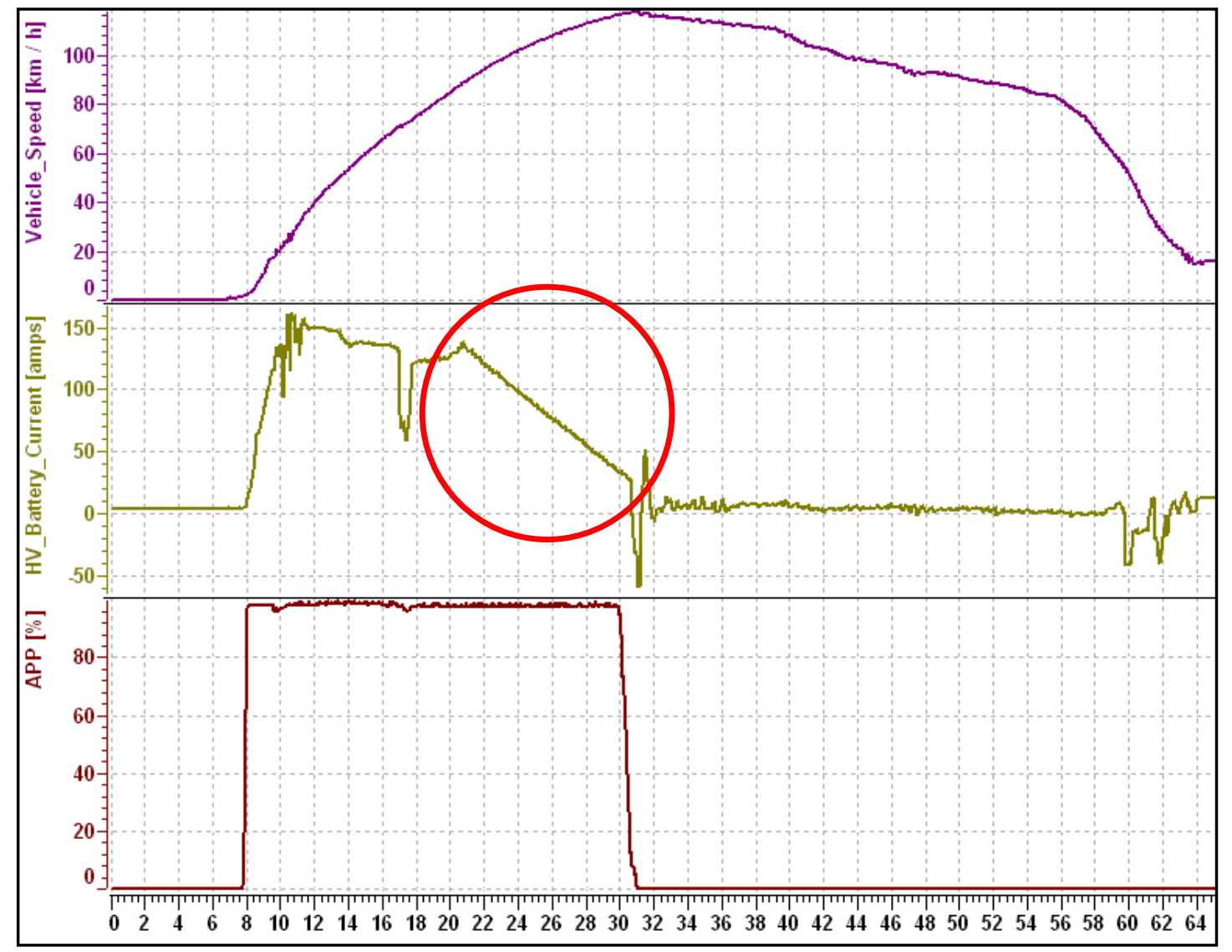

Figure 79. Electric Boost Reduction

The bottom plot is the accelerator pedal position. For this acceleration test, the accelerator pedal was held at $100 \%$ until the vehicle speed reached about $70 \mathrm{mph}$. The brown plot in the middle of the 
figure is the current coming out of the high-voltage battery. About ten seconds into the acceleration test, the high-voltage battery current began to ramp down and continued decreasing until the accelerator pedal was released. This is shown inside the red circle in the figure.

Transmission shift points and engine on/off limits were tested during this time as well to determine which combination provided the best balance of vehicle performance and energy efficiency. Initially, more emphasis was placed on drivability and performance to ensure that the project vehicle was safe to be driven at-speed on public roads. The engine was required on at vehicle speeds above $20 \mathrm{mph}$ and could be turned off again once the vehicle speed dropped below $15 \mathrm{mph}$. The 2-mode transmission was upshifted once the vehicle speed exceeded $27 \mathrm{mph}$ and downshifted when the vehicle speed dropped below $24 \mathrm{mph}$. Figure 80 is a plot of engine speed and vehicle speed data during one of these initial test runs.

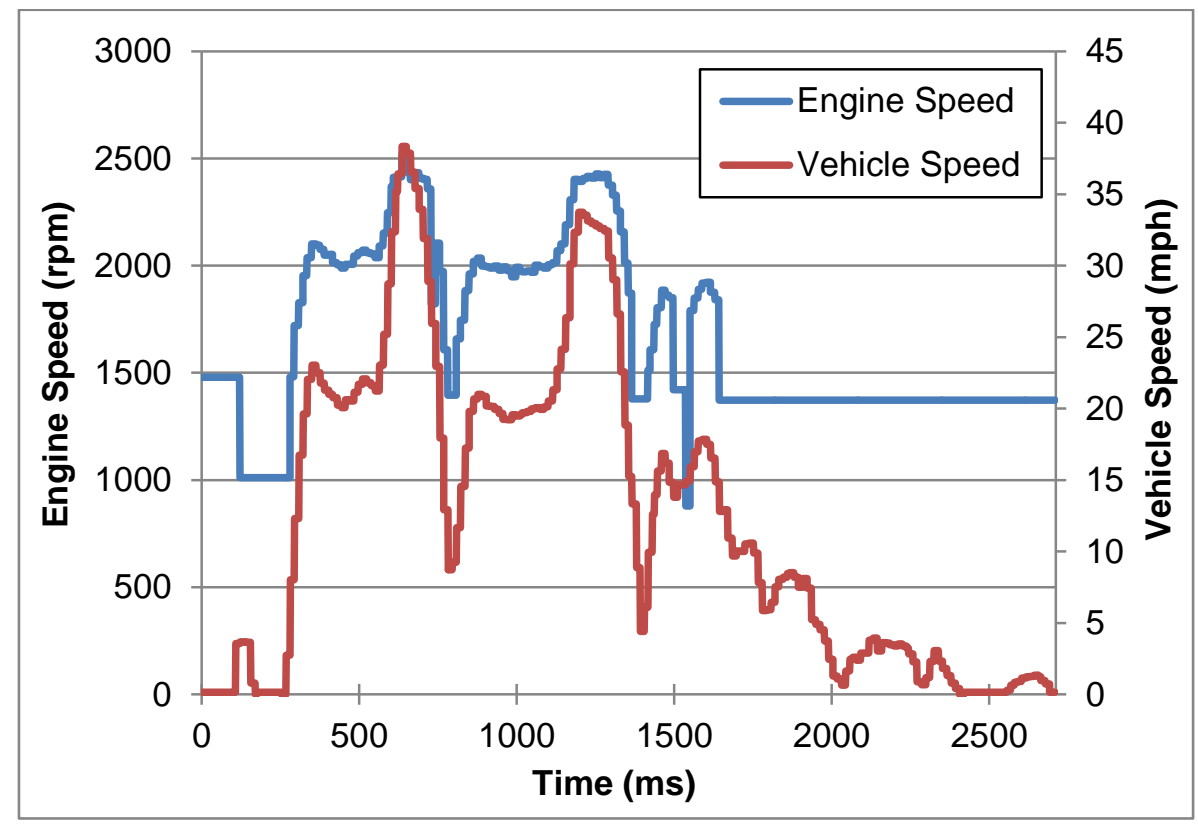

Figure 80. Engine Speed Control

The project vehicle was accelerated up to approximately $40 \mathrm{mph}$ with the engine turning on just as the vehicle speed reached over $20 \mathrm{mph}$. The plot illustrates how the engine speed followed the vehicle speed as the project vehicle sped up and slowed down. Once the vehicle speed dropped below $15 \mathrm{mph}$, the diesel engine turned off. With the diesel engine ECU powered off, the final engine speed reported remained on the CAN bus which is why the blue line representing engine speed remains constant until the end of the test.

With these powertrain and high-voltage battery control parameters set, the vehicle was shipped to the GM Milford Proving Ground at the end of May, 2011 for the final event in the EcoCAR competition. 


\subsubsection{EcoCAR Final Competition}

In order to compete in dynamic events at the final competition, each vehicle needed to first pass a safety technical inspection. This inspection checked everything from tire pressure to ground clearance to full functionality of the vehicle airbag system. The project vehicle required a minor change to the control algorithm that would disable the vehicle if it were started without the brake pedal depressed. Once this change was made, the vehicle was the eighth to pass the technical inspection and be cleared to compete in all dynamic events.

\subsubsection{EcoCAR Final Competition Events}

There were many different events designed to test the performance, build quality, efficiency, and emissions of the 16 vehicles. Some events were scored while others were simply pass/fail. The scored events included the lane change, acceleration, braking, AVL drive quality, and emissions and energy consumption tests. The pass/fail events included the on-road safety evaluation (ORSE) and towing events.

The on-road safety evaluation was the first event the project vehicle entered after passing safety inspection. The ORSE event involved various handling and braking tests performed at both low and high speeds. The first portion of the ORSE involved driving the project vehicle through a cone slalom at a speed of about $30 \mathrm{mph}$ and then performing a moderate stop. Next, the vehicle was accelerated around a skid-pad to a speed of $60 \mathrm{mph}$ and run through another slalom followed by a hard stop. The final test began with accelerating the project vehicle to a speed of $75 \mathrm{mph}$ and performing an emergency lanechange maneuver followed by a hard stop, engaging the vehicle's anti-lock braking system. The WVU project vehicle passed the ORSE and was allowed to enter the remaining dynamic events

The lane change event was a test of the maximum road holding ability of the vehicle, measured in $\mathrm{g}$ of lateral acceleration. The vehicle was driven at a constant $70 \mathrm{mph}$ while the driver gradually turned the vehicle, reducing the radius of the turn to the point where the vehicle began to lose traction. The WVU vehicle earned the highest score in this event, producing a maximum lateral acceleration of $0.84 \mathrm{~g}$ and earning the maximum 20 points.

The vehicle's acceleration times from 0-60 mph and from 50-70 mph were measured in seconds and the score was reported as the average of three runs. However, the WVU vehicle was unable to accelerate from 50-70 $\mathrm{mph}$ in the distance allowed and received participation points only for that event. Also, the vehicle failed to reach $60 \mathrm{mph}$ on one attempt due to the engine operating in a reduced power state so the score represents the average of only two runs instead of three. Braking distance from 60-0 mph was measured in feet with the final score being the average of three attempts. WVU scored 3.2 out of 20 points in both of the acceleration tests, lowest of all teams that entered the events. In the braking event, WVU earned 7.94 out of a possible 15 points.

The emissions and energy consumption events involved driving the vehicle over a distance of 160 miles around a 4.5 mile circle track and measuring energy consumption and emissions. It was during 
this test that the WVU vehicle broke down with two miles to go. Because the engine was not producing rated power, the high-voltage battery was slowly discharged to the point where it became nearly fully discharged. Although the project vehicle returned to the garage under its own power, the break-down lasted for about five minutes and WVU received 16.5 participation points out of a possible 105 points for each of these four events. Were the WVU vehicle able to complete the final 2 miles without breaking down, the WVU team would have likely finished the competition in seventh place or better as the highestfinishing 2-mode vehicle.

The dynamic consumer acceptability event involved measuring drive-by noise during acceleration and interior noise while driving the vehicle over rough surfaces. Shift firmness, engine on/off smoothness, and sound deadening were all scrutinized for this test. The diesel engine in the project vehicle was prone to rough, noticeable start-ups and shutdowns. In spite of this, the vehicle passed this event and scored the lowest drive-by noise level. The WVU vehicle earned 39.2 out of a possible 50 points, second place behind Virginia Tech.

The towing event involved pulling a $500 \mathrm{lb}$ trailer up a simulated $5 \%$ grade for 20 minutes at a constant $45 \mathrm{mph}$. The trailer contained an eddy current dynamometer connected to the wheels to apply a resistance equivalent to that of driving up a $5 \%$ grade and the vehicle was driven around a flat circular track. The WVU vehicle passed the towing event and earned 15 out of 15 points.

The AVL drive quality event was a test of vehicle drivability with particular emphasis placed on throttle tip-in and powertrain responsiveness. The vehicle would be stopped and the accelerator depressed a set percentage and held until a specified speed was reached. Then, the accelerator was released and the vehicle allowed to coast down to a specified speed. For this test, the low power output of the diesel engine was a benefit as the vehicle earned high scores for smooth responses to accelerator inputs. However, some of the tests required the vehicle to coast down to low speeds and the WVU vehicle would not slow down enough due to the amount of creep or off-throttle torque programmed into the drive train. Fortunately, the judge performing the test was willing to overlook that fact and the vehicle passed the AVL event scoring 31.86 out of a possible 45 points.

At the end of the competition week, the final event was an autocross in which the project vehicles were raced against the clock around a cone course laid out in a large paved area inside the Proving Ground. This event was optional and only 10 of the 16 teams participated. Each team got three runs with the best time being the scored time. The WVU vehicle finished mid-pack with a time of $61.30 \mathrm{sec}$, around seven seconds behind the leader earning 17.08 out of a possible 25 points. Figure 81 is a photograph of the project vehicle in action on the autocross course. 


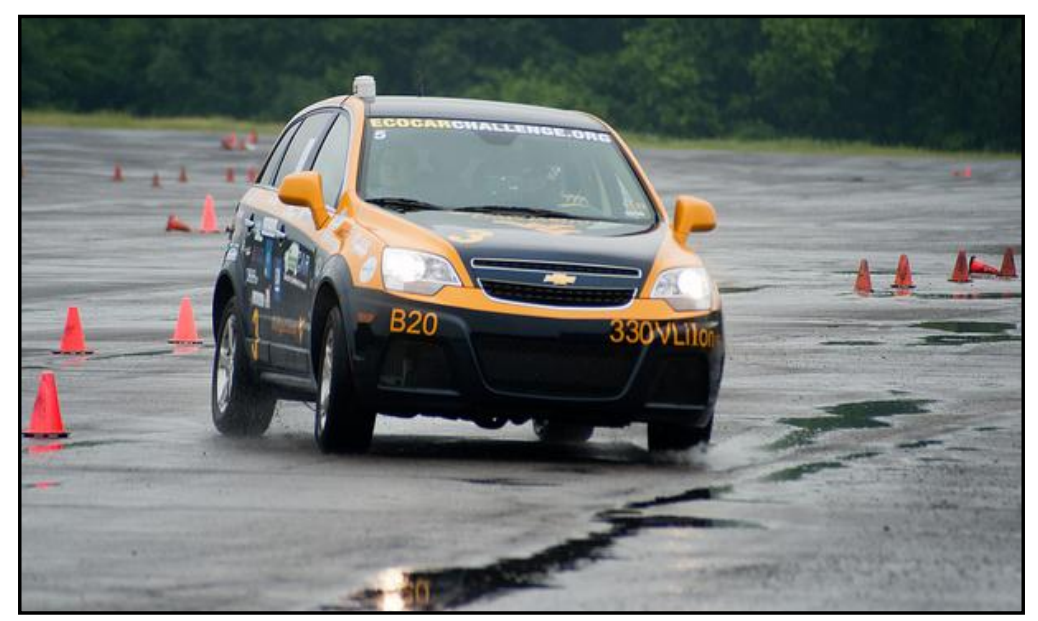

Figure 81. WVU Vehicle Navigating the Cones

\subsubsection{EcoCAR Final Competition Results}

After seven days at the Proving Ground, the dynamic events were closed and the scores were tabulated. All teams but one passed technical inspection and were allowed to compete. Over the course of the week, teams broke parts, replaced major components, and one completely redefined their propulsion strategy. Fortunately, the WVU vehicle was very reliable and competed in every event. Table 25 displays how the project vehicle performed compared to the stock vehicle in the scored events. The data for the stock vehicle were recorded at the time of the final competition.

Table 25. Final Competition Performance Results

\begin{tabular}{|r|c|c|}
\hline & Stock & WVU \\
\hline Maximum Lateral Acceleration & $0.85 \mathrm{~g}$ & $0.8372 \mathrm{~g}$ \\
\hline Acceleration $\mathbf{( 0 - 6 0} \mathbf{~ m p h})$ & $11.81 \mathrm{sec}$ & $25.78 \mathrm{sec}$ \\
\hline Acceleration $\mathbf{( 5 0 - 7 0} \mathbf{~ m p h})$ & $6.76 \mathrm{sec}$ & DNF \\
\hline Braking Distance $\mathbf{( 6 0 - 0} \mathbf{~} \mathbf{~ p h})$ & $141.66 \mathrm{ft}$ & $148.53 \mathrm{ft}$ \\
\hline
\end{tabular}

The sluggish acceleration performance of the project vehicle compared to stock can be attributed to the diesel engine's inability to produce over $100 \mathrm{~N}-\mathrm{m}$ of torque when the stock 3.6 liter gasoline engine was capable of producing $336 \mathrm{~N}-\mathrm{m}$ of torque. The lower maximum lateral acceleration and longer stopping distance are results of the increased mass of the vehicle when compared to the base vehicle. An unmodified base model front-wheel-drive 2009 Saturn Vue with the 2.4 liter engine weighed $3664 \mathrm{lb}$ while the WVU vehicle weighed $4552 \mathrm{lb}$, an increase of $888 \mathrm{lb}$. This weight increase was due to the addition of the compound-split hybrid drive train and high-voltage battery pack that alone weighed an estimated $500 \mathrm{lb}$. Additionally, the braking distance could have been shorter were the author not as timid during the first run, resulting in a distance of over $150 \mathrm{ft}$. Both subsequent attempts were around $145 \mathrm{ft}$. 
Following the completion of dynamic testing in Milford, the project vehicles were shipped to Washington, D.C. for the closing ceremonies and finish line event held outside the U.S. Department of Energy on L'Enfant Plaza. In addition to scoring the dynamic events, teams were required to give technical presentations in Washington. There was also a public relations aspect to the competition requiring the schools to get media attention for the project. All of these activities were also scored. Once the final scores were computed, the WVU team officially was scored in $10^{\text {th }}$ place overall. However, a 10 point deduction was wrongfully applied to the score for a non-functional air conditioning system. Removing this deduction, the WVU team earned a $9^{\text {th }}$ place finish in EcoCAR: The NeXt Challenge.

\subsection{Final Testing \& Validation}

In order to validate the functionality of the compound-split diesel hybrid-electric powertrain and control strategy, a dynamic on-road testing plan was established. Tests were designed to measure the performance and efficiency of the project vehicle under different driving conditions. Because the university did not have a functional light-duty chassis dynamometer for simulated on-road testing of passenger vehicles, dynamic testing needed to be performed with the project vehicle on the ground driving on public roads. This required the development of testing schedules similar to those used by the EPA to measure the fuel efficiency of new automobiles. Performance characteristics such as acceleration and braking would also need to be tested.

When searching for suitable locations to conduct on-road testing in Morgantown there were two major concerns: elevation changes and traffic. A flat location was desired to remove any effects grade may have had on the vehicle's performance and fuel consumption. A traffic-free location would be more controllable so that repeat tests could be performed under nearly the same conditions. Also, some of the tests would require stopping and starting and it would be safer to perform these tests without other vehicles on the road.

Flat roads are scarce in and around Morgantown. Some of the locations considered but not chosen included the parking lot around the WVU Law School and the access road around the Suncrest Towne Centre shopping area. These locations, while flat, were too confined to allow safe testing of the vehicle at speeds above $30 \mathrm{mph}$. However, it was while scouting the location around the Suncrest Town Centre that the diesel engine began producing maximum power for the first time since being installed in the project vehicle. This was an interesting development as no changes had been made to the vehicle or the control algorithm since it had returned from the EcoCAR final event. Fortunately, this development meant that the subsequent testing would be performed with a fully functioning vehicle.

To test the fuel efficiency of the project vehicle, the decision was made to mimic as closely as possible the EPA's test cycles for city and highway driving. This was done to produce fuel efficiency results that could be compared to EPA-rated fuel economy for different vehicles, making the results more intuitive and easier to interpret and understand. 


\subsubsection{Mall Urban Driving Schedule}

The first step in developing an on-road test cycle to simulate city driving was selecting a suitable location. As discussed previously, the major concerns were grade and traffic. Searching the area and using elevation data provided by Google Earth, the selected location for city testing was the loop surrounding the Morgantown Mall. The minimum elevation was $1046 \mathrm{ft}$ and the maximum was $1069 \mathrm{ft}$, a change of $23 \mathrm{ft}$. The length of one circuit was $1.02 \mathrm{mi}$. This produced an average grade of $0.43 \%$ which was deemed acceptably flat. Figure 82 shows the location for city driving testing. The test route is outlined in green.

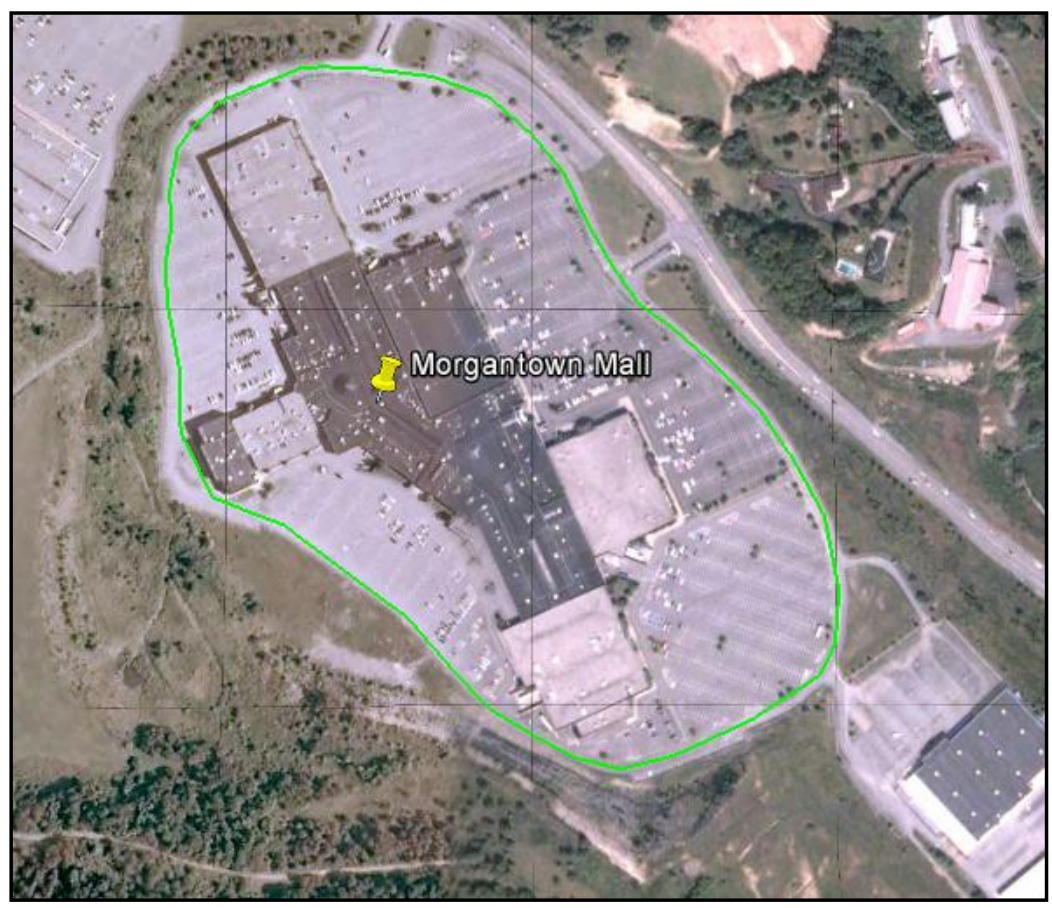

Figure 82. City Cycle Test Location

The EPA runs two different test cycles to obtain what they refer to as "city" and "highway" fuel efficiency. The EPA city cycle, known as the Urban Dynamometer Driving Schedule (UDDS), consists of multiple starts and stops with a top speed of $56.7 \mathrm{mph}$. During this test cycle, the vehicle is subjected to many periods of acceleration and deceleration with one high-speed portion with speeds above $50 \mathrm{mph}$ and one period of sustained driving at a speed of about $26 \mathrm{mph}$. The test is 1369 seconds in duration, covers 7.45 miles, and the average vehicle speed is $19.59 \mathrm{mph}$ [4]. Figure 83 is a trace of the EPA UDDS cycle. 


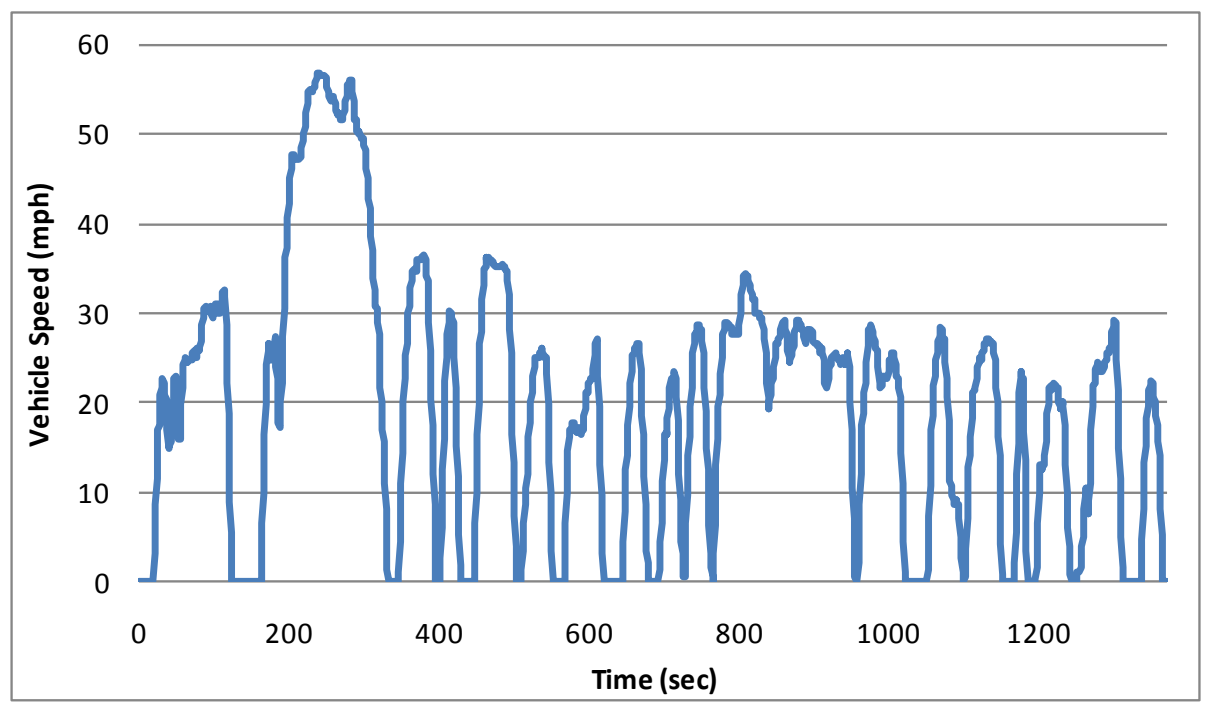

Figure 83. EPA UDDS City Cycle [4]

Using the UDDS as a guide, a new city cycle was designed to be run around the Morgantown Mall. The first step in the design process involved analyzing the UDDS in great detail. The rate of acceleration, vehicle speed, and the lengths of every dynamic and stationary event were scrutinized and this information was recorded for use when designing the new cycle.

Certain characteristics of the UDDS would have been difficult to replicate at the chosen location. For example, a maximum speed of $56.7 \mathrm{mph}$ was deemed unsafe to attain at the Morgantown Mall. Additionally, some of the dynamic events in the UDDS lasted for nearly one mile and this would have required that the project vehicle disregard two Stop signs during testing which was also decidedly unsafe as well as illegal. However, many of the details of the UDDS were possible to be re-created around the selected test route.

To build the new city cycle, the vehicle was driven around the Morgantown Mall while a laptop was recording all CAN communications including the vehicle speed. The passenger was charged with telling the driver when to accelerate and how quickly, what speed to attain, how long to hold that speed, when to stop, and how long to remain stationary based on the notes taken about the UDDS. Between 10 and 20 runs were made with each run including three circuits of the test route. This data was then analyzed and averaged to produce the Mall Urban Driving Schedule. Figure 84 shows the newly designed MUDS city cycle. 


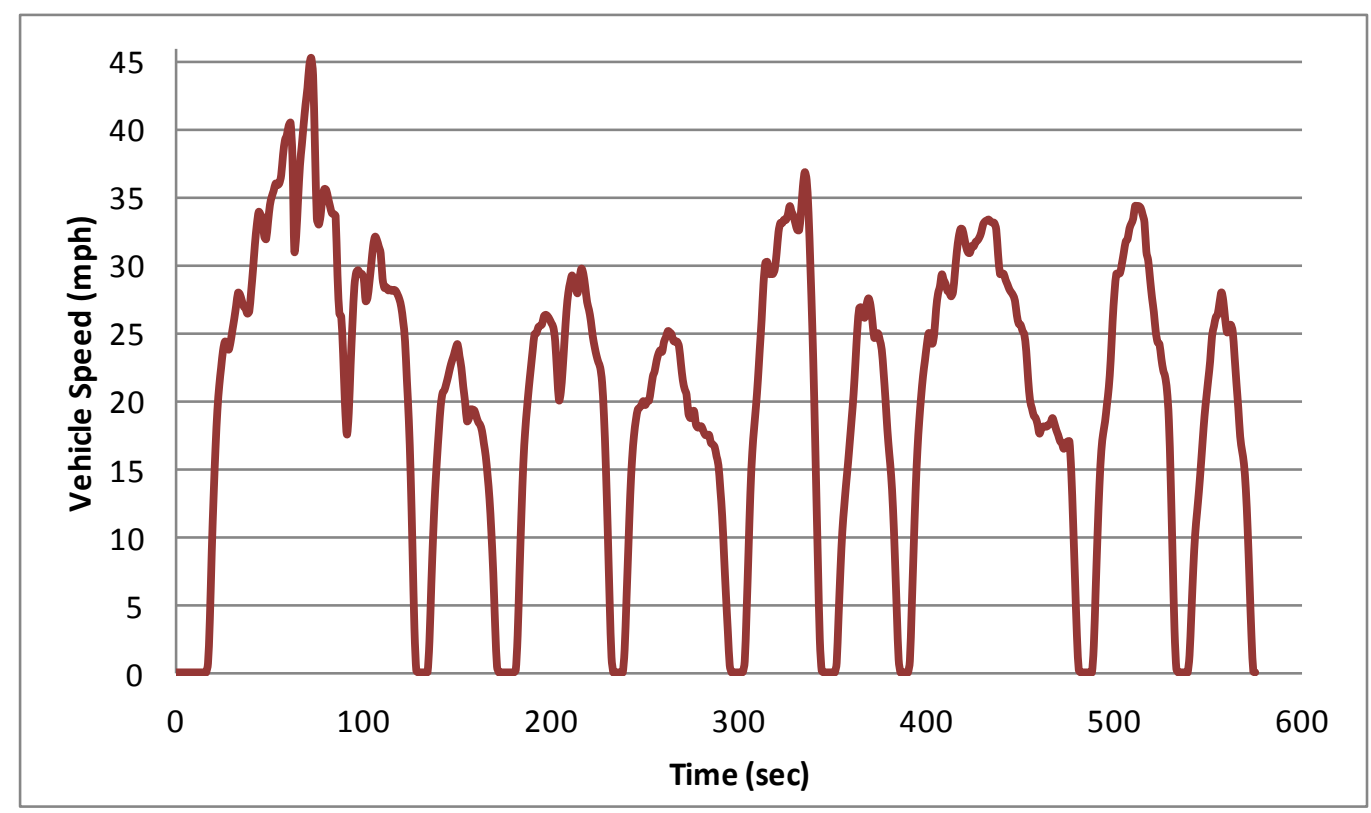

Figure 84. WVU MUDS City Cycle

The MUDS included multiple starts and stops, similar to the UDDS with a high speed period at the beginning. The new cycle was very similar to the UDDS, only shortened by around $60 \%$. This was to allow more tests to be performed in the short amount of time in the morning before traffic would become an issue. Table 26 is a comparison between the EPA's UDDS and WVU's MUDS.

Table 26. UDDS vs. MUDS Comparison

\begin{tabular}{|r|c|c|}
\hline & UDDS & MUDS \\
\hline Duration & $1369 \mathrm{sec}$ & $575 \mathrm{sec}$ \\
\hline Distance & $7.45 \mathrm{mi}$ & $3.2 \mathrm{mi}$ \\
\hline Maximum Speed & $56.7 \mathrm{mph}$ & $45.3 \mathrm{mph}$ \\
\hline Average Speed & $19.59 \mathrm{mph}$ & $20.1 \mathrm{mph}$ \\
\hline Number of Stops & 17 & 8 \\
\hline Average Time Between Stops & $80.5 \mathrm{sec}$ & $71.9 \mathrm{sec}$ \\
\hline
\end{tabular}

The two most important characteristics of the two cycles are the average speed and the average time between stops. A shorter average time between stops indicates that the vehicle would spend more time accelerating and braking which are the two most inefficient actions encountered during driving. Comparing these values between the two cycles, the MUDS test cycle would produce slightly lower fuel efficiency compared to the UDDS due to the slightly higher average speed and shorter average time between stops. 


\subsubsection{Route 19 Highway Fuel Efficiency Test}

Similar to the design of the MUDS city test cycle, the first step in designing a simulated highway driving cycle was finding a suitable test location. High speed testing limited the possible test locations to those with speed limits above $50 \mathrm{mph}$. The selected location was a 2.98 mile stretch of U.S. Route 19 beginning just past the Sheetz convenience store at the intersection of U.S. 19 and Route 7/Monongahela Boulevard and ending at the first major hill. The minimum elevation of this route was $903 \mathrm{ft}$ and the maximum was $1055 \mathrm{ft}$, a total change of $152 \mathrm{ft}$. This produced an average grade of $0.97 \%$. While a grade of less than $1 \%$ is generally accepted as flat, one test would include driving the test route in both directions in an attempt to negate any effect grade may have had on the amount of fuel consumed. Figure 85 shows the route selected for highway testing. The test route is outlined in blue.

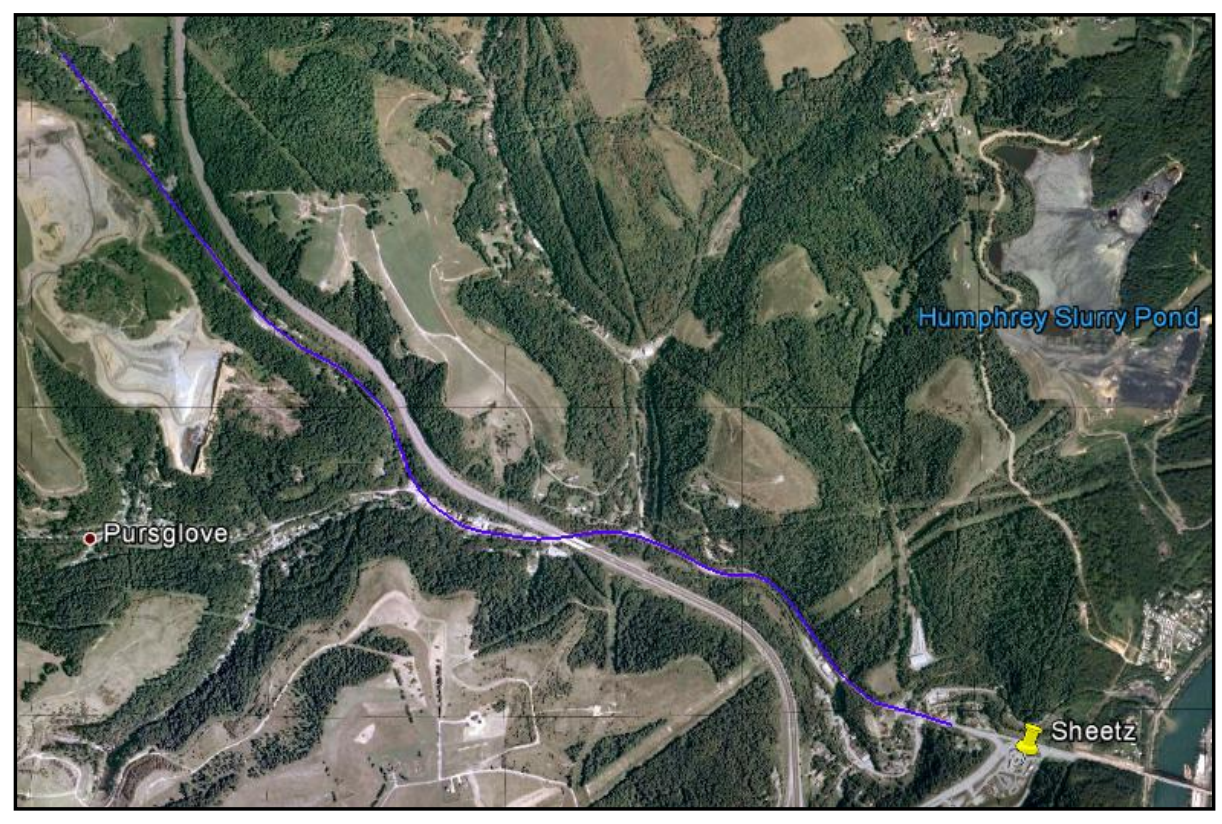

Figure 85. Highway Cycle Test Location

The EPA's Highway Fuel Efficiency Test (HWFET) is used to measure the "highway" fuel efficiency of new vehicles. This test cycle includes sustained high-speed driving with no stops and less acceleration than the UDDS cycle. The test is 765 seconds in duration, covers a total distance of 10.2 miles, and has an average speed of $48.2 \mathrm{mph}$. The maximum speed attained during the HWFET cycle is $60 \mathrm{mph}[5]$. Figure 86 is a trace of the EPA HWFET cycle. 


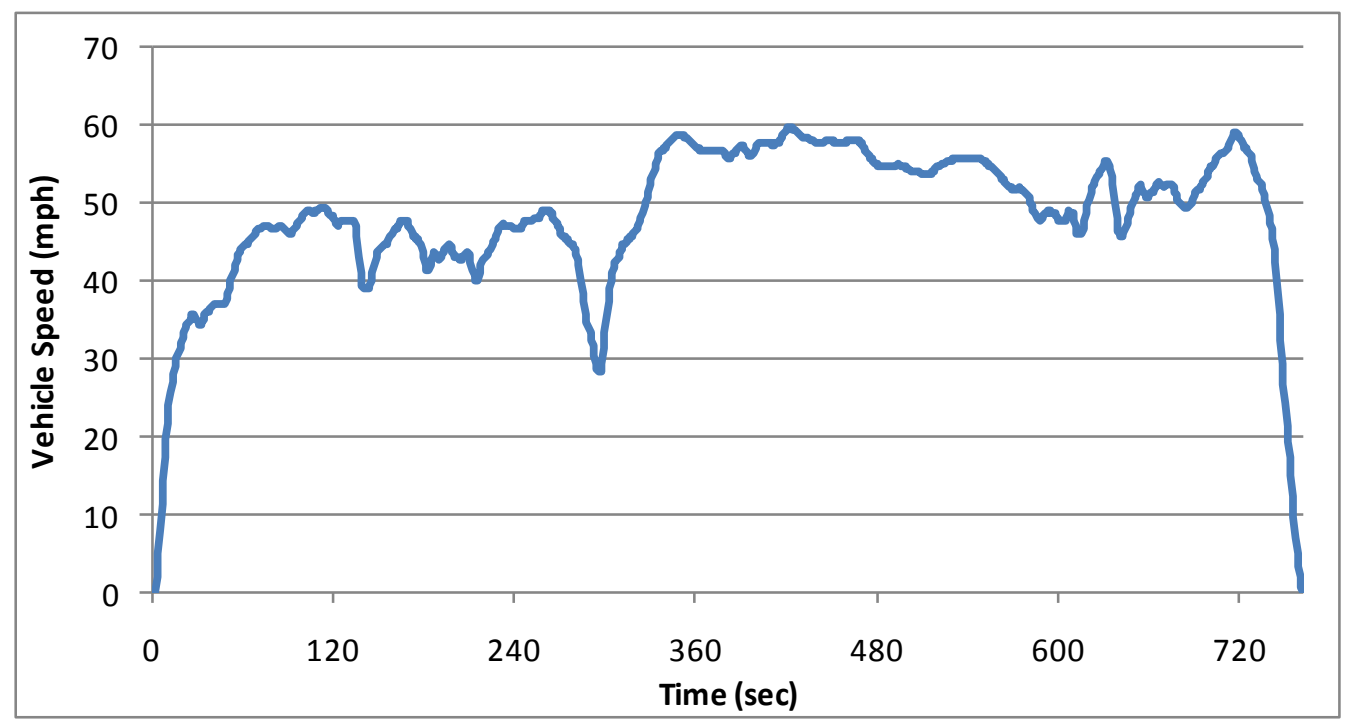

Figure 86. EPA HWFET Highway Cycle [5]

The HWFET cycle can be broken into two distinct pieces; a period of sustained $45 \mathrm{mph}$ driving and a portion of sustained $55 \mathrm{mph}$ driving. The Route 19 Highway Fuel Efficiency Test was designed following the EPA's HWFET very closely. Fortunately, the selected stretch of U.S. Route 19 had an initial speed limit of $45 \mathrm{mph}$ with an increase to $55 \mathrm{mph}$ in the middle. This simplified the design process, enabling the driver to simply follow the speed limit over the selected test route. The R19 HWFET cycle was constructed by connecting a laptop to the vehicle's CAN and recording the vehicle speed while running the route multiple times. The data collected during these runs were averaged and the WVU R19 HWFET cycle was completed. Figure 87 is a trace of the R19 HWFET cycle.

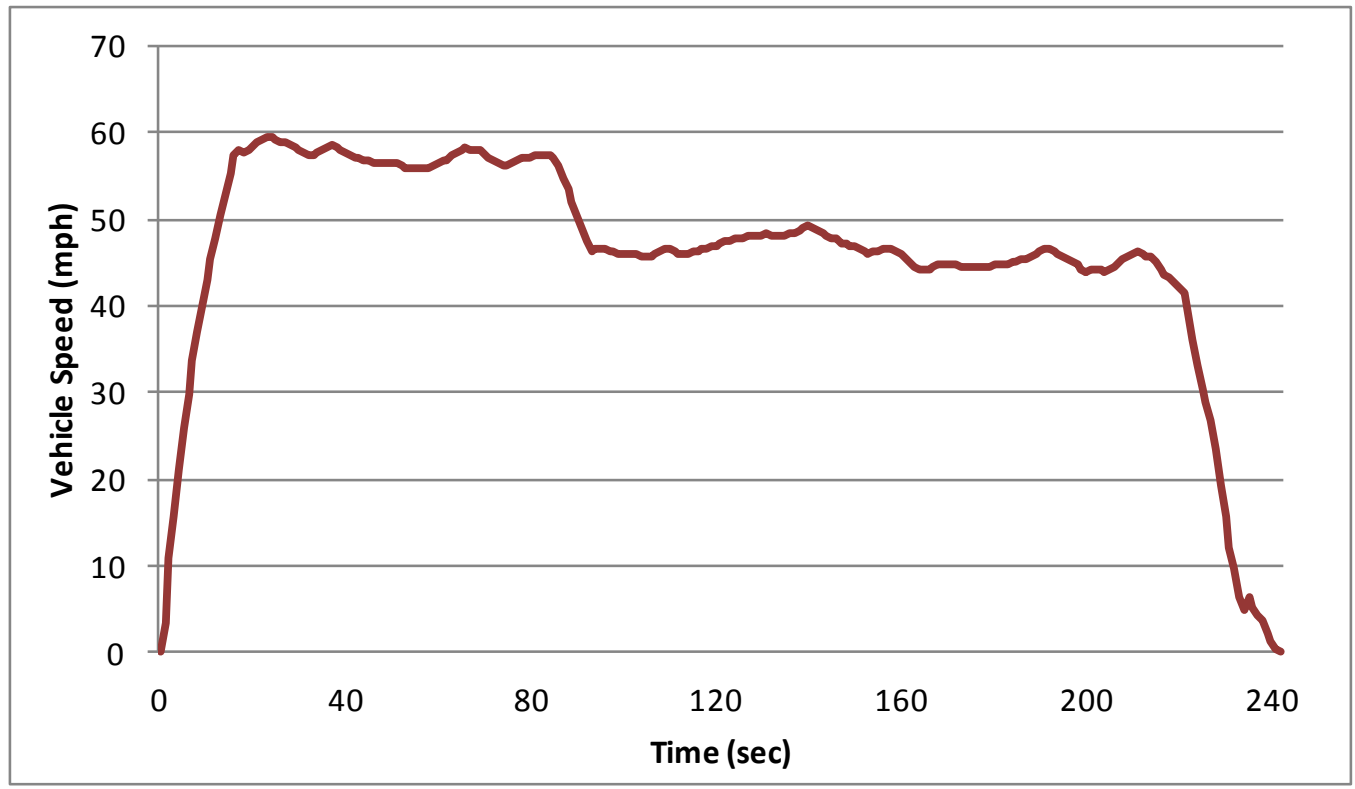

Figure 87. WVU R19 HWFET Highway Cycle 
As stated previously, a full R19 HWFET sequence would include running the route in both directions for a total distance of 5.94 miles. One direction would have the $45 \mathrm{mph}$ portion first and the return trip would start with the $55 \mathrm{mph}$ section. The new cycle was shorter than the EPA's HWFET cycle by about $40 \%$. Table 27 is a comparison between the EPA's HWFET cycle and WVU's R19 HWFET.

Table 27. HWFET vs. R19 HWFET Comparison

\begin{tabular}{|r|c|c|}
\hline & EPA HWFET & WVU R19 HWFET \\
\hline Duration & $765 \mathrm{sec}$ & $484 \mathrm{sec}$ \\
\hline Distance & $10.2 \mathrm{mi}$ & $5.94 \mathrm{mi}$ \\
\hline Maximum Speed & $60 \mathrm{mph}$ & $59.6 \mathrm{mph}$ \\
\hline Average Speed & $48.2 \mathrm{mph}$ & $45.8 \mathrm{mph}$ \\
\hline
\end{tabular}

The R19 HWFET cycle had a lower average speed and fewer accelerations and decelerations than the EPA's HWFET. Due to these differences, the WVU-designed test cycle would produce slightly higher fuel efficiency results than if the vehicle were to run the EPA's highway cycle.

Regardless of the differences between the EPA's test cycles and the cycles designed by WVU, these new cycles were very repeatable and could possibly be made into standard cycles for testing future advanced vehicle technology project vehicles constructed at the university. All of the information regarding the new cycles will remain at WVU including speed vs. time information and plots of the traces.

\subsubsection{Testing Procedure}

Prior to on-road testing, a test plan was developed to compare the performance of the project vehicle with different control algorithms to determine what configuration produced the best combination of fuel efficiency and vehicle performance. A total of ten different control strategies were written, each with different values set for parameters such as transmission shift points, engine on/off limits, high voltage battery SOC target, and engine speed. Each configuration was tested with regenerative braking enabled and disabled to determine how this function affected fuel efficiency and drivability.

Once the drive cycles were designed and the selected locations deemed acceptable, final testing of the project vehicle commenced in the Summer of 2011. In order to avoid traffic, all testing was performed in the mornings between 6 a.m. and 9 a.m. over multiple days. While testing at night would have reduced the risk of running into traffic even more, daylight testing was preferred both for safety and repeatability of the tests. The driver needed to be able to see ahead of the vehicle to locate reference points used to set the vehicle speed. All testing was performed with one passenger in the vehicle to run the data logger and inform the driver how fast to drive and when to accelerate and brake.

Once the vehicle systems were all up to operating temperature, the first fuel efficiency test could be performed with the base control algorithm loaded into the vehicle. After completing a full test cycle, regenerative braking was disabled and the test was run again with the same control algorithm as the 
previous test. After running the test with regenerative braking disabled, the project vehicle was parked and turned off so the next control algorithm could be flashed to the SCU. This process was repeated for each of the ten control algorithms. Each control algorithm was tested over both the MUDS and R19 HWFET cycles.

For city testing at the Morgantown Mall, cones were setup around the test route to use as reference points for accelerations and stops. Each MUDS test cycle included three full circuits of the test route with each lap including different unique events and varied target speeds. Each test took roughly ten minutes to complete. If another vehicle entered the test route and affected the cadence of the project vehicle while running the MUDS, that test was disregarded and the vehicle was returned to the start point to begin that test cycle again.

Highway testing simply involved following the posted speed limit over the selected test route. The R19 HWFET route was run in both directions, turning the vehicle around halfway through the test. Because the engine was turned off and thus not burning any fuel while the vehicle was stationary at the turnaround point, the data logger remained on during this period. Traffic was more of a concern during highway testing as U.S. Route 19 was fairly busy at most times during the day. Many R19 HWFET cycles were thrown out due to traffic intrusions.

In addition to fuel efficiency testing, each control algorithm was also subjected to acceleration testing. Testing the acceleration performance of the project vehicle involved recording the vehicle speed through CAN and accelerating the vehicle from a standstill to $75 \mathrm{mph}$. This test was performed on a straight stretch of Route 19 located at the end of the R19 HWFET test route.

During fuel efficiency and performance testing, careful attention was paid to the drivability and performance of the project vehicle. Engine starting, transmission shifting, and available axle torque were considered the most important characteristics with regard to drivability. Turning the engine on and off at higher vehicle speeds was tested in an attempt to quell the rough nature of the engine during start-up and shutdown. However, this also meant that the vehicle would have less available power during low speed acceleration so there was always a trade-off between efficiency, drivability, and performance. Similarly, shifting the transmission at higher vehicle speeds helped provide more low speed axle torque. However, this lowered the efficiency of the electric motors by spinning them beyond their most efficient operating speeds. The purpose of testing ten different control configurations was to find the best combination of fuel/energy efficiency and performance.

\subsubsection{Control Algorithm Configurations}

The different control strategies were based on a single configuration. The base configuration was built with the various parameters set in the middle of their respective safe ranges to allow adjustments to be made in either direction in an attempt to improve efficiency, drivability, and/or performance. Table 28 lists the values set for the control parameters being tested in the base program. 


\section{Table 28. Base Control Algorithm}

\begin{tabular}{|r|c|}
\hline Shift Up Speed & $30 \mathrm{mph}$ \\
\hline Shift Down Speed & $25 \mathrm{mph}$ \\
\hline Engine On Speed & $20 \mathrm{mph}$ \\
\hline Engine Off Speed & $15 \mathrm{mph}$ \\
\hline Target SOC & $45 \%$ \\
\hline
\end{tabular}

The design of the 2-mode transmission necessitated that the engine be running at vehicle speeds above $30 \mathrm{mph}$ to decrease the rotational speed of the pinion gears in the planetary gear set. Because of this fact, the maximum vehicle speed for engine-off operation was set at $28 \mathrm{mph}$ to protect the transmission. The parameters listed in the table were all changed and a total of ten unique control algorithms were written and tested.

The ten different control algorithms were all based on the base control algorithm with only one parameter adjusted with the final best configuration containing all the best-performing adjustments. For example, one configuration included a lowered upshift speed while another contained a higher upshift speed. The same was done to test the effect of raising or lowering the downshift speed as well as the vehicle speeds at which the engine was turned on and off. The target state-of-charge of the high-voltage battery was adjusted as changing this parameter affected the ability of the vehicle to maintain a suitable SOC buffer in the high-voltage battery. Each control algorithm was tested for fuel efficiency and drivability over the MUDS and R19 HWFET cycles as well as performance tested for 0-60 mph and 50-70 mph acceleration.

\subsubsection{Final Vehicle Control Algorithm}

The final control algorithm provided the best balance between vehicle performance and fuel efficiency. Table 29 lists the control parameters set in the final vehicle control algorithm.

Table 29. Final Control Algorithm

\begin{tabular}{|r|c|}
\hline Shift Up Speed & $35 \mathrm{mph}$ \\
\hline Shift Down Speed & $30 \mathrm{mph}$ \\
\hline Engine On Speed & $25 \mathrm{mph}$ \\
\hline Engine Off Speed & $20 \mathrm{mph}$ \\
\hline Target SOC & $50 \%$ \\
\hline
\end{tabular}

The best control configuration included higher upshift and downshift speeds as well as higher engine on and off speed limits. Raising the transmission shift point caused the 2-mode transmission to spend more time in the low-range mode 1 . Mode 1 provided more mechanical advantage by producing 
numerically higher gear ratios, improving the acceleration performance of the project vehicle. However, this meant that more fuel and electrical energy was being consumed at low vehicle speeds. This effect was offset by raising the vehicle speeds at which the engine was required to be turned on and off. At low vehicle speeds when the driver was requesting low axle torque, the engine could remain off for longer, reducing fuel consumption during city driving. Varying the target state-of-charge of the high-voltage battery had little effect on the project vehicle's ability to maintain suitable charging and discharging buffers.

This configuration produced the best balance between acceleration performance and overall energy efficiency. For instance, increasing the upshift point of the transmission to $45 \mathrm{mph}$ produced quicker acceleration times and improved low-speed throttle response, but city fuel economy was compromised. Turning the engine on and off at lower vehicle speeds also improved low-speed vehicle performance, but this also produced undesirable vibrations that were transferred into the passenger compartment. By turning the engine on and off at higher vehicle speeds, these vibrations blended into those produced by the road surface and thus were less noticeable to passengers and the driver. 


\section{Discussion \& Results}

\subsection{Fuel Efficiency \& Performance Results}

Once the diesel engine began producing full power, final vehicle testing commenced in June of 2011. This was an important development because the vehicle could be tested for fuel efficiency and performance while fully functioning as-designed. In addition to on-road testing, the PSAT simulation model was updated to include the final control algorithm in an attempt to validate the simulation results.

\subsubsection{Simulation Validation}

To validate the simulations performed in PSAT, the new city and highway fuel efficiency test cycles were transferred into the simulation program. The final vehicle control algorithm was simulated in PSAT before it was tested on-road. Table 30 displays the results of performance testing in PSAT and the actual on-road test results.

Table 30. PSAT Performance Simulation Validation

\begin{tabular}{|r|c|c|c|}
\hline & PSAT & On-Road & Difference \\
\hline $\mathbf{0 - 6 0}$ mph Acceleration & $14.6 \mathrm{sec}$ & $16 \mathrm{sec}$ & $-9.6 \%$ \\
\hline $\mathbf{5 0 - 7 0}$ mph Acceleration & $8.6 \mathrm{sec}$ & $10 \mathrm{sec}$ & $-16.3 \%$ \\
\hline Braking Distance & $150 \mathrm{ft}$ & $148.5 \mathrm{ft}$ & $1.0 \%$ \\
\hline
\end{tabular}

Much time was spent building the PSAT simulation so that it matched as closely as possible the project vehicle built at WVU. The PSAT simulation produced acceleration times lower than those recorded during on-road testing. However, each acceleration time produced by the simulation was only 1.4 seconds lower than the actual acceleration times achieved by the project vehicle. The differences could have been due to the unknown algorithm running in the HCP and how torque was divided between the diesel engine and electric motors. In addition, PSAT did not take into account the elevation of Morgantown as well as the local atmospheric pressure, air temperature, and humidity on the day of onroad testing. The braking distance from $60-0 \mathrm{mph}$ reported by PSAT was essentially identical to the actual on-road result.

While PSAT was capable of simulating vehicle performance, it was primarily developed as a fuel efficiency testing program for advanced and alternative vehicles such as hybrid-electrics like the WVU project vehicle. Fuel efficiency results were listed as city, highway, and a calculated combined value. The EPA calculates combined fuel economy according to the following equation [53]:

$$
F E_{\text {Combined }}=\left(\frac{0.55}{\text { City } F E}+\frac{0.45}{\text { Highway FE }}\right)^{-1}
$$


In this calculation, city fuel efficiency is weighted more heavily than highway fuel efficiency. Table 31 displays the results of fuel efficiency testing over the MUDS and R19 HWFET cycles in PSAT and the actual on-road results. Note that the on-road testing results are listed in gasoline-equivalent miles per gallon.

Table 31. PSAT Fuel Efficiency Simulation Validation

\begin{tabular}{|r|c|c|c|}
\hline & PSAT & On-Road & Difference \\
\hline $\begin{array}{r}\text { MUDS City Fuel } \\
\text { Efficiency }\end{array}$ & 28.4 mpgge & 24.5 mpgge & $13.6 \%$ \\
\hline $\begin{array}{r}\text { R19 HWFET Fuel } \\
\text { Efficiency }\end{array}$ & 29.4 mpgge & 31.5 mpgge & $-7.1 \%$ \\
\hline $\begin{array}{r}\text { Combined Fuel } \\
\text { Efficiency }\end{array}$ & 28.8 mpgge & 27.2 mpgge & $5.5 \%$ \\
\hline
\end{tabular}

While the combined fuel economy reported by PSAT was close to the actual observed fuel economy, the city fuel economy predicted by PSAT was higher than the actual city fuel economy by 3.9 mpgge. The highway fuel efficiency predicted in PSAT was $1.1 \mathrm{mpgge}$ lower than the actual on-road highway fuel efficiency. These differences could have been due to the control algorithm governing the split of engine and electrical power in the inverter module and production hybrid control processor, neither of which were modified. The program in the HCP was approximated based on data collected during onroad testing and written into PSAT for simulation. Regardless, the simulation built in PSAT was deemed to be a valid indicator of both vehicle performance and combined fuel economy which, according to the EPA, is the most accurate predictor of observed vehicle fuel efficiency assuming typical vehicle usage and driving characteristics.

\subsubsection{On-Road Testing Results}

\subsubsection{Performance Testing Results}

The performance of the project vehicle was tested by measuring its ability to accelerate and brake. After weighing the vehicle with a full tank of fuel and no driver, the vehicle's 0-60 mph and 50-70 $\mathrm{mph}$ acceleration times were taken. Then the project vehicle's stopping distance from 60-0 mph was measured. Table 32 lists the results of on-road performance testing.

Table 32. On-Road Performance Test Results

\begin{tabular}{|r|c|c|c|}
\hline & Base 2.4L Vue & 3.6L 2-Mode Vue & WVU 2-Mode \\
\hline 0-60 mph Acceleration & $11.8 \mathrm{sec}$ & $7.3 \mathrm{sec}$ & $16 \mathrm{sec}$ \\
\hline $\mathbf{5 0 - 7 0} \mathbf{~ m p h ~ A c c e l e r a t i o n ~}$ & $6.8 \mathrm{sec}$ & - & $10 \mathrm{sec}$ \\
\hline Braking Distance & $141.7 \mathrm{ft}$ & $140 \mathrm{ft}$ & $148.5 \mathrm{ft}$ \\
\hline Curb Weight & $3875 \mathrm{lb}$ & $4125 \mathrm{lb}$ & $4552 \mathrm{lb}$ \\
\hline
\end{tabular}


The increased mass of the project vehicle was likely to blame for its sluggish acceleration performance and increased braking distance compared to both the base Vue and the gasoline-powered 2-mode version. The 1.3 liter diesel engine also produced less torque than the 3.6 liter V-6 by a margin of $136 \mathrm{~N}-\mathrm{m}$. However, the project vehicle performed much better once the engine began producing maximum power. Table 33 shows the improvement in acceleration performance from the EcoCAR acceleration event results where the engine torque was limited to $100 \mathrm{~N}-\mathrm{m}$.

Table 33. Acceleration Improvement with Full Engine Power

\begin{tabular}{|c|c|c|c|}
\hline & $\begin{array}{c}\text { EcoCAR } \\
\text { Results }\end{array}$ & $\begin{array}{c}\text { Full Engine } \\
\text { Power }\end{array}$ & Improvement \\
\hline Acceleration $\mathbf{( 0 - 6 0} \mathbf{~ m p h )}$ & $25.78 \mathrm{sec}$ & $16 \mathrm{sec}$ & $37.9 \%$ \\
\hline Acceleration $\mathbf{( 5 0 - 7 0} \mathbf{~ m p h )}$ & DNF & $10 \mathrm{sec}$ & - \\
\hline
\end{tabular}

The project vehicle was unable to reach a speed of $70 \mathrm{mph}$ at the final event in Milford due to the limited engine power. At full engine power, the project vehicle was capable of reaching speeds in excess of $90 \mathrm{mph}$.

\subsubsection{Fuel Efficiency Testing Results}

With the final powertrain control algorithm loaded into the SCU and the diesel engine producing its rated power and torque, the project vehicle was tested on-road over both the MUDS and R19 HWFET cycles for fuel efficiency and drivability. Table 34 lists the on-road fuel economy testing results.

Table 34. On-Road Fuel Efficiency Test Results

\begin{tabular}{|c|c|c|c|}
\hline & Base 2.4L Vue & 3.6L 2-Mode Vue & WVU 2-Mode \\
\hline City Fuel Economy & $19 \mathrm{mpg}$ & $27 \mathrm{mpg}$ & $\begin{array}{c}28 \mathrm{mpg} \\
(24.5 \mathrm{mpgge})\end{array}$ \\
\hline Highway Fuel Economy & $26 \mathrm{mpg}$ & $30 \mathrm{mpg}$ & $\begin{array}{c}36 \mathrm{mpg} \\
(31.5 \mathrm{mpgge})\end{array}$ \\
\hline Combined Fuel Economy & $22.2 \mathrm{mpg}$ & $28.4 \mathrm{mpg}$ & $\begin{array}{c}31.6 \mathrm{mpg} \\
(27.2 \mathrm{mpgge})\end{array}$ \\
\hline
\end{tabular}

The project vehicle performed without fault during on-road testing and returned improved fuel economy when compared to the base 2.4 liter Vue. City fuel efficiency improved by $28.9 \%$ and highway fuel economy improved by $21.2 \%$ compared to the base vehicle based on the calculated gasoline equivalent results. Combined fuel economy improved by $22.5 \%$ on a gasoline equivalent basis. While highway fuel efficiency improved by $5 \%$ compared to the 3.6 liter 2-mode Vue on a gasoline equivalent basis, city fuel economy reduced by $9.3 \%$. Gasoline equivalent combined fuel efficiency reduced by $4.2 \%$ compared to the gasoline-powered 2-mode Vue. This indicates that the project vehicle became less energy efficient after replacing the 3.6 liter gasoline engine and small $\mathrm{NiMH}$ battery pack with the 1.3 liter 
diesel engine and A123 lithium-ion battery system. This could be attributed to both the increased mass of the project vehicle and the powertrain control algorithm. Unfortunately, the required voltage of the highvoltage battery necessitated the size and mass of the high-voltage battery installed in the project vehicle.

However, while gasoline equivalent fuel economy is indicative of an alternative vehicle's actual energy efficiency compared to conventional gasoline-powered vehicles, volumetric fuel economy is what drivers will experience in real-world driving. In this respect, the project vehicle was able to improve upon the gasoline-powered 2-mode Vue's fuel economy. Table 35 shows how the project vehicle's gasoline equivalent and volumetric fuel economy compared to the base Vue and gasoline-powered 2-mode.

Table 35. Project Vehicle Fuel Economy Comparison

\begin{tabular}{|r|c|c|c|c|}
\hline & \multicolumn{2}{|c|}{ Gasoline Equivalent } & \multicolumn{2}{c|}{ Volumetric } \\
\cline { 2 - 5 } & $\begin{array}{c}\text { Improvement } \\
\text { over Base }\end{array}$ & $\begin{array}{c}\text { Improvement } \\
\text { over 2-Mode }\end{array}$ & $\begin{array}{c}\text { Improvement } \\
\text { over Base }\end{array}$ & $\begin{array}{c}\text { Improvement } \\
\text { over 2-Mode }\end{array}$ \\
\hline City & $28.9 \%$ & $-9.3 \%$ & $47.4 \%$ & $3.7 \%$ \\
\hline Highway & $21.2 \%$ & $5.0 \%$ & $38.5 \%$ & $20.0 \%$ \\
\hline Combined & $22.5 \%$ & $-4.2 \%$ & $42.3 \%$ & $11.3 \%$ \\
\hline
\end{tabular}

Because diesel fuel contains more energy per gallon than gasoline, equivalent fuel economy is always lower than volumetric fuel economy. Switching to the real-world volumetric consumption comparison, the project vehicle achieved $11.3 \%$ better combined fuel efficiency compared to the gasoline-powered 2-mode Vue and improved upon the base model's combined fuel economy by $42.3 \%$.

\subsubsection{Emissions Reduction Results}

While the total exhaust emissions were not directly measured, the carbon dioxide emissions can be calculated based on the fuel economy results according to the following equation:

$$
\mathrm{CO}_{2}=\frac{\mathrm{CO}_{2} \text { FromFuel }}{\text { FuelEconomy }} \times 1000
$$

The $\mathrm{CO}_{2}$ produced from burning one gallon of gasoline is $8.8 \mathrm{~kg}$ and $10.1 \mathrm{~kg}$ from burning one gallon of diesel fuel. The fuel economy used in the calculation should be the actual volume-based fuel economy of the vehicle. This equation gives results in terms of grams per mile of vehicle travel. Table 36 lists the results of the $\mathrm{CO}_{2}$ analysis. 
Table 36. Carbon Dioxide Production Results

\begin{tabular}{|r|c|c|c|}
\hline & Base 2.4L & 3.6L 2-Mode & WVU 2-Mode \\
\hline Combined Fuel Economy & $22 \mathrm{mpg}$ & $28.4 \mathrm{mpg}$ & $31.6 \mathrm{mpg}$ Diesel \\
\hline $\mathrm{CO}_{2}$ From Fuel & $8.8 \mathrm{~kg} / \mathrm{gal}$ & $8.8 \mathrm{~kg} / \mathrm{gal}$ & $10.1 \mathrm{~kg} / \mathrm{gal}$ Diesel \\
\hline $\mathrm{CO}_{2}$ Produced & $400 \mathrm{~g} / \mathrm{mi}$. & $310 \mathrm{~g} / \mathrm{mi}$. & $320 \mathrm{~g} / \mathrm{mi}$. \\
\hline Reduction & $20 \%$ & $-3.2 \%$ & - \\
\hline
\end{tabular}

The project vehicle reduced carbon dioxide emissions by $20 \%$ compared to the base 2.4 liter Vue. However, the higher carbon content of diesel fuel compared to gasoline caused the $\mathrm{CO}_{2}$ emissions of the project vehicle to be $3.2 \%$ higher than the emissions from the gasoline-powered 2-mode Vue. For further comparison, a non-hybrid 3.6 liter Vue achieved $19 \mathrm{mpg}$ combined fuel economy, producing $\mathrm{CO}_{2}$ at a rate of $463 \mathrm{~g} / \mathrm{mi}$. The project vehicle improved upon the non-hybrid 3.6 liter Vue's carbon dioxide emissions by $30.9 \%$.

\subsection{Conclusions}

The three year vehicle design process for this project included solving countless problems related to the control algorithm and overall vehicle layout and design. Along the way, the proposed architecture was modified slightly but the resulting project vehicle was essentially constructed as-intended when the compound-split diesel hybrid-electric powertrain was selected during the simulation and modeling activities. While the project vehicle achieved $4.2 \%$ lower combined fuel economy than the pre-production gasoline-powered 2-mode Vue, it returned 22.5\% improved fuel economy compared to the base 2009 Saturn Vue. In addition, the project vehicle produced 3.2\% more $\mathrm{CO}_{2}$ than the gasoline 2-mode but $20 \%$ less than the base vehicle.

While some of the differences between the actual vehicle performance and the original PSAT model results may have been due to the limitations of the computer model, the control algorithm was likely responsible as well. The final powertrain control strategy developed through this research was mostly based on vehicle speed while the control strategy used during the preliminary modeling exercise was much more complicated, utilizing fixed gear ratios in the transmission and varying engine speed and torque based on the input command from the accelerator pedal. The revised PSAT results listed in Table 35 on page 115 included a more accurate representation of the final control algorithm with the project vehicle missing the combined fuel efficiency PSAT prediction by $5.5 \%$.

The project vehicle achieved significantly improved fuel efficiency and reduced $\mathrm{CO}_{2}$ emissions compared to the base vehicle through the implementation of the diesel hybrid-electric powertrain and control strategy. The control algorithm included all of the desired hybrid functions and proved to be very robust throughout testing with the diesel engine functioning properly. The on-road test plans developed were very repeatable and may be used by future advanced vehicle technology projects at the university. 
A CUV that holds five people comfortably and returns $36 \mathrm{mpg}$ diesel (31.5 mpgge) would be very appealing in the current automotive marketplace. The completed project vehicle drove well, performed adequately, achieved excellent fuel economy, and maintained all of the functions and capabilities expected of new cars through the implementation of the powertrain control algorithm developed as a result of this research.

\subsection{Recommendations}

Although further testing of the project vehicle is currently on-hold until the transmission can be repaired, there are some recommendations the author can make regarding future testing and control algorithm development.

\subsubsection{Fuel Efficiency Testing}

The fuel efficiency testing performed in the Summer of 2011 was based solely on CAN communication regarding the instantaneous fuel injection rate of the diesel engine and vehicle speed information. The results were calculated based on the CAN data recorded during the different test runs. Ideally, this type of testing would be performed by removing and weighing the fuel tank prior to and immediately after completing the designated test cycle. This would have been difficult to accomplish based on the locations of the WVU-designed city and highway test cycles due to the amount of traffic that may have been encountered en route to either location.

Traffic, as well as the different grades between the Engineering Sciences Building and the test locations, would reduce the repeatability of fuel efficiency testing so the CAN-based method was selected. If a mass-based method were employed, the best way to eliminate these repeatability issues would be to remove and weigh the fuel tank on-site at the test location. However, removal of the fuel tank currently installed in the project vehicle would be difficult without access to a vehicle lift so a fuel tank could be designed and employed specifically for fuel economy testing. For ease of removal, the new fuel tank could be installed in the cargo area of the vehicle with new fuel lines run up to the engine. The test crew would need to bring extra fuel and an accurate scale for weighing the fuel tank before and after each test run.

\subsubsection{Future Control Development}

The final control algorithm loaded into the project vehicle included a somewhat simplistic method for controlling the compound-split diesel hybrid-electric powertrain and high-voltage battery. The 2-mode transmission installed in the project vehicle was a new and untested technology at the time and the control algorithm was written conservatively in an effort to protect the transmission hardware. The commanded engine speed was directly related to vehicle speed such that no matter what axle torque the driver commanded with the accelerator pedal, the engine speed would not change until the vehicle speed changed. Ideally, if the driver commanded maximum axle torque, the engine would speed up to a point 
where it could produce as much torque as possible in an attempt to meet the driver's torque request. A load-based engine speed control algorithm would provide improved vehicle performance at low speeds and improve the high-speed fuel efficiency of the project vehicle as the current control algorithm has the diesel engine spinning at $4000 \mathrm{rpm}$ when the vehicle is travelling $70 \mathrm{mph}$. In addition, limiting the engine to operate only in its most efficient speed and torque envelope would further improve the fuel efficiency of the project vehicle.

Likewise, the transmission shift strategy could also be converted to a load-based method where the transmission would allow downshifting at higher speeds if the driver requested more axle torque than could be provided in the current gear or EVT mode. The current transmission control algorithm only makes use of the two EVT modes with fixed gear 2 used for speed-matching during the shift between modes. This was done at the recommendation of the GM engineers as requesting fixed gears required more in-depth control of the 2-mode transmission. However, under certain circumstances such as towing heavy loads or traversing grades at high speeds, it would be more energy efficient to utilize one of the 2mode transmission's four fixed gear ratios instead of the EVT modes. Future control algorithm development could explore commanding fixed gear ratios at high speeds. 


\section{References}

1. Wood, J.H., Long, G.R., and Morehouse, D.F. "Long Term Oil Supply Scenarios." U.S. Energy Information Administration. August 18, 2004. Accessed 08/11. http://www.eia.gov/pub/oil_gas/petroleum/feature_articles/2004/worldoilsupply/oilsupply04.html.

2. Davis, S.C., Diegel, S.W. and Boundy ,R.G. "Transportation Energy Data Book, 30th Edition." Oak Ridge National Laboratory. June, 2011. Accessed 09/11. http://cta.ornl.gov/data/tedb30/Edition30_Full_Doc.pdf.

3. "The World Factbook." U.S. Central Intelligence Agency.

4. "EPA Urban Dynamometer Driving Schedule (UDDS)." U.S. Environmental Protection Agency. September 17, 2009. Accessed 09/11. http://www.epa.gov/otaq/standards/light-duty/udds.htm.

5. "Fuel Economy and Greenhouse Gas Exhaust Emissions of Motor Vehicles." U.S. Environmental Protection Agency. 40 CFR Part 600 Subpart B Section 111-08. July 6, 2011.

6. Tamai, G., Reeves, S. and Grewe, T. "Truck Utility and Functionality in the GM 2-Mode Hybrid." Society of Automotive Engineers International. Technical Paper 2010-01-0826. April 12, 2010.

7. Zhu, Z., Ward, D. and Wayne, W. S. "Control and Testing of a 2-Mode Front-Wheel-Drive HybridElectric Vehicle." Society of Automotive Engineers International. Technical Paper 2012-01-1192. April 26, 2012.

8. $\quad$ "Fuel Economy of 2009 Saturn Vue." U.S. Environmental Protection Agency. February 7, 2012. Accessed 09/11. http://www.fueleconomy.gov/feg/bymodel/2009_Saturn_Vue.shtml

9. "EcoCAR Challenge Non-Year Specific Rules." Argonne National Laboratory. September 25, 2010.

10. WVU EcoCAR Team. "Year 3 Progress Report 3." April 7th, 2011.

11. Corstz, R., Ivarsson, A. and Schramm, J. "Steady State Investigations of DPF Soot Burn Rates and DPF Modeling." Society of Automotive Engineers International. Technical Paper 2011-24-0181. September 11, 2011.

12. "NOX: How Nitrogen Oxides Effect The Way We Live And Breathe." U.S. Environmental Protection Agency. EPA-456/F-98-005. September, 1998.

13. Lambert, C. et. al. "Urea SCR and DPF System for Tier 2 Diesel Light-Duty Trucks." U.S. Department of Energy Division of Energy Efficiency\& Renewable Energy. DEER 2006. August 24, 2006.

14. Brandes, E.A. and Brook, G.B. "Smithells Metals Reference Book." $7^{\text {th }}$ Edition. Elsevier. 1998.

15. "EPA US06 or Supplemental Federal Test Procedure (SFTP)." U.S. Environmental Protection Agency. September 17, 2009. Accessed 10/11. http://www.epa.gov/otaq/standards/light-duty/sc06-sftp.htm

16. WVU EcoCAR Team. "WVU ESS Design V4." Report submitted to A123 Systems. April 15, 2010.

17. "Standard Details Book Volume 1: Drainage, Guardrails, Pavement, Fence and Markers." West Virginia Department of Transportation Division of Highways. January 1, 2000. 
18. Sulzberger, Carl. "Electric Vehicles In The Early Years Of The Automobile." IEEE Power Engineering Society. May, 2004.

19. Diesel, Rudolf. "Internal-Combustion Engine." United States Patent Number US608,845. August 9, 1898.

20. Benz, Karl. "Vehicle With Gas Engine Operation." German Patent Number DRP-37435. January 29, 1886.

21. Pulkrabek, Willard W. "Engineering Fundamentals of the Internal Combustion Engine." Pearson Prentice-Hall. Upper Saddle River, NJ 07458. 1997.

22. "Light-Duty Diesel Vehicles: Market Issues and Potential Energy and Emissions Impacts." U.S. Energy Information Administration. January, 2009.

23. "Clean Alternative Fuels: Compressed Natural Gas." U.S. Environmental Protection Agency. EPA420-F-00-033. March, 2002.

24. Tamai, G. et. al. "Development of the Hybrid System for the Saturn VUE Hybrid." Society of Automotive Engineers International. Technical Paper 2006-01-1502. April 6, 2006.

25. "Hybrid Electric Vehicle Basics." U.S. Department of Energy Division of Energy Efficiency\& Renewable Energy. September 22, 2011. Accessed 11/11. http://www.afdc.energy.gov/afdc/vehicles/electric_basics_hev.html

26. "2012 The Outlook for Energy: A View to 2040." ExxonMobil Corporation. 2012. http://www.exxonmobil.com/Corporate/energy_outlook.aspx

27. "Annual Energy Outlook 2011." U.S. Energy Information Administration. April 26, 2011.

28. "Vehicle Electrification." Society of Automotive Engineers International. November 4, 2010.

29. "All Electric Vehicle Basics." U.S. Department of Energy Division of Energy Efficiency \& Renewable Energy. September 22, 2011. Accessed 01/12. http://www.afdc.energy.gov/afdc/vehicles/electric_basics_ev.html

30. "Comparing Energy Costs per Mile for Electric and Gasoline-Fueled Vehicles." U.S. Department of Energy Division of Energy Efficiency \& Renewable Energy. September 22, 2011. Accessed 01/12. http://avt.inel.gov/pdf/fsev/costs.pdf

31. "Batteries for Hybrid and Plug-In Electric Vehicles." U.S. Department of Energy Division of Energy Efficiency \& Renewable Energy. September 22, 2011. Accessed 01/12. http://www.afdc.energy.gov/afdc/vehicles/electric_batteries.html

32. "First Numbers on Hybrid Battery Failure." Newsweek Article. May 29, 2008.

33. "Under the Hood (part 2)."Hybrid Center Article. Accessed 01/12. http://www.hybridcenter.org/hybrid-center-how-hybrid-cars-work-under-the-hood-2.html

34. Smith, B. "Chevrolet Volt Battery Incident Overview Report." National Highway Traffic Safety Administration. January 20, 2012.

35. Tran, L. "NHTSA Statement on Conclusion of Chevy Volt Investigation." National Highway Traffic Safety Administration Press Release. January 20, 2012. 
36. Grewe, T., Conlon, B. and Holmes, A. "Defining the General Motors 2-ModeHybrid Transmission." Society of Automotive Engineers International. Technical Paper 2007-01-0273.

37. Hanlon, R., Conklin, B., and Wayne, W. S. "Energy Storage System Design." Fourth Version. EcoCAR Competition Submission. April 15, 2010.

38. Ochiai, S. and Ohnuki, Y. "Description of the Hybrid Technology Mounted to Production Model." Society of Automotive Engineers International. Technical Paper 2001-01-3418. October 1, 2001.

39. Abe, S. and Murata, M. "Development of IMA Motor for 2006 Civic Hybrid." Society of Automotive Engineers International. Technical Paper 2006-01-1505. April 3, 2006.

40. lijima, T. "Development of Hybrid System for 2006 Sedan." Society of Automotive Engineers International. Technical Paper 2006-01-1503. April 3, 2006.

41. Hawkins, S., Bittolo, F. et. al. "Development of General Motors' eAssist Powertrain." Society of Automotive Engineers International. Technical Paper 2012-01-1039. April 16, 2012.

42. Hosoda, M. "Powertrain for a New Compact Sporty Hybrid Vehicle." Society of Automotive Engineers International. Technical Paper 2010-01-1095. April 12, 2010.

43. WVU EcoCAR Team. "Pre-Competition Report." Fourth Version. EcoCAR Competition Submission. April 15, 2009.

44. Hendrickson, J., Holmes, A. and Freiman, D. "General Motors Front Wheel Drive Two-Mode Hybrid Transmission." Society of Automotive Engineers International. Technical Paper 2009-01-0508. April 20, 2009.

45. Inoue, T., Kusada, M., Kanai, H., Hino, S., and Hyodo, Y. "Improvement of a Highly Efficient Hybrid Vehicle and Integrating Super Low Emissions." Society of Automotive Engineers International. Technical Paper 2000-01-2930. October 16, 2000.

46. Matsubara, T., Yaguchi, H., Tadaoka, T. and Jinno, K. "Development of New Hybrid System for Compact Class Vehicles." Society of Automotive Engineers International. Technical Paper 2009-011332. April 20, 2009.

47. "Fuel Economy of Toyota Prius." U.S. Environmental Protection Agency. June 18, 2012. Accessed 06/12. http://www.fueleconomy.gov/feg/Find.do?action=sbs\&id=26425\&id=19813\&id=17634

48. "History of the Clean Air Act." U.S. Environmental Protection Agency. February 17, 2012. Accessed 06/12. http://epa.gov/oar/caa/caa_history.html

49. Clean Air Act Amendments of 1990. Title III: Hazardous Air Pollutants, Section 112. Library of Congress. Accessed 06/12. http://thomas.loc.gov/cgi-bin/query/D?c101:2:./temp/ c101NYQNS6::

50. "Cars and Light-Duty Trucks - Tier 2." DieselNet Article. Updated 2006. Accessed 06/12. http://www.dieselnet.com/standards/us/ld_t2.php

51. "Cars and Light-Duty Trucks - Tier 1." DieselNet Article. Updated 2006. Accessed 06/12. http://www.dieselnet.com/standards/us/ld.php 
52. "Light-Duty Vehicle, Light-Duty Truck, and Medium-Duty Passenger Vehicle -- Tier 2 Exhaust Emission Standards." U.S. Environmental Protection Agency. October 26, 2009. Accessed 06/12. http://www.epa.gov/otaq/standards/light-duty/tier2stds.htm

53. "Code of Federal Regulations". 40CFR Part 600. Appendix II. July 6, 2011. Accessed 10/12. http://ecfr.gpoaccess.gov/cgi/t/text/text-idx?c=ecfr\&sid=51bc05b2e532407de2212c42ab7d4dd1\&rgn $=$ div5\&view=text $\&$ node $=40: 31 \cdot 0 \cdot 1 \cdot 4 \cdot 43 \&$ idno $=40 \%$ 